\title{
Fostering learner autonomy in an EFL Malagasy context
}

By Dominique Vola Ambinintsoa Razafindratsimba

A thesis submitted to Te Herenga Waka - Victoria University of Wellington in fulfilment of the requirements for the degree of Doctor of Philosophy in Applied Linguistics

School of Linguistics and Applied Language Studies

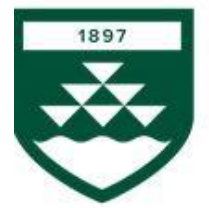

VICTORIA UNIVERSITY OF

WELLINGTON

TE HERENGA WAKA

2020 


\section{Abstract}

This research intends to bring insights into learner autonomy in a Malagasy EFL setting.

Despite being a topic of research in language education for about four decades, learner autonomy is still almost unknown in countries like Madagascar. Most empirical studies on learner autonomy have taken place in either ESL settings in Western countries or EFL settings in some Asian countries. Very little research has been conducted in African developing countries.

In order to foster learner autonomy in a Malagasy setting, the research encompassed two main phases. Phase one focused on exploring the existing conditions for learner autonomy in a Malagasy rural school; while phase two aimed to promote one dimension of learner autonomy with student teachers through a "reflective learning" course.

Phase one examined the affordances of learner autonomy in a Malagasy rural school. It investigated three dimensions of learner autonomy, namely self-initiation, self-regulation, and independence, via class observations and interviews with four EFL teachers. The data revealed some elements of autonomy. Self-initiation was fostered through encouragement and opportunities to learn outside class, while independence (from teachers) was mainly promoted through peer collaboration. Though the presence of the elements was not consistent, the fact that they were promoted at all implies possibilities to further exploit them in such a setting. Self-regulation - composed of planning, monitoring, and selfevaluation - was not promoted probably due to the teachers' unawareness of its importance, and their lack of experience with self-regulation as former learners.

The aim of phase two was to promote self-regulation at a Teacher Training College among a group of 22 first-year EFL student teachers as participants. A nine-week "reflective learning" course was designed to achieve three main objectives: (1) to help the student teachers improve their self-regulation skills via reflective journal writing, in order (2) to help them improve their writing proficiency. In addition, experiencing the benefits and the challenges of reflective learning would lead them (3) to be aware of the significance of selfregulation on their own writing and/or learning in general, and on their future teaching. To reach these objectives, the student teachers were given writing tasks and reflection prompts to answer before, during, and after the writing tasks. Each of the writing task was a 200word argumentative essay, and was repeated twice or three times in order to facilitate the student teachers' self-evaluation. The pre-task prompts intended to help them plan their 
writing (including goal setting), the during-task prompts helped them monitor, and the posttask prompts helped them self-evaluate. A session of group discussion was held each week to allow peer collaboration. The writing tasks, the journal reflections on the tasks, on the group discussions, along with journal reflections on the course were included in portfolios.

The findings of phase two revealed that reflective learning was conducive to the development of the student teachers' self-regulation of writing. They became aware of their difficulties, which they turned into goals. This awareness enabled them to develop strategic behaviour and a sense of responsibility towards their learning in general. They also realised their capability to improve with little help from teachers, which triggered positive affect. Moreover, they generally improved their writing performances mainly thanks to the sense of responsibility, the positive affect, and the habit of paying attention to details, which they had also developed throughout the course. Furthermore, reflective learning influenced their perspectives on teaching.

The development of self-regulation and that of the improvement of writing varied from one student to another. In order to have a more in-depth analysis of such development (or lack of development), two case studies were used to illustrate the variations and the possible reasons behind such variations.

The research leads to a few teaching implications. Firstly, learner autonomy has its place in developing countries like Madagascar. Secondly, the development of learner autonomy should be included in teacher training so that teachers know and value its benefits and challenges, based on their own learning experience. Thirdly, not every student would reach the same level of autonomy in a given time. Weaker students may need more guidance in terms of strategies than other students. 


\section{Acknowledgements}

I would like to acknowledge Victoria University of Wellington for the financial support in the form of Victoria Doctoral Scholarship during the researching and writing of this thesis. Without the scholarship, I would not have been able to do my PhD in New Zealand.

I would like to express my profound gratitude to my two supervisors, Associate Professor Peter Gu and Associate Professor David Crabbe for their patience, invaluable guidance, and generous support. Thanks to them, I have developed my research skills, my awareness that there is always room to improve, and more importantly, my own learner autonomy. It has been three years of productive peer collaboration. I will definitely miss our meetings and the atmosphere we had. I feel really privileged and honored to work with both of them.

I am grateful to the staff at the School of Linguistics and Applied Language Studies, including ELI, for providing a stimulating, friendly, and professional research and study environment. Special thanks to Dr. Sara Cotterall, who has spent time with me discussing learner autonomy, doing shut-up-and-write sessions, and giving advice regarding PhD life, thesis writing, well-being, and future careers.

I am thankful to the support I received from my friends. Special thanks to Allison, who has been there for good and bad times throughout the three years; to Stuart for the squash games, the laughter, and for all the help in many areas; to $\mathrm{Ha}$, for her help with the thesis and beyond the thesis; to Judy, for the mental support in form of listening and dining out; to Naheen and Olcay for the rugby games and the fun lunch time; to Ben for the enjoyable times we spent walking, cycling, eating, plus our conversations full of laughter; to Juliet and Minh for their constant encouragement; to Anna for praying for me; and to friends who have been away physically but have continuously provided me with mental support and good thoughts. Their friendships have greatly contributed to my well being and have given me the motivation to keep going.

My heartfelt thanks go to the people in charge of the rural school and the Head of Department at the University in Madagascar, where the research took place. My sincere gratitude to the teacher and learner participants in Madagascar for their enthusiasm and insights during my research. The teachers welcomed me to their classes and accepted to be observed and to spend time discussing with me. The learners also welcomed me, trusted my "learner autonomy approach", and embraced the learning experience. This thesis would not 
have been possible without them, as they are the heart of the research. I cannot thank them enough.

I am especially indebted to my dad, Dominique Razafindratsimba, who has been playing the roles of a father and a mother at the same time, who has always believed in me, been proud of any small achievements I have had, encouraged me to pursue my dreams wherever they may lead me, but also taught me to always be appreciative of what I have. Last but not least, a huge thanks to Haja, Liva, Tiana, Mampita, Hoby, Miary, Rindra, Nick, Kanto, Nathan, Mael, Nathanael, and Soa who have always covered me with love and support despite the distance. Having such a supportive family, valuing education, is a blessing! 


\section{Table of Contents}

1 INTRODUCTION $\ldots \ldots \ldots \ldots \ldots \ldots$

$\begin{array}{lll}1.1 & \text { Learner autonomy (LA) } & 1\end{array}$

$\begin{array}{llr}1.2 & \text { LA in Madagascar } & 1\end{array}$

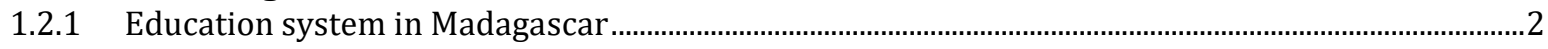

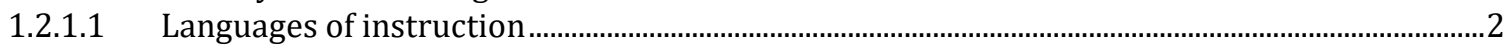

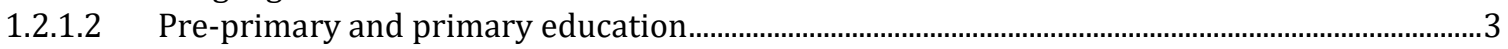

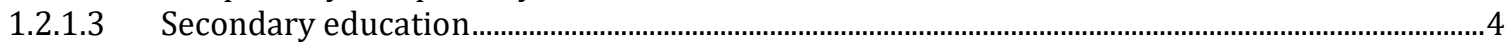

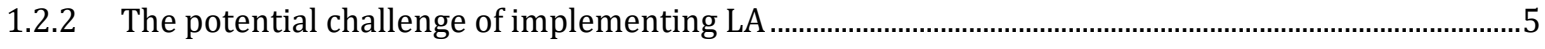

$\begin{array}{lll}1.3 & \text { Aims of the research } & 6\end{array}$

$\begin{array}{llr}1.4 & \text { Organisation of the thesis } & 8\end{array}$

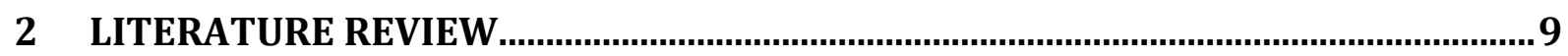

$\begin{array}{llr}2.1 & \text { What is LA? } & 9\end{array}$

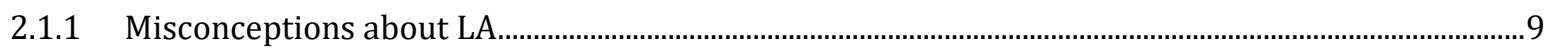

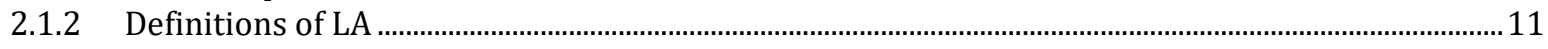

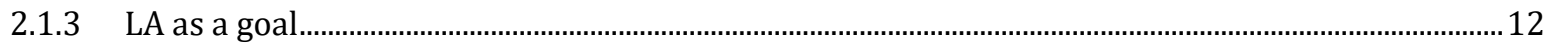

$\begin{array}{llr}2.2 & \text { Theories related to LA } & 13\end{array}$

2.2.1 Cognitive psychology, humanistic psychology, and self-determination theory...............................13

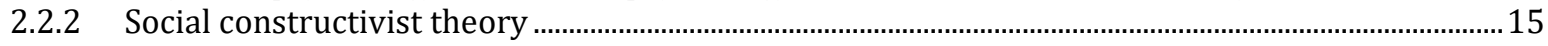

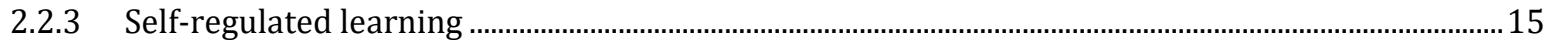

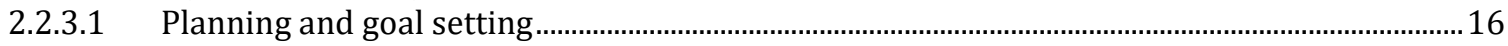

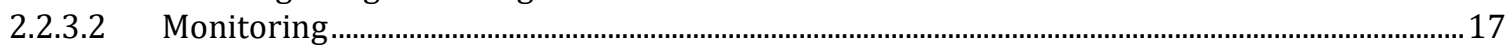

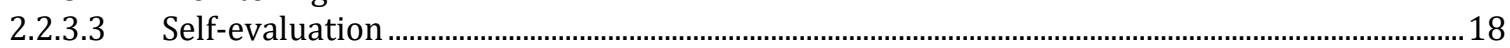

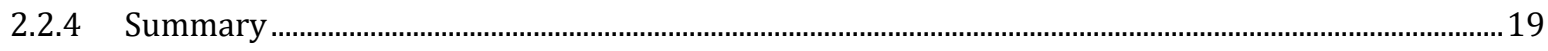

$\begin{array}{llr}2.3 & \text { Versions, dimensions or components of LA } & 19\end{array}$

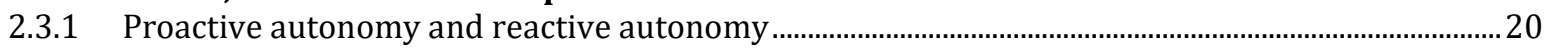

2.3.2 Strong and weak versions of pedagogy for LA .............................................................................21

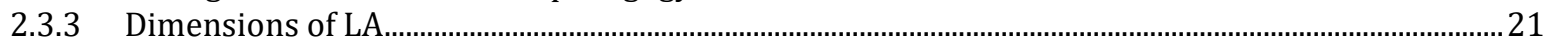

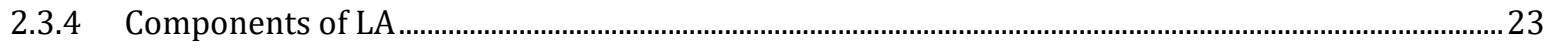

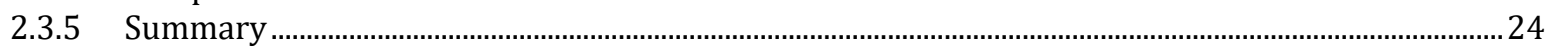

$\begin{array}{llr}2.4 & \text { Affective factors, social factors, and LA } & 24\end{array}$

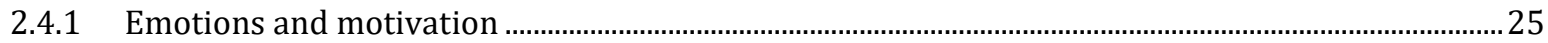

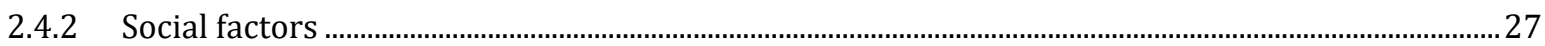

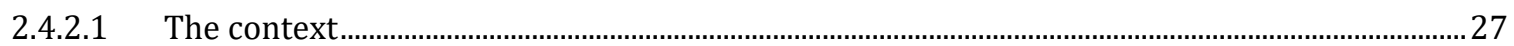

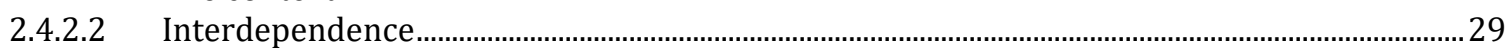

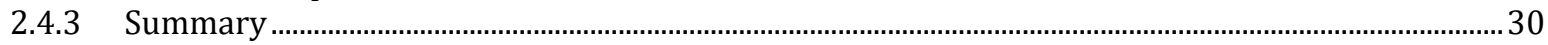

$\begin{array}{llr}2.5 & \text { Promoting LA } & \mathbf{3 0}\end{array}$

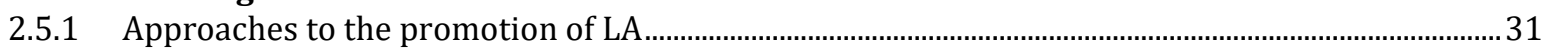

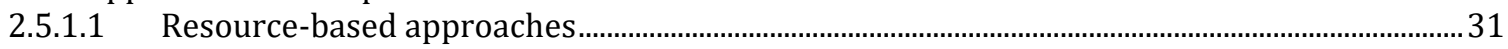

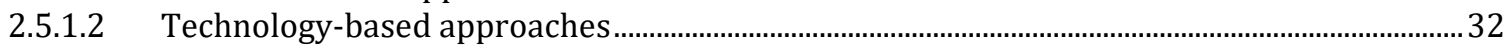

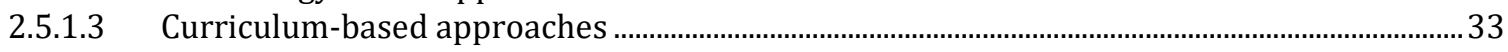

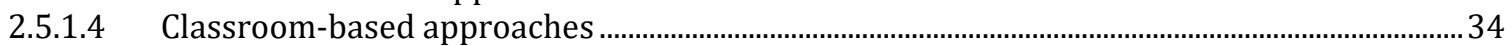

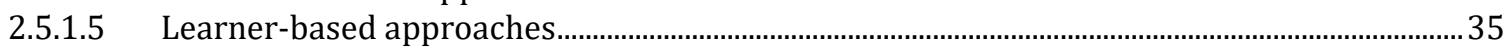

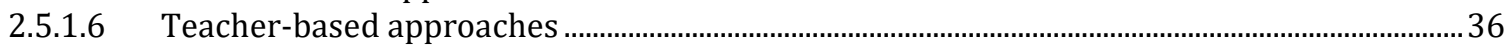

2.5.1.6.1 Teacher autonomy as a capacity for self-directed teacher-learning....................................3 37

2.5.1.6.2 Teacher autonomy as a capacity for self-directed teaching........................................................39

2.5.1.7 Summary of approaches.............................................................................................................. 40

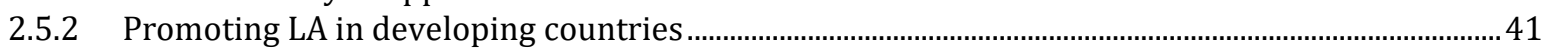




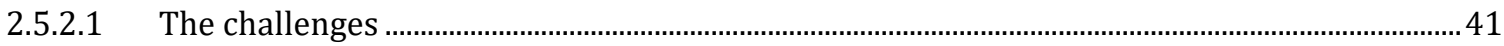

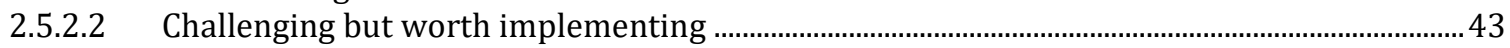

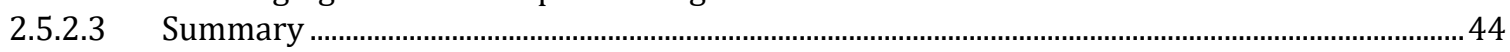

2.6 Conceptualising and operationalising LA in this research $\quad 44$

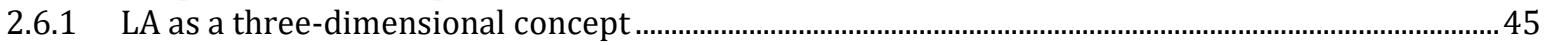

2.6.1.1 Self-regulation as the most important dimension ........................................................................45

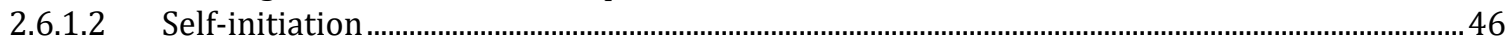

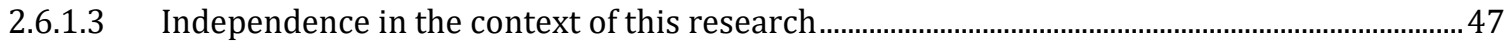

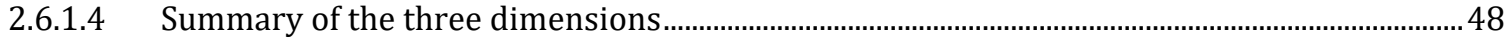

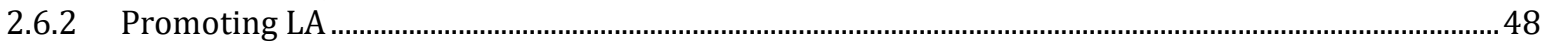

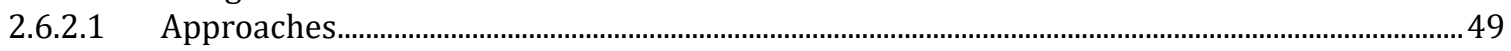

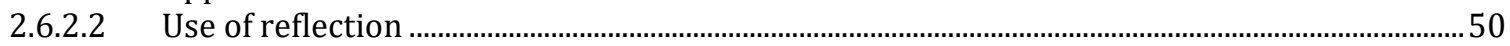

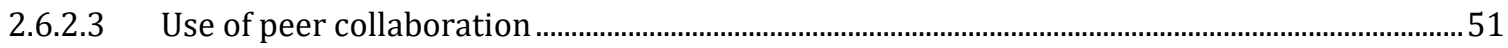

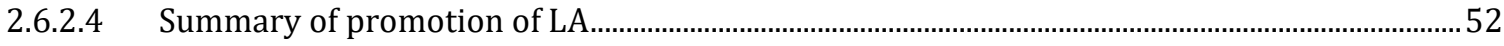

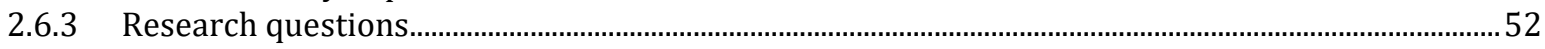

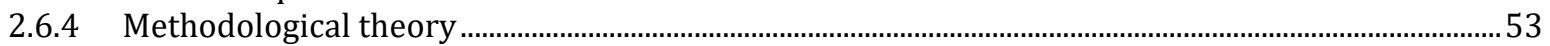

3 PHASE ONE - EXPLORING LA IN A MALAGASY RURAL SCHOOL .............................54

$\begin{array}{llr}3.1 & \text { Research goals } & 54\end{array}$

3.2 Research context $\quad 55$

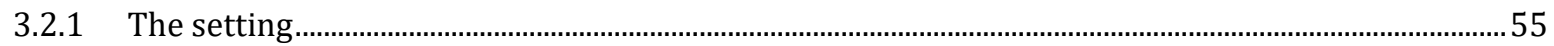

3.2.2 The language used in class ......................................................................................................................56

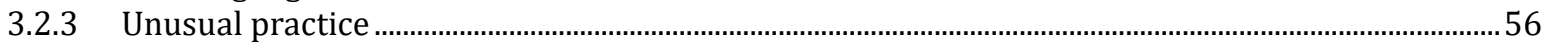

$\begin{array}{lll}3.3 & \text { Methodology } & \mathbf{5 7}\end{array}$

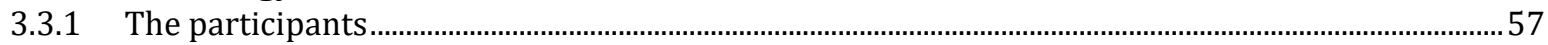

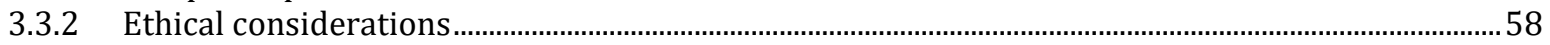

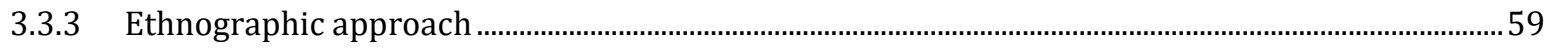

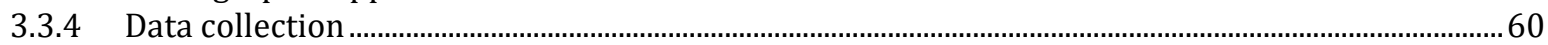

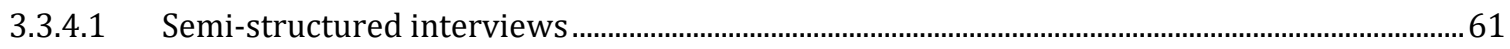

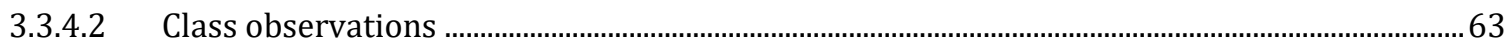

3.3.5 Data analysis..........................................................................................................................................6

3.4 Findings $\quad 64$

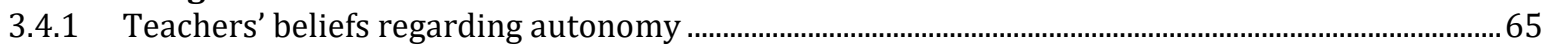

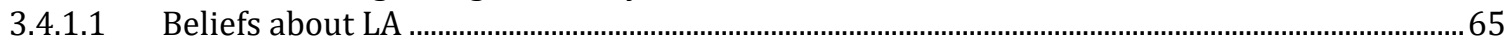

3.4.1.1.1 Self-initiation and independence from teacher ..........................................................................66

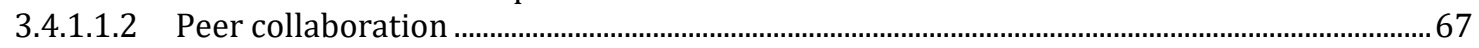

3.4.1.1.3 Peer evaluation and self-evaluation ...................................................................................6

3.4.1.1.4 Consideration of affect in teachers' learning .........................................................................6

3.4.1.1.5 Consideration of affect in their students' learning ...................................................................69

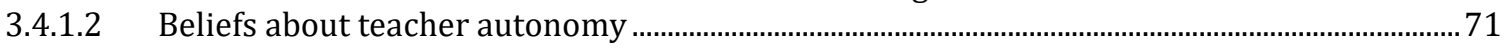

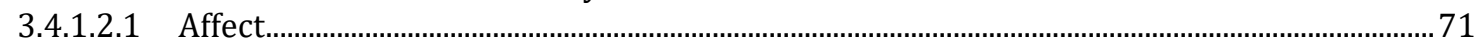

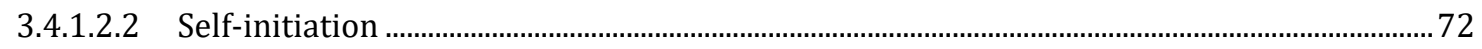

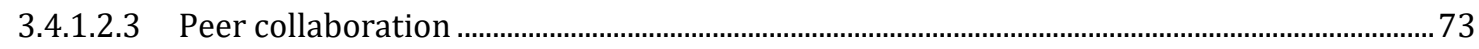

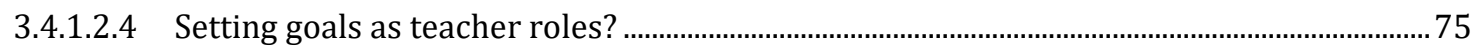

3.4.1.2.5 Self-evaluation................................................................................................................................

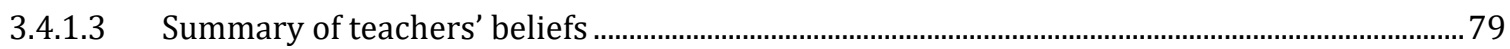

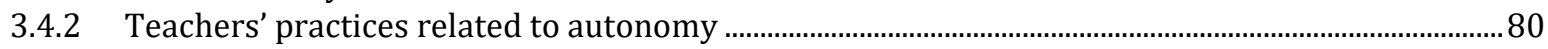

3.4.2.1 Practices in promoting LA ................................................................................................................ 80

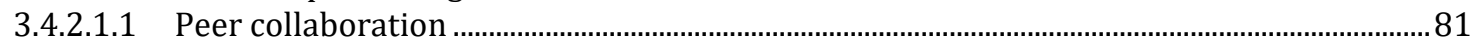

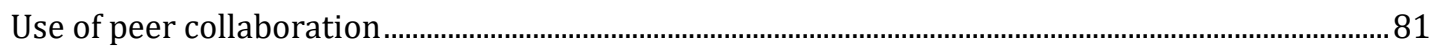

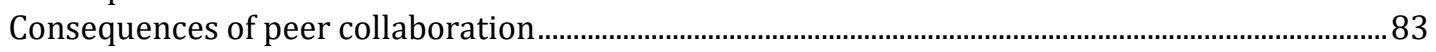

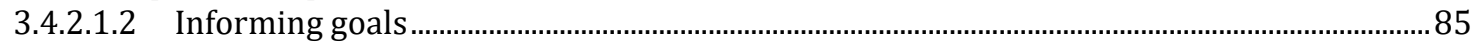

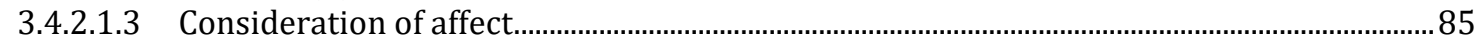

3.4.2.1.4 Letting students have their say ................................................................................................. 86

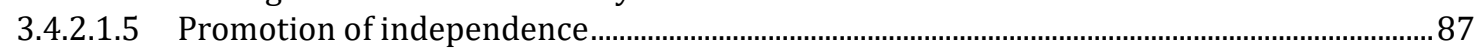




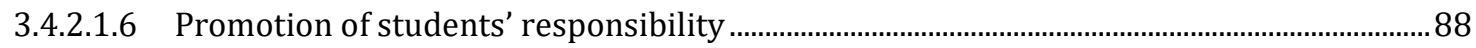

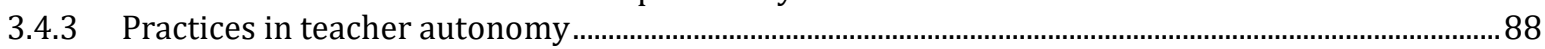

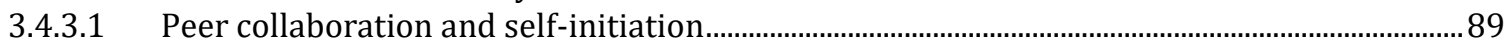

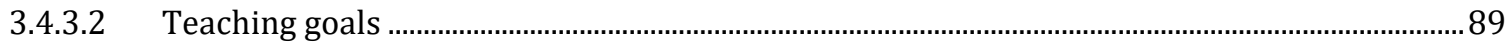

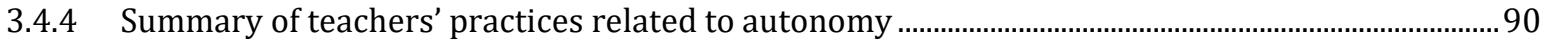

$\begin{array}{llr}3.5 & \text { Conclusion } & 90\end{array}$

\section{PHASE TWO - DEVELOPING STUDENT TEACHERS' SELF-REGULATION}

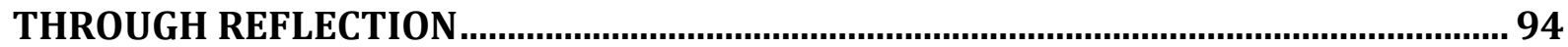

$\begin{array}{llr}4.1 & \text { Methodology } & 94\end{array}$

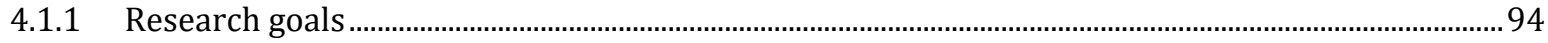

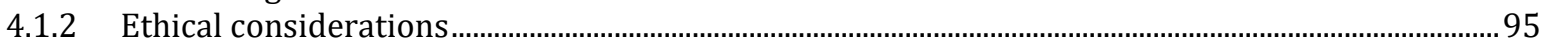

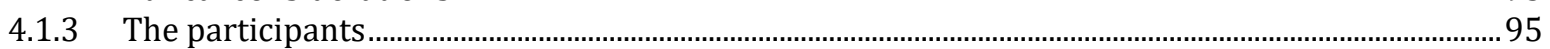

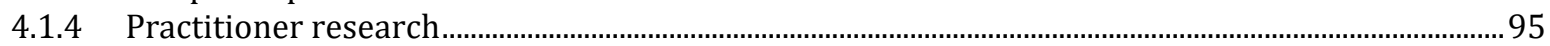

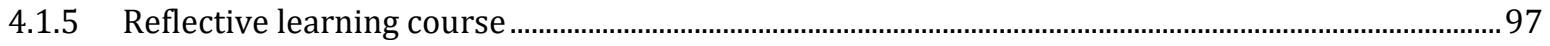

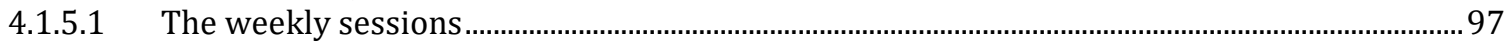

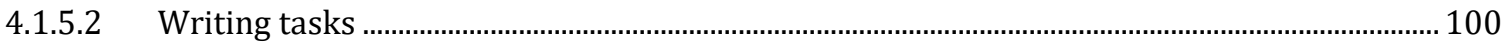

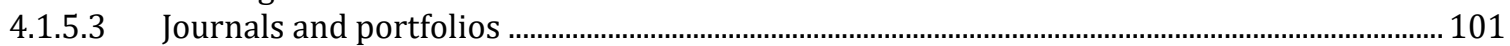

4.1.5.4 Peer collaboration through group discussions ............................................................................... 102

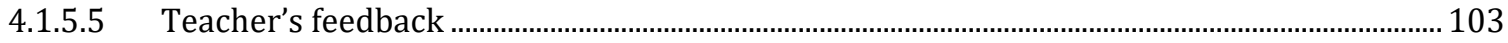

4.2 Data analysis $r \begin{aligned} & 104 \\ & 4.2 .54\end{aligned}$

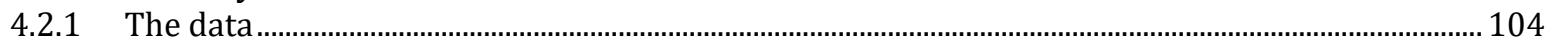

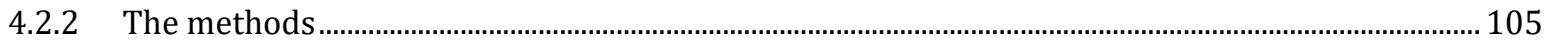

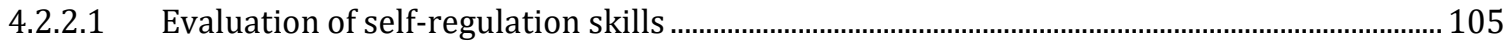

4.2.2.2 Evaluation of the writing performances ..................................................................................... 107

$\begin{array}{lrr}4.3 & \text { Findings } & 110\end{array}$

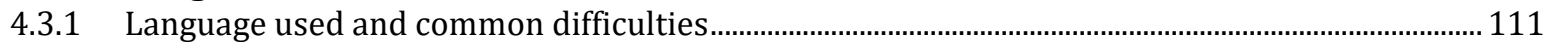

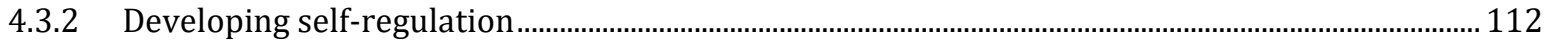

4.3.2.1 Being aware of difficulties - the key to self-regulation ............................................................... 112

4.3.2.2 Developing strategic behaviour ............................................................................................ 117

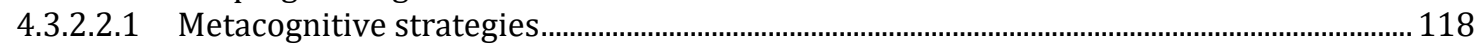

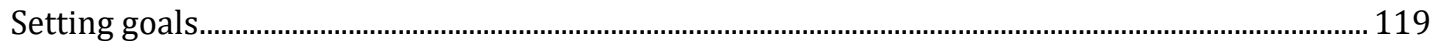

Awareness of the importance of goal setting..................................................................................... 127

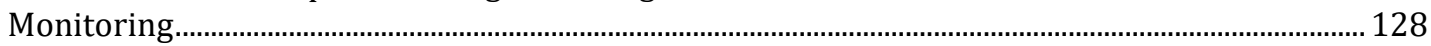

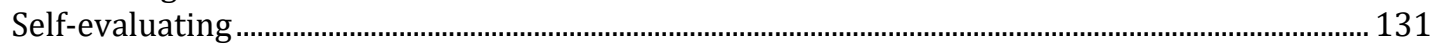

Developing self-evaluation skills......................................................................................................... 132

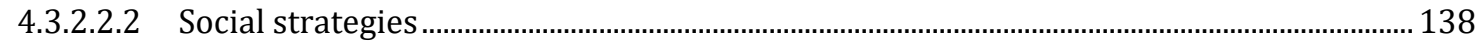

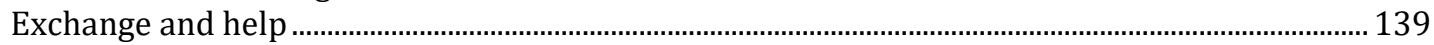

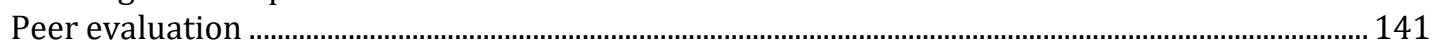

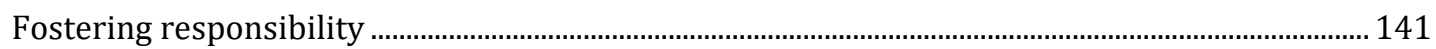

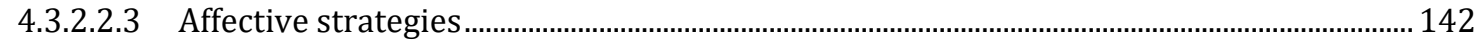

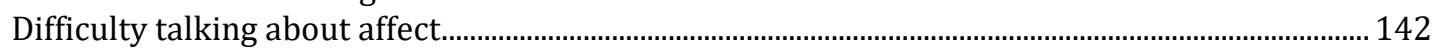

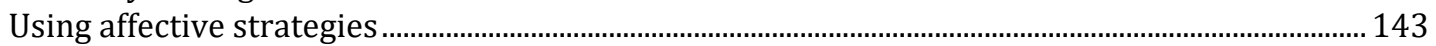

Fluctuating feelings ......................................................................................................................... 144

4.3.2.2.4 Increasing positive feelings such as motivation and self-confidence................................. 148

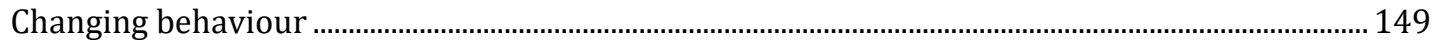

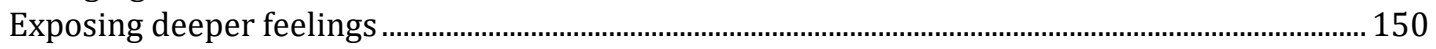

4.3.2.2.5 Cognitive strategies ..................................................................................................................... 151

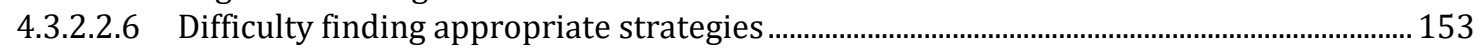

4.3.2.3 Summary of the development of self-regulation .......................................................................... 154

4.3.3 Reflective learning and writing performance................................................................................... 155

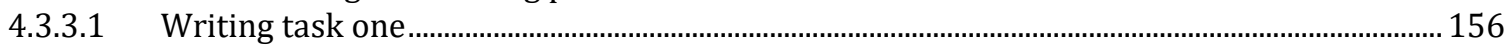

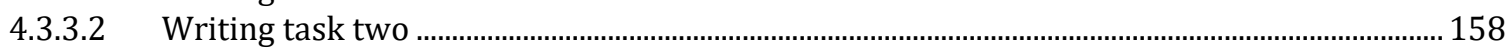

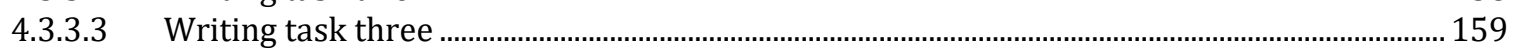

4.3.3.4 Difficulties seen by the teacher versus improvement perceived by the students................ 161

4.3.3.5 Summary of reflective learning and writing performance ...................................................... 164 


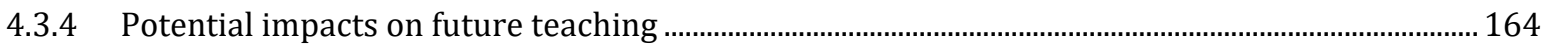

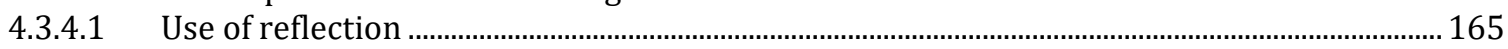

4.3.4.2 Taking charge of their own learning ................................................................................................ 166

4.3.4.3 Goal setting and self-evaluation............................................................................................ 166

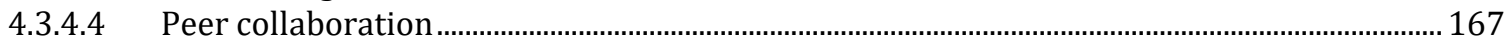

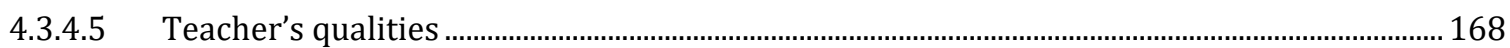

4.3.4.6 Writing practice and explicit teaching ......................................................................................... 168

4.3.4.7 Summary of potential impacts on future teaching ....................................................................... 169

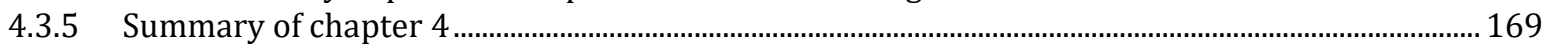

$5 \quad$ PHASE TWO - CASE STUDIES …….................................................................171

$\begin{array}{lll}5.1 & \text { Methodology } & 171\end{array}$

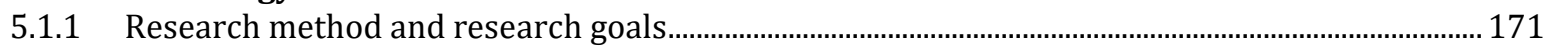

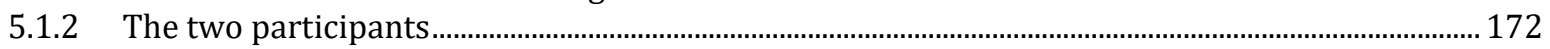

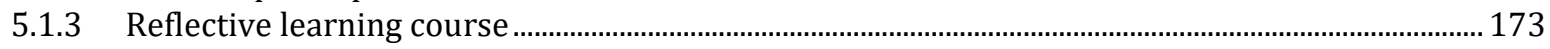

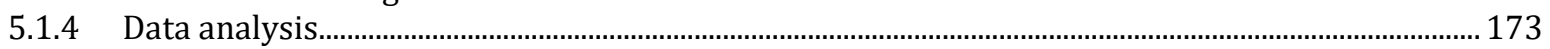

$\begin{array}{lrr}5.2 & \text { Naia } & 174\end{array}$

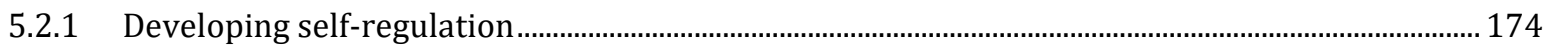

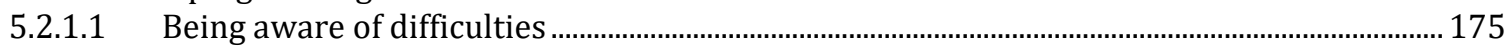

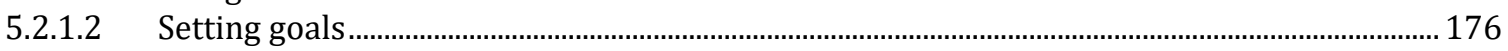

5.2.1.3 Responding strategically to difficulties ............................................................................ 177

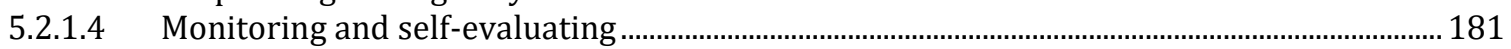

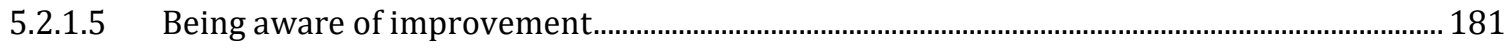

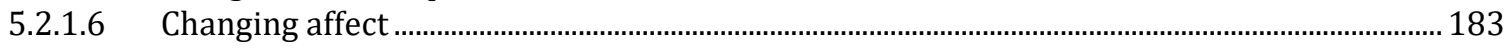

5.2.1.7 Summary of Naia's development of self-regulation ............................................................. 184

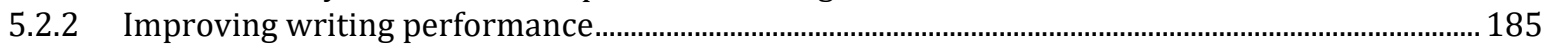

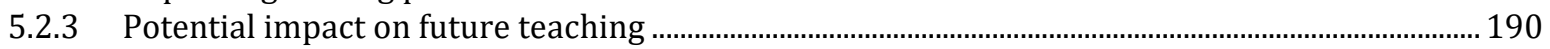

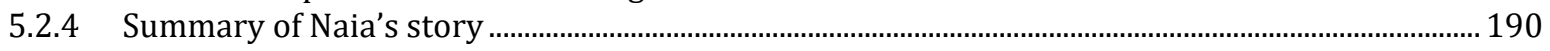

$\begin{array}{llr}5.3 & \text { Katherine } & 192\end{array}$

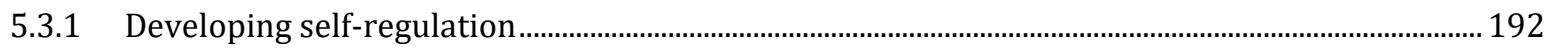

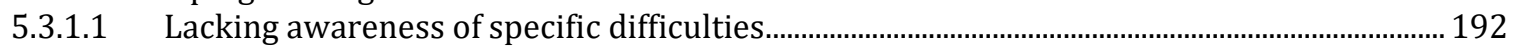

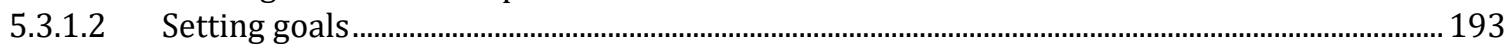

5.3.1.3 Monitoring and self-evaluation - Lacking strategic responses to difficulties........................ 193

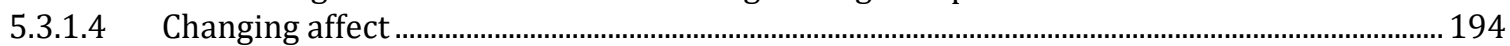

5.3.1.5 Summary of Katherine's development of self-regulation........................................................... 195

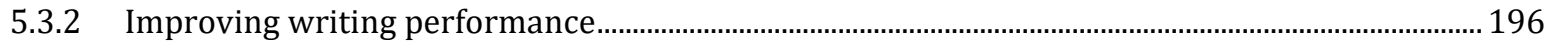

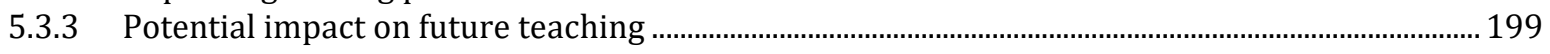

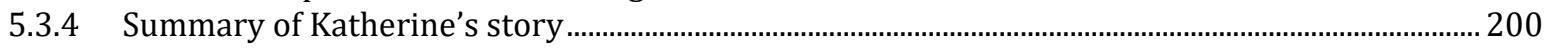

$\begin{array}{llr}5.4 & \text { Summary and conclusions of the two case studies } & 201\end{array}$

6 DISCUSSION

6.1 Taking the context into account when implementing autonomy 205

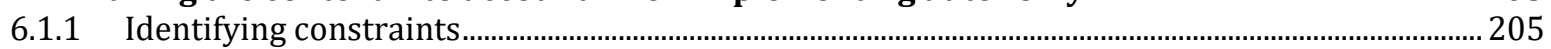

6.1.2 Decisions regarding goals and content....................................................................................... 206

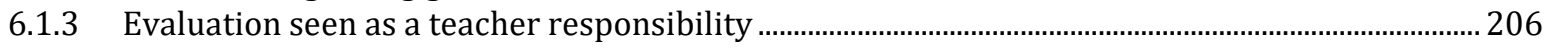

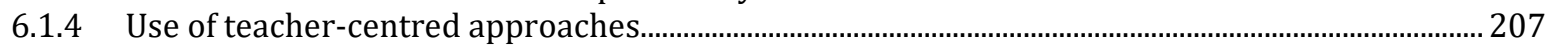

$\begin{array}{llr}6.2 & \text { Recognising constraints to better implement LA } & 208\end{array}$

$\begin{array}{llr}6.3 & \text { Highlighting affordances } & 208\end{array}$

6.3.1 Using interdependence to develop autonomy ….................................................................................2 209

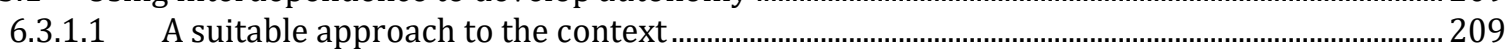

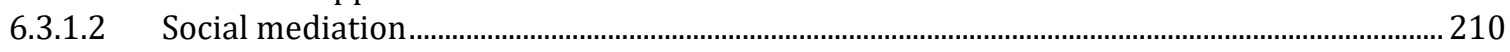

6.3.1.3 Boosting motivation and self-confidence ................................................................................. 211 


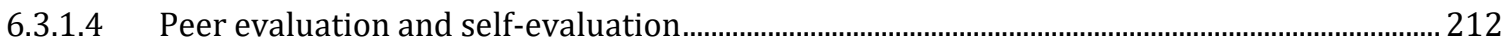

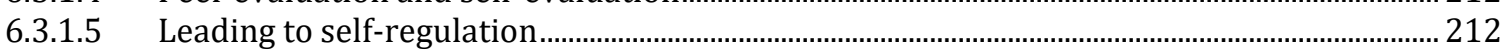

6.3.2 Highlighting affect to promote autonomy ………................................................................................... 213

6.3.2.1 Evident links between affect, self-initiation, and self-regulation ............................................. 214

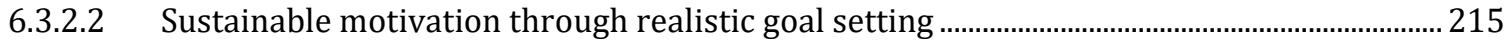

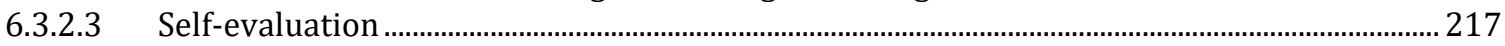

6.3.2.4 Change of perceptions on teacher and learner roles................................................................ 217

6.3.3 Summary of autonomy in the Malagasy context .................................................................................. 218

6.4 Dynamic interrelation of three dimensions of LA 219

6.4.1 A strong connection between self-regulation and self-initiation ........................................................220

6.4.1.1 Necessity of promoting self-regulation ................................................................................... 220

6.4.1.2 Development of self-regulation through reflective journal writing .......................................... 221

6.4.1.3 Self-initiation as a result of self-regulation.................................................................................. 222

6.4.2 Independence as a result of interdependence, self-regulation and self-initiation.......................... 223

6.4.2.1 Interdependence leading to independence ……………………...................................................... 223

6.4.2.2 Caution with interdependence ............................................................................................................. 224

6.4.3 Promoting independence through the promotion of self-regulation ................................................225

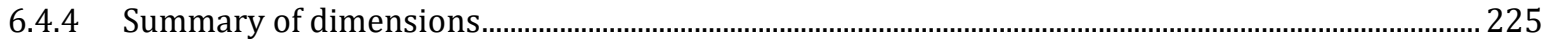

6.5 LA and language proficiency $\quad 226$

6.5.1 Self-initiation and self-regulatory skills lead to better English proficiency in general.................. 226

6.5.2 Self-regulation results in better writing performances ...................................................................... 227

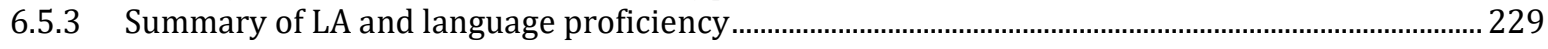

6.6 Promoting LA to (student) teachers 230

6.6.1 Developing teacher-learner autonomy …………………………………………………………….... 230

6.6.2 Teacher autonomy as a goal in itself ............................................................................................... 232

6.6.3 Summary of promoting LA to (student) teachers .............................................................................. 233

6.7 Summary of the chapter 233

7 CONCLUSION

7.1 Theoretical contributions $\quad 235$

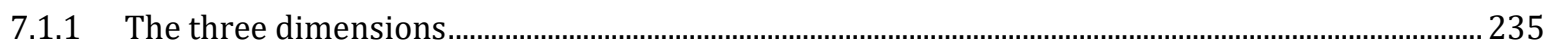

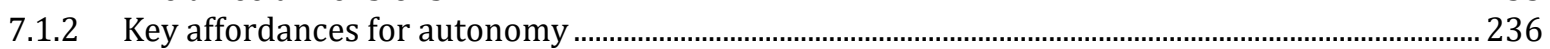

7.1.3 Self-regulation and language learning ................................................................................................ 237

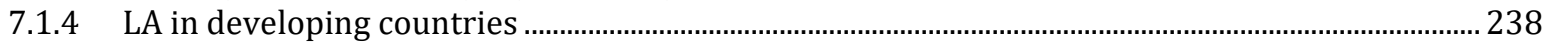

7.1.5 Summary of theoretical contributions............................................................................................ 239

7.2 Methodological contributions 239

7.2.1 A rich contextual understanding via an ethnographic approach.......................................................239

7.2.1.1 Discovering affordances via interviews and class observations ................................................ 239

7.2.1.2 More information through "immersion" ...................................................................................... 241

7.2.1.3 Using practitioner research to develop self-regulation .............................................................. 241

7.2.2 Summary of methodological contributions ………………...................................................................... 242

$\begin{array}{lll}7.3 & \text { Pedagogical contributions } & \mathbf{2 4 2}\end{array}$

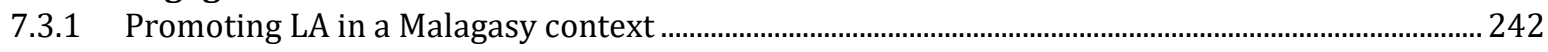

7.3.1.1 Starting with teacher training..................................................................................................... 243

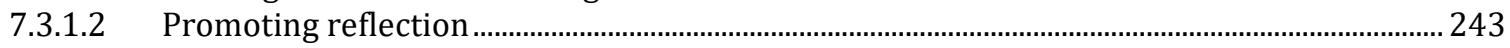

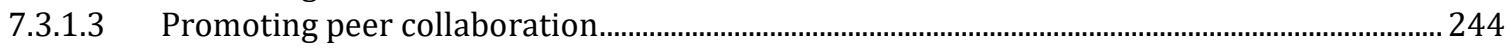

7.3.2 General implications for classroom teaching ……………………………………………………...... 246

7.3.2.1 Revising teacher roles ................................................................................................................ 247

7.3.2.2 Choosing engaging tasks .............................................................................................................. 248

7.3.2.3 Providing autonomy-supportive strategies................................................................................ 248

7.3.2.4 Developing strategic behaviour through repetition ...................................................................... 249

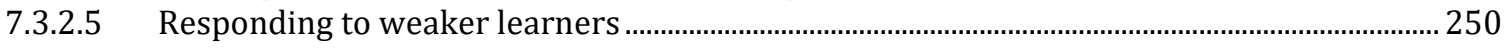

7.3.2.6 Using think-aloud protocol as an alternative option................................................................. 250 
$\begin{array}{llr}7.4 & \text { Limitations } & 252\end{array}$

$\begin{array}{llr}7.5 & \text { Directions for further research } & 253\end{array}$

$\begin{array}{llr}7.6 & \text { Conclusion } & 254\end{array}$

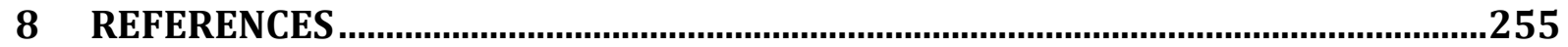

9 APPENDICES

$\begin{array}{llr}9.1 & \text { APPENDIX 1. Interview questions } & 266\end{array}$

$\begin{array}{llr}9.2 & \text { APPENDIX 2. Samples of interview transcripts } & 269\end{array}$

$\begin{array}{llr}9.3 & \text { APPENDIX 3. Class observation checklist } & 272\end{array}$

9.4 APPENDIX 4. Sample of my notes during class observations 2273

9.5 APPENDIX 5. Reflection prompts (phase two) 275

$\begin{array}{llr}9.6 & \text { APPENDIX 6. Samples of reflection (phase two) } & 276\end{array}$

$\begin{array}{lll}9.7 & \text { APPENDIX 7. Sample of coding for interviews (phase one) } & 278\end{array}$

9.8 APPENDIX 8. Sample of coding for class observations (phase one) 279

9.9 APPENDIX 9. Sample of coding for reflections (phase two) 280

9.10 APPENDIX 10. Ethics approval
281

9.11 APPENDIX 11. Teachers' information sheet in English (phase one) 282

9.12 APPENDIX 12. Teachers' information sheet in French (phase one) 284

9.13 APPENDIX 13. Teachers' consent letter in English (phase one) 286

9.14 APPENDIX 14. Teachers' consent letter in French (phase one) 287

9.15 APPENDIX 15. Students' information sheet in English (phase two) 288

9.16 APPENDIX 16. Students' information sheet in French (phase two) 290

9.17 APPENDIX 17. Students' consent letter in English (phase two) 292

9.18 APPENDIX 18. Students' consent letter in French (phase two) 293 


\section{List of figures}

Figure 2.1 Dimensions of LA $\quad 22$

Figure 2.2 Student-directed learning cycle 35

Figure 4.1 Areas of difficulties perceived by the students during and after tasks 116

Figure 4.2 Areas of difficulties perceived by the students in reflection on the course 117

Figure 4.3. Students' different types of goals 121

Figure 4.4. Types of language-related goals 127

Figure 4.5. Areas of improvement perceived by the students during and after tasks 136

Figure 4.6. Areas of improvement perceived by the students in reflections on course 137

Figure 4.7 Students' expressed feelings during tasks 146

Figure 4.8 Students' expressed feelings during reflections on course 146

Figure 4.9 Students' positive feelings during tasks and reflections 147

Figure 4.10 Students' negative feelings during tasks and reflections on course 147

Figure 4.11 Students' scores in 1T1 (out of 12) 157

Figure 4.12 Students' difficulties perceived by the teacher 158

Figure 4.13 Comparison of 1T3 and 2T1 scores (out of 12)

Figure 4.14 Comparison of 2T3 and 3T1 (out of 12) 160

Figure 4.15 Students' scores in 3T2R (out of 12) 161

Figure 4.16 Comparison of difficulties perceived by the teacher and improvement perceived by the students 163

Figure 4.17 Implementations in students' own future classes 165

Figure 5.1 Naia's cyclical pattern 175

Figure 5.2 Naia's scores throughout the course 188

Figure 5.3 Katherine's cyclical pattern 196

Figure 5.4 Katherine's scores throughout the course 198

Figure 6.1 Summary of the findings of the two phases 204

Figure 6.2 Interrelation between self-regulation and self-initiation 223

Figure 6.3 Development of self-regulation and improvement in writing 229

\section{List of tables}

Table 2.1 Types of autonomous learners according to LA dimensions 23

Table 3.1 Elements of LA promoted in class 81

Table 3.2 Elements of LA 93

Table 3.3 Elements of teacher autonomy 93

Table 4.1 The three-week cycle within the course structure 98

Table 4.2 Pre-codes - Tasks and reflection work in order 105

Table 4.3 Sample of inter-coder reliability on reflection entries 107

Table 4.4 Writing rubric 109 
Table 4.5 A sample of reliability data for rating students' writing

Table 4.6. Matching of difficulties and goals on vocabulary

Table 5.1 Impacts of reflective learning on Naia's performance - task 1

Table 5.2 Impacts of reflective learning on Naia's performance - task 2

Table 5.3 Impacts of reflective learning on Naia's performance - task 3

Table 5.4 Impacts of reflective learning on Katherine's performance - task 1 198

Table 5.5 Impacts of reflective learning on Katherine's performance - task 2 199

Table 5.6 Impacts of reflective learning on Katherine's performance - task 3 


\section{Introduction}

"Ny fianarana no lova tsara indrindra." "Education is the best legacy." (A Malagasy proverb)

\subsection{Learner autonomy (LA)}

"Learner autonomy! What is that?" It has been one of the most frequent questions I have been asked these last three years. And despite the frequency, I was not able to provide a straightforward answer each time. The other question was, "Why did you choose learner autonomy?" I hope this thesis will shed light on both those questions.

Learner autonomy (LA) has been a topic of research in language education for about four decades. Theorists and advocates of LA have argued that it should be seen as an educational goal (Aoki \& Smith, 1999; Boud, 1988; Cotterall, 2000; Little, 1995, 1999; Smith, 2003a). Among the most common reasons for this are the fact that learners cannot be accompanied by a teacher throughout their lives, and the perception that LA leads to more efficient learning.

In support of the theories, LA has been implemented in EFL and ESL classes by a number of researchers (Cotterall, 2009; Dam, 1995, 2009, 2011; T. Lamb, 2009; Natri, 2007). These studies show the practical side of autonomy, advocating that the implementation of LA is feasible regardless of the levels of the learners and the settings they are in. Dam's studies $(1995,2009,2011)$, for instance, demonstrate that LA can be applied with primary school children. Fonsenka's (2003) research also shows how LA can be implemented with 8 to 13 year olds in a Sri Lankan poor rural setting. The findings of those different studies all confirm the importance and the advantages of having learners take charge of their learning. They are in keeping with Lamb's (2009) emphasis that "[c]hanges in classroom practices can make a difference" (p. 83) as far as the development of LA is concerned; and this is also what this research would like to try to confirm.

\subsection{LA in Madagascar}

Most of the empirical studies on LA have taken place either in an English as a Second Language (ESL) setting, where English is the first language, in western countries or in an English as a Foreign Language (EFL) setting in a few Asian countries, where English is not the first language. However, those EFL settings are mostly well-resourced (Smith, Kuchah, \& 
Lamb, 2018). The notion of LA is almost unknown in other countries like Madagascar. While being trained to become a teacher of English in my undergraduate studies for five years at the University of Antananarivo, and even while working as an EFL teacher in Madagascar for more than seven years, I never heard of LA in any institutional exchanges. My encounter with this topic was through personal readings only. My interest in LA grew when I constantly noticed that most of my supposedly advanced students did not master English at all at the end of their studies in the language centre where I worked. I understood that implementing LA in the Malagasy context would be challenging but the results could be rewarding.

Before talking about the potential challenges, it is necessary to briefly describe the education system in Madagascar in order to understand the context and to gauge the place English has in the context.

\subsubsection{Education system in Madagascar}

The education system in Madagascar is divided into two major categories: primary school and secondary school. In addition to these categories, pre-primary education is provided in some areas. Before looking at primary and secondary education in more detail, the next section addresses the languages of instruction, as they are also related to the instruction of English, and they are one of the important factors on which students' learning and achievement depend on (Caillods \& Postlethwaite, 1995).

\subsubsection{Languages of instruction}

The language of instruction in Malagasy schools is continuously debated in education conventions, and no clear agreement seems to be reached (Ministère de l'Éducation Nationale, 2016). Like in most developing countries, the mother tongue and the ex-colonial language are both used in class, making teachers' jobs more challenging:

[...] they are expected to teach beginning literacy in the mother tongue, communicative language skills in the exogenous (ex-colonial) language, and curricular content in both, requiring that they be as bilingual and biliterate as possible. In addition, they must bridge the linguistic and cultural gap between home and school, become respected members of the community, and manage any opposition to educational use of the mother tongue. (C. Benson, 2004, p. 204) 
In primary school, some school subjects, such as citizenship education and history are taught in Malagasy while other subjects such as geography and mathematics are in French. This is the case even with the curricula, as shown by Ministère de l'Éducation Nationale (2016): the objectives and the descriptions of each school subject are in the languages they should be taught. In secondary school, all the school subjects are taught in French, except for teaching languages such as Malagasy and English. This means that the notes the students take from lessons are in French. However, the explanation of the lessons from their teachers can be done entirely in Malagasy. This is also the case for English as a school subject: notes are in English, but the explanation is provided in Malagasy or in French.

The extent to which Malagasy and French are used in class depends on teachers, on each school policy, and on the location of the school. School teachers in rural areas tend to use Malagasy more than French, which has its advantages: "Use of local language gives access to lesson content and encourages verbal interaction" (Westbrook et al., 2014, p. 39). The students are able to choose between Malagasy and French when dealing with school subjects such as history, geography, philosophy, and science in the secondary school national examinations.

\subsubsection{Pre-primary and primary education}

Pre-primary education has been expanded and integrated in the Public Primary Schools throughout Madagascar in the last decade. In 2016, there were 9498 pre-schools throughout Madagascar (Ministère de l'Éducation Nationale, 2016). However, they do not suffice for all the children of pre-primary age, as $60 \%$ of them are still not enrolled, hence the necessity of prioritising pre-primary education in Madagascar (UNICEF, 2019). According to the Ministry of National Education, pre-schooling lasts one year. However, in schools in cities, it lasts two years. The inclusion of the teaching of English, mainly through songs, is up to each school manager.

Primary education lasts five years. At the end of the fifth year, the students sit for a national examination, the results of which determine their ability to go to junior secondary school. Though the curriculum set by the Ministry of National Education does not stipulate the inclusion of the teaching of English in primary school, many private schools start teaching English from the first or second year of primary school. This is the case of the school involved in phase one of this research. 


\subsubsection{Secondary education}

Secondary school is divided into two levels: junior and senior. Junior lasts four years and senior three years. The first year of junior secondary school is marked by the introduction of new school subjects, including English, in an official way (as it is stipulated in the curricula designed by the Ministry of National Education).

The curriculum for each level of the secondary school set by the Ministry of National Education includes general objectives and specific objectives for each unit and sub-units. The general objectives of the teaching of English in the secondary school are mainly to enable the students to:

- communicate orally and in written form

- express their personal opinions

- appreciate other values and cultures

- comprehend new notions

- finding about outside facts and phenomena, notably in the fields of science, technology and business

German and/or Spanish are introduced in the third year of junior secondary school. However, the introduction depends on each school and the availability of teachers.

At the end of the fourth year of junior secondary school, the students sit for a national examination, the results of which determine their ability to go to senior secondary school. In the national examination, the students have two options (which they have to choose in the middle of the school year): choosing option A means having English or either of the two other foreign languages as a subject during the examination, while choosing option B means not having any of the three foreign languages but having a higher ratio of mathematics and physics. Statistics about the national examination in 2016 showed that approximately 51\% of the students chose option B, 48\% chose option A with English, and only 1\% chose Spanish or German (Ministère de l'Éducation Nationale, 2016).

The first year of senior secondary school ends with a decision of the students whether they would like to continue with a more literature-oriented education (option A) or a more science-oriented one (options $C$ and $D$ ). The three options cover the same subjects, but the depth and balance in the national examinations are different. For instance, the allocated weekly amount for English for option A classes (four hours) is double the amount for options C and D. In the national examination at the end of senior secondary school (which is of high 
importance, as students need to pass it to be able to go to university), the students in all the three options can choose to have English or the other foreign languages. Nevertheless, like in junior secondary school, English remains the language that most students choose, as few schools provide the teaching of German and Spanish.

The Ministry of Education provides the curricula for English (and all school subjects) for junior and senior secondary school levels, but not all schools follow them to the letter. The curricula include suggestions of textbooks to use, but it is up to each school to use them or not, as it depends on the budget of each school.

In addition to the information about the Malagasy education system above, it is worth mentioning that the Malagasy people's awareness of the importance of English has risen in the past twenty years. This has resulted in the creation of many English language centres in urban and semi-urban areas.

\subsubsection{The potential challenge of implementing LA}

Implementing LA in Madagascar can be viewed as a huge challenge. In Western countries, learners are highly expected to take charge of their learning, and teachers are supposed to provide them with opportunities to exert self-regulated learning, as "[s]elf-direction, selfdetermination, and choice are key concepts" in education (Kirschner \& van Merriënboer, 2013, p. 177). In developing countries like Madagascar, the education system tends to be more "traditional". Though it is not fair to have a broad generalisation for a whole country (and surely, exceptions exist) (Littlewood, 1999), the following traits seem to predominate in the Malagasy education system. Firstly, the approaches used in class tend to be teachercentred. Learners are accustomed to rote learning, choral repetitions, and memorisation, which are approaches often considered as typical in developing countries (Westbrook et al., 2014). Teachers mainly use these approaches because they have inherited them from their own learning (Mulkeen, Chapman, DeJaeghere, \& Leu, 2007). Secondly, as in East Asian cultures, the Malagasy culture tends to have a "high acceptance of power and authority" (Littlewood, 1999, p. 81), which is reflected in most Malagasy classrooms. Learners are generally accustomed to having the teacher as an authority figure telling them what to do; and teachers are used to playing such a role. Such learners are what Oxford (2003b) labels "concrete-sequential" (p. 81). Thirdly, in language classrooms, they are used to the IRE pattern of discourse (Initiation from teacher - Response from learner - Evaluation/Feedback from teacher) (J. M. Sinclair \& Coulthard, 1975). Most of the communication in the 
classroom sounds artificial, as the questions asked by the teacher are not genuine questions for communicative purposes. They are asked to elicit answers already known. There is very little spontaneous talk, and therefore, minimal contributions from learners (Little, 2007). Next, students do the assigned tasks: reviewing lessons, doing exercises, homework, and small projects, but they are not really encouraged to reflect on how the intended learning is related to their goals or how it might be useful in their lives. Like the Vietnamese students discussed in Nguyen's (2008) study, they concentrate on covert learning in class, but they do not feel the necessity to do extra work. It is not surprising, then, that after graduating from secondary school (having had seven years of English), most Malagasy students can barely use English in real life.

The use of reflection, which is the main tool used to develop autonomy in this research, might not be an innovative approach in the Western world, but in the EFL Malagasy context, it definitely is. Fonseka (2003) states:

In a society without basic survival problems it may be relatively easy to establish autonomy and self-directed behaviour in learners. However, to be independent in one's thoughts, words, acts, dreams, and behaviour, one needs a strong backing from the environment. (p. 153)

Additionally, it is worth pointing out that the term "LA" (or its translation) is not used at all in the curricula designed by the Ministry of Education.

\subsection{Aims of the research}

The present research has two main aims. The first aim is to know the affordances for LA in a Malagasy rural context. This aim is based on the belief that the fact that the concept of LA is not known in a particular setting does not necessarily mean that it does not exist at all. Some elements of autonomy may be perceived inside and outside class, but they have not been labelled as such. The study of such elements may lead to a better understanding of the way they can be further developed in the given context (Allwright, 1988), and therefore, should not be underestimated (Smith et al., 2018). Phase one in this research, thus, studies the beliefs of teachers regarding LA as well as their current practices that foster autonomy in a Malagasy rural setting in order to see how they can be further explored. In addition to LA, this research also looks at the teachers' beliefs and practices with regard to teacher autonomy, a notion closely linked to LA, as will be explained in this thesis. The setting was 
particularly chosen as a focal point because four out of five Malagasy people live in rural areas (UNICEF, 2018a).

Taking into account the contextual affordances and constraints found in phase one, the second aim is to provide EFL Malagasy student teachers with the "strong backing" (Fonseka, 2003 , p. 153) that they need to develop autonomy. For that purpose, reflection is used, in phase two, as a tool to help 22 student teachers develop their self-regulation skills in order to foster their LA, while improving their writing. The choice of the participants and the setting for phase two was supported by the belief that LA can be promoted via some changes in classroom in any context under three conditions (Lamb, 2009). Firstly, the contextual learning conditions should be considered when attempting to implement LA (Ambler, 2012; P. Benson \& Lor, 1999; Fonseka, 2003; Hacker \& Barkhuizen, 2008); approaches to fostering different levels of autonomy differ from learners in one setting to learners in another one (Fonseka, 2003). My experience as a former student teacher in that university, as an EFL teacher in Madagascar for seven years, as well as phase one, which I conducted in the rural school resulted in an understanding of the context. Secondly, in order to promote LA, teachers should have intentions to do so. Thirdly, teachers should have ideas on how to realise these intentions in their classrooms. The last two conditions are not likely to happen if their own education does not enable them to learn about LA (Little, 1995). Therefore, the research intends to foster LA in these student teachers through "reflective learning", a nine-week course, in which they use reflection accompanied by peer collaboration. It studies how reflective learning might lead to the student teachers' development of LA, and how the latter might be conducive to the improvement of their writing performances. Apart from experiencing the promotion of LA as learners, the student teachers might also see how LA can be fostered so that they can do the same in their own classes later. Therefore, reflective learning was intended to foster LA, but it was also in itself the starting point for fostering what is referred to as teacher(-learner) autonomy.

This research intends to bring insights regarding LA in the EFL Malagasy setting, and to promote LA in such a setting, an area that seems to be unexplored. Thus, this research will be among the pioneer studies dealing with LA in Madagascar. It will also contribute in shedding light on education in Madagascar, including tertiary education, on which empirical studies are scarce (Venart \& Reuter, 2014). Furthermore, it will add to the literature on LA in African and developing country settings, which needs expanding. 


\subsection{Organisation of the thesis}

This thesis consists of seven chapters. This chapter introduces the aims of the research. As this thesis is the first to deal with LA in a Malagasy context, it is deemed necessary to include information about the Malagasy education system as well as the potential challenges of implementing LA in Madagascar. This chapter is followed by a literature review (Chapter two) providing an in-depth discussion about theories and research regarding LA. It encompasses definitions of LA, theories related to $L A$, dimensions of LA and aspects related to the dimensions. It also includes approaches to promote LA and the methodological theory underpinning this research.

As this thesis is composed of two different phases, each phase is written as an integrated study including the methodology and findings. Chapter three is devoted to phase one of the research, investigating affordances for autonomy in a Malagasy rural school. The chapter includes the descriptions of the study purposes, the participants, and the setting. It then discusses the procedures for data collection as well as the data analysis. Next, it presents a detailed account of the findings, encompassing the contextual affordances, discovered through teachers' beliefs and practices.

Chapters four and five discuss phase two, which aimed to help student teachers develop their self-regulation of writing through reflective learning. Chapter four describes the study purposes, the 22 participants (the cohort), the reflective learning course, and the procedures for data collection and data analysis. It presents a detailed discussion of the findings. Chapter five deals with two case studies, selected from the cohort. The chapter provides a thorough discussion about the development and lack of development of self-regulation of the two student teachers, and the impacts on their writing.

Chapter six draws all the main findings from both studies together. It discusses the relevance of autonomy in the Malagasy context by highlighting the affordances for autonomy perceived in phase one and promoted in phase two. Then, it talks about the importance of reflective journals, and the link between LA and teacher autonomy.

Chapter seven concludes the thesis by emphasising the theoretical, methodological, and pedagogical contributions of the research. It also encompasses limitations and directions for future research. 


\section{Literature review}

A large and growing body of literature has investigated the effectiveness of LA on language learning. Though the literature has constantly reiterated the initial definition of LA by Holec (1981), "the ability to take charge of one's own learning" (p. 3), it has also claimed the necessity to define LA more specifically or to conceptualise it.

This chapter is divided into five sections. Section 2.1 discusses what LA is. It begins by reviewing the main misconceptions about LA, as it is from misconceptions that LA is sometimes seen as inappropriate in some given contexts, including the Malagasy context. Then, it looks at the definitions of LA, and explains the reasons why it should be seen as a goal both in general education and language education. Section 2.2 discusses theories related to LA. Section 2.3 talks about versions, dimensions, and components of autonomy that are considered relevant to the present research. Section 2.4 focuses on other aspects conducive to LA, which are affective factors and social factors. Section 2.5 discusses approaches to the promotion of LA, putting more emphasis on learner-based and teacherbased approaches. The section also discusses studies investigating the promotion of LA in developing countries, involving potential challenges. Section 2.6 discusses how LA is conceptualised and operationalised in this research, which approaches are used, what research questions are going to be answered, and what methodology theory underpins the research.

\subsection{What is LA?}

LA is such a complex concept that is hard to define in a simple way. This explains why despite the great number of research on autonomy in language teaching and learning, the term 'autonomy' is not specifically defined (P. Benson, 2009). Before looking at the various attempts to define definitions of LA and the reasons why LA should be viewed as a goal, it is necessary to recognise that LA is often misconceived. The misconception has led to the belief that LA does not fit in certain contexts.

\subsubsection{Misconceptions about LA}

LA is not always viewed as an appropriate educational goal because it is sometimes seen as 'associated with a radical restructuring of language pedagogy' with 'the rejection of the traditional classroom and the introduction of wholly new ways of working' (Allwright, 1988, 
p. 35). It is misinterpreted as self-instruction and linked with individualism. It is important to understand these misconceptions and their origins, as they are often related to culture and settings, which are crucial factors to be considered before implementing LA or any other learning approaches.

Firstly, the origin of LA (beyond language learning) is linked to the Western idea of an ideal society, putting emphasis on exercising individual autonomy and respecting others' autonomy (P. Benson, 2007). This might be a reason why the concept of LA has often been seen as related to Western culture and individualism (Aoki \& Smith, 1999; Palfreyman, 2003). Little (1999) puts it, "[i]t is sometimes thought that LA necessarily entails total independence - of the teachers, of other learners and of formally approved curricula" ( $p$. 178). Indeed, LA tends to be seen as a "do-as-you-like undertaking for the learners" (Dam, 2011, p. 49). This misconception has triggered the belief that LA does not have its place in a context inclined to collectivist culture.

Secondly, interest in LA in language learning resulted from early experiments with adults not having time to attend classroom-based courses (P. Benson, 2007) and early work in selfaccess language learning, aiming to promote autonomy by providing learners with direct access to target language materials, enabling them to be the sole decision-makers regarding goals, content, materials, and strategies (Murray, 2014a). Murray continues by stating that this type of promotion of autonomy does have its success. Yet, its predominance has spread the misinterpretation that LA implies learning in isolation and, thus, necessarily promotes individualism. It also caused the misleading view that the implementation of LA has to take place in special places such as self-access centres equipped with technological resources (Palfreyman, 2003; Smith, Kuchah \& Lamb, 2018), which cannot be created in developing countries like Madagascar.

Another reason for the misconception about or possible misuse of LA is the non-existence of a single definition and the existence of broad definitions. P. Benson (2009) states that broad definitions, such as the one he provides in P. Benson (2001, p. 41), "[Autonomy] is a multidimensional capacity that will take different forms for different individuals, and even for the same individual in different contexts or at different times", may lead novice researchers to think that "autonomy can be almost anything that we want it to be!" (p. 15). 


\subsubsection{Definitions of LA}

The foundational definition of LA given by Holec (1981) has been the most cited in the literature. According to Holec, this ability is acquired by "natural" means (not "inborn") or by formal learning. Holec further defines "taking charge of one's learning" as having the responsibility for making decisions about the learning objectives, contents and progressions, methods and techniques, monitoring the procedures of acquisition, and evaluating what has been acquired.

Holec's definition has been criticised for not being specific enough in a way that it describes what autonomous learners are able to do rather than how they are able to do it (P. Benson, 2007). Furthermore, it emphasises only abilities, but not attitudes or dispositions, which are other essential components of autonomy (P. Benson, 2009). Also, it seems to encompass a contradiction in terms of whether linguistic and communicative goals should be distinctly separate from the goal of becoming autonomous or not (Little, 2007).

Since Holec's definition, a considerable amount of research has been devoted to LA in language learning, demonstrating the complexity of LA, leading to a difficulty in agreeing on a single definition of 'autonomy'. However, it seems that the necessity to reconceptualise autonomy if applied to the classroom suggested by Allwright (1988) has brought about significant theoretical implications (P. Benson, 2007). Instead of reaching one single definition, researchers and theorists seem to concur that LA "manifests itself in different ways and to differing degrees" (Cotterall, 1995, p. 195). It has been advocated that LA has different components (Littlewood, 1996; Tassinari, 2012), different levels (P. Benson, 2001; Littlewood, 1999), different versions (P. Benson, 2007; Smith, 2003a), different perspectives (Oxford, 2003b), different dimensions (P. Benson, 2007, 2011; Gu, 2009; Huang \& Benson, 2013), and a multifaceted nature (P. Benson, 2007, 2009, 2011). Also, it has been claimed to depend on other aspects, such as the context (P. Benson, 2011; Little, 1999; Nakata, 2011; O'Leary, 2014; Ryan, 1991), including the beliefs and perceptions related to the context (P. Benson, 2011; Cotterall, 1995; Littlewood, 1996; Ryan, 1991), relatedness (Little, 1991; Murray, 2014a; Ryan, 1991; Tassinari 2012), affective factors, especially, motivation (P. Benson, 2011; Dickinson, 1995; Ushioda, 1996; Yamashita, 2015), and metacognition (P. Benson, 2011; Murray, 2011; Mynard, 2010). These aspects are all interconnected, and therefore, have to be considered when implementing LA and to be added or included in what is referred to as "taking charge of one's learning". 
Due to the multifaceted nature of $L A$, it is possible to come up with different definitions. In order to make LA more specific and "researchable", P. Benson (2011) recommends conceptualising LA when conducting research, which this research will do in section 2.6. Before conceptualising LA, I will discuss why LA is viewed as an educational goal, the theories that may be viewed as the foundations of $L A$, and the versions, dimensions or components of $L A$, according to the literature.

\subsubsection{LA as a goal}

LA should be seen as an educational goal, as advocated by many researchers (e.g. Aoki \& Smith, 1999; Boud, 1988; Cotterall, 2000; Little, 1995, 1999; Littlewood, 1996, 1999; Smith, 2003a) for different reasons. Aoki \& Smith (1999), for instance, view autonomy as a potential solution to economic and political issues in the Japanese context. They state, "for socially aware educators, autonomy may be a particularly important goal to pursue with Japanese students at the present time, given the uncertain economic situation and the wide range of unresolved social and political problems affecting their lives" (p. 24). Other researchers like Ryan (1991) go as far as viewing the attainment of autonomy as a vital necessity and purpose of human beings. There may be other various reasons to see LA as a goal according to the context, but the most common reason remains the fact that learners will need to take charge of their learning at some point, including making decisions on every aspect of their learning, because they will not have teachers to help them throughout their lives. Thus, they need to become more self-reliant regarding their learning:

If we define autonomy in educational terms as involving students' capacity to use their learning independently of teachers, then autonomy would appear to be an incontrovertible goal for learners everywhere, since it is obvious that no students, anywhere, will have their teachers to accompany them throughout life. (Littlewood, 1999, p. 73)

Moreover, as learners' needs are likely to change over time, LA will assist them in any types of learning they will undertake (Bayat, 2011; Boud, 1988; Chu, 2007; Crabbe, 1993; Scharle \& Szabó, 2000). Chu (2007) adds that learners need to know that they are the ones holding the power to improve their learning. Setting one's own goals and finding ways to attain the goals are highly likely to lead to efficient learning (Little, 1999).

In language learning and teaching, LA is a goal in its own right, but also used to achieve another goal, that of better proficiency in the target language, which is the primary goal of 
foreign language learners and teachers (Nguyen, 2008). In fact, not many language learners consciously aim to become autonomous. They would be more concerned about improving their proficiency. Because autonomy triggers responsibility, motivation, and then, efficient learning (Little, 1999), its development is highly likely to result in the improvement of the target language proficiency. Little (2007) states, "the development of learner autonomy and the growth of target language proficiency are mutually supporting and fully integrated with each other" (p. 14). Therefore, like in any teaching, LA should be the goal for language teaching, and should be implemented in the methodology used in the classroom:

[...] if we are teaching language for communication, it follows from this that the goal is to develop a capacity to communicate autonomously [...], that is, without the control and support of a teacher. It also seems intuitively likely that students cannot be properly prepared for this goal unless their classroom experiences, too, include forms of interaction in which they contribute autonomously to the development of the discourse [...]" (Littlewood, 1999, p. 73)

LA does need promoting in the classroom, implying minimum control on the part of the teacher, as Littlewood states, but I strongly believe that the learners need support from the teacher. This will be further discussed later in the Section 2.5 about promoting LA.

\subsection{Theories related to LA}

This research is underpinned by theories in the fields of cognitive psychology, humanistic psychology, self-determination, social constructivism, and self-regulated learning, which have shaped or are closely related to LA. This section discusses these theories.

\subsubsection{Cognitive psychology, humanistic psychology, and self-determination theory}

Autonomy has its roots in cognitive and humanistic psychologies (Broady, 1996). Cognitive psychology views knowledge, learning, and behaviours as interconnected: learning is a process in which learners acquire and use knowledge actively; knowledge, therefore, results from learning; and knowledge can change behaviour (Woolfolk, 2004). Cognitive psychology highlights the importance of two types of knowledge related to memory: procedural knowledge and declarative knowledge. Procedural knowledge refers to "knowledge of how to do things" and declarative knowledge is related to the storage of 
what has been learned (Ten Berge \& Van Hezewijk, 1999, pp. 607-608). Understanding and using these two types of knowledge in a more conscious way can result in more effective learning and autonomy, which points out the significance of cognitive strategies. Gagne (1975) states that if "strategies of attending, coding, retrieving, transfer, and problem solving can be learned and improved by formal educational means, the learner will increasingly become a self-learner and independent thinker" (p. 64).

Human psychology has an experiential and holistic view of learning. Learning involves well-being, feelings, and personal meanings (Rogers, 1983). According to Rogers, learning incorporates five features: (1) personal involvement related to both cognitive and affective factors, (2) self-initiation, implying that "the sense of discovery, of reaching out, of grasping and comprehending comes from within" (p. 20), (3) pervasiveness, in a way that learning brings about differences in behaviour and attitudes, (4) self-evaluation, involving learners' consideration of their learning needs and wants, (5) and a focus on the meaning of what is learned to the learner. The combination of these features would result in self-awareness and development. More recently, the importance of well-being in learning, and particularly, in language learning, has been emphasised in what is called Positive Language Education (PLE), which sees wellbeing as "the foundation for effective learning and a good life more generally" (Mercer, MacIntyre, Gregersen, \& Talbot, 2018, p. 11). Mercer et al stress the link between self-awareness, socio-cultural competence, and positive relationships. Selfawareness is said to be the key factor on which the self-regulation of emotions, internal motivation, empathy, and social skills depend (Mercer \& Gregersen, 2020).

Self-determination theory (SDT) also stresses the importance of learners' well-being or "wellness" and describes it as "the orienting, assimilating, and creative contact with the world and one's values" (Ryan \& Deci, 2017, p. 241). The development of that wellness is related to basic psychological needs (BPNs) including autonomy. Autonomy is defined as "the need to self-regulate one's experiences and actions" and involves self-endorsement and congruence with one's interests and values (ibid, p. 10). The other two BPNs are competence, the need to feel that one's endeavours are effective in a given context, and relatedness, the feeling of connectedness and belonging to a society or a group. The three BPNs are essential for well-being and intrinsic motivation. 


\subsubsection{Social constructivist theory}

Based on Vygotsky's (1978) work, social constructivism focuses on the collaborative nature of learning and the strong connection of learning to the social context where it happens ( $\mathrm{Au}$, 1998). Learning is seen as a process "within and from social forms and processes" (Adams, 2006 , p. 246). Adams enumerates the following principles, which pedagogy based on social constructivism, is likely to have:

- Focus on learning not performance

- View learners as active co-constructors of meaning and knowledge.

- Establish a teacher-pupil relationship built upon the idea of guidance not instruction.

- Seek to engage learners in tasks seen as ends in themselves and consequently as having implicit worth.

- Promote assessment as an active process of uncovering and acknowledging shared understanding

In other words, social constructivism puts a strong emphasis on learners and views teachers being more of facilitators rather than instructors. It sees learners as humans constructing knowledge through social interactions. It focuses on the process of learning (including the social interactions) rather than the product of learning.

Drawing from the social constructivist theory and the other theories stated in the previous section, researchers in LA have theoretically established the link between LA, affect, and interdependence, which will be discussed in 2.4 .

\subsubsection{Self-regulated learning}

Self-regulation involves self-generated thoughts, feelings, and behaviours oriented to achieving goals (Zimmerman, 2000, 2002). According to the SDT mentioned earlier, selfregulation is included in the definition of autonomy (Ryan \& Deci, 2017), and is considered as the trigger to "authentic" actions (Ryan 1991). Though not all researchers agree and consider self-regulation and LA as two different concepts mainly because of their different origins (for example, Murray, 2014b), the same research recognises that both have common key features such as active engagement, goal-directed behavior, metacognitive skills, and intrinsic motivation. 
According to Zimmerman $(1998,2002)$, self-regulated learning consists of a cycle of three phases: forethought, performance, and self-reflection. Forethought involves task analysis including goal setting and strategic planning, and self-motivation beliefs including the valuing of the task and the learning, the beliefs of self-efficacy, interest and outcome expectations. Performance comprises self-control, in which the strategies during the forethought phase are implemented, and self-observation consisting in self-monitoring in terms of what strategies work best and of how much time is spent. Self-reflection encompasses selfevaluation involving the evaluation of performance and the causal attribution to their success or failure, and self-reaction including feelings towards the performance. Selfregulated learning is, thus, "an active, constructive process whereby learners set goals for their learning and then attempt to monitor, regulate, and control their cognition, motivation, and behavior, guided and constrained by their goals and the contextual features in the environment" (Pintrich, 2000, p. 453).

The cycle described by Zimmerman and Pintrich's definition above imply that selfregulation has the three skills of planning, monitoring, and evaluation as its main components. These three skills are often referred to as metacognitive skills (Chamot, 2005; Murray, 2011; Nguyen \& Gu, 2013; Schraw, 1998; Wenden, 1991). They are also known as metacognitive strategies; and their use, together with cognitive strategies such as transferring information and summarising, can be viewed as what "effective learning" in L2 involves (Oxford, 2002, p. 125). The development of these metacognitive skills increase learners' awareness of their learning processes and strategies (Dickinson, 1988). Such awareness is crucial, as it allows learners to perceive which strategies work and which do not, which results in more effective learning.

\subsubsection{Planning and goal setting}

Planning encompasses setting goals, which is seen as a feature of autonomous learning (Dickinson, 1993). Every learner has a general goal related to the success of their learning. For instance, a driving learner's goal is to be able to drive. Similarly, a language learner aims to be able to use the language. However, having such a vague goal is not sufficient, especially, when dealing with multifaceted subjects such as language. Goals should be sufficiently specific in order to be "efficient": learners' performance is likely to get better if they are committed to specific goals rather than being told to do their best (Locke \& Latham, 2002) because specific goals act like clear directions. Once the goals are clear, it is easier to 
decide what to focus one's effort on: "So long as a person is committed to the goal, has the requisite ability to attain it, and does not have conflicting goals, there is a positive, linear relationship between goal difficulty and task performance" (Locke \& Latham, 2006, p. 265). Therefore, if goals are too vague or not specific enough, dividing them into sub-goals may be required so as to have better performance results, as shown in a case study presented in Murray (2011), where the learner himself realized he had to identify smaller and achievable goals. This is strongly related to the "present" and future-oriented sources of motivation described in section 2.3: the future-oriented sources are the big goals to be attained over a long period of time, while the present sources consist of the achievement of day-to-day subgoals. Indeed, goals are linked to affect because they "set the primary standard for selfsatisfaction with performance" (Locke \& Latham, 2006, p. 265).

As explained above, motivation and goals are inter-related. Goals are "a key element in self-regulation" (Locke \& Latham, 2006, p. 265), as setting them requires learners to be the decision makers (Chu, 2007): the more learners make decisions about their own learning, the more they are motivated, and become more engaged in their learning. The decision about what goals to focus on generally derives from the learners' awareness of difficulty or dissatisfaction with their current ability or knowledge (Locke \& Latham, 2006). On the other hand, giving opportunities and practice to make decisions enables learners to realise that they have excellent ideas on how they should learn (Chu, 2007). Being aware of how they should learn makes them autonomous.

Goal setting has four crucial moderators: feedback, commitment to the goal, task complexity, and situational constraints (Locke \& Latham, 2006). Feedback helps students evaluate their progress. Commitment to the goal is key because if they do not see their goal as important, they will not make effort to reach it. The task should be sufficiently complex to trigger the necessity to set a goal. However, attention should be paid so that there is no overload.

\subsubsection{Monitoring}

Monitoring is one feature of self-regulation (Dickinson, 1993). It consists of observing one's own feelings, progress towards goals, focus and performance while doing the task (Nguyen $\& \mathrm{Gu}, 2013)$. It is through such observations that learners' awareness of their affect and discovery of their difficulties arise, that they ask themselves questions about their learning process (Wenden, 1991). The awareness of such difficulties may push them to make 
decisions and to react; and such reactions are referred to as cognitive strategies. In monitoring, they also gauge whether these strategies work or not. As they assess the effectiveness of these strategies, their progress and performance, they do some selfevaluation and give feedback to themselves. As Cotterall (1995) puts it, "[s]elf-monitoring provides learners with feedback on their language performance" (p. 199). Thus, monitoring includes self-evaluation "during the act of learning" (Wenden, 1991, p. 27).

If compared to planning and evaluating, monitoring seems to be more difficult to exercise (Nguyen \& Gu, 2013; Sert, 2006; White, 1995), due probably to this simultaneity that monitoring requires. Attention tends to be mainly focused on task completion rather than on the cognitive strategies. In other words, the task itself is likely to attract more emphasis than the observations about it. Therefore, it is hard to be fully aware of monitoring, to keep track of it, let alone to feel the benefits from it. For successful monitoring, Murray (2011) suggests providing learners with criteria or a model which they can refer to.

\subsubsection{Self-evaluation}

The word "self" included in "self-evaluation" already implies the idea of autonomy. Selfevaluation is an important feature of metacognition (Nguyen \& Gu, 2013), and its practice is considered to be contributory to the development and the exercise of LA (Little, 2011).

Firstly, self-evaluation can be utilised as a planning strategy, and can occur with goal setting, in which learners "draw upon the knowledge gained through monitoring to assess their knowledge and skills" (Wenden, 1991, p. 27). In other words, from monitoring, learners evaluate their own work, and then, set goals according to their perceived difficulties and improvement. Indeed, self-evaluation has to be closely related to goals in that learners can evaluate their learning effectively if they refer to their goals, and may feel satisfaction or dissatisfaction accordingly (Locke \& Latham, 2002). Though self-evaluation does allow learners to compare their own performances with a given standard, or their own prior performances, or their peers' performances, it is best to self-evaluate against personal goals, as doing so results in better self-satisfaction with improvement and willingness to make effort towards more improvement (Zimmerman, 2002).

According to Smith (2003a), self-evaluation increases student reflection and control. His study shows that most students felt they had made important progress towards attaining their goals. Therefore, like monitoring, self-evaluation enables learners' awareness of their strengths and weaknesses (Anderson, 2012). However, unlike monitoring, which is done 
during the act of learning or performing, self-evaluation focuses more on the outcome of the strategy used (Wenden, 1991).

Secondly, particularly in writing, the language skill that is focused in this research, having the opportunity to self-evaluate helps learners develop responsibility for their writing (Seow, 2002). Self-evaluation includes self-editing. According to Ferris (2002), self-editing makes students aware of how errors in writing affect understanding, which enables them to correct their peers' errors as well as their own. The ability to self-correct is indeed a sign of LA (Dam, 2011); and peer editing is also proven to reduce rule-based errors, as it makes students aware of their grammatical weaknesses and the fact that meaning and form are related (Diab, 2010). Both self- and peer corrections allow learners to use and, hence, to enhance their evaluation skills (Nguyen \& Gu, 2013). In order to enable learners to self-evaluate effectively, they should be made aware of the criteria to do so (Anderson, 2012; Murray, 2011; Seow, 2002).

\subsubsection{Summary}

This section explained that LA has emanated from or at least strongly related to different grand theories. From these theories, the following principles have been highlighted and serve as foundations for this research: firstly, the knowledge of cognitive strategies and metacognitive strategies is key to effective learning. Helping learners use metacognitive strategies or metacognitive skills helps them develop self-awareness, self-regulation, and responsibility towards their learning. Secondly, the context plays an important role in learning, and LA is constructed within the context and through social interactions. Thirdly, the focus should be on the learners and the process of learning. Last, learners' well-being should be taken into account.

The following two sections ( 2.3 and 2.4) discuss versions and dimensions of LA, affective and social factors, which are all linked to the theories described in this section.

\subsection{Versions, dimensions or components of LA}

As LA can be drawn from different theories, there is no one single definition of LA. Also, it can vary from one learner to another and depends on many factors. Autonomous learners' behaviour "can take numerous different forms, depending on their age, how far they have progressed with their learning, what they perceive their immediate learning needs to be, and so on" (Little, 1991, p. 4). While some researchers view LA as a concept with different 
levels, others see it as multidimensional or constituted by different components. Some of the dimensions or components mentioned by the researchers overlap. The literature on the versions, dimensions or components of LA is so abundant that it is not possible to look at each one of them in this thesis. Instead of discussing each one, I will talk about those which may have direct connections with developing country contexts and with learners who have not experienced the promotion of LA yet, as are the cases of the participants and the context in this research. The present section, thus, discusses proactive autonomy and reactive autonomy (Littlewood, 1999), strong and weak versions of pedagogy for LA (Smith, 2003a), dimensions of LA (Gu, 2009), and components of LA (Huang \& Benson, 2013). Though Gu's dimensions and Huang \& Benson's components may not be seen as directly linked to the context in this research, the development of some of the components/dimensions are particularly relevant or necessary in the context, which will be explained in section 2.5 .

\subsubsection{Proactive autonomy and reactive autonomy}

One of the most cited levels or versions of autonomy is Littlewood's (1999) proactive autonomy and reactive autonomy. Proactive autonomy refers to self-directed learning, in which learners take the initiative of regulating their learning by setting their own goals, by making decisions about learning methods, and by self-evaluating. Littlewood states that despite the significance of proactive autonomy, it should not be considered as the only version of LA. Reactive autonomy, which is a type of autonomy that needs triggering instead of being self-directed, also has its importance. This type of autonomy requires some guidance and direction, but once the direction is set, learners will be able to regulate their learning, as they will be more aware of their learning. Reactive autonomy "is a form of autonomy that stimulates learners to learn vocabulary without being pushed, to do past examination papers on their own initiative, or to organize themselves into groups in order to cover the reading of an assignment" (Littlewood, 1999, p. 76). Reactive autonomy can be the forerunner of proactive autonomy, but it can also be a goal in its own right. It is the type of autonomy that learners in East Asian contexts and probably in the Malagasy context usually have. In brief, learners may not be proactively autonomous from the beginning, but with guidance and support, they develop their ability to direct their own learning. 


\subsubsection{Strong and weak versions of pedagogy for LA}

The recognition of the existence of reactive autonomy seems to be in keeping with the "strong version" of pedagogy for LA advocated by Smith (2003a). Smith distinguishes "weak" and "strong" versions of pedagogy for LA. The weak version is based on the assumption that autonomy is a product of instruction. The latter is set by the teacher or the institution, with little negotiation with the learners, implying that LA is a capacity the learners lack. On the other hand, the strong version views learners as already autonomous to a certain extent, and focuses on cooperating with them to create "optimal conditions for the exercise of their own autonomy, engaging them in reflection on the experience, and in this manner [...], developing their capacities, which are then brought to bear in further exercise of LA" ( $p$. 131). The strong version values awareness-raising constructed from students' own experiences and perceptions. It also views LA as developing gradually, and thus, emphasises process rather than products, as Smith puts it, "the goal is ongoing improvement of existing learning capacities, rather than delayed attainment of autonomy as a 'product' of instruction" (pp. 131-132). Smith advocates the importance of this version and its appropriateness in any context, as it is "jointly" created with the students. This view is also supported by P. Benson (2007) who recognises that the strong version tends to be more legitimate than the weak one in that it gives learners opportunities to develop step by step and exercise their own autonomy, instead of imposing them "levels" of autonomy they need to reach.

\subsubsection{Dimensions of LA}

LA is defined as a three-dimensional concept by Gu (2009). The three dimensions are learner independence, learner agency, learner self-control. Learner independence alludes to the degree to which learners depend on the teacher and other experts regarding their learning decisions. Learner agency includes the degree of volition, proactiveness, and self-initiation. Learner self-control or selfregulation refers to learners' ability to plan their learning objectives and content, to monitor their learning process, and to evaluate the results of their learning. Using the three dimensions as a cube (see Figure 2.1, p. 22), Gu presents the types of autonomous learners according to the degrees of each of the dimensions, as shown in 
Table 2.1, p. 23. This demonstrates again the high likelihood of having different types and/or degrees of autonomy for each learner.

\section{Key dimensions of learner autonomy}

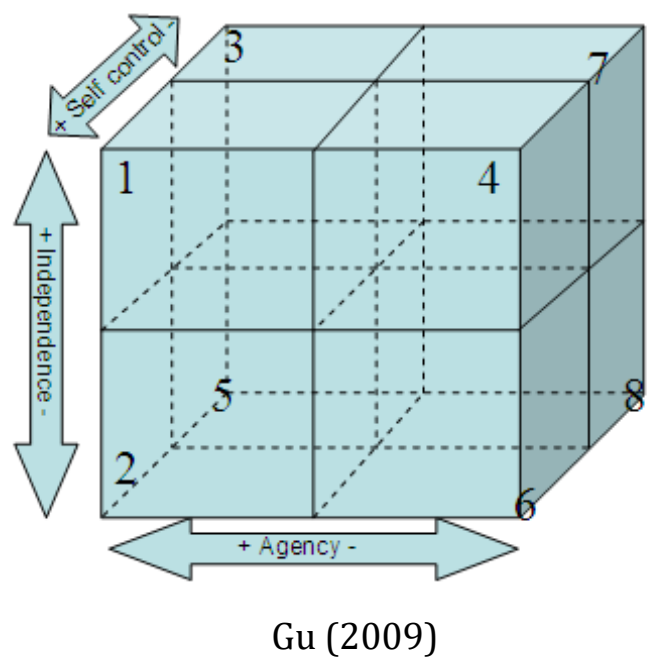

Figure 2.1 Dimensions of LA 
Table 2.1 Types of autonomous learners according to LA dimensions

\begin{tabular}{|c|c|c|}
\hline $\begin{array}{l}\text { Types of } \\
\text { learner }\end{array}$ & Descriptions & Examples \\
\hline 1 & $\begin{array}{l}\text { completely independent from teachers } \\
\text { total volition and proactive engagement in } \\
\text { learning } \\
\text { complete self-control and management }\end{array}$ & $\begin{array}{l}\text { A self-taught gardener who wants to } \\
\text { create her garden by herself. }\end{array}$ \\
\hline 2 & $\begin{array}{l}\text { dependent on teacher } \\
\text { volition and proactive engagement in } \\
\text { learning } \\
\text { self-control and management }\end{array}$ & $\begin{array}{l}\text { A student learning in a formal } \\
\text { classroom where teachers are in } \\
\text { control of the learning. }\end{array}$ \\
\hline 3 & $\begin{array}{l}\text { independent from teachers } \\
\text { volition and proactive engagement in } \\
\text { learning } \\
\text { no self-control or management }\end{array}$ & $\begin{array}{l}\text { A very diligent student who can study } \\
\text { on her own but constantly asks her } \\
\text { teachers for confirmation. }\end{array}$ \\
\hline 4 & $\begin{array}{l}\text { independent from teachers } \\
\text { no volition, passive engagement in learning } \\
\text { self-control and management }\end{array}$ & $\begin{array}{l}\text { A bright student but only does what is } \\
\text { needed. }\end{array}$ \\
\hline 5 & $\begin{array}{l}\text { dependent on teacher } \\
\text { volition and proactive engagement in } \\
\text { learning } \\
\text { no self-control or management }\end{array}$ & $\begin{array}{l}\text { A student who is very keen to study but } \\
\text { has no idea of how to study. }\end{array}$ \\
\hline 6 & $\begin{array}{l}\text { dependent on teacher } \\
\text { no volition, passive engagement in learning } \\
\text { self-control and management }\end{array}$ & $\begin{array}{l}\text { A bright but bored and lazy student } \\
\text { who might become frustrated because } \\
\text { she finds it too easy for her to learn in } \\
\text { class. }\end{array}$ \\
\hline 7 & $\begin{array}{l}\text { independent from teachers } \\
\text { no volition, passive engagement in learning } \\
\text { no self-control or management }\end{array}$ & $\begin{array}{l}\text { A distance student who is distracted by } \\
\text { distance modes of learning. }\end{array}$ \\
\hline 8 & $\begin{array}{l}\text { totally dependent on teachers } \\
\text { no volition, passive engagement in learning } \\
\text { no self-control or management }\end{array}$ & $\begin{array}{l}\text { A student, who is not interested in the } \\
\text { subject, never studied it before but } \\
\text { now she is compelled to study it by her } \\
\text { parents. }\end{array}$ \\
\hline
\end{tabular}

$(\mathrm{Gu}, 2009)$

\subsubsection{Components of LA}

Three dimensions were also suggested by P. Benson (2011). They are related to the exercise of learner control: learning management, cognitive processes, and learning content. The interrelation of the three dimensions is explained as follows:

Effective learning management depends upon control of the cognitive processes involved in learning, while control of cognitive processes necessarily has consequences for the self-management of learning. Autonomy also implies that self-management and control over cognitive processes should involve decisions concerning the content of learning. ( $p$. 
Later, Huang and Benson (2013) add capacity to learner control, the latter still being composed of learning management, cognitive processes, and learning content. Learning management involves the place, the time, and the way (putting emphasis on behaviour) learning is done. Cognitive processes consist in the way learning is done, but putting emphasis on cognition. Learning content refers to what and how much is learned, involving the consideration of learners' purposes. On the other hand, capacity includes ability, desire, and freedom. Ability mainly consists of metacognitive skills: planning, monitoring, and evaluation. Desire encompasses motivation. Freedom is concerned with the extent to which the learning situations allow learners to control their learning.

\subsubsection{Summary}

This section looked at some of the versions, dimensions, and components of LA that have emerged in the last two decades, and that have relevance in the developing country contexts. It has been said that there is no single definition of LA, and the latter is multifaceted, as the versions, the dimensions, and the components also have their own components.

When comparing the strong version and the dimensions/components of autonomy, some common important points can be noticed. They all agree on the emphasis on learning process, which explains the inclusion of the metacognitive skills of planning, monitoring, and self-evaluation. The emphasis on process is likely to result in awareness-raising and may lead to proactiveness, which is related to motivation and volition. Both Littlewood (1996) and Smith (2003a) highlight the consideration of the context. Section 2.4 talk more about these aspects often related to (the development of) autonomy: affective factors including motivation, context, and interdependence or relatedness.

\subsection{Affective factors, social factors, and LA}

The importance of affect, mainly motivation and emotions, in the development of LA has been advocated by many theorists and researchers. It has also been widely accepted that LA develops through interdependence, following Little's (1991) Vygotskyan view, "Because we are social beings our independence is always balanced by dependence; our essential condition is one of interdependence" (p. 5). The notion of interdependence not only implies the importance of collaboration in the classroom but also the significance of the social context outside the classroom. 


\subsubsection{Emotions and motivation}

Affect is a factor playing a significant role in language learning. This explains the wide reference to affective strategies, defined as "strategies dealing with the management of emotions, attitudes, and motivation" (Cohen, 1999, p. 62), by researchers in strategies (Macaro, 2006; O'Malley \& Chamot, 1990; Richards \& Renandya, 2002). The importance of affect in the development of LA along with language learning has become a focal point in recent literature and research, advocating that affect is the emotional dimension of autonomy (Martinez, 2008). It is said that while positive feelings should be "celebrated", negative feelings should be "discharged or sublimated; otherwise, they may continually distort all other perceptions and block understanding" (Boud, 2001, p. 14). Both positive and negative feelings towards learning must, therefore, be attended to, and the first step to do so is to raise learners' awareness on these feelings as they happen (referred to as "present" feelings) (Yamashita, 2015). Attending to learners' feelings or emotions is a means to develop learners' accountability for their learning, as it enables them to analyse where their difficulties lie exactly, if they are provided with guidance (Bennett, 2018; Valdivia, McLoughlin, \& Mynard, 2011). Thus, affect should be exploited in a way that it is turned into a trigger to take charge of learning. Bennett (2018) puts it, "[To] promote learner autonomy [...], teachers must not only be aware of the relationship between affect and language learning but also take action by implementing effective affective strategies in our pedagogical practices" (p. 128).

Motivation is strongly related to affect, and its impacts on language learning have been largely discussed. Among the pioneers leading the theoretical work on motivation were Gardner and Lambert (1972), who classified motivation into "integrative" and "instrumental". As its name denotes, integrative motivation is triggered by the longing to integrate in a group or a community who speaks the target language. Learners arriving in or planning to go to a foreign country, for instance, are likely to have this type of motivation. Instrumental motivation implies the perception of the ability to use the target language as a tool to reach other goals, such as passing an examination or getting a job. These two types of motivation may not always be easy to maintain because they are related to long-term or future-oriented sources.

Another classification of motivation is "intrinsic" versus "extrinsic". Extrinsic motivation is related to instrumental motivation, in a way that an extrinsically motivated person would do 
a task in order to achieve a separable outcome (Ryan \& Deci, 2000). On the other hand, intrinsic motivation is defined as "the doing of an activity "for its own sake," for example, out of curiosity, sense of challenge, or for the inherent satisfactions that accompany mastery" (Ryan, 1991, p. 214). According to Ushioda (1996, pp. 19-20), intrinsic motivation has the following features:

- It is self-sustaining because it generates its own rewards;

- It leads to voluntary persistence in learning;

- It focuses on skill development and mastery;

- It is an expression of personal control and autonomy in the learning process

Intrinsic motivation is pervasive and important in humans, and it is the type generating high-quality learning and creativity (Ryan \& Deci, 2000). It is the one closely linked to or leading to autonomy (Ryan, 1991) and building self-determination, as Martinez (2008) puts it, "Autonomy has an emotional as well as a cognitive dimension: the autonomous learner has an intrinsically motivated, a 'self-determined' approach to language and language learning" (p. 117).

Learners can, therefore, be autonomous only if they have motivation to learn (Ushioda, 1996). Indeed, motivation is acknowledged as an influential factor in language learning (and in learning in general), as it is related to pursuing goals and determines the extent to which learners would make effort, engage, and persist in their learning (Ushioda, 2014). This explains why motivation is said to be an element of self-initiation (Nguyen, 2008), and why high motivation tends to enable learners to accept that there is a link between their behaviours and their learning outcomes (T. Lamb, 2009).

More recent literature on motivation (e.g. Dörnyei and Otto, 1998, Dörnyei, 2009, Ushioda, 2009, Yamashita, 2015) stresses the dynamics of motivation. Motivation is said to be dynamic in a way that it is related to individuals and the contexts they are in at a specific time. Thus, the literature advocates the consideration of "present" sources of motivation, which are as important (if not more important) as future-oriented sources. Future-oriented motivation is, indeed, essential, as it constitutes long-term goals to work towards. However, it may not suffice if learners are to sustain their engagement in their learning. They need present sources of motivation that keep their desire to learn on a day-to-day basis. These present sources mainly encompass self-fulfilling feelings resulting from the successful completion of tasks. 


\subsubsection{Social factors}

\subsubsection{The context}

The social factors defined by the context may influence the definition of LA and the best way it can be implemented. It is not reasonable to see LA as a globalised concept, as Schmenk (2005) puts it, "it is pivotal that people begin to reflect on the theoretical and practical background of autonomy as a cultural and political concept and seek to relocate it in specific social and cultural settings" (p. 115). Considering and understanding the contextual factors for the implementation of LA have been advocated by many researchers because of the influential nature of these factors (Ambler, 2012; P. Benson \& Lor, 1999; Fonseka, 2003; Hacker \& Barkhuizen, 2008; Nakata, 2011).

Firstly, LA does involve individual dispositions and skills, but the social environment around the learners also has great significance (Fonseka, 2003) because they have been formed by this social environment, as "all learning is socially situated and culturally constrained" (Little, 1999, p. 16). Their social and cultural environment has built their beliefs and perceptions about learning and teaching (Littlewood, 1999), which deeply influence their learning behaviour (Cotterall, 1995). These beliefs include teachers and learners' roles and responsibilities. These beliefs need to be understood before attempting to implement autonomy, as understanding them helps with the evaluation of learners' readiness for autonomy (Cotterall, 1995). More importantly, understanding the beliefs enables the planning of a smooth introduction and promotion of LA, as LA cannot be simply forced upon learners. It needs nurturing in a way that learners themselves should perceive its necessity and, therefore, change their beliefs gradually, or as Little (1999) puts it:

LA cannot be externally imposed as a form of behavior modification; it must grow, quasi-organically, out of the ongoing encounter between the critical goals of the educational enterprise and the particularities of cultural context. (p. 16)

In other words, the aim of the implementation of LA is not to impose, but to adjust the approach to the context and to raise awareness so as to build beliefs in the efficiency of LA. Smith (2003a) makes a similar point:

if learners in a particular context do not appear to respond well to a particular approach to developing autonomy, this - in itself - is no reason 
to assert that they lack autonomy or that the goal of autonomy is inappropriate: it might be the approach which needs to be criticized, not the students or the validity of autonomy itself. (p. 130)

Dişlen (2011) for instance, studies Turkish university students' perceptions of LA. His study has shown that learners (especially at higher levels) may be aware that their learning is their responsibility. However, they may not be totally ready to take the responsibility due to the fact that they had been used to traditional language teaching, and also, that they do not consider themselves knowledgeable enough to do so. For learners in such a context, Dişlen suggests an increase of English class time and the use of simple activities to introduce the notion of autonomy so that learners can see autonomy as a source of motivation and selfconfidence instead of a challenge to be feared.

Secondly, as stated earlier, LA is a complex and multifaceted concept. Thus, it may manifest in different forms from one learner to another, and from one circumstance to another by the same learner, which also means that the manifestation of LA is highly likely to differ from one cultural context to another (P. Benson, 2011). This is further advocated by Nakata (2011) who states that LA can be defined in different ways according to the educational context, even in the same cultural context:

On the grounds that autonomy is deeply woven into the fabric of the social/cultural context, however, what autonomy means and how best one can promote autonomy in learners and teachers, or even ideal figures of autonomy, are likely to differ in each educational context. (p. 900)

That is why it would be important to recognise the different types of LA that may exist according to the context, such as Littlewood's (1999) proactive autonomy and reactive autonomy. As Madagascar shares most of the cultural features often assigned to East Asia, cited by Littlewood (such as collectivism, high acceptance of power and authority, not accustomed to exercising proactive autonomy), it would be reasonable to claim that Malagasy learners may also possess reactive autonomy. This means that in spite of their being used to traditional education, they are capable of developing autonomy if the latter is prompted. This is in keeping with what Little (1999) says about LA not being a new notion, and it can be reached by anybody, not only by highly intellectual people. It just needs to be nurtured by the social environment, starting in the classroom:

[T] he learning context can influence how much control an individual 
believes he or she has over his or her learning outcomes. In other words, it should not be assumed that some individuals are pathologically unable to accept control over and responsibility for learning. Changes in classroom practices can make a difference. (T. Lamb, 2009, p. 83)

The influence of contextual factors on the quality of autonomy was also mentioned by earlier literature on self-regulation: "Although the qualities of self-regulation and autonomy are largely defined within the actor, it is nonetheless the case that these qualities are influenced by circumstances in the social environment" (Ryan, 1991, p. 219).

Finally, it is crucial to recognise that limitations on promoting autonomy exist in any educational contexts, which is definitely the case with the context that this research focuses on: "Clearly, freedom and decision-making may well be limited by the way a classroom, school or society is structured" (Palfreyman, 2018, p. 54). However, such limitations do not imply the impossibility of fostering affordances for autonomy. Allwright (1988) refers to those affordances as 'seeds' of autonomy. There can be many different types of seeds in traditional classes, such as impromptu questions and small decision-making actions, according to Allwright. If highlighted and nurtured, these seeds would flourish. Thus, the awareness of the limitations or constraints and the affordances in a given context definitely helps determine how to better implement LA.

\subsubsection{Interdependence}

The importance of the social context implies the significance of interdependence. Though researchers in LA have not agreed on a single definition of $L A$, they seem to have reached a consensus that autonomy incorporates interdependence. They seem to agree that autonomy does not mean total independence, that autonomy develops through interdependence or relatedness (Aoki \& Smith, 1999; Boud, 1988; Little, 1999; Littlewood, 1999; Palfreyman, 2018), that "control over learning necessarily involves actions that have social consequences" (P. Benson, 2011, p. 60), and that an autonomous learner is able to act both independently and interdependently. The definition, referred to as Bergen definition by Dam, Eriksson, Little, Miliander, and Trebbi (1990) tends to be more widely accepted:

LA is characterized by a readiness to take charge of one's own learning in the service of one's needs and purposes. This entails a capacity and willingness to act independently and in cooperation with others, as a social responsible person. (p. 102) 
Thus, the aim of the promotion of LA is not to isolate learners from others, but to help them build responsibility towards their learning, bearing in mind that they are an active member of a society. It is based on the view that on the one hand, "[I]earner autonomy does not arise spontaneously from within the learner but develops out of the learner's dialogue with the world to which he or she belongs" (Little, 1994, p. 431). On the other hand, "our ability to learn is dependent upon our participation in social life and our membership of communities of learning" (Esch, 2009, p. 34). This entails the ability to adapt learning to the social situation and the capacity to make the most of interactions for learning (Palfreyman, 2018). This is where the view that LA belongs to individualistic culture is proved to be a misconception.

Another reason why interdependence contributes to the development of LA is that it enables learners to get away from the reliance on the teacher, and allows peer feedback, resulting in active participation (P. Benson, 2011; Scharle \& Szabó, 2000). The wide acceptance of the importance of interdependence is such that the latter is seen as a dimension or an essential component of LA (Murray, 2014a; O'Leary, 2014; Tassinari, 2012), a mediation, "an affordance for or a "necessary, initial stage" of learner autonomy" (Palfreyman, 2018, p. 59). This implies the need to promote interdependence when fostering LA in the language classroom (Littlewood, 1999; Murray, 2014a) through guidance and support on the part of the teacher, and peer collaboration (Dam, 1995; Martinez, 2008; Palfreyman, 2018). This also implies the need for interactions and dialogues, advocated in literature on advising in self-access language learning (Tassinari, 2012), which will be discussed in section 2.5 .

\subsubsection{Summary}

This section shows that the view of LA as having an individualistic nature (see 2.1.1) is merely a misinterpretation, as the literature on LA seems to agree that taking charge of learning involves interdependence. The literature also advocates that taking charge of learning depends on affective factors, including emotions, motivation, and beliefs gained from the context. These aspects need to be considered when promoting LA.

\subsection{Promoting LA}

Considering the reasons why LA should be viewed as an educational goal, researchers and practitioners have attempted to promote LA in different ways. This section discusses the six 
approaches suggested by P. Benson (2011). Then, it reviews a few studies on promoting LA in developing country contexts.

\subsubsection{Approaches to the promotion of LA}

P. Benson (2011) recommends six approaches to promote LA: resource-based, technologybased, curriculum-based, classroom-based, learner-based, and teacher-based. The approaches can be interrelated and/or overlap. The approaches have been applied in empirical research on LA.

\subsubsection{Resource-based approaches}

Resource-based approaches involve providing learners with materials (from which they select), which they use for their learning, and with which they interact. A major form of these approaches is self-access language learning. The initial idea of having self-access language learning centres is to develop individualisation and learner independence (Sheerin, 1997). Learners take charge of their learning in a way that they make decisions on the learning content and the materials according to their needs and interests. However, selfaccess language learning centres have been criticized for not enabling learners to use their creativity and to reflect on their learning (Littlejohn, 1997). It is, thus, recommended that the centres should provide not only materials and activities, but also allow learners to make decisions on the evaluation of their learning, to adjust and respond to their learning plans and strategies, to work in cooperation with other learners, and to reflect on their learning experience through a language learning advising service (Esch, 1996). Probably due to the criticisms and the recommendations, self-access language learning tends to encompass an advising service that provides learners with much more than advice on what materials or activities to use, and focuses more on collaboration between the learner and the advisor than on knowledge transmission on the part of the advisor.

Advising in language learning in self-access learning centres has become a topic of interest in the field of LA in the past decade. Advising in language learning "involves the process and practice of helping students to direct their own paths so as to become more effective and more autonomous language learners" (Carson \& Mynard, 2012, p. 4). The research on advising advocates learners' individual differences and helps learners be aware of their needs (Cotterall \& Crabbe, 2008; Reinders, Hacker, \& Lewis, 2004) and their learning process including their feelings, by using written reflective dialogue (Thornton \& Mynard, 
2012), oral reflective dialogue (Kato \& Mynard, 2016; Yamashita, 2015), and "counselling meetings" in combination with online tools (Karlsson, Kjisik, \& von Boehm, 2012). Thus, the aim of advising encompasses learners' awareness raising, which is the key to change:

[...] an advisor supports a learner in going beyond improving language proficiency. The learner's existing beliefs are challenged in order to raise awareness of learning, translate the learner's awareness into action, and finally, make a fundamental change in the nature of learning." (Kato \& Mynard, 2016, p. 9)

All the examples of studies cited above advocate the efficiency of advising in the development of LA due to learners' becoming more aware of their learning process through reflective dialogue. Advising, thus, has a metacognitive function, but it also has a cognitive function (encouraging action by asking questions on specific learning activities, for example), and an affective function (supporting learners affectively by reassuring them) (Thornton \& Mynard, 2012).

\subsubsection{Technology-based approaches}

As denoted in the name, technology-based approaches place emphasis on the use of technology. One form of technology-based approaches is Computer-Assisted Language Learning (CALL), in which learners use CD-ROM materials and the Internet. Another form is E-tandem. In the past decades, technology in communication has evolved and made it possible for people around the world to interact with one another wherever they are. In language learning, this advance in technology has enabled methods like tandem learning via email (Ushioda, 2000), involving language learning exchanges between pairs of students from two different countries. For instance, in Ushioda (2000), Irish university students learning German are paired with German university students learning English. The pairs of students would then email one another, giving corrections and feedback on one another's writing (email) and exchanging cultural information. The students in that study found email tandem beneficial because it enabled them to use the target language genuinely. The use of the language along with the corrections and feedback helped them improve their proficiency. Furthermore, as the interactions were based on their interests and needs, they had high motivation, which pushed them to learn more.

More recently, further advances in technology have enabled live interactions with images, enabling online conferencing and what is referred to as "teletandem". Thus, instead 
of emailing, learners can see one another through different types of software such as Skype and Zoom, a practice that takes place in some self-access language centres, such as the one in the National Autonomous University of Mexico (Peña Clavel, 2018).

E-tandem develops metacognitive awareness, according to Little (2003) because learners have to reflect on both their first languages and their target languages so as to be able to provide corrections and feedback to their partners. It, thus, enables learners to make decisions in the learning process. Also, it allows them to indirectly negotiate the help they give to one another, to some extent, as the help received tends to depend on the help provided (Lewis, 2013). Nevertheless, support from teachers or advisors and training in strategies are strongly recommended to make technology-based approaches efficient (Littlemore, 2001).

\subsubsection{Curriculum-based approaches}

Curriculum-based approaches emphasise learners' participation regarding decision making on learning content, activities, tasks and evaluation. P. Benson (2011) classifies curriculumbased approaches in two forms: the weak and the strong versions of the process syllabus. The weak version involves defining learning content and methods through learners' group project work. Working collaboratively, learners determine topics they would like to cover, for instance, and figure out among themselves how they would like to practise language skills (e.g. Cunningham and Carlton, 2003; Nix, 2003). In the strong version, the syllabus is not pre-defined. Instead, it is selected, organised, negotiated and renegotiated between learners and teachers. An example of the strong version is Dam's (1995) study, in which the students are given maximum opportunities to make decisions on content, materials, activities, and to practise peer evaluation and self-evaluation. The study demonstrates that reflection (using diaries), negotiations (teacher-students and students-students), and the teacher's skill and willingness to let go are the key features to develop LA. The necessity for teachers to let go is reiterated and emphasised in Dam (2011), where she points out that it is less difficult for learners to take over responsibility on their learning than for teachers to pass over it sometimes.

According to Gu (2009), curriculum-based approaches are "seen as "deep-end" approaches, in which learners are expected to develop autonomy through autonomy". Gu also highlights the necessity of scaffolding and support from the teacher in this type of approaches. 


\subsubsection{Classroom-based approaches}

Classroom-based approaches consist in having learners manage their own learning within the classroom context. Managing their learning involves a focus on learning process, including planning and evaluation sessions regarding specific tasks, incorporating reflection (through journal writing and portfolios) and peer collaboration, with support from the teacher. This implies that classroom-based approaches tap into learners' metacognitive skills to allow them to better regulate their own learning. This also requires the changes of roles and relationships in the classroom.

To promote LA in the classroom, Crabbe (1993) suggests that the goals for each task should be negotiated with the learners. Also, potential difficulties related to tasks as well as strategies to deal with the difficulties should be discussed in the classroom. Crabbe adds that, apart from the necessity for the goals for the task to be clear, the task should be appropriate to the level of the learners, and they should be able to perceive the progress of the task performance.

A clear example of classroom-based approaches is Smith's (2003) "student-directed learning style" (Figure 2.2, next page). Smith implemented this style in order to put the strong version of pedagogy for LA into practice (see 2.3.2). The style is composed of planning, student-directed learning, and evaluation sessions. Smith argues that despite the challenges the approach presented, his study revealed that the approach enabled learners to develop their self-evaluation skills, which helped them improve their autonomy as well as their English proficiency. However, he stressed the importance of considering the context, and the necessity to revise the style, according to the learners' responses to it. The efficiency of Smith's student-directed learning style can serve as an evidence of Lamb's statement, "Changes in classroom practices can make a difference" (p. 83). 
Planning session:

- Students clarify individual learning goals.

- Students share ideas and experiences,

and draw up individual plans for out-of-class

learning activities.

- Brainstorming of ideas for within-class

learning activities; formation of groups.

- Students draw up plans for (individual or

group-based) within-class learning

activities.

Student-directed learning sessions:

- Student-directed within-class learning

(generally group-based).

- Ongoing out-of-class learning.

Evaluation session:

- Groups/individuals give presentations on within-class learning.

- Written reflection on out-of-class and

within-class learning for homework

Figure 2.2 Student-directed learning cycle

Smith, 2003, p. 135

In addition to learner development, Smith claims that classroom-based approaches can also result in teacher development. While applying the learning cycle in his class, he developed his trust in his students and developed his autonomy as a teacher:

I gained a sense of being 'in control' of my own learning of teaching - in other words, I became less dependent than previously on external sights into how I 'should' be teaching, much more in touch with students' priorities. [...] Thus, teaching these classes became a positive source of teaching-related learning for me: a resource, in other words, for the development of my own autonomy as a teacher. (p. 143)

\subsubsection{Learner-based approaches}

Learner-based approaches are grounded on the assumption that LA would result from learner training. In other words, the belief is that if learners know what strategies to use for their learning, they will be more autonomous. Instead of giving learners opportunities to control their own learning, as the other five approaches do, learner-based approaches focus on training learners in order to change their behaviours. This implies providing them with instructions on how to learn more effectively. The major forms of learner-based approaches are learning strategies instruction and learner training incorporating the use of metacognitive skills. 
Learning strategies are defined as "mental steps or operations that learners use to learn a new language and to regulate their efforts to do so" (Wenden, 1991, p. 18). In order for them to result in the improvement of performances, they must be combined simultaneously or in sequence, into strategy clusters, according to the situation (Macaro, 2006). Strategies develop naturally since childhood, continue to accumulate with time and experience, and their uses depend on the person, the context and the tasks involved. Thus, learners may know different types of strategies, but they may not be able to apply them on their own when they should, hence, the necessity of strategy instruction (Gu, 2019).

There exist different types of strategies that can be applied in language learning. Among them are cognitive, metacognitive, social and affective strategies. According to Oxford (2002), these four types of strategy are all necessary, as "the learner [...] uses intellectual, social, emotional, and physical resources and is therefore not merely a cognitive/metacognitive information-processing machine" (p. 128). Cognitive strategies include the use of reasoning, analysing, summarising, and practising. Metacognitive strategies involve the use of planning, monitoring, and self-evaluation, as described earlier in section Error! Reference source not found.. Social strategies involve collaborations with $p$ eers, teachers or other people. Affective strategies include self-encouragement and selfreward.

An example of studies using a learner-based approach, making use of cognitive, metacognitive, and social strategies is Rubin and McCoy (2008). Their study investigated how task analysis, which is part of planning, impacted the language performances of two groups of learners. The task analysis consisted of having learners set goals based on their understanding of the task, and reflecting on criteria or behaviours that would help them attain their goals. After the completion of the task analysis, they had to think of an action plan. The study showed the learners' development of knowledge of task analysis, their improvement in their language performances (examination scores), and their making use of task analysis in their learning process.

\subsubsection{Teacher-based approaches}

All the five approaches stress the importance of the teacher's (or advisor's) support in the development of LA, implying the dependence of LA on the teacher. In other words, the teacher has a crucial role in the development of autonomy. As Little (2007) states,

The purpose of education remains the same as ever: to give learners access 
to the multifaceted culture into which they have been born. Learners cannot construct their knowledge out of nothing, neither can they know by instinct how to conduct focused and purposeful learning conversations that shape themselves to the ways of thinking characteristic of the subject in question. Teachers remain indispensable, both as pedagogues and as discipline experts. (p. 20)

It can be said, thus, that all the approaches are all, to some extent, related to teacherbased approaches, which are based on the assumption that teachers should be aware of the importance of LA in order to be able to promote it. This entails the redefinition of teacher roles and an adjustment regarding the relationship between the teacher and learners:

Learner autonomy is an achievement, attained interrelationally between the learner and the teacher. It depends upon how the teacher and the learner relate to each other: on their capacities to develop their relationship in ways conducive to learner autonomy. Learner autonomy is constantly being negotiated within the teacher-learner relationship. Indeed, as the learner initiates and progresses a piece of work, learner autonomy depends upon the capacity of the teacher and the learner to develop and maintain an interrelational climate characterized by the teacher's holding back from influencing the learner, and the learner's holding back from seeking the teacher's influence. (La Ganza, 2008, p. 65)

The redefinition and the adjustment involve change in teachers' beliefs, and therefore, the significance of including the promotion of LA in teacher education. The latter has led theorists and researchers to focus on a concept referred to as "teacher autonomy". Nevertheless, teacher autonomy is not only the capacity to promote LA, but also involves other dimensions (La Ganza, 2008; McGrath, 2000; Smith, 2003b; Smith \& Erdoğan, 2008). Like LA, teacher autonomy is hard to define due to its being multidimensional. However, there seems to be an agreement that 'teacher autonomy' can be used to refer to either the "capacity for self-directed teacher-learning", and the "capacity for self-directed teaching" (Smith, 2003b, p. 5).

\subsection{Teacher autonomy as a capacity for self-directed teacher-learning}


The need for a teacher to be able to self-direct their own learning (teacher-learner autonomy) is based on the assumption that, in order for teachers to be able to promote LA, they should have (had) experience in LA in their own learning (P. Benson, 2011; Hacker \& Barkhuizen, 2008; Little, 1995; B. Sinclair, 2009; Smith, 2000). This assumption has led to the suggestion that the promotion of LA should be encompassed in teacher education or teacher training. As Little (1995) puts it, "language teachers are more likely to succeed in promoting LA if their own education has encouraged them to be autonomous" (p. 180). Providing them with opportunities to experience LA in their own learning would be much more influential than merely "teaching" them some theories about LA (Nakata, 2011; Smith, 2003b; Smith \& Erdoğan, 2008), as teachers form their beliefs regarding teaching and learning mostly from their own experience (de los Angeles Clemente, 2001; Nakata, 2011; Prabhu, 1992). Their beliefs inevitably influence their teaching in many ways (M. Borg, 2001).

Teacher-learner autonomy is not limited to pre-service teacher training. It is an ability that teachers use throughout their teaching experience. As teachers are lifelong learners, they have to deal with their own LA constantly (Little, 2000). For language teachers, they need to exercise teacher-learner autonomy to improve their language, their knowledge about the language, and also to improve their teaching skills. Like LA, teacher-learner autonomy involves interdependence, hence, the definition given by Smith (2003b): "Teacher-learner autonomy, by analogy with previous definitions of language LA, might be defined as the ability to develop appropriate skills, knowledge and attitudes for oneself as a teacher, in co-operation with others" (p. 1). Teacher-learner autonomy also depends on the context (Nakata, 2011).

An example of studies related to the development of teachers' teacher-learner autonomy is Hacker and Barkhuizen's (2008). With the assumption that the teachers' awareness of their beliefs about teaching and learning is crucial in order for them to "meet the challenges of autonomy" (p. 161), the study investigated twenty language teachers' personal theories of teaching. The study took place as the teachers were taking a course on course design and methodology in their education programme. Throughout the course, the teachers were assigned to write reflective journals with the aim to raise their awareness of their personal theories, and to develop these theories for better teaching. The study revealed that the reflective journal writing, firstly, did raise the teachers' awareness of their personal theories by reflecting on and examining their practices critically. Secondly, it enabled them to perceive the links between their own experience and the new information provided in the 
course. The awareness that their practices were actually based on theories (which they had not been aware of before the course), and thus were relevant, gave them confidence in their teaching. One of the major implications of the study is that, with the benefits the teachers gained from their experience in the course, they would be in a better position to encourage the same awareness-raising process with their own students.

Another example of the promotion of teacher-learner autonomy is the collaborative, autonomous, and reflective learning (CARL) approach (Kojima, 2008, 2012). The aim of the approach is to help student teachers develop their ability to self-direct and build their responsibility for their own learning through collaboration and reflection work. Kojima (2008) used CARL with 56 Japanese pre-service EFL teachers in a course about English teaching methodology in order to investigate the efficiency of CARL in promoting teacherlearner autonomy. As the student teachers had been used to traditional teaching and that they had lacked background knowledge on the task they were assigned to, they had difficulty with the approach. Therefore, Kojima gave some suggestions in order to make the approach more efficient. Among the suggestions is to help the student teachers to develop their metacognitive skills, to provide them with more opportunities to experience the approach, and to give them ideas on how the approach can be implemented in their own classrooms.

\subsection{Teacher autonomy as a capacity for self-directed teaching}

Teacher autonomy as a capacity for self-directed teaching is an objective in itself (Smith, 2001). It is the capacity enabling teachers to exercise autonomy in their teaching, or to take charge of their teaching. It encompasses reflection and self-managing process on their own teaching (Little, 2007; McGrath, 2000; Smith, 2003b; Smith \& Erdogan, 2008). It is, thus, "an important goal in its own right [...], being the engine which powers career-long professional development" (Smith \& Erdoğan, 2008, p. 87). This is supported by Shaw (2008) who states that though this type of teacher autonomy may not necessarily lead to the promotion of LA, it is an asset in itself.

Nakata (2011) investigates Japanese EFL high school teachers' readiness for promoting LA by studying both the teachers' teacher-learner autonomy and their capacity for self-directed teaching, through a survey and a focus group interview. Though the study started with an assumption that the capacity of self-directed teaching may not result in promotion of LA in the classroom, the findings demonstrated an interdependence between teacher-learner 
autonomy and self-directed teaching (the combination of both is referred to as "professional autonomy" in the study), and the capacity to promote LA (referred to as "teaching autonomy").

Drawing from her own experience, Ambler (2012) suggests the use of autobiographical vignettes as tools to promote teachers' self-reflection, which is viewed as an indispensable aspect of teaching. According to Ambler, writing autobiographical vignettes enables teachers to have a better understanding of their students, and to enhance their own teaching, by reflecting on new theoretical knowledge, on their teaching practices, and on changes to make to their practices. Thus, writing autobiographical vignettes raises teachers' awareness of their students' needs and of adjustments they need to make in their teaching. It also makes them aware of the significance of the context vis-à-vis teaching and learning. Ambler does stress the importance of considering the social environment where learning and teaching take place, and of co-constructing experiences and negotiating knowledge together with students.

\subsubsection{Summary of approaches}

This section described the six approaches to promote LA suggested by P. Benson (2011) and included some examples of empirical studies for each approach. Though the six approaches have their own distinctions, they all emphasise the necessity of support from teachers or advisors and interactions with peers and teachers or advisors. Even advocates of resourcebased and technology-based approaches, which seemed to be initially based on the idea of promoting independence through the use of available materials, later recognised that interactions with the materials only do not necessarily lead to the development of LA, and learning requires human interactions and support. This, firstly, highlights the importance of interdependence in the promotion of LA. In addition to interdependence, the interactions and support are meant to help learners reflect on their learning and, to some extent, make use of their metacognitive skills. Secondly, this stresses the significance of teacher autonomy, meaning that teachers are more likely to promote LA if they are aware of what LA entails. Such awareness is likely to be raised through their own learning experience or their capacity for self-directed teaching, which implies the importance of the inclusion of LA in teacher education. 


\subsubsection{Promoting LA in developing countries}

No matter what approaches are used to promote LA, they have to be adjusted to fit the context (see 2.4.2.1). As this research was conducted in a developing country, it is deemed necessary to discuss studies that have been carried out in developing country contexts.

Despite the great number of studies on LA in EFL settings, only very few have been conducted in Africa or developing countries such as Madagascar. Two of the few studies done in African settings (whether regarding education in general or related to LA) seem to suggest that the promotion of LA does not fit the developing country or African contexts (Ampiah, 2008; Sonaiya, 2002). The main reasons for this stated in those studies were respectively the lack of resources and of teacher training, and the 'individualistic' characteristic of LA, which is not suitable to communities in which collectivism is the norm. While the second reason is clearly a misconception (see section 2.1.1), the reason related to resources and teacher training stands out.

This section discusses the challenges, including the lack of resources and teacher training that developing countries face. It is crucial to know and to talk about these challenges before deciding how to implement LA in such contexts. The section goes on with a discussion about two studies demonstrating that LA does fit in developing country contexts.

\subsubsection{The challenges}

It is true that, in developing countries like Madagascar, teaching and learning resources are scarce, as stated in Ampiah (2008). Madagascar is indeed among the poorest countries in the world (Osborne, 2016; Venart \& Reuter, 2014). 78\% of its population live below the international poverty line (UNICEF, 2018a). It can be labelled as "under-resourced" (Smith et al., 2018, p. 8) as far as education is concerned. Many pedagogical aspects are flawed due to poor management and neglect of tasks on the part of directors and teachers, especially in public schools (for example, no strict control of absenteeism, no track of students' progress, such as student reports, no lesson planning) (Lassibille, Tan, Jesse, \& Van Nguyen, 2010), which partly explains why only one child out of three completes primary education (UNICEF, 2018b).

Scarcity does not concern only the pedagogical aspect, but also the infrastructural aspect (Glewwe \& Kremer, 2006; Venart \& Reuter, 2014): classrooms in dilapidated states, without 
doors or windows, without desks or benches, sometimes even without walls. Moreover, most students' parents cannot even afford school fees and basic school equipment such as textbooks (Glewwe \& Kremer, 2006). These conditions especially concern rural areas more than urban areas, as is the case in most poor countries (C. Benson, 2004; Westbrook et al., 2014). However, some urban areas in Madagascar also suffer from such shortages. It would be easy, then, to conclude that it is hard for the Malagasy learners to learn autonomously as they are not likely to find appropriate resources.

It cannot be denied either that in Madagascar, like in most developing countries, the dearth of trained teachers results in the recruitment of untrained teachers (Glewwe \& Kremer, 2006). The report of UNICEF (2018a) states that less than $1 \%$ of in-service teachers in Madagascar have an international standard of teaching qualification. What often happens is that secondary school graduates (or even non-graduates sometimes) become teachers in their villages without any teacher training at all, as the rare qualified teachers are not willing to go and teach in remote areas. This explains the flaws in the pedagogical aspects identified by Lassibille et al. (2010) above. Thus, expecting these teachers to be able to foster LA in their classrooms seems unreasonable. Most qualified teachers in Madagascar may not even be aware of the importance of LA and its implementation in class. From my own experience as a former trainee, LA was not mentioned in any subjects of the teacher training programme; and during my teaching experience, LA was not discussed in any professional meetings or conferences related to education either.

Apart from the features described above, teachers in developing countries face many challenges. Firstly, as far as language teachers are concerned (especially if they are untrained), they do not necessarily master the language they teach (M. Lamb, 2007). Secondly, they have to follow the "centralized" curriculum set by the State, which does not match the levels and the needs of their students nor the resources at their disposal (Glewwe \& Kremer, 2006; M. Lamb, 2007). Thirdly, due to financial distortion and/or underinvestment in education, classes are overcrowded and teachers underpaid (Glewwe \& Kremer, 2006; Lie, 2007), leading to teachers' demotivation. Another challenge can also be simply to keep the students in class during class hours (Fonseka, 2003). Due to poverty, students have to help their parents earn income to support their households, especially in rural areas (Wills, Reuter, Gudiel, Hessert, \& Sewall, 2014). Therefore, attending classes is not seen as a priority for both students and parents (Lassibille et al., 2010). 


\subsubsection{Challenging but worth implementing}

Considering the elements characterising teaching and learning in developing countries described above, the promotion of LA would indeed appear to be unsuitable (Smith et al., 2018). It has been, however, suggested (Fonseka, 2003; Kuchah \& Smith, 2011; Smith et al., 2018) that these common features: shortage of resources, too large classes and insufficient teachers, should be reasons for rather than against developing LA. The more difficult the circumstances are, the more necessary it is to help learners engage in their learning autonomously.

One bottom-up study conducted by Kuchah and Smith (2011) has shown the pertinence of LA in a Cameroonian EFL setting, with similar developing country challenges in the schools. Though it was not the explicit goal of that study, Kuchah's practice with his 235 students (in one class) did promote LA by firstly building rapport with them and then allowing them to take responsibility regarding materials and the organisation of different group activities, according to their interests. That study demonstrates that autonomy can be fostered in countries with problematic conditions, and is even a solution to such conditions. Furthermore, the study clearly shows that autonomy can have its place in a community inclined to collectivism. The students in the study use collaboration to make decisions on learning materials and contents, confirming that perceiving LA as an individualistic trend is a misconception.

Autonomy as a solution or "rescue strategy" for resource-poor settings is also advocated by Fonseka (2003) whose study involves using songs to develop his Sri Lankan pupils' sense of responsibility, self-direction, metacognition, and motivation:

[...] by developing autonomy within [children in resource-poor situations] it is possible to empower them to take the initiative in relation to their own learning requirements and to build up their character to be resilient in the face of the numerous challenges they experience in their school and home life. [...] Once pupils develop autonomy in the context of language learning they can apply it to all their learning efforts. They will find greater meaning in the instruction they receive from teachers and will attempt to carry out recommended tasks with greater diligence. (pp.152-153) 
Fonseka's study shows that LA can develop through the promotion of entertainment, which he thinks is the most appropriate means to raise his pupils' interests, as it enables them to forget about their miserable daily lives. Working with songs aroused the pupils' motivation, pushed them to find strategies to help them memorise lyrics, to set their own goals (for learning a song), to develop their creativity (as they presented the songs in the form of narratives and dialogues, according to their choices), and to erase the hierarchical barriers between them and their teacher.

\subsubsection{Summary}

In developing countries, the challenges in the field of education can be easily viewed as impediments to the implementation of LA. However, studies like Fonsenka (2003), and Kuchah and Smith (2011) demonstrate that LA can be promoted in students in developing countries. Both studies also show that the implementation of LA depends on the context. They had to take into account the limitations on the one hand, and what is important for their learners on the other hand.

\subsection{Conceptualising and operationalising LA in this research}

With the multidimensional nature of LA and all the different aspects related to it, there has been a concern about the practicality and the measurement of LA. P. Benson $(2009,2011)$ talks about the necessity of construct validity in order to conduct research on autonomy effectively. He advocates that the definition of autonomy needs narrowing down to make autonomy more "describable" and, therefore, "researchable". He states, "Autonomy may be recognised in a variety of forms, but it is important that we are able to identify the form in which we choose to recognise it in the contexts of our own research and practice" (Benson, 2011, pp. 58-59). This is a view that is also advocated earlier by Crabbe (1999): "In principle, interventions made to foster autonomous language learning need to be based on clearly articulated statements of what it means to take charge of one's own learning and what the benefits of that are" (p. 5). Thus, when attempting to implement LA in classrooms and especially to evaluate its development and its efficiency on language proficiency, having an operationalised definition is required (Murase, 2015; Nguyen, 2008; Nguyen \& Gu, 2013). To help novice researchers choose or narrow down their own definitions of LA, P. Benson (2009) suggests they should include the following features in their definitions: the notion of 
control over learning, implying learning management, psychological capacities, and the capacity and freedom to control learning content.

Underpinned by the theories described in 2.2 , this research emphasises the importance of different types of awareness, which according to Porto (2007), constitute LA in classroom life: self-awareness (involving attitudes vis-à-vis the target language), awareness of learning goals (encompassing not only the importance of having goals, but also the learners' strengths and weaknesses), awareness of learning strategies and resources to help learners with their learning, and language awareness (involving the knowledge of how language works). To develop such awareness, learners need to focus on their learning process and to develop their self-regulation or metacognitive skills. The focus on the process and the development of metacognition will foster self-initiation and personal involvement in learning both cognitively and affectively. Learners are, therefore, seen as co-constructors of meaning and knowledge. This research also considers the well-being of learners as a significant factor in learning, and acknowledges that feelings are inseparable from learning (Kato \& Mynard, 2016). Another factor that cannot be separated from learning is the context where it takes place. Learners are indeed part of a society, which plays a major role in the formation of their knowledge.

This section includes the definition of LA, or more precisely, the dimensions it contains, used in this research. It also discusses the approach and the tool to be used in the research.

\subsubsection{LA as a three-dimensional concept}

Considering P. Benson's (2009) suggestion, all the aspects related to LA described in this chapter, and the need to make LA "describable in terms of observable phenomena" (P. Benson, 2011, p. 58), LA is operationalised in this research as a three-dimensional concept made up of self-regulation, self-initiation, and independence. The three dimensions are adapted from Gu's (2009) dimensions (see section 2.3.3). The dimensions are interconnected, and their combination is in line with P. Benson's (2007) proposed components of LA, and with Huang \& Benson's (2013) components of LA (see section 2.3.4). Among the three dimensions, self-regulation will be more emphasised for reasons, that are outlined below.

\subsubsection{Self-regulation as the most important dimension}


Self-regulation combines metacognition and affect. More focus will be placed on selfregulation in this research for three reasons. Firstly, self-regulation corresponds to all the components of "ability" and "control", the two main components of LA described by Huang \& Benson (2013) (see section 2.3.4). Self-regulation incorporates metacognitive skills: goal setting, self-monitoring, and self-evaluation. It encompasses motivation, which is included in affect; and it involves freedom in that learners set their own goals and find appropriate resources for their learning. The use of metacognitive skills results in learning management and the use of cognition, as learners use cognitive strategies, solve their own problems, and make decisions. That is why it is said that to enable learners to actively engage in their learning process and to set their own learning goals, their self-regulation and metacognitive skills need developing (Chamot, 2005; LaVaque-Manty \& Evans, 2013; Schraw, 1998).

Secondly, the development of self-regulation can be done through practice in class (Zimmerman, 2002). Considering the context where the research takes place (and the challenges in the context, see 2.5.2.1), it would be more appropriate to (at least start to) practise the exercise of autonomy in class rather than out of class. A combination of a classroom-based approach and a learner-based approach would be more efficient. This will be discussed further later in this section.

Thirdly, learners may be able to learn independently and may have self-initiation or willingness to learn, but because of their lack of self-regulation, they are not able to decide what they should focus on. In other words, they may have difficulty with their choice of learning content, and they may not even have specific goals. Because of the emphasis on the importance of having goals when learning and doing a task, "goal setting" is used instead of "planning" throughout this research.

For these three reasons, the hypothesis of this research is that with the development of self-regulation, the other two dimensions of LA will grow. In this view, LA starts with clear goal setting, which triggers active engagement in the learning process.

\subsubsection{Self-initiation}

The second dimension of LA studied in this research is self-initiation. According to Nguyen (2008), self-initiation is composed of the "initial motivation to learn" and "effortful behaviours both inside and outside the classroom" (p. 68). It can be said that self-initiation also includes some of the components of LA described by Huang and Benson (2013). Self- 
initiation integrates desire (the motivation to learn) and learning management, which is part of effortful behaviour.

Self-initiation is an important dimension simply because without motivation, learners would have difficulty with learning, and it would be even more difficult for them to develop their leaner autonomy. As explained in 2.4.1, motivation is a key generator of LA.

Unlike self-regulation, self-initiation is not really teachable (Nguyen, 2008). It can be promoted through encouragement, for instance, but it cannot develop through training, as it has to come from within the learner. However, as stated in 2.4.1, it is possible to cultivate motivation in learners by giving them opportunities to set their own goals about specific tasks, which they would turn into "present" sources of motivation.

\subsubsection{Independence in the context of this research}

In everyday life, the terms "independence" and "autonomy" seem to be used interchangeably. This is another reason why LA is often misinterpreted as the ability to learn without anyone's help. In fact, the initial definition of LA given by Holec (1981) implies selfreliance and independence, advocating what Lewis (2013) calls a "revolutionary truth" at that time: "that learners are capable of gaining knowledge and skills without necessarily having to be taught in a conventional classroom manner" (p. 198). The notion of independence is also dominant in the definition provided by Boud (1981): "the capacity of an individual to be an independent agent, not governed by others" (p. 22). Later, the growing understanding that autonomy is much more than mere independence has led to a necessity to distinguish between autonomy and independence. The distinction given by Deci (1996) is a convincing one, according to (Little, 2011):

Independence means to do for yourself, to not rely on others for personal nourishment and emotional support. Autonomy, in contrast, means to act freely, with a sense of volition and choice. It is thus possible for a person to be independent and autonomous (i.e., to freely not rely on others), or to be independent and controlled (i.e., to feel forced not to rely on others). (Deci 1996, 89)

Independence, here, seems to have a rather negative connotation and to be in line with what Ryan (1991) refers to as "detachment", which he defines as "a wrenching away of important connections and emotional ties with others" (p. 223). Following Deci's distinction, 
Little (2011) concludes that independence means freedom from the control of others whereas autonomy refers to willing commitment and self-regulation.

Due to the wide acceptance that LA has a social dimension, and that education and life in general necessitate collaborating with others (Palfreyman, 2003), interdependence tends to be more emphasised than independence in theory and empirical research on LA. Yet, it should not be forgotten that independence is also another dimension of LA (Gu, 2009). Though it does not fit in "the more, the better" category, like self-agency and self-control (Gu, 2009), it is an indispensable dimension. Like interdependence, it is included in LA. At least, it is related to autonomy in a way that the development of autonomy can result in that of independence, as stated by Dişlen (2011): “An autonomy-supportive learning climate does not allow students to be passive receivers of information and it stimulates them to become critical thinkers. The more autonomous and active they are, the more independent they become" (p. 128).

Particularly, in contexts inclined to collectivism, as the case of this research, interdependence can overrule independence, which may result in learners' over-reliance on others, and therefore, their lack of ability to make any decisions on their own. Crabbe (1993) states that learners should be given opportunities to prepare for the "dynamics of working alone" (p. 447), as they will have to work alone at some point in their lives. That is why independence is considered as a dimension of LA in this research.

\subsubsection{Summary of the three dimensions}

This research conceptualises LA as having three dimensions: self-regulation, self-initiation, and independence. Self-regulation is more emphasised in this research mainly because exercising its component skills (goal setting, monitoring, and self-evaluation) enables more awareness raising about the learning process. Furthermore, promoting self-regulation is more practicable than promoting the other dimensions, and its promotion might be conducive to the promotion of self-initiation.

\subsubsection{Promoting LA}

Before discussing the approaches and the tool to use to promote LA in this research, it is worth pointing out that this research advocates that autonomy can be promoted in any context if, instead of labelling cultural stereotypes (claiming that students from such countries cannot be autonomous because of their "passiveness", for instance), teachers try 
to understand learners as they are (Holliday, 2003) and promote autonomy, taking the context into account. Therefore, this research, firstly, acknowledges the necessity to study the context in terms of affordances and constraints vis-à-vis LA.That is why the first part of this research (referred to as 'phase one') is devoted to the investigation of affordances for autonomy in a Malagasy rural school. Secondly, it recognises that LA is appropriate in any context as long as it is jointly created with the learners, valuing awareness-raising built from the learners' own experiences and perceptions, advocated in Smith's (2003a) "strong version" of autonomy. Still related to the first and second points, this research acknowledges the existence of types of autonomy, such as the "reactive autonomy" described by Littlewood (1999). Reactive autonomy implies that in certain contexts, learners may need guidance and directions to trigger LA or a capacity for self-directed learning. Those beliefs constitute the basis of the second part of this study, referred to as 'phase two'.

\subsubsection{Approaches}

Phase two uses features of teacher-based, classroom-based, and learner-based approaches: teacher-based because it is grounded on the belief that the development of LA depends on the teacher. To perform this role, the teachers should have experienced LA in their own learning. That is why the participants are Malagasy EFL student teachers in their first year of university. It is classroom-based, with students doing in-class writing tasks and reflection work individually as well as working in collaboration with peers to find solutions to problems. The learner-based features are the focus on the metacognitive skills (which is also part of the classroom-based features) and the discussion on strategies in class. It is worth mentioning that this research does not aim to explicitly teach strategies. Instead, it encourages the exchange of strategies and advice among learners and between learners and the teacher.

Combining these approaches together, LA, or more specifically, self-regulation, is promoted in this research through the use of reflection and peer collaboration. The student teachers are prompted to reflect using journals while dealing with writing argumentative essays. Writing is the content on which this study focuses, firstly because writing enables learners to produce language output; and while producing, it is a process where the creation and the discovery of meaning take place (Zamel, 1982). It has been argued that output is an important variable in language learning in that it gives learners the opportunity to notice their knowledge gap, to test hypotheses, and to reflect on language use (Swain, 1995). Thus, 
output allows learners not only to put the language into practice, but also to seek more knowledge about the language. This is supported by researchers such as Izumi (2002), Nation (2007) and Webb (2005), who claim that in addition to productive knowledge, writing has beneficial impacts on receptive knowledge. Secondly, writing enables learners to explore themselves and to record their experiences (Graham \& Perin, 2007). As the aim of the study is to lead the learners to reflect on their learning and to evaluate their own progress, the "permanence of writing" (Graham \& Perin, 2007,p. 445) makes it easier for them to do so. It is this permanence of writing that gives them the opportunity to self-correct and give feedback to themselves (Raimes, 2002). Thirdly, writing is claimed to be the hardest skill to grasp for foreign language learners (Chamot, 2005; Richards \& Renandya, 2002), and yet a necessary skill for opportunities for further academic studies and employment (Graham \& Perin, 2007). Therefore, this study aims to be substantially helpful to the participants by enabling them to reflect on their difficulties and then to try to address these difficulties by using appropriate strategies.

\subsubsection{Use of reflection}

Reflection has often been used as a tool for the development of LA for a number of reasons. Reflection is defined as "an important human activity in which people recapture their experience, think about it, mull it over and evaluate it. It is this working with experience that is important in learning" (Boud, Keogh, \& Walker, 1985, p. 19). As this study acknowledges the importance of having learners focus on their own process, this definition is added with Moon's assertion (2013) that reflection implies processing linked to thinking and to learning. Moon adds that capturing the process through writing results in better understanding of the learning process for learners. Thus, reflection should be used not only to "recapture" experience, but also to anticipate and to capture the experience or process as it happens.

Those are the three benefits of reflection also suggested by Boud (2001).

Reflection is claimed to help learners explore their problems, which are usually presented in a "messy" way (Boud, 2001). It is not always easy for learners to identify what exactly they struggle with and why unless they are given the opportunity to consciously reflect. That is why reflection is claimed to be a problem-solving process (Silver, 2013). According to Schön (1983), reflection leads to problem setting, bringing prior knowledge into the surface, and figuring out ways to solve the problems In other words, learners perceive their difficulties in a clearer and more specific way thanks to reflection. The more their awareness of their 
difficulties, the better their decision-making and strategic thinking develop. The attempt to solve their problems brings their known strategies into their consciousness, which is crucial particularly in this study, as the aim of the study is not to teach strategies overtly. Leki (1995) recommends to "build[...] from what students already know and not attempt to teach them something they already do" before suggesting new strategies to them (p. 259). Then, when known strategies do not work, the attempt to solve problems pushes them to seek others.

All the reasons stated above imply that reflection is an 'affordance' enabling metacognition development (Cotterall \& Murray, 2009). It enables learners to improve their awareness and decision-making regarding their learning (Tassinari, 2015). It also helps them evaluate what they have learned in order to better plan what they are going to do (Cotterall, $2000,2017)$. With such an engagement in their learning, learners develop their selfregulation and autonomy.

Reflection should not focus only on weaknesses (Chu, 2007). Learners should also be encouraged to reflect on their improvement and their strengths, from which they draw strategies that work for their learning.

Apart from strengths and difficulties/weaknesses, reflection is claimed to raise learners' awareness on their thoughts and feelings towards their learning (Boud, 2001), which is fundamental, as feelings and self-beliefs are involved in self-regulation (Zimmerman, 2000). Therefore, reflection allows learners to have a better understanding of themselves (Chu, 2007). Additionally, the reflection and metacognitive skills that learners have developed can be used for any learning they might conduct in the future (LaVaque-Manty \& Evans, 2013, p. 141), which is what is referred to as transfer of learning (Cotterall, 2009). This ability to put into practice what they have learned gives them power (Anderson, 2012; Fonseka, 2003), and is the goal of developing LA: we do not learn for the sake of learning; we learn so as to make the most of it (Holec, 1990).

\subsubsection{Use of peer collaboration}

Peer collaboration is used in phase two to foster interdependence (see the importance of interdependence in the development of LA in 2.4.2.2), a key concept of social constructivism. Peer collaboration is used to allow the student teachers to "combine and synergize a diversity of approaches and perspectives" (Palfreyman, 2018, p. 58) regarding writing and learning in general. Palfreyman (2018) also stated that, apart from the development of interdependence, conducive to $L A$, the interactions resulting from peer 
collaboration are vital elements in language, and must, therefore, be extensively included in both content and means of learning. Though the focus is put on writing in this research, it should not be forgotten that what is learned/taught is language learning, which must involve interactions (P. Benson, 2011; Neumann \& McDonough, 2015; Oxford, 2003b).

The term "peer collaboration" is used throughout this thesis to refer to any acts of doing work together with peers. It can involve common classroom practices among learners, such as trying together to figure out the answer to a question correctly, explaining rules to one another, trying to find solutions to a problem together, making decisions on common goals and materials. Therefore, it may include "peer teaching" or "peer tutoring", in which learners provide explanations to their peers (Kao, 2011). In terms of teacher autonomy, this thesis does not take into account the distinction between "cooperation" and "collaboration" stated by Hord (1986) and Littlewood (1999), which highlights that collaboration involves making decisions about common teaching practices together, which is much more than mere cooperation.

\subsubsection{Summary of promotion of LA}

This section discussed approaches and tools mainly used in phase two. Combining teacherbased, classroom-based, and learner-based approaches, the study uses reflection and peer collaboration in order to foster self-regulation. While reflection is an essential tool for the development of metacognition, peer collaboration is indispensable for the development of interdependence and for language learning.

This section also stressed the importance of the context in this research. The latter is based on the belief that the context must be taken into consideration when promoting LA, implying the necessity to study or to know the context well before conducting any implementation. This is why this research is divided into two phases, which focus on the research questions below.

\subsubsection{Research questions}

Phase one focuses on the exploration of the affordances for autonomy in the Malagasy rural school, and attempts to answer the following research questions:

1. What are the EFL Malagasy teachers' beliefs about LA and teacher autonomy?

2. What are their practices in terms of teacher autonomy and the promotion of LA? 
Taking the findings in phase one into consideration, phase two deals with student teachers' in-class practice involving the development of their self-regulation of writing, and addresses the following questions:

3. To what extent is reflective learning conducive to the development of the Malagasy EFL student teachers' self-regulation of writing?

4. To what extent does reflective learning impact their writing performance?

5. What implications on their future teaching do they see as a result of the reflective learning experience?

\subsubsection{Methodological theory}

Underpinned by social constructivism (see 2.2.2), this research maintains that the development of LA depends on factors such as the context and individual affective factors, implying that LA does not exist by itself. It is an embedded and contextualised construct. In order to enable such a construct to develop in learners, it is necessary to have some knowledge about the context they are in, and then, to give them opportunities to reflect on themselves and their learning processes. The appropriate method to do so was qualitative. As Dörnyei (2007) states, insights into contextual conditions and influences are best obtained through qualitative research. Qualitative research is said to enable researchers to focus on individual meaning (Creswell, 2009), and to capture experiences involving different features such as memories, emotions, and senses (sights, sounds, and smells), in other words, experiences that "cannot be meaningfully expressed by numbers" (Berg, 2001, p. 4). The two phases of the research respectively consisted in 1) investigation about affordances for LA through teachers' beliefs, learning and teaching experiences, reflections, attitudes, affective factors, such as motivation, and 2) an attempt to promote LA taking into account the results of the investigation. Though the participants and the contexts were not the same in the two phases, phase one being with teachers in a rural area school and phase two being conducted with student teachers at a university, the two phases were linked. Firstly, the student teachers are likely to be appointed to teach in rural settings later, given that $4 / 5$ of the Malagasy people live in rural areas (UNICEF, 2018a). Secondly, the affordances discovered in phase one could be emphasised in phase two in order to help the student teachers develop their LA. Therefore, the methods used consisted of ethnographic approach in phase one and practitioner research in phase two. 


\section{Phase one - Exploring LA in a Malagasy rural school}

Before attempting to foster autonomy in a particular context, it is fundamental to learn what is implemented in real classrooms through observations, and through listening to teachers so as to understand their perspectives and beliefs regarding learning and teaching, including the place of autonomy. An in-depth study of the perspectives and the practices of the people concerned in the given context is, thus, necessary. As Breen (1991) puts it, "in order to understand, we are obliged to hear the multiplicity of meanings given to what is done by the people who undertake teaching and learning" (p. 232). This chapter focuses on phase one of this research project, consisting of exploring affordances for LA and teacher autonomy in a Malagasy rural school.

\subsection{Research goals}

The main purpose of this phase one was to investigate the existing affordances for LA in a Malagasy context. Before promoting and implementing LA in class, it was deemed important to have an understanding of what elements of autonomy are present already in EFL Malagasy classrooms, and to study the conditions in which teachers in Madagascar work, in order to build more knowledge about the context. It is significant to see the "system" already set in such a (cultural) context "in its own terms" - in lieu of using criteria outside the culture to judge it (Coleman, 1992, p. 238) . Furthermore, "the development of learner autonomy and teacher autonomy is constantly influenced by contextual factors" (Nakata, 2011, p. 902). These factors need to be understood, before attempting to implement any approach leading to LA (Ambler, 2012; Benson \& Lor, 1999; Fonseka, 2003; Hacker \& Barkhuizen, 2008; Little, 1999), in order to avoid any seeming 'failure' and blaming it on the learners or the unsuitability of autonomy (Smith, 2003a). Understanding teachers' learning histories, beliefs and views about language learning and teaching is a prerequisite to the implementation of LA (Martinez, 2008). Moreover, it is crucial to take into account the challenges these teachers face (Lamb, 2007) before thinking of bringing about any changes. Additionally, learners' small decision-making actions, such as impromptu questions and references to 'real life' when dealing with any language areas, labelled as 'seeds' of 
autonomy must be present already even in traditional classes, but they need to be found, then, nurtured in order to flourish (Allwright, 1988). It is important to be aware of and to study those existing elements because as 'seeds', they can be the starting points for any possible development; and this is even more important in developing country settings:

[...] in developing country contexts where education is in a rapid state of development and where teachers and physical resources are in short supply [...], teachers may actually need to tap into and engage the existing autonomy of students to a greater extent than in better-resourced settings. (Smith, Kuchah, \& Lamb, 2018)

Thus, this phase one investigated (1) EFL Malagasy teachers' beliefs about LA and teacher autonomy, and (2) their practices in terms of teacher autonomy and the promotion of LA.

\subsection{Research context}

\subsubsection{The setting}

The school where the study took place was chosen for four reasons. Firstly, the school was located in a rural setting. As stated earlier, four out of five Malagasy people live in rural areas. Therefore, a rural school would be likely to serve more as a representative of schools in Madagascar than an urban one. Secondly, it had all the school levels, which enabled me to observe all the different classes, in which English is taught (from primary to secondary senior school) in one place. Thirdly, the school had a guest house, where I could stay for three weeks. Finding hotels in a rural area in Madagascar is almost impossible, unless the area has special touristic attractions. Lastly, the Head of the School and the four teachers of English all gave me their permission to conduct my research in the school.

The school may be more privileged than most rural schools, as it is run by a foreign charity organisation (the nationality of the organisation will not be revealed for confidential reasons). It has more resources and is sometimes visited by English-speaking foreigners. Nonetheless, it still presents many of the characteristics that Malagasy rural schools generally have. Such characteristics include teachers having no teaching degrees, fewer resources than urban schools, underperforming students (compared to those in urban schools) because of poverty and little time for homework due to the necessity to contribute to household chores and, sometimes, to help parents earn income to support the family (Wills, Reuter, Gudiel, Hessert, \& Sewall, 2014). The combination of these characteristics is 
what Smith et al. (2018) refer to as "difficult circumstances" that developing country schools face in general. Thus, the school is somewhat representative of Malagasy rural schools in general.

\subsubsection{The language used in class}

Though the teachers in this study taught English, the instruction, the explanation, and the interactions (teacher-students and students-students) during the class were done in Malagasy. Translation was very common at all levels. To check students' understanding of task instruction or a question, for instance, the teacher would ask them the equivalence of the question in Malagasy. Translation was also used in the teaching of vocabulary, not only to check students' understanding, but also to introduce the vocabulary itself. Thus, all genuine communication occurred in Malagasy. Speaking practice in English was limited generally to greeting the teacher and dialogue practice. Though teachers encouraged the students to speak English both in and outside class, the four teachers stated it was too hard for the students to do so. Furthermore, speaking English outside class can be considered as showing off, as pointed out by one of the teachers in the two interviews, which is indeed typical in Madagascar (especially outside cities). The limited speaking opportunities as well as the fear of speaking makes speaking the hardest skill to teach and to learn according to three of the teachers.

\subsubsection{Unusual practice}

An unusual practice in the school was communication with pen pals. The school gives the students opportunities to communicate with English-speaking foreign students (the same nationality as the organisation sponsoring the school). Most of the students have pen pals and communicate with them via letter writing about twice a year. The students who did not have pen pals were either new to the school or were in grades 5,9 , or 12 . As the students in these grades sit for national examinations at the end of the school year, they do not do any extra activities. The letters vary according to the class levels. While primary school students would write only one or two sentences accompanied by a drawing, senior secondary school students would write "proper" letters. The primary school students' letters are usually written in Malagasy, as their main teachers do not speak English. Then, one of the English teachers writes the translations under the Malagasy versions. The letters were then brought to the foreign students by the head of the foreign organisation. The foreign pen pals reply to 
their letters about twice a year. Despite the infrequency of the communication, this pen-pal "project" is considerably appreciated by the students and motivates them.

\subsection{Methodology}

\subsubsection{The participants}

The participants in the study were four teachers of English in the rural school. They all speak Malagasy, French, and English, which means that they have all experienced language learning. They will be called John, Norah, Ariane, and Christina. They all started studying English in junior secondary school (grade 6) and attended English courses after graduating from senior secondary school. Apart from Christina, they did not have tertiary education. Like most teachers in rural areas, the four teachers did not receive official teacher training. However, they had some informal training, which was held in the school by some foreign volunteers from time to time.

John has 17 years of EFL teaching experience. After graduating from high school, he attended courses in an institute (not a university) to become a tour guide. After finishing the courses, he was offered a job as an English teacher at the institute. Though his goal at that time was to work in tourism, he accepted to become an English teacher, mainly to maintain his English. Motivated by his students' positive feedback on his teaching, he decided to pursue his teaching career. Later, he decided to teach in the rural school, where he now teaches all the classes in the primary school. What distinguishes John from the other teachers was that he had received training about Accelerative Integrative Methodology (AIM) by some foreign volunteers visiting the school a few years before this study. AIM is a method emphasising the use of story-telling, gestures, repetition, and peer collaboration (Maxwell, 2001). AIM was originally designed to teach French as a Second Language, but its use had been expanded to the teaching and learning of other languages. John was using AIM in all his classes: one grade 2 , one grade 3 , one grade 4 , and two grades 5.

Before becoming an EFL teacher, Norah taught history, geography, and science in other schools, and then, in the rural school. She still taught science along with English. She decided to become an English teacher for three specific reasons about two years before this study. Firstly, she was pushed by motivation, which was largely integrative in nature (Gardner \& Lambert, 1972): she was longing to communicate with the occasional English-speaking visitors of the school. She viewed the ability to communicate with those people as an 
integration into a foreign community (though it is logically the other way around) and as an opportunity to widen her horizon. Secondly, she wanted to understand the English books in the school library. Thirdly, she was thinking of the future of the school. She noticed that, as John had been the only English teacher in the school at that time, he was extremely busy. Not only was he supposed to teach all the classes, from primary to senior secondary, but he was also the only one who was able to communicate with foreign visitors and to show them around. Moreover, he had other administrative responsibilities within the school. Norah was thinking, then, that if John was not present someday, the school would have a serious problem. Therefore, she decided to attend weekly English classes in a language institute in the nearest town. As her English improved, she was offered an English teaching job in the school, and she now teaches grade 6 and grade 5 classes.

Ariane is the youngest teacher in the school. Graduating from the school herself two years before this study, she was offered a two-year training at the school. In the first year of the training, she worked with English and French teachers in the secondary school. She observed their classes and was asked to help with lesson planning. In the second year, she worked with pre-school and primary school teachers. At the end of the second year, there was a vacant English teaching post for grade 9 classes, and she was appointed to take it. The fact that she had to teach grade 9 (grade 9 students sit for a national examination at the end of the school year) encouraged her to make lots of effort and to do her best to improve her English. Thus, she decided to attend weekly English classes in a language institute, like Norah did.

Christina was writing her Master's dissertation on English for Specific Purposes at one of the largest universities in Madagascar while teaching grades 10 to 12 in the rural school. Apart from attending courses at the university, she had also had English classes at a large language institute in the capital. She decided to teach English because she thought it was the best way to practise and to maintain it.

\subsubsection{Ethical considerations}

In order to be able to conduct the research at the school, I requested the permission from the Head of School, providing her with the information about the research (see appendix 11 and appendix 12, pp. 282-283), the research ethics approval (see appendix 10, p.281), and the consent form (see appendix 13 and appendix 14, pp. 286-289) for the teachers. After obtaining the Head of school's permission, I asked the four teachers' permissions to observe 
their classes and to interview them by giving them the same documents. When I had their permissions, I had a meeting with them one by one. I made sure the teachers understood that they had the right not to take part in the study. Also, I explained to them clearly that my ultimate aim was to learn about how teaching and learning English really look like in a Malagasy rural context, that my goal was not to assess or to judge their teaching performances in any way. In addition, I said that teachers may have different beliefs and different ways of teaching according to their learning and teaching experiences as well as the context they are in. Thus, their beliefs and their opinions as experts in learning and teaching in their context would be extremely valuable. I finally added that in order for me to try to contribute to the improvement of education in Madagascar, I need to know what reality is. Those explanations were given with the aim for them to see me totally as a researcher as opposed to an expert in teaching. Also, the explanations intended to reduce the Hawthorne effect, which involves "the consequent awareness of being studied, and possible impact on behavior" (McCambridge, Witton, \& Elbourne, 2014, p. 267).

\subsubsection{Ethnographic approach}

As the goals of phase one were to know about the affordances and constraints for the fostering of LA, and to understand teachers' beliefs and practices in relation to LA and teacher autonomy, a qualitative method using an ethnographic approach was conducted.

The aims were to explore, to adopt a flexible approach to allow for the "emergent nature" of data, and to be immersed in the setting so as to be able to "capture a sufficient level of detail about the natural context" (Dörnyei, 2007, p. 38). An ethnographic approach was especially chosen, as it enables the following:

[...] direct and sustained contact with human agents, within the context of their daily lives (and cultures), watching what happens, listening to what is said, asking questions, and producing a richly written account that respects the irreducibility of human experience, that acknowledges the role of theory, as well as the researcher's own role, and that views humans as part object/part subject (O'Reilly, 2005, p. 3).

An ethnographic approach, thus, intends to explore and to give an understanding of a social (and cultural) life, and the system(s) governing that social life. However, it cannot be purely inductive, as not having preconceived ideas at all is impossible; and it is essential to recognise existing theory (Braun \& Clarke, 2006), and at the same time, to have an open 
mind to any emerging data. This is what is referred to as "iterative-inductive" by O'Reilly (2005, p. 27). O'Reilly adds that ethnographic research does not only consist in conversing with participants. It should also encompass observations. Moreover, the researcher needs to become integrated into the community he/she is studying, in order for the participants to act comfortably (as if they were not being observed and studied). The key factor enabling this to happen is an extended period of time. The longer the researcher stays and works with the participants, the more accustomed the latter are to the researcher's presence. An extended period is also essential for the researcher to "settle in and start to see things more clearly" (p. 99), to notice changes, and to attain acculturation and a "prolonged engagement" with the target community (Dörnyei, 2007, p. 131). It should not be forgotten that the researcher is also an "active agent" of the ethnographic research, though he/she may only use observation (Agar, 2004, p. 20).

From such exploration, using an ethnographic approach allows the researcher to produce hypotheses that may be replicated in circumstances that have similarities with the community being studied (Blommaert \& Jie, 2010). Similar circumstances to those found in this study are likely to exist not only in other Malagasy rural schools, and in some cases, in Malagasy urban schools, but also in schools in other developing countries. Therefore, the findings may give some general insights into the feasibility of the implementation of LA in developing countries.

\subsubsection{Data collection}

The three-week stay enabled ten days of class observations, which were dependent on each teacher's time-table, and on their willingness to be observed or not. In total, thirty class observations were carried out during the ten days.

Due to the teachers' tight schedules, two interviews per teacher were done, instead of three (the ideal number of interviews according to Polkinghorne (2005)), as had been planned. Nevertheless, the second interview included the prompts which were supposed to belong to the second and the third interviews. Apart from the observations and the interviews, the immersion enabled some informal interactions with the teachers to take place outside class during the three-week stay (while having lunch together and during breaks), which helped build comfort and familiarity, hence, decreasing the "disturbance" of my presence in their classes. 


\subsubsection{Semi-structured interviews}

The first interviews took place in the first week. They lasted between 35 and 60 minutes. In order to understand the teachers' beliefs in terms of autonomy, it was considered necessary to have some knowledge about their English language learning background first by asking them to think back to the ways they had been taught English in class. More precisely, they were asked to think of any effective methods, strategies and/or activities their English teachers had used in class, and also of any 'failing' they perceived that their English teachers had had. Then, they were asked how they have been maintaining and improving their level of English after graduating from school.

The first interviews also intended to obtain insights into the teachers' pedagogical approach. The questions were about the teachers' views on their own teaching: the language aspects they thought to be the most important to teach, the most difficult to teach (or that their students found the most difficult), and the easiest to teach. They were also asked to think about tips on how to overcome students' specific difficulties, and about methods, strategies, or activities they use and consider as useful to help their students improve some particular aspects of language.

As stated above, the main aim of the study was to know the teachers' practices in terms of the promotion of LA. For this purpose, they were asked specific questions on promoting aspects of self-regulation in the first interviews: whether helping their students set their own learning goals, monitoring their learning, and self-evaluating were part of their practices in class. They were also asked about the promotion of self-initiation or independence (from teachers): whether they encouraged their students to learn or to practise English outside class, and to find their own answers to questions or problems they may have, and whether they gave their students opportunities to help one another. Additionally, there were questions about the promotion of volition and motivation: whether they gave students opportunities to choose materials to use in class, to give opinions on what to learn in class, and whether they encouraged their students by giving them positive feedback.

Knowing the teachers' practices in terms of their own autonomy, or more precisely, selfdirected teaching was also a goal in this study. The teachers were, therefore, asked about their self-regulation in teaching: if they set their own teaching goals, if they keep a record of their reflection on their teaching, if they evaluate their own teaching, including identifying their problems and finding solutions. There were also questions about their self-initiation as 
teachers: whether they made an effort to improve their teaching skills, to share and exchange ideas about teaching with other teachers, and whether they asked their students for feedback on their teaching.

The second interviews took place towards the end of the third week, mostly after all the class observations. They lasted between 15 and 40 minutes. The first aim was to gather the teachers' reflection on their teaching during the last week: on the in-class "successes" and the "failures", the reasons for the successes and failures, and what they planned to do next as a response to the failures. The second aim was to record their perceived changes (or not) in their beliefs in relation to autonomy. For this aim, they were asked if they found the affordances cited earlier for both LA and teacher autonomy important:

- for self-regulation: learners setting goals, expressing their feelings, saying what they found difficult/easy, self-reflecting and self-evaluating

- for self-initiation and/or independence from teachers: learners learning and practising English outside class, giving them opportunities to help one another, encouraging them to find the answers to their own questions or problems

- for volition and motivation: giving the learners opportunities to have their say on teaching materials and/or teaching content, encouraging them by giving positive feedback

- for self-directed teaching: setting their own teaching goals, reflecting on and evaluating their own teaching, making effort to improve their teaching skills, exchanging ideas about teaching with other teachers, requesting feedback on their teaching from students.

To enable the teachers to express themselves freely and to be as comfortable as possible during the interviews, they were given the choice to speak in Malagasy, French, or English. Christina and John chose to speak in English during the two interviews; Norah chose to speak Malagasy during the two interviews; Ariane chose Malagasy for the first interview, and English for the second interviews. The interviews were audio-recorded, transcribed, and the ones in Malagasy were translated into English. In this thesis, the excerpts translated from Malagasy are marked "translated". A sample of the translation was checked by a Malagasy person having done his graduate studies in an English-speaking country, to make sure the translation was accurate. 
The first and second interview questions are enumerated in appendix 1 (pp. 266-268) and samples of interviews can be seen in appendix 2 (p. 269).

\subsubsection{Class observations}

Interviews enable the researcher to build knowledge about the social life of his/her target community. However, they may not always be sufficient, as participants may tend to say in interviews what they should do in lieu of what they do in reality (O'Reilly, 2005). Therefore, observations, considered as powerful tools to build more understanding on given situations (Cohen, Manion, \& Morrison, 2002), were used. Observations enable a comparison between the teachers' statements and their actions in class (Nicolaides, 2008), and hence, can supplement the semi-structured interviews.

Thirty class observations were conducted in total. The classes ranged from grade 2 to grade 12. During each class observation, a checklist was used. The checklist included predetermined elements that may promote self-regulation, volition and motivation, selfinitiation and independence from the teacher, but it also encompassed a miscellaneous column, where any signs that may be related to autonomy were noted down (see appendix 3, p. 272). Additionally, I noted down everything happening in each class in another sheet of paper (a sample can be seen in Appendix 4, p. 273). The classes were audio-recorded, and the recordings were used later to check the notes I took during class and to add information I had missed.

\subsubsection{Data analysis}

The data from phase one consisted of the audio-recorded interviews, the completed class observation checklists, the notes during classes, the class audio-recordings, and some notes related to outside-class informal discussions with the teachers.

To analyse the data, thematic analysis was used. Thematic analysis was chosen because of the advantages it presents. Among these are flexibility, being user-friendly to novice researchers (because of the clear phases of analysis to follow), enabling a 'thick description' of the data set, enabling easier perceptions of similarities and differences across the data set, and enabling a social interpretation of the data (Braun \& Clarke, 2006). These features of thematic analysis make it suitable for studies in "under-researched" areas and/or studies involving participants whose perspectives on the topic are unknown (Braun \& Clarke, 2006), which is the case in this study. 
The analysis for this study involved the iterative-inductive method and encompassed the phases of thematic analysis described by Braun \& Clarke (2006). First, each of the interviews was transcribed, and the ones in Malagasy were translated into English. After reading and re-reading all the interviews, the data were coded through NVivo. Initial codes emerged, and then, were classified into themes. The themes were reviewed, reorganized, and defined.

I listened carefully to all the recorded sessions while looking at the corresponding completed observation checklists. Then, more notes were added to the checklists, which were also analysed, using NVivo coding. Codes, in the form of a list of elements of autonomy, emerged. The frequency at which these elements appeared in each teacher's class was studied. Also, comparisons between the teachers' statements during the interviews and what had been observed in class were made.

To have inter-rater reliability (Duff, 2012), a trained researcher (second coder) and I coded independently randomly 3 notes about class observations and one interview, which made up $10 \%$ of the data. After coding half of the data, we had a discussion on the units of analysis and the codes we came up with. We also discussed some subjects of disagreement. For instance, while I was seeing John self-evaluating (or evaluating one's own teaching) when he mentioned that he was thinking to make the students use notebooks from the following year on (because he had realised that they did not have anything to review when they went home), the second coder did not see that as part of self-evaluation. After that discussion, we coded the rest of the selected sample on our own. We had a session of comparison and discussion again until we had satisfactory inter-coder reliability scores. The latter were calculated using percentage agreement. The percentage agreement is the sum of the agreement codes, divided by the total number of the codes multiplied by 100 . In the case of class observations, the sum of the agreement codes is 4 , and the total number of codes is 5 . The percentage agreement is therefore $4 * 100 / 5=80 \%$. In the case of interviews, the sum of agreement codes is 12 , and the total number of codes is 14 . The percentage agreement is therefore $85.71 \%$. A sample of coding for interviews can be seen in Appendix 7 (p. 278) and a sample for class observations in Appendix 8 (p. 279).

\subsection{Findings}

The three-week study including the class observations, the interviews, and the informal discussions with the teachers enabled the discovery of affordances for autonomy both in 
terms of the teachers' beliefs and their practice. "Seeds" of autonomy (Allwright, 1988) could be observed in the teachers' perceptions of what teaching and learning should entail, as well as in their real classes. However, some seeds were easier to identify in the beliefs than in the practices.

\subsubsection{Teachers' beliefs regarding autonomy}

Attitudes towards LA, including beliefs, can determine the extent to which learners are willing to take charge of their learning (Wenden, 1991). Nevertheless, it is not limited to the learners' attitudes. It also depends on the teachers' attitudes to a large extent. More precisely, LA is fostered in an educational context only if the teacher-learner relationship allows it to (Dam, 2011; La Ganza, 2008). Therefore, the teachers' beliefs regarding LA are crucial, as these beliefs must influence their implementation (or not) of autonomy in class. Likewise, their beliefs with regard to teacher autonomy may contribute to their potential promotion of autonomy (Hacker \& Barkhuizen, 2008; Nakata, 2011). Thus, these two types of beliefs in themselves can be considered as seeds or constraints in the fostering of autonomy. These beliefs were brought to the teachers' awareness while they were answering the interview questions. This section discusses these beliefs, based on the themes extracted from the teachers' interviews. In addition to the information from interviews, other information reflecting perceived changes in beliefs was also gathered during informal talk with the teachers.

\subsubsection{Beliefs about LA}

Their language learning experience helped the four teachers build what is referred to by Wenden (1991) as "metacognitive knowledge about language learning" encompassing "beliefs, insights and concepts that [language learners] have acquired about language and the language process" (p. 34). In other words, their learning experience taught the four teachers challenges, strategies, and all the requirements of language learning. Their experience also enabled them to have empathy towards their students. That is why learning a foreign language is suggested as one of the prerequisites for language teachers in order to be able to promote LA efficiently: "To be able to create an autonomous atmosphere [...], [t]eachers need to learn another foreign language to be able to empathise with the difficulties of language learners" (Tütüniş, 2011, p. 162). It can be said, therefore, that the 
teachers' learning experience built their beliefs about what learning a foreign language involves.

From their learning experience, the four teachers believed that elements of LA such as self-initiation are fundamental. Without self-initiation, they would not have attained their goal, which had been to become teachers of English. Their experience in both learning and teaching also enabled them to recognise the importance of peer collaboration and the consideration of affect. This section will discuss these beliefs as elements of LA. The beliefs were related to self-initiation, peer collaboration (including peer evaluation), self-evaluation, and consideration of affect.

\subsection{Self-initiation and independence from teacher}

Based on their language learning experience, the four teachers understood the necessity of self-initiation. They especially emphasised the efficiency of "effortful behaviours" outside class, which is an essential component of self-initiation (Nguyen, 2008, p. 68). All of them were convinced that the levels of English they had managed to reach were mostly the fruit of their work outside class, along with patience, perseverance, and determination. They pointed out their awareness of the insufficiency of in-class learning or the inefficiency of the methods used by their teachers, which pushed them to make all effort possible and spend a large amount of time "teaching themselves".

Having lived in a Malagasy village most of their lives, two of the teachers had not always had the support they needed for their language learning (and learning in general). After secondary school, they only had Saturday classes in a language institute located at about two hours walk from the village. However, they succeeded in being fluent in English in less than two years and in gaining enough confidence to teach it, thanks to the extra work they did outside class.

Due to their learning experience, the teachers believed in the necessity and effectiveness of self-initiation as well as of independence from teachers. That is why they constantly encouraged their students to read books and to practise as much as they could outside class. Ariane not only encouraged her students but also provided them with strategies for practising:

I tell them to practise English, to use what they know, while playing with other children, such as their little siblings, though the latter don't speak yet. I encourage them to practise English even by themselves, for example, 
we had the lesson "What do you do before going to school?" I asked them to say to themselves what they do while doing it at home, for example, "I'm taking my breakfast. Now, I'm brushing my teeth, etc..." I know some students do, but some don't. Those who are really interested in English do. (Ariane, first interview, translated)

Moreover, the teachers stated they encouraged students to answer their own questions when the latter had difficulty with vocabulary or to ask for help from their peers, as exemplified in the next section on peer collaboration. However, the teachers emphasised that this encouragement to find their own answers only applied to vocabulary, not to other areas. Still related to difficulty with vocabulary, one teacher made his students aware of reading strategies such as guessing the meaning of words.

\subsection{Peer collaboration}

Peer collaboration is an important factor leading to the development of LA, as it cultivates students' active participation, peer feedback, and independence from teachers (Benson, 2011; Dam, 2011; Scharle \& Szabó, 2000). That was basically the teachers' reasons why they widely promoted peer collaboration through pair and group work in class, as demonstrated in the excerpt below. They believed in the efficiency of peer collaboration because of the help, the sharing and the exchanges among the students as well as the avoidance of overreliance on teachers it generates, leading them gradually to autonomy, not only in learning, but in life in general.

[...] when they ask me a question, I tell them to think about it. I tell them I cannot answer them right away, because in life, you don't get answers easily. So, you have to think and ask your friend if you can. (John, first interview)

Moreover, peer collaboration improves the knowledge of those helping as well as those needing help, according to the teachers. It can be a source of motivation, not only because it engages the students actively in cooperative efforts and peer interactions (Wright, 1987), but it also engenders self-satisfaction, as helping their peers raises students' awareness of their strengths:

In the group, there is always someone who is better than the others. So I ask them to help the others, and I ask the others to ask for help if they 
have any problems. If one of them can explain or knows the answer, he knows that he's better than the others. That one can then evaluate himself and says to himself that he's better and can help his friends. (John, first interview)

\subsection{Peer evaluation and self-evaluation}

Along with the sharing and the help, peer collaboration generates peer evaluation. Three of the teachers stated that they enabled their students to do peer evaluation, mainly because the students appreciate evaluating their peers' work: "From my experience, when you ask them to evaluate one another, they're happy. When I ask them to exchange their notebooks and evaluate one another's exercises, they really like it" (Norah, second interview, translated).

Another advantage of peer evaluation is that it provides a way towards self-evaluation, according to John (as shown in his statement above). He stated that the peer feedback and their own comparisons between their work and their peers' made the students aware of their improvement, and thus gave them more incentives. On the other hand, the comparisons also made them realise what they could do better in the future:

I see that when they're between themselves, they are honest to [each other]. When they see what the others did, they can think that "maybe next time, I will do better than this one". For example, today they write a short silly sentence, and when they see other pupils writing a very long sentence, they will think of making a longer one next time. (Second interview)

Two of the teachers specified that peer evaluation and self-evaluation were possible only when dealing with grammar-related tasks: "Only when dealing with grammar, but not in writing for example. Grammar rules are available for them to check. I put the rules on the board and they evaluate themselves" (Norah, first interview, translated).

\subsection{Consideration of affect in teachers' learning}

Affect plays an important role in the development of LA (Bennett, 2018; Yamashita, 2015) and in language learning in general (Oxford, 2013). From their own learning experience, the four teachers were aware of the importance of affective factors in language learning. As stated earlier, they strongly believed that self-initiation had effectively contributed to their 
achievements regarding their English levels. They especially talked about their effort outside class, and also emphasised their motivation and determination leading to such effort, which is also encompassed in self-initiation (Nguyen, 2008). Their main motivation was their strong interest in and/or passion for English. Nevertheless, they did not always have a positive experience as far as learning English is concerned.

This is what Ariane said in her first interview, when talking about a teacher of English who constantly picked on her: "As a teacher, you are supposed to do your best to help weak students. I wasn't really weak but her attitude made me feel I was. Thus, every time I went to class, I felt discouraged". However, she did not let her discouragement win. She was so determined to 'succeed' that, although she did not participate in class because of the fear of being criticised, she made tremendous effort outside class. This experience of adversity made her realise the power of determination, on the one hand, and the attitude to avoid as a teacher, on the other hand. This is what La Ganza (2008) refers to when she talked about the strength gained from negative experience with "internalized" teachers. The negative experience constrains freedom in class as a learner, but once the learner becomes a teacher, he/she is determined to make up for his/her experience by behaving or doing the opposite of what his/her former teacher had done. Therefore, in the case of Ariane, the negative experience helped her build beliefs in what teaching should entail.

While Ariane and the two other teachers had been motivated by their long-term passion for English, Norah was pushed to improve her English (with the aim of teaching it eventually) by the thought of the future of the school and the longing to be able to communicate with foreign visitors at the school. Before even starting to work on her English, she knew the risk she was taking and the challenge she would face, given her level at that time:

I took a great risk when deciding to become a teacher of English. I used to be very bad at English. 2 years ago, I was really zero as far as English was concerned. Sometimes, in our staff meeting, we were asked to read an English passage, and I refused each time to read. That's why my colleagues were very surprised when they knew that I had decided to teach English. But I was determined. (Second interview, translated)

\subsection{Consideration of affect in their students' learning}

Acknowledging that motivation is the key to language learning, the teachers stated that they were doing their best to nurture motivation in their classes, firstly, by providing the students 
with positive feedback even on the slightest effort they made and by giving them encouragement in case they found some language aspects too difficult. Secondly, they would not stick to their lesson plans when they noticed boredom or tiredness. They would ask students whether they would like to do activities such as playing games or singing.

I have to be flexible to avoid them being very tired in class. I want them to be very lively, active and to be interested in what we do, not to be bored. When they're bored, I change a little bit, and do something else. (John, second interview)

Norah emphasised that learning should involve comfort and pleasure. She stated that students would be more willing to learn if they enjoyed what they were learning, if they felt that the teacher considered their feelings, and if they did not feel forced "like prisoners". Furthermore, she expressed her longing to close the "gap" between her and the students so as to build trust.

My problem is the gap between us, between teacher and students. I want them to see me as a teacher and a friend. If they considered me as a friend, they wouldn't hide anything from me, and they would dare speak. So, I'm thinking how I can help them get rid of their fear and to erase that gap between us. (Norah, second interview, translated)

Nevertheless, asking students' opinions on tasks or asking them about their difficulties was not frequent, according to the teachers. Firstly, they felt time was limited. Secondly, the teachers were convinced that asking the students would not be necessary, as they knew the students so well that they would notice when the students were not happy or had difficulty:

I don't ask, but I notice it. Like today, I noticed that it was hard for them to build sentences. I always know when something is too difficult for them, so, we review it again and again. (Ariane, first interview, translated)

Only John asked his students about what they had found difficult after doing a task, time permitting. Norah stated that her students would tell her their difficulties without being asked sometimes. The other two teachers admitted they had never asked but as a result of the interview, said that they definitely would.

Likewise, none of the teachers was used to asking their students' opinions on materials and lesson content due to a perceived time constraint and a lack of choice in the materials. Nevertheless, the interview question made one of them realise that giving students 
opportunities to do so may turn into incentives, as it would lessen the authoritative image of the teacher:

I've never done that, but I think I should. You see, you're helping me by asking these questions as these questions are giving me ideas. They make me think that I should do such or such things. I think giving them opportunities to have their say on teaching materials and/or teaching content may be important, but I didn't know about that before [you asked me the question]. It might give them more motivation. What's happening now is that teachers tend to be too much authoritative. So, if students are given such opportunities, that may change things. That may open them up. (Norah, second interview, translated)

\subsubsection{Beliefs about teacher autonomy}

As stated earlier, this study refers to teacher autonomy as a "capacity for self-directed teacher-learning" and as "a capacity for self-directed teaching" (Smith, 2003b; Smith \& Erdoğan, 2008) . The first capacity is also called "teacher-learner autonomy", defined as "the ability to develop appropriate skills, knowledge and attitudes for oneself as a teacher, in cooperation with others." (Smith, 2003b, p. 1). It is what has been considered as a prerequisite to the promotion of LA, with the view that teachers should have experience in implementing autonomy in their own (ongoing) learning in order to be able to promote it (Benson, 2011; Hacker \& Barkhuizen, 2008; Little, 1995; Sinclair, 2009; Smith, 2000). The second capacity is also conducive to the promotion of LA, but it involves teachers' reflection and self-managing processes on their own teaching (McGrath, 2000; Smith, 2003b; Smith \& Erdoğan, 2008). Some elements of these two capacities were extracted from the interviews with the four teachers, which will be discussed in this section. The elements consisted of affect, selfinitiation, peer collaboration, teaching goals, and self-evaluation.

\subsection{Affect}

As in LA, affect also plays an important role in teacher autonomy, whether it is for selfdirected teacher-learning or self-directed teaching. Teachers need incentives to keep up their passion for teaching and to continue working on the improvement of both their English and their teaching skills. Incentives came from different sources for each of the four teachers: students' positive feedback, the longing to fully master the language, the thought 
of the future of the school, and the desire to help their students while practising English (in order not to lose it) at the same time. These incentives pushed them to constantly look for ways to improve themselves regarding both their English and their professional development. This following statement clearly shows the determination to improve both fields:

Some people dream of having lots of money, having a house, but I dream of becoming really professional. I make lots of effort to improve my teaching skills. I have decided that whatever happens, I'Il always be teaching. I went to an institute to improve my English. As a graduate from senior secondary school, I could have become a teacher of English [in the countryside] right away, but I wanted to be better at English at first. (Norah, first interview, translated)

\subsection{Self-initiation}

Driven by the incentives described above, the four teachers felt a strong willingness to make every possible effort as both learners (of English) and teachers. Despite their lack of formal teacher training, they wanted to learn more in order to avoid having their students use only rote learning, which they had inherited from their former teachers (Mulkeen, Chapman, DeJaeghere, \& Leu, 2007). Firstly, self-initiation was present in the teachers' self-directed teacher learning. As explained earlier, the four teachers believed that self-initiation plays a major role in language learning, based on their own learning experience. Even with their English teaching experience, they were aware that their English still needed improving, and that teaching only would not maintain or increase their English level. Thus, they continuously worked on their language while developing their teacher-learner autonomy more and more. They continued with their approaches such as reading books (any types, including grammar books), and made the most of any opportunities to learn and practise more, such as attending a Saturday English course and practising with visitors (including me).

Secondly, the teachers were not only concerned about their English but also their teaching. All of them expressed the necessity for them to learn unremittingly so as to improve their teaching skills, and to implement what they had learned in their teaching:

I think that, as a teacher, we have to learn, not to be tired of learning. I think that it's very important to improve ourselves. There are different ways of learning. So, we also have to look for different ways of teaching 
and different skills. If I think that I didn't do things correctly, I say [to myself] "ok, next time, l'll do it that way". So, I have to improve, always improve. (John, second interview)

Although the teachers did not have formal teacher training, they were aware of attitudes teachers should have (see Ariane's statement about teachers' attitudes towards weak students on p. 69). They also believed that the "traditional" way of teaching (which they had experienced as learners) had not been efficient and therefore, should be replaced, taking students' affect more into account, as shown in the extract below. Though they had not found the best approaches to substitute for the 'old way' yet, their awareness and their willingness to look for these approaches clearly demonstrated their teacher autonomy (involving both capacities): "[Teacher Autonomy] involves the autonomous teacher in a continual search for better answers to the different problems inevitably arising in individual teaching and learning situations." (Shaw, 2008, p. 190)

Giving vocabulary with their translation is an old-fashioned method. We need to find other ways to teach students vocabulary. We should think of what they like. (Norah, first interview, translated).

I don't want to use the old way, that is, writing and explaining; teaching is not limited to that. I don't want to do that. (Norah, second interview, translated)

\subsection{Peer collaboration}

Comments from the four teachers seemed to align strongly with Smith's (2003b) claim that “teacher autonomy necessarily involves interdependence, or 'relatedness', not just individualism [...]" (p. 7). They all considered peer collaboration as a key towards improvement of both their ongoing language learning and their teaching skills. Their continual work on the improvement of their teaching discussed earlier entails "critical reflective enquiry" (Shaw, 2008, p. 190), which involves peer collaboration through dialogue.

Language teachers tend to choose avoidance as the usual solution when there is a risk of having their weaknesses regarding their language proficiency revealed; and the "antidote" to such avoidance is the promotion of peer support (Smith, 2000). The four teachers did choose peer support over avoidance. Among themselves, they knew their levels of English were different. The two having lower levels did not hesitate to seek help from the other two in 
terms of pronunciation, grammar, and speaking practice. Particularly, Norah appreciated peer observations (including my class observations), as they enabled peer correction, which was the solution she found to her inability to self-evaluate:

I had asked you to help me by correcting my mistakes. And when you corrected my pronunciation, I realized that I cannot evaluate myself if there is no one to evaluate me first. It's because I cannot notice I'm wrong if no one tells me. So, I'll keep making the same mistakes. Yet, I need to know if what I do is right or wrong, and for that, I need help. I was thinking of inviting Ariane to visit my class, and asking her permission to visit her class as well. The goal is to ask each other feedback on our teaching afterwards. (Norah, second interview, translated)

The teachers, thus, used peer collaboration for the development of their self-directed teacher-learning.

Norah's statement above shows her awareness of the importance of peer observations for the improvement of both her English and her teaching skills. She clearly understood the advantages of peer observation, including acquisition of knowledge and reflection leading to self-awareness vis-à-vis teaching, described by Endo (2011):

Peer observations can be an excellent stimulus for professional development, both for the observer and the observed. The benefits of peer observation are to construct and reconstruct our own knowledge about teaching and thereby learn more about ourselves as teachers. (p. 177)

This is also in keeping with what Murray (2014) states about observations being part of social situations and being a means of acquiring knowledge on the part of the observer:

When we think of learning from each other in social situations we have a tendency to focus on interaction involving oral communication; however, we can also learn from others in social settings through quiet observation of their behaviour or demeanour. (p.4)

The three other teachers did not mention peer observation. Nevertheless, like Norah, they believed in the usefulness of peer collaboration among teachers for their professional development. Always in quest of better methods and strategies to teach, they valued exchanges of ideas:

I think it is very important to exchange ideas because I don't know... I'm 
not perfect. I can't say that I am a good teacher. Maybe I have my own method, but there is also another person's method. So, I have to exchange ideas and see what is good with the other one. (John, second interview)

They did implement what they had learned during those exchanges in their classrooms, and experienced some positive results:

[...] when you talk with another teacher, you can see that there are methods that you can use in your class too. For example, last week, I talked with an English teacher. She doesn't teach here, but she teaches over there, at the market. And she talked about her teaching methods, like dictating or something like that, and I have tried this week and it worked because they really focus on the things you do and do not speak. (Christina, second interview)

However, not all teachers (not among the four teachers but other colleagues) were openminded and willing to learn, as they would like to stick to the methods they were using. Therefore, peer collaboration was not always welcomed:

I like discussing and sharing ideas with people, but sometimes, people are not interested in what I say. I want to improve my teaching skills, but some teachers seem to be content with what they have. They think that just standing in front of the students is enough. I want to promote the idea that we're teachers and we need to exchange ideas with one another. (Norah, second interview, translated)

\subsection{Setting goals as teacher roles?}

The teachers believed that the role of setting goals was restricted to teachers whether the goals were related to in-class specific tasks or general learning: "It is the teacher who should set the goal, and the students follow it" (Norah, second interview, translated). Thus, they did not give students opportunities to think of any individual goals. This belief is not uncommon, as it was also perceived in other researchers' previous studies such as Nakata (2011): "Teachers themselves, they argued, do not have such an idea of helping learners to set their own goals, because they are trapped by the stereotypical view that it is the teacher's job to set the learners' goals, not the learners'"' (p. 907). 
Instead of helping their students set up their learning goals, the four teachers informed them about practical advantages of the ability to speak English: being able to communicate with their foreign pen pals and maintain friendships with them (stated by John), with foreigners visiting the school (stated by Ariane). They also informed the students about the usefulness of English in their future studies and careers (stated by Christina and Norah). Furthermore, the teachers were aware of the importance of the students' awareness of the purpose of each task or lesson they had. According to them, they gave their students clear instructions (which are referred to as goals by the teachers) before each task so that the students know why doing the task is necessary vis-à-vis their language learning outcome, as stated in Norah's quote below. The teachers understood that "[I]earners must know why they are being asked to perform a task to appreciate its significance" (Wenden, 1991, p. 42).

[...] if I teach them language functions, such as asking the way, I tell them why it's important. I tell them the objective is to be able to show the way to someone. Another example is the weather. It's important to know the weather in English because it's about the environment around us. So, I tell them why we do a specific task. Objectives should always be told to the students in whatever subject matters. (Norah, first interview, translated)

The four teachers recognised the importance of having teaching goals, and they demonstrated in their statements (see below) some "informed and principled decisions about managing their own teaching context" (B. Sinclair, 2009, p. 184), including flexibility regarding goals. Indeed, being aware of the differences of levels and opportunities between their students and students in cities, they had to adjust their goals and break them down into realistic sub-goals:

I have my own teaching goals. The curriculum has been written by intellectual people who surely have lots of knowledge [...], but not people who really know what's going on in real schools, especially, in rural areas. That's why I set my own teaching goals. For example, I would set a goal for a week, a realistic one, and I do my best to reach it. (Norah, first interview, translated)

The unsuitability of what is stated in the curriculum to their students' levels was also emphasised by Ariane, who also created her own curriculum with its own goals, accompanied by various tasks, according to the level of her students: 
When I plan lessons, I don't follow the curriculum set by the ministry, because I think of the level of my students. That's why it's not easy for me to plan lessons. I think about ways how I can make the lesson understood by the students. If I followed the ministry's curriculum, we wouldn't be able to finish it. I try to give my students lots of exercises, oral exercises, writing at the beginning of the year, and I see from there, what their difficulties are. And I set my objectives for the school year from there. (Ariane, first interview, translated)

Nevertheless, Norah admitted in the second interview that due to time constraint and the curriculum that she had to follow somehow, it was not always possible to reach her goals. On the other hand, Ariane stressed that, in addition to having the specific goals she had set, the ultimate teaching goal should not be to fill in students' notebooks. According to her, the goal should be, firstly, to inform the students about the rationale behind any learning subjects. The students should know why they learn a particular point and what outcome is expected from the learning. This is a pivotal point that goals should be set and stated in class when promoting LA according to literature (for example, Dam 2011). The second teaching goal Ariane mentioned was the providing of opportunities for students to practise what they have learned, which she thought was missing in the Malagasy education system.

A few days after the first interviews, a potential change, or at least a questioning of the belief that setting goals is exclusively the teacher's role, was perceived through a question from one of the teachers at lunch time. She asked me whether she should ask the students to set their own goals sometimes, and whether she should do more than stating clear instructions. Her questions showed that she had been reflecting on the implications of the interview questions and on her teaching practices, demonstrating not only that the interview triggered self-awareness (Hurd, 2011) but also that the teacher was open to reflection on her practice.

\subsection{Self-evaluation}

The teachers did practise self-evaluation in their teaching. All of them seem to view selfevaluation as retrospection on their teaching (not in written form), enabling them to perceive improvement and to adjust their teaching approach:

Last year, I used methods that I don't use anymore this year. I've found that they don't really help. Sometimes, I change a little bit. (Christina, first 
interview)

When teaching, I can see that I have improved. Now, when I look back at what I did in the past, I realise there were things I was not good at. And I think this realisation means that I evaluate myself. (Norah, first interview, translated)

Norah's statement may suggest that she considered self-evaluation as a quick observation resulting in a realisation. However, from her second interview, deeper self-evaluation could be perceived. She showed she was aware of her problems. Though she did not find the exact solutions to these problems, she was doing her best to improve herself by exploring any possible resources she could find: “I have problems, I don't have self-confidence in what I teach, as I'm a learner at the same time. I don't have enough self-confidence and I don't master strategies." She further expressed her worries about her lack of confidence when teaching some specific points, which kept her awake at night.

Norah did practise self-evaluation, but she would not refer to her awareness of problems as self-evaluation. In fact, the interview questions raised her awareness of the perception that she did not 'practise' self-evaluation. That was demonstrated by her remark two days after the second interview while having lunch with me. She said that after the interview, she decided to ask Christina if she evaluated her own teaching. Like her, Christina did selfevaluation by doing some retrospection, but as it was not written, she did not label it as selfevaluation. After discussing, both came to the conclusion that they should think of ways to evaluate themselves.

While Christina and Norah's statements above imply the evaluation of their own teaching in relation to the 'realistic' goals they had set, only John explicitly expressed an association between self-evaluation and goal setting. According to him, having goals enabled him to evaluate his own teaching:

Without a goal, I don't know exactly if I have succeeded or not, if I have completed my task or not. Without a goal, I don't know exactly if I have reached it or not. [...] For example, today, I'm going to do this. So, my goal is then to finish this program, this task, this activity, for example. So, if I don't have it, I don't know if I have done the right way or not. (John, second interview) 
When asked about students' feedback on their teaching to help them self-evaluate, all the teachers stated they were not accustomed to doing so. They did ask students' opinions on some specific tasks but that was limited to whether they liked the tasks or not, and then only occasionally. A teacher said that asking them for feedback would be in vain as they would not dare criticise teachers. During the interviews, two teachers stated they had never thought of asking their students for feedback on their teaching, but they would definitely consider doing so. One of them stated that students' feedback would enable him to know what the students really think of his teaching, and what may need some adjustment. This shows once again that the interview questions triggered the teachers' reflections on their teaching, making them aware of potentially useful new practices and signalling their openness to reflection, a basis for teacher autonomy.

\subsubsection{Summary of teachers' beliefs}

The teachers' beliefs regarding LA were mainly built from their own language learning experience. Aware of the insufficiency of in-class learning, they had developed self-initiation as learners. The self-initiation included a strong intrinsic motivation and the adoption of a "self-determined" approach to language learning, which are characteristics of autonomous learners (Martinez, 2008, p. 117). They maintained their self-initiation as teachers, in improving both their language and their teaching. They understood that "teacher-learning [...] is inevitably a career-long, largely self-directed enterprise" (Smith, 2000, p. 96). In addition to independent effort, they agreed that peer collaboration is indispensable both for themselves as teacher(-learners) and for their students. Thus, it can be said that they had developed a degree of teacher-learner autonomy. Their statements also showed instances of capacity for self-directed teaching, such as the adjustment of teaching goals to the context. Furthermore, their questions and statements during informal talk demonstrated that the interview questions had been an awareness-raising factor, as they encouraged the teachers to reflect on their actual teaching practice and think about future implementations. This might imply that the interview questions triggered metacognitive awareness, as the teachers started to evaluate their own teaching practices, to plan what could be done, and perhaps to monitor their teaching more consciously. On the other hand, with their growing teacherlearner autonomy and their capacity for self-directed teaching, they seemed to have already had a certain readiness to think critically on their teaching. In other words, they had already been in an enquiry mode, which helped the trigger from the interview questions. The degree 
of teacher-learner autonomy, their capacity for self-directed teaching, along with that readiness can be considered as seeds of autonomy.

\subsubsection{Teachers' practices related to autonomy}

The first part of this section will discuss the affordances for LA, which were perceived during the thirty class observations. As Nicolaides (2008) states, observations allow comparison between statements and actions. Effectively, the thirty class observations enabled the identification of links between the teachers' beliefs regarding elements of LA and the teachers' practices.

The three-week stay in the village enabled not only the observations of practices in class, but also some teachers' practices outside class. These practices demonstrated elements of teacher-learner autonomy, and, again, emphasised interdependence through peer collaboration. These elements, along with some instances of self-directed teaching perceived in class, will be talked about in the second part of this section.

\subsubsection{Practices in promoting LA}

During the class observations, the most outstanding element that could be perceived was peer collaboration, as shown on Table 3.1 (next page). The latter engendered peer evaluation, which resulted in some self-evaluation (though it was rare). Through peer collaboration, an instance of both monitoring and self-evaluation could be observed. Other elements promoting independence and students' responsibility were also noticed. Furthermore, the teachers showed their consideration of affect and the importance of informing their students about task goals. All these elements will be discussed in this section. 
Table 3.1 Elements of LA promoted in class

\begin{tabular}{|c|c|c|c|}
\hline \multicolumn{2}{|c|}{ Elements of LA promoted by teachers } & $\begin{array}{l}\text { Frequency in } \\
\text { classroom } \\
\text { practice (from } \\
\text { the } 30 \text { class } \\
\text { observations) }\end{array}$ & Examples \\
\hline \multirow[t]{3}{*}{$\begin{array}{l}\text { Peer } \\
\text { collaboration }\end{array}$} & $\begin{array}{l}\text { Involving decision } \\
\text { making }\end{array}$ & 3 & $\begin{array}{l}\text { Preparing a presentation on a Malagasy } \\
\text { recipe }\end{array}$ \\
\hline & $\begin{array}{l}\text { Miscellaneous tasks } \\
\text { (assigned by the } \\
\text { teachers) }\end{array}$ & 24 & $\begin{array}{l}\text { Answering reading comprehension in pairs } \\
\text { Trying to figure out the rules of past simple } \\
\text { vs past continuous }\end{array}$ \\
\hline & $\begin{array}{l}\text { Solving problems } \\
\text { (assigned by the } \\
\text { teachers) }\end{array}$ & 9 & $\begin{array}{l}\text { Asking the students who have finished a } \\
\text { grammar exercise to help those who say } \\
\text { they need help }\end{array}$ \\
\hline \multicolumn{2}{|c|}{$\begin{array}{l}\text { Peer evaluation (assigned by the } \\
\text { teachers) }\end{array}$} & 10 & Looking at one another's sentences \\
\hline \multicolumn{2}{|c|}{ Self-evaluation } & 5 & $\begin{array}{l}\text { Asking students what they found difficult } \\
\text { when doing a task }\end{array}$ \\
\hline \multicolumn{2}{|c|}{ Consideration of affect } & 18 & Giving students positive feedback \\
\hline \multicolumn{2}{|c|}{ Informing goals } & 12 & $\begin{array}{l}\text { Stating the expected outcomes of doing a } \\
\text { task }\end{array}$ \\
\hline \multicolumn{2}{|c|}{$\begin{array}{l}\text { Students having their say (activities to } \\
\text { use and opinions on tasks) }\end{array}$} & 11 & $\begin{array}{l}\text { Asking students if they would like to sing } \\
\text { (as they looked sleepy) }\end{array}$ \\
\hline \multicolumn{2}{|c|}{$\begin{array}{l}\text { Promotion of independence (working } \\
\text { alone) }\end{array}$} & 2 & Picking a book to present in class \\
\hline \multicolumn{2}{|c|}{$\begin{array}{l}\text { Promotion of responsibility (reflection on } \\
\text { mistakes and behaviours) }\end{array}$} & 5 & $\begin{array}{l}\text { Asking students questions encouraging } \\
\text { them to reflect on their behaviours }\end{array}$ \\
\hline
\end{tabular}

\subsection{Peer collaboration}

The section on teachers' beliefs showed that the four teachers believed in the effectiveness of peer collaboration. Peer collaboration was indeed widely promoted in each of the classes observed. Pair work and group work prevailed. Although the interactions during the pair and group work were in Malagasy, they had to produce some output in English, and to do so, they had to help one another. This section talks about the teachers' use of peer collaboration and the consequences of peer collaboration.

\section{Use of peer collaboration}

The students had plenty of opportunities to interact and cooperate while doing different tasks and when solving problems related to language. Tasks such as dialogue practice (ask and answer dialogue involving genuine answers) and figuring out some grammar rules did necessitate conversations or discussions, and therefore, peer collaboration. However, as the teachers wanted them to help one another, peer collaboration was fostered even when the students dealt with other tasks such as answering reading comprehension questions and 
grammar exercises, which could have been done individually. As shown in Table 3.1 (p. 81), the number of times the teachers assigned the students to work together was the highest in terms of frequency of elements of LA observed in class.

Peer collaboration was not only promoted when doing specific tasks, but also when encountering problems. Problems ranged from not knowing a word in a text to formulating a question to ask the teacher in lower-level classes. For instance, in John's class, a pair of students in grade 5 had to come up with the sentence "Can we have another marker, please?" before John accepted to give them another marker. In classes with higher levels, problems also encompassed difficulties with the implementation of grammar rules in grammar exercises. That happened in Norah's and Christina's classes. What Norah usually did was to ask students who were struggling if they needed help. With the latter's permission, students who had finished their exercise would provide help. It is worth noting though that Norah stressed that the helping ones should provide explanation rather than the right answers. This type of interdependence can contribute to the development of autonomy, as the help provided consists in building understanding and knowledge in lieu of spoon-feeding, as explained by Murray (2014): “Getting the help they need in a learning situation from a more skilled and knowledgeable fellow classmate or teacher enables learners to perform independently, thereby rendering them more autonomous." (p. 6)

There were also occasional cases when the students had tasks involving making decisions together. In John's and Christina's classes, the students were given tasks in which they had a total control of their output. Though the decision-making in these tasks involved only the choice of topics, but not the learning content, materials, or goals, this can be a starting point of promotion of independence from the teacher, and of a sense of ownership (Porto, 2007). As Dam (2011) states, the ability to choose can bring about motivation, reflection, awareness-raising, the feeling of responsibility and boosts self-esteem. John used two specific tasks involving students' decision making. The first (which he used in two out of the eleven classes observed) was having the students write "silly" sentences in pairs as a warmup activity or at the end of the class. That task was very much appreciated by the students because they were free to build any sentences of their choice, which were supposed to be hilarious. The second task (which he used in four out of the eleven classes observed) was a drawing activity, in which the students were asked to draw pictures related to the story they had just worked on. In pairs, they chose the part of the story they wanted to focus on. Though that activity did not necessarily enable them to use English (they sometimes put a 
title in English), it showed their comprehension of the story. In Christina's classes, the students were assigned to work in groups to decide on Malagasy recipes they would like to present to the class. They were responsible outside class for a week for choosing the dishes and for finding out all the vocabulary needed. Table 3.1 (p. 81), shows (among other elements of LA) the frequencies at which peer collaboration was promoted in class. The frequencies regarding miscellaneous tasks, solving problems, and peer evaluation (which will be discussed in the next section) concerned only the ones assigned by the teachers (see Table 3.1, p. 81).

Peer collaboration was so much encouraged that it became the norm to some extent, and it was hard to define whether a task was individual or pair. Even when the students were doing a task individually at the beginning, they would ask for help from their peers or simply compare their answers at some point (without being asked). Thus, peer collaboration became the students' choice. This was confirmed by John when he was talking about the importance of group work: "Even though they work alone [...], I allow them to ask their friends in their groups if they have problems [...]" (Second interview).

\section{Consequences of peer collaboration}

The habit of peer collaboration resulted in spontaneous interactions in class, not only among the students, but also with the teacher. The students did not hesitate to ask questions to the teacher when they did not understand, or to say aloud what they thought the answers were. It also allowed instantaneous peer evaluation, self-evaluation, and monitoring.

The teachers encouraged the students to do peer evaluation by comparing their work after dealing with tasks.Table 3.1 (p. 81), shows that the teachers assigned the students to evaluate one another's work ten times during the thirty class observations. Nevertheless, the times the students did peer evaluation were not limited to those. In fact, spontaneous peer correction was perceived in every class. Whenever a student made a mistake, the others would correct him/her immediately. Correction seemed natural in anything they were dealing with, from correction of grammar exercises on the blackboard to informal talk. Likewise, the spontaneous tendency to compare their work enabled them to evaluate themselves as well as their peers. Other types of peer evaluation were also used in John's classes. After the drawing activity and the silly sentence building activity described earlier, he would ask the students to move around to see one another's sentences or drawings. Then, he would ask them which ones they found the best. The students were eager to reply 
and add positive comments. However, they did not comment only on the best ones. They also gave some constructive feedback, such as suggesting having a title for the drawing, for instance.

Self-evaluation, including reflection, was promoted in John's and Norah's classes through questions about their difficulties vis-à-vis particular tasks. They would ask the students what mistakes they made and encourage them to think about the nature of the mistakes. In addition to difficulties, John also asked students about their improvement on particular tasks and about what they found easiest.

In his second interview, John expressed his belief that peer evaluation resulted in selfevaluation. This proved to be true in his classes, as the students did demonstrate they were self-evaluating while or after looking at their peers' work. They would have comments such as "Our sentence was not as funny as theirs" or "We did not draw enough trees to show that it was a forest."

Peer collaboration enabled the students not only to help one another, but also to monitor and to evaluate themselves, though these may not have been the teachers' goals. The monitoring and the self-evaluation were observed through a conversation in Christina's class, between a student, who will be called Jenny, and the person sitting next to her. As I was sitting in front of the two of them (I had to sit where there was an available seat each time), I was able to clearly hear and record what they were saying during the whole class session. Jenny demonstrated she was actively reflecting on her learning throughout the class. The active reflection included monitoring through comments (in Malagasy) about problems she was encountering while doing a grammar exercise on past simple and past continuous (for example, "I don't really understand this sentence"), about her understanding of a certain rule (for example, "So, in the past continuous, we don't really care if the verb is irregular or not, right?"), and about her feeling about the first activity ("I like learning poems because I like teaching them to the children at home. They really liked the last poem I taught them.") She also asked her partner for help from time to time: "Is "burn" a regular or irregular verb?" During and after the correction of the grammar exercise, her comments showed self-evaluation: "I don't really understand this thing! [...] Jesus! That was difficult! I had everything wrong!" Then, after translating their homework instructions to herself in Malagasy, she expressed her uncertainty about her ability to do the homework, as she was not capable of building sentences in English. 
The active reflection Jenny was engaging in is what Swain labels as "languaging". Swain defines it as "a process of making meaning and shaping knowledge and experience through language" (Swain, 2006, p. 98), and therefore, considers it as a learning source (Swain, 2010). Though I was not able to record other students practising languaging, monitoring and self-evaluation (because where I was sitting did not always allow me to hear what the students were discussing during pair or group work), it is likely that Jenny was not the only one to do so.

\subsection{Informing goals}

As stated in the previous section (on teachers' beliefs), the teachers referred to task goals as clear instructions. In their classes, they did give clear instructions and kept reminding their students until the latter finished the tasks. For instance, John constantly reminded his students when doing reading comprehension (seven out of the eleven lessons he dealt with were reading comprehension) that they should aim to answer with correct and complete sentences. On the second day that I observed Norah's classes (which took place after the first interview), she stated what the students were supposed to do before each task. She also said the reason why she had to use Malagasy when telling them a story, and she clearly explained what the students' goals should be while giving them homework. She did the same during the other class observations onwards.

What Norah did was worth pointing out because that on the first day of observation of her classes, she had not mentioned goals and her instructions were not clear. The change may have been caused by the interview questions, which made her more aware of the value of stating goals.

\subsection{Consideration of affect}

As discussed in the previous chapter, affect and motivation are important factors related to LA. That is why consideration of affect was one of the elements of LA studied during the class observations. As shown in Table 3.1 (p. 81), consideration of affect through providing positive feedback was one of the most frequent elements of LA perceived during the class observations. The teachers encouraged their students by praising them each time they finished a task, or they knew the answers to a question (or a translation of a word, for example). Particularly, Norah encouraged her students to volunteer when they did not, 
(which was rare in her classes) by reassuring them that in case of mistakes, the other students would help.

When students made mistakes, the teachers would ask them questions encouraging them to reflect on the nature of the mistakes. The same happened when the students did not do their homework or did not behave well in class, which occurred once each in Christina's class and John's class. The teachers' goals were to make the students aware of their responsibilities through their own answers, instead of telling them off.

\subsection{Letting students have their say}

Allowing students to have their say on what to do in class is a way to foster their LA (Dam, 2011). Yet, as stated in the interviews, the teachers did not often provide their students with opportunities to state their opinions on tasks or their difficulties. During the class observations, only Norah asked her students whether they would like to sing (at the beginning of the class, or when she noticed that their level of enthusiasm dropped) or what activities they would like to do (at the end of the class). Nine out of the eleven times that students were asked to have their say (see Table 3.1, p. 81) occurred in Norah's classes. Her reasons for doing so was to build comfort and trust by not focusing only on intellectual work, and therefore, to "close the gap" between her and her students, as she had stated in her two interviews:

I don't forget that it's not all about intellectual work. I want them to consider school as a place of pleasure. I ask them what they want to do, if they want to sing, for instance. When we deal with a lesson, I ask them at a certain time if they still want to continue or if they are tired. And I stop if they say they are. Then, I ask them what they want to do then, and we do what they want. (First interview, translated)

Having their say in what to do resulted in enthusiasm and strong willingness to volunteer. Indeed, it was always hard for Norah to choose which students to send to the blackboard for a correction of a grammar exercise, for instance, as everyone volunteered to go. There were two particularly striking examples in her classes showing the students' self-initiation and the use of the target language at appropriate times in an autonomous way.

The first time I was in Norah's class, she asked me to introduce myself to the class. After my self-introduction, a student raised her hand and said she wanted to introduce herself to me too. Norah allowed her to do so. Then, three other students raised their hands and did 
the same. When I asked Norah after class if she had asked the students to volunteer to introduce themselves earlier before I came to the class, she said she had not.

The other example was when Norah asked the students ten minutes before the class finished what they would like to do. They said they wanted to know me more and to ask me questions. I told them I could answer any questions provided that they were in English. Therefore, with motivation and curiosity, they helped one another formulate questions in English, and managed to ask me a few personal questions.

In Ariane's classes, she did not ask students' opinions on tasks. However, she asked them genuine questions that helped build comfort and, along with peer collaboration, were likely to contribute to spontaneous interactions (as explained earlier) and elimination of the gap between the teacher and the students. She encouraged them to share village news or what they did in the weekend, to which they delightfully answered in detail in Malagasy. They surely did not have any benefits regarding their English from doing so, but they felt motivated as their answers were listened to for the content, not for the language.

It can be said that the more the students were able to have their say, the motivated they became. The enthusiasm and the willingness to volunteer resulting from having their say is aligned with what Dam (2011) and Porto (2007) stated about the relationship between the ability to decide and motivation.

\subsection{Promotion of independence}

Tasks promoting students' individual learning were scarce (see Table 3.1, p. 81). The students were given tasks which were meant to be individual, such as fill-in-the- blank activities, but as explained earlier, they always tended to help one another even with those tasks. The rare tasks giving individual students opportunities to discover new words, to use and to evaluate the vocabulary they had already known, and to practise what they had learned in class, were homework enabling them to build sentences (once in Norah's class), and paragraphs about activities they had done in real life (once in Christina's class). In Norah's and Christina's classes, the students were asked to find out (by themselves) the translation of some words they did not know as well as to think of answers to their own questions, and report them in the following classes. This may be considered as a beginning of the encouragement of self-initiation. All these individual tasks were supposed to be done outside class. 
From the class observations, only one task in Christina's class enabled the students to make decisions and to learn individually. The task consisted of choosing an English book about wild animals or about technology from the library and making a presentation about it two weeks later. Again, that task was done outside class.

Learning has its social aspect, which should be maintained through pair and group work, and which is essential in promoting LA (Dam, 2011). However, individual tasks should also have their place in the classroom so as to prepare the students for life outside the classroom, requiring them to work by themselves (Crabbe, 1993). Due to the strong emphasis on the social aspect, which seems to reflect the collectivist tendency of the Malagasy countryside, the individual aspect seemed to be largely absent in the classes observed.

\subsection{Promotion of students' responsibility}

As shown in the examples in 3.4.1.1.5., the promotion of students' responsibility was not restricted to language learning. These examples are worth pointing out, as they demonstrate a triggering of reflection, which is a useful way to foster LA. Another example of promotion of students' responsibility could be observed in John's classes. Like in all Malagasy schools, students get in line before entering the classroom, after hearing the school bell. Usually, the teacher stands in front of them, waits for them to be quiet and perfectly in line (or asks them to do so most of the time) before allowing them into the classroom. That was the case for all the classes, except for John's ones. Instead of waiting for John, one of the students stood in front and played the role of the teacher. John said the students decided among themselves who should stand in front.

The elements of LA promoted by the teachers during the thirty class observations are summarised in Table 3.1 (p. 81), below, which clearly shows the predominance of peer collaboration and the scarcity of the promotion of independence.

\subsubsection{Practices in teacher autonomy}

The class observations did not really enable the perception of different elements of teacher autonomy "in action" like it did for the elements promoting LA, which explains why this section is much shorter than the previous ones. The elements of teacher-learner autonomy that could be perceived outside class were peer collaboration and self-initiation, while the 
elements of self-directed teaching were related to setting teaching goals. All these elements were in line with what the teachers had stated in their interviews.

\subsubsection{Peer collaboration and self-initiation}

In keeping with their beliefs, the teachers did value peer collaboration and implemented it outside class. In particular, the two teachers with lower levels of English requested help from the other two by meeting them from time to time. The goals of the meetings were especially to practise their English. If the two teachers with higher levels were not able to meet, the two lower-level teachers still met and practised together. They would choose a topic for each meeting and discuss it for about an hour. The two lower-level teachers invited me to join those meetings twice during my stay. While discussing, they would take down some new vocabulary and make sure they had the pronunciation right.

The meetings were generated by self-initiation, arising from intrinsic motivation and selfdetermination, which are features of autonomous learners (Martinez, 2008). With strong determination, the two teachers sought ways to improve their English. One of the ways was interdependence through peer collaboration, which was in line with what they said during the interviews. Another way was to read English books of any type. They did spend time in the library in their free time and also took borrowed books home. Apart from their organised meetings, they practised their speaking with me as much as they could (during their break, at lunchtime, before and after class). It can be said that they were indeed autonomous teacher-learners.

\subsubsection{Teaching goals}

The teachers often stated what the goals of each lesson (or task) were (see Table 3.1, p. 81). Some of the goals they set were not related to the curricula designed by the Ministry of Education. For instance, the curricula do not include the teaching of a play (or the topic related to that particular play). Furthermore, the teachers would spend more time teaching a grammar point than specified in the curricula, for example, because they knew their students did not quite understand. They also digressed from their teaching goals when necessary and used activities, which they thought would help their students overcome their tiredness. For instance, Norah once asked her students to close their eyes while drawing a picture she was describing. When asked why she chose that activity, she said,

I wanted them to relax. I noticed that they were tired, but also, I wanted 
them to concentrate at the same time. That's why I wanted them to close their eyes. I wanted them to draw a big semi-circle because l've learned that when your brain is tired, your body should be moved, especially your hands. When you move your right hand, the left part of your brain works, and when you move your right hand, the right part of your brain works. (Second interview, translated)

These examples are evidence of the teachers' self-directed teaching. They were flexible with regard to the goals they had set and made some impromptu decisions in order to make their students comfortable, help them concentrate, and give them more practice.

\subsubsection{Summary of teachers' practices related to autonomy}

The four teachers did foster LA in class firstly by promoting peer collaboration, resulting in peer evaluation and to a much lesser extent self-evaluation. They promoted interdependence in order to enable the students to help one another, hence avoiding dependence on the teachers. Secondly, two of the teachers let students have their say on activities used in class. Thirdly, in order to boost students' confidence and motivation, which are significant aspects in the promotion of $L A$, the teachers provided them with positive feedback and encouragement. Promotion of responsibility through reflection on mistakes and behaviours was also perceived.

The element of teacher autonomy that stood out during the three-week stay was, once again, peer collaboration with colleagues. Pushed by self-determination, the teachers, especially the ones with lower levels of English, initiated meetings among themselves, where they could practise speaking and acquire more vocabulary. This demonstrated their autonomy in learning, and the matching of their beliefs and their practice regarding teacherlearner autonomy.

\subsection{Conclusion}

The three-week study spent in the Malagasy rural school enabled the discovery of seeds of autonomy or affordances for LA in this setting, including teachers' beliefs as well as their inclass practices regarding autonomy. The seeds included teachers' awareness of some elements of autonomy and evidence of promotion of some of these elements in their classes and outside class. 
When asked about their own English learning experience, the teachers demonstrated their understanding of the importance of self-initiation and independence from teachers. They discussed their determination regarding their mastery of English, on which they were still working through practice and search for resources in a constant way. They were doing the same for their teaching skills. They were aware of and strongly agreed with the necessity for teachers to learn continuously. They had strong motivation, though it had not always been easy to maintain it. It can be said, therefore, that they had been working on their own LA along with their professional development through self-initiation. However, in their classes, the promotion of self-initiation or guidance of students towards the awareness of their accountability for their learning seemed limited. In other words, they did not give students opportunities to set personal goals and rarely allowed them to self-evaluate. The teachers stated that they encouraged their students to read books and to practise outside class, but such encouragement was rarely perceived during the class observations. Practising outside class was assigned only through homework exercises. They did ask their students to find out the answers to their own questions in terms of vocabulary, but that was mostly done quickly in class by asking peers.

The teachers believed in the significance and the effectiveness of peer collaboration, both for their professional development and for the development of their students' autonomy, probably because of the collective norm of the rural society they lived in. For professional development, they benefitted from sharing ideas and providing help to each other. One of the teachers also emphasised the value of peer evaluation among colleagues regarding both teaching and language. Evidence of peer collaboration supporting teacher-learner autonomy could be seen outside class. In class, peer collaboration among students was the most outstanding affordance that was perceived. It was promoted when doing diverse tasks, enabling students to exchange ideas and occasionally to make decisions together. It was also encouraged when students encountered difficulties, fostering students' interdependence, and their independence from the teachers. Peer collaboration became such a habit that the students would start doing tasks in pairs or asking one another for help without being encouraged by the teachers. Peer collaboration generated natural interactions, peer evaluation, which occasionally led to self-evaluation. Furthermore, the prevalence of peer collaboration probably led to the scarcity of tasks designed for individual learning, and to the infrequency of self-evaluation. 
The teachers knew the importance of considering affect when teaching. That was demonstrated in class through positive feedback and the promotion of reflection regarding mistakes (rather than reprimanding). To make students comfortable, one of the teachers asked her students' opinions on what tasks to do when she noticed they were tired or found it hard to concentrate.

The teachers indicated the need to set their own teaching goals, taking the levels of their students into account, which required constant adjustment and flexibility. One of them discussed the link between the teaching goals he set and his self-evaluation. Though the other teachers may not have perceived that link, they were also self-evaluating in such a way that they could observe some improvement in their teaching, and they changed approaches they had gauged unsuccessful.

Believing that setting goals is a teacher's role, the teachers did not ask the students for their learning goals, whether they were task-related or general ones. The teachers suggested long-term learning goals that were likely to motivate the students, such as communicating with foreign visitors of the school or with their foreign pen pals. In class, they made sure the students knew what outcome they were expected to produce, which, according to them, constituted the task-related goals. Subsequent to the first interviews, some questions about who sets goals and when emerged during informal talk.

The promotion of student self-evaluation and reflection was rare. Nevertheless, the incidental overhearing of Jenny's 'languaging' conversation with her partner (see section 3.4.2.1.1) showed that students reflected on their learning actively while doing tasks. They did monitor and evaluate themselves, though they were not encouraged to do so or aware of doing so. The conversation showed Jenny's awareness of difficulties, which were to distinguish the use of the past simple and the past continuous, and to build sentences in English. Such awareness is important, as it can trigger problem-solving attitudes and goal setting, and therefore, the use of metacognitive strategies, which will develop selfregulation. However, students may not always react positively to their difficulties despite their awareness. The awareness may even cause discouragement, as they may think they are not able to solve their problems, especially if they keep these problems for themselves. That would suggest that they need help to make them realise the significance of such awareness and to see for themselves the benefits of the development of self-regulation. Phase two of this research aimed to do this. More specifically, the goal of phase two was to enable 
students to attend to their active reflections while doing tasks in order to enhance their selfregulation.

The elements of LA and the elements of teacher autonomy perceived during phase one are shown respectively in Table 3.2 and Table 3.3 below. Both tables summarise what has been stated above and compare the number of teachers believing in the importance of the elements and the number of teachers who actually practised or promoted the elements in or out of class. As explained earlier, some elements of teacher autonomy were difficult to notice. For instance, the teachers might have done some self-evaluation during or after class, but there was no evidence of this.

Table 3.2 Elements of LA

\begin{tabular}{|c|c|c|c|}
\hline \multicolumn{2}{|c|}{ Elements of LA } & $\begin{array}{l}\text { Teachers believing in the } \\
\text { importance of the } \\
\text { elements (out of } 4 \text { ) }\end{array}$ & $\begin{array}{c}\text { Teachers promoting } \\
\text { the elements in class } \\
\text { (out of } 4 \text { ) }\end{array}$ \\
\hline \multicolumn{2}{|c|}{ Self-initiation and independence } & 4 & 2 \\
\hline \multirow{3}{*}{$\begin{array}{l}\text { Peer } \\
\text { collaboration }\end{array}$} & Involving decision making & 1 & 2 \\
\hline & Miscellaneous tasks & 4 & 4 \\
\hline & Solving problems & 4 & 4 \\
\hline \multicolumn{2}{|c|}{ Peer evaluation } & 3 & 4 \\
\hline \multicolumn{2}{|c|}{ Self-evaluation } & 3 & 2 \\
\hline \multicolumn{2}{|c|}{ Consideration of affect } & 4 & 4 \\
\hline \multicolumn{2}{|c|}{ Informing goals } & 4 & 2 \\
\hline \multicolumn{2}{|c|}{ Students having their say } & 4 & 1 \\
\hline \multicolumn{2}{|c|}{$\begin{array}{l}\text { Promotion of responsibility (reflection on } \\
\text { mistakes and behaviours) }\end{array}$} & 0 & 2 \\
\hline
\end{tabular}

Table 3.3 Elements of teacher autonomy

\begin{tabular}{|l|l|l|l|}
\hline $\begin{array}{l}\text { Types of teacher } \\
\text { autonomy }\end{array}$ & $\begin{array}{l}\text { Elements of teacher } \\
\text { autonomy }\end{array}$ & $\begin{array}{l}\text { Teachers believing in } \\
\text { the necessity of the } \\
\text { elements (out of 4) }\end{array}$ & $\begin{array}{l}\text { Teachers "practising" } \\
\text { the elements in class } \\
\text { and out of class (out } \\
\text { of 4) }\end{array}$ \\
\hline \multirow{2}{*}{$\begin{array}{l}\text { Teacher-learner } \\
\text { autonomy }\end{array}$} & Affect & 4 & Not observed \\
\cline { 2 - 4 } & Self-initiation & 4 & 2 \\
\cline { 2 - 4 } & Peer collaboration & 4 & 2 \\
\hline Self-directed teaching & Affect & 4 & Not observed \\
\cline { 2 - 4 } & Self-initiation & 4 & Not observed \\
\cline { 2 - 4 } & Peer collaboration & 4 & 2 \\
\cline { 2 - 4 } & $\begin{array}{l}\text { Setting own teaching } \\
\text { goals and changing } \\
\text { them if necessary }\end{array}$ & 4 & \\
\cline { 2 - 4 } & $\begin{array}{l}\text { Asking for students' } \\
\text { feedback }\end{array}$ & $\begin{array}{l}2 \text { (triggered by the } \\
\text { interview questions) }\end{array}$ & Not observed \\
\cline { 2 - 4 } & Self-evaluation & 4 & Not observed \\
\hline
\end{tabular}




\section{Phase two - Developing student teachers' self-regulation through reflection}

The previous chapter showed that self-regulation seemed to be the least promoted dimensions of learner autonomy in the rural setting in phase one. The learners were not given opportunities to set their own goals, to monitor, or to evaluate their own learning. The probable reason is that the teachers had not, as learners themselves, experienced activities that might be counted as self-regulating. This relates to Little's (1995) claim about the dependence of learner autonomy on teacher autonomy: teachers whose education did not include the promotion of autonomy are less likely to be successful in fostering it. In the light of this assumption, it would be indispensable to include teacher-learner autonomy in teacher education, and this was the prime objective of phase two of this research. This study focuses on using reflection in order to develop self-regulation along with writing skills.

\subsection{Methodology}

\subsubsection{Research goals}

Phase two aimed firstly to foster EFL student teachers' LA, or more precisely, their selfregulation through reflection, while helping them improve their writing. That first aim was directed to the student teachers as learners, as they were developing their writing skills in English. It attempted to investigate to what extent "reflective learning" (explained in this chapter) is conducive to the development of the Malagasy EFL student teachers' selfregulation of writing. At the same time, it looked at the extent to which reflective learning impacts the student teachers' writing performance. Secondly, this study intended to demonstrate the promotion of learner autonomy to the participants as student teachers, to make them experience its benefits and its challenges, so that they would be able and willing to promote it in their own classes later when they teach. Therefore, it also investigated the implications the student teachers see for their future teaching as a result of the reflective learning experience. Due to these aims, phase two was conducted at a Teacher Training College, which is part of a university in Madagascar. The selection of the college was due to its exclusive objective of training pre-service teachers, as opposed to faculties. Also, the college has an English department, which is not the case of other Teacher Training Colleges in Madagascar. 


\subsubsection{Ethical considerations}

Before starting the study, I needed the permission from the Director of the College and the Head of the English Department. As all the courses in the College are mandatory, having my course as optional could not be considered at the beginning (see the information sheet in Appendix 15 and Appendix 16, pp. 288-290). However, after a face-to-face meeting, it was agreed that the course was solely for the purpose of my research, that it would be considered as extra-currical, therefore, not graded. Also, the students had the right to withdraw from the course (see the consent form in Appendix 17 and Appendix 18, pp. 292293), and to be absent without providing any excuses. That alleviated the power imbalance between me and the students and must also have reduced the Hawthorne Effect.

What must have helped with the alleviation of power imbalance was also my role as a facilitator rather than a teacher and the structure of the course. It was clear from the beginning that the course would be different from any other courses the students had ever had in a way that there would be no actual teaching. They were given reflection prompts and a topic to write about (which will be further discussed in 4.1.5), but they were not provided with strategies or explanation about how to write. Instead of traditional teaching, a collaborative atmosphere among the students were nurtured throughout the course (see 4.1.5.4).

\subsubsection{The participants}

I was given permission to work with the first-year university students due to their lighter workload compared to higher level students'. From the 24 first-year students, 22 agreed to take the course. Apart from one student who studied tourism for a year, they had just graduated from senior secondary school. English is the main medium of instruction in the department. However, it does not mean that the students' English proficiency is high. Actually, students' English proficiency is still quite limited after secondary school graduation in general, which explains why the level of these participants was (pre-) intermediate.

\subsubsection{Practitioner research}

After the exploration of affordances for LA through the study of teachers' beliefs and practices in a rural Malagasy setting through an ethnographic approach in phase one, phase two focused on the implementation of LA with student teachers. Since the objective was 
essentially to practice LA in a classroom, a method allowing practice, intervention, and exploration was deemed necessary. Practitioner research seems to answer those criteria. As its name indicates, practitioner research combines practice and research. It is defined by Dadds and Hart (2001) as "a central commitment to the study of one's own professional practice by the researcher himself or herself, with a view to improving that practice for the benefit of others" (p. 7). Allwright (2003) recommends that instead of focusing solely on the effectiveness of the practice, practitioner research should consider the quality of life in the language classroom as a priority and view learning as a social matter. Also, he suggests the following cycle as practitioner research characteristics: "think globally, act locally, think locally" (p. 115). Thinking globally consists in identifying the principles on which the language teaching research is based without directly thinking of the context. Acting locally refers to the implications of such principles on the context, trying to find a way to integrate the principles into the local situation. This engenders more thinking about the principles, which may be challenged, adjusted, or further developed. Allwright states that the cycle does not have to be linear or start necessarily with "think globally". For the present research, "think globally" refers to my belief that LA is an educational goal, a belief that has been shaped through reading, different forms of lectures, own learning and teaching experiences. "Act locally" refers to the thinking and planning on how to promote LA in the EFL Malagasy context, including the study of affordances for LA in the context (in phase one). "Think locally" involves the adjustment and further development of the resources and strategies used while "acting locally" on the one hand, and thinking about how LA is better defined and implemented in similar contexts on the other hand.

Practitioner research, also referred to as "action research" by some authors (e.g. Kemmis, 2009 , Barlett \& Burton, 2006), is the type of research, which is seen as the most appropriate in terms of the development of LA, as it takes place with genuine learners in a given context:

[...] the best research on autonomy is often not research concerned with 'grand theory', but action research conducted by practising teachers on the specific conditions of teaching and learning within which they work. In order to do this kind of action research, we must make some attempt to foster autonomy among the learners we work with (Benson, 2011, p. 2).

Furthermore, practitioner research is said to be "key to the operationalization of the learner autonomy construct, and the development of associated practices, within formal 
educational structures" (O'Leary, 2014, p. 18). The goal of the present research was indeed to help first year student teachers (the formal educational structure) develop their selfregulation (the operationalisation of the LA construct) of writing through reflection (the practice).

\subsubsection{Reflective learning course}

I designed the reflective learning course, which was among the courses scheduled for the first-year university students in the department. The course ran for one semester over nine weeks. The course had two main objectives: (1) to help the students improve their metacognitive skills or self-regulation ability: their ability to plan, to monitor, and to evaluate their own learning, through reflection, in order (2) to help them improve their writing proficiency.

To attain these objectives, each student maintained a portfolio where all their productive work was included: writing tasks, reflective journals corresponding to the tasks and in-class group discussions, and reflective journals related to the overall course. Portfolios have been proven to be appropriate tools to help learners manage and evaluate their learning (Cotterall \& Murray, 2009; Murray, 2011) and to prompt learners to revise their writing (Raimes, 2002). The use of portfolios is also said to be one of the efficient classroom-based approaches to developing learner autonomy (Nguyen \& Gu, 2013).

\subsubsection{The weekly sessions}

There were two sessions of two hours each week. The first session was spent on the writing task along with the journal writing, while the second session was devoted to group discussions. The structure of the course is summarised in Table 4.1. 
Table 4.1 The three-week cycle within the course structure

\begin{tabular}{|c|c|c|c|}
\hline Week & Session & Focus & Activities \\
\hline \multirow[t]{2}{*}{$\begin{array}{l}\text { Week 1- } \\
4-7\end{array}$} & 1st Session & $\begin{array}{l}\text { - } \\
\text { - } \quad \text { Metting goals } \\
\text { - } \quad \text { Self-evaluation }\end{array}$ & $\begin{array}{l}\text { New writing task + journal writing: } \\
\text { - Pre-task prompts } \\
\text { - Task + during-task prompts } \\
\text { - Post-task prompts }\end{array}$ \\
\hline & $2^{\text {nd }}$ Session & $\begin{array}{l}\text { - Discussing the writing process, problems, feelings, (asking for) } \\
\text { solutions / strategies } \\
\text { - Reflecting on what they learned from the discussions }\end{array}$ & $\begin{array}{l}\text { - Group discussions } \\
\text { - Journal writing }\end{array}$ \\
\hline \multirow[t]{2}{*}{$\begin{array}{l}\text { Week 2- } \\
5-8\end{array}$} & 1st Session & $\begin{array}{l}\text { - } \\
\text { - } \\
\text { - } \\
\text { - Setting gonitoring } \\
\text { Selfaluation }\end{array}$ & $\begin{array}{l}\text { Same writing task + journal writing: } \\
\text { - } \text { Pre-task prompts } \\
\text { - } \quad \text { Task + during-task prompts } \\
\text { - } \quad \text { Post-task prompts }\end{array}$ \\
\hline & $2^{\text {nd }}$ Session & $\begin{array}{l}\text { - Discussing the writing process, problems, (asking for) solutions / } \\
\text { strategies + looking for strategies for other specific problems } \\
\text { - } \quad \text { Reflecting on what they learned from the discussions }\end{array}$ & $\begin{array}{l}\text { - Group discussions } \\
\text { - Journal writing }\end{array}$ \\
\hline $\begin{array}{l}\text { Week 3- } \\
6-9\end{array}$ & 1st Session & $\begin{array}{l}\text { - } \\
\text { - } \\
\text { - } \\
\text { - Setting gonitoring } \\
\end{array}$ & $\begin{array}{l}\text { Same writing task + journal writing: } \\
\text { - Pre-task prompts } \\
\text { - Task } \\
\text { - Post-task prompts }\end{array}$ \\
\hline
\end{tabular}




\begin{tabular}{|c|c|c|c|}
\hline Week & Session & Focus & Activities \\
\hline & $2^{\text {nd }}$ Session & $\begin{array}{l}\text { Discussing the } 3 \text { weeks: the writing task, their goals, whether they } \\
\text { have been attained or not, their problems, the strategies they } \\
\text { learned, and the challenges of writing the journal } \\
\text { - Reflecting on the course (how they find the journal reflection and the } \\
\text { group discussions) + reflecting on how they might implement in their } \\
\text { future teaching from the course (6th and 9th weeks) }\end{array}$ & $\begin{array}{l}\text { - Group discussions } \\
\text { - Journal writing }\end{array}$ \\
\hline
\end{tabular}




\subsubsection{Writing tasks}

Throughout the nine weeks, the students were given three writing tasks. Each task was a 200-word argumentative essay. They dealt with the same writing task for two or three weeks: the first and the second tasks were repeated three times, and the third task twice, in order for the students to notice their improvement easily, as repeated performance enables self-evaluation to develop (Crabbe, 1993). Doing the same task for three weeks allowed students to focus entirely on their writing, that is, firstly, to discover what they wanted to express, then, to write, to revise, to edit and to rewrite. These steps are claimed to be significant, and learners should be made aware of the importance of revision in particular, which is a big part of the writing process, and is not only limited to proofreading and editing (Zamel, 1982). Useful for their revision were the in-class discussions among peers and feedback from the teacher, which will be further discussed later in this chapter.

The initial plan was for the students to do the same writing task focusing on a different goal each week: goals for week 1 should be related to content, week 2 related to format and language, and week 3 related to the overall effect (combination of content, format, and other aspects). These were pre-set in order to help the students decide on what goals to focus on. It was considered necessary to provide them with such assistance, considering the newness and the challenge of doing the reflection work along with the writing tasks, as Locke and Latham (2006) state:

Focusing on reaching a specific performance outcome on a new, complex task can lead to "tunnel vision" - a focus on reaching the goal rather than on acquiring the skills required to reach it. In such cases, the best results are attained if a learning goal is assigned $-[\ldots]$ (p. 266)

However, some students requested to set their own goals from the second session on for two main reasons: either they did not attain their goals in the previous writing, and they wanted to keep them until they reached them, or they wanted to relate their goals to difficulties they had noticed in their previous writing. Due to these requests and in order to encourage them to make their own decisions, or to feel ownership of their learning (Porto, 2007), it was decided that goal setting for each week would be individualised.

A task should be related to learners' goals or enable them to 'rehearse' the use of language in real life in order to promote learner autonomy (Cotterall, 2000). Also, the topics should be engaging enough to motivate students (Raimes, 2002) or to make them feel 
involved (Zamel, 1982). Thus, the writing tasks had been chosen according to students' general objectives, interests or topics they are very likely to talk about in real life. The three tasks were to convince respectively 1 ) young people to become teachers 2) tourists to choose Madagascar as their holiday destination 3) Malagasy young people to learn foreign languages. The tasks are enumerated on Table 4.1 (p. 98).

\subsubsection{Journals and portfolios}

Journal writing is the core of reflective learning, as it was the tool not only to promote but also to gauge the development of self-regulation of writing as well as the improvement of the writing itself. Journal writing was the means for the students to reflect. As reflection can be difficult, especially when related to the goal of changing behavior, and "the capacity to reflect purposefully needs to be fostered or coached" (Moon, 2013, p. 9), the students were given guidance through clear prompts (see Appendix 5, p. 275), categorized in three sets: pre-task, during-task, and post-task. These sets of prompts were provided respectively before, during, and after each writing task every week. The prompts helped them articulate their learning steps in the journal: setting goals, making decisions regarding resources and strategies, self-monitoring, and self-evaluating. They were encouraged to follow the prompts, but they were also able to write whatever they thought was appropriate regarding their writing or learning in relation to the tasks.

The pre-task prompts asked them to think of their goals, to have a plan before writing, and to think of what they know and what they still need to know about the topic. The latter point aimed to raise their awareness on their weaknesses regarding the writing content, in response to the argument that "unskilled" writers tend to focus on form and on accuracy rather than on content (Raimes, 1985). The during-task prompts aimed to encourage them to think about and to express their feelings, their difficulties, their strategies, and any comments they might have while writing. Recording these as they happen makes it possible to "intrude" into the students' thinking, which is not the case with retrospective self-reports (Raimes, 1985). However, retrospective reports are also useful, and are part of the study (post-task) as they enable the students to reflect on what they did, what they learned, how they dealt with their difficulties, whether their goals were attained, and what goals they should focus on next time.

In addition to the reflection on the writing task, the students also reflected on the course itself every three weeks. This course-related reflection aimed to raise students' awareness of 
the usefulness of the journal writing and the group discussions for their writing or learning. Once the teacher had read and given feedback on each student's journal entry and each writing task, they were included in each student's portfolio. The portfolios were kept by the students and brought to class in each session so that they could look back at their previous work in their group discussions and while doing a new (or repeated) task. Also, keeping the portfolios enabled them to compare their writing, their difficulties over time, the strategies they had used to solve some specific problems, and to perceive the progress they had made.

It should be noted that the students had the choice to use English, French, or Malagasy for their journal reflection as well as during the group discussions. Though it is recommended to use the target language for both task performance and metacognitive reflection, as doing so is considered as "the essential characteristic of language learner autonomy" (Little, 2007, p. 23), the use of L1 was encouraged. The use of L1 helps learners psychologically when dealing with tasks that are cognitively demanding (Brooks \& Donato, 1994). L1 as a strong "cognitive resource" is also advocated by Swain and Lapkin (2005, p. 181) when "languaging" (talking about how language works), and when expressing affective states regarding learning (Yamashita, 2015). The use of L1 allows comfortable expression and, thus, better and deeper reflection.

\subsubsection{Peer collaboration through group discussions}

Time was provided for dialogues in the classroom to discuss learning, difficulties, and strategies (Crabbe, 1993). That is why the second session of each week was spent on group discussions, including peer evaluation (see Table 4.1, p. 98). The group discussions enabled the students to talk about their reflections while doing the writing task in the previous session, to share their experience, to do peer-correction, to work together on solutions to their problems, and to exchange ideas and strategies. They were given questions to discuss. Most of the questions were based on the mistakes seen in their writing, and difficulties mentioned in their reflections. During the discussions, the students were taking notes of any advice or strategies they thought they might need to revise their essays. In order to help them focus on the discussions and work more efficiently, each group member was assigned a role, which they picked randomly in every discussion. Besides their roles as participants in the discussions, one of them was a presenter, another one a timekeeper, and another one a note taker. Where there were four people in the group, the last one would be a simple participant. 
After the group discussions, one group was selected randomly to present what they had discussed to the class. The other groups added more information when they had some, such as strategies and difficulties, which had not been mentioned during the presentation. Time permitting, after the presentation, each student was asked to reflect on what they had learned from the group discussion and the presentation, and write down the reflections in their journals. Again, the students were allowed to use any language they liked during the discussions.

\subsubsection{Teacher's feedback}

Feedback is a necessary "intervention" to let students know about their improvement (or not) in relation to their goals (Graham \& Sandmel, 2011; Locke \& Latham, 2002, 2006; Zamel, 1982). Thus, after each task (every week), I provided feedback firstly by underlining mistakes (vocabulary, grammar, spelling) without explaining why they were mistakes. The students, then, had to figure out the nature of the mistakes most of the time, to correct them by themselves, or if they were not able to do so, to ask for help during the group discussions. The feedback has the characteristic of what Seow (2002) refers to as "responding" which is significant in process writing. It consists of teacher's reaction to the writing, instead of evaluation or editing. The latter is done by the students themselves. However, when the students did not seem to be able to identify their mistakes and kept repeating them, or the mistakes were common to most of the students, the mistakes had to be pointed out (Lightbown \& Spada, 2013). Those mistakes consisted mainly of incomplete sentences, misuse or absence of punctuation, poorly organised ideas, or a lack of audience awareness.

The feedback also included encouragement and positive remarks about the reflections and the writing. Encouragement was crucial, firstly because it is always daunting for students to do activities or tasks they are not familiar with. They needed to be reassured that what they were doing was relevant, and that they were free to uncover their feelings and any thoughts they came up with during the reflection. Secondly, doing the writing task along with the reflection work required a considerable effort. Not only did they have to produce a 200-word argumentative essay, which was a hard task in itself, but also, to note down their reflection simultaneously. Thirdly, being exposed to their weaknesses or difficulties can be demotivating, especially, when they have to solve them by themselves. Yet, the aim was to help them nurture their desire to learn (autonomously) and develop positive affect towards 
learning. The encouragement and the positive remarks were intended to give them the "present" motivation they needed on a daily basis (Yamashita, 2015). Lastly, the course was part of their training to become teachers. Thus, it was important to show them a "model" of teacher's positive attitude, and to see the benefit of such an attitude on their own affect.

\subsection{Data analysis}

\subsubsection{The data}

The data collected for phase two comprised the portfolios of each of the 22 students. Except for six students who missed some sessions (four missed one session each, one missed two sessions, and one missed five sessions), each portfolio contained 8 writing pieces (tasks) and 13 journal entries, made up of:

- 8 reflections related to each writing piece

- 3 reflections related to the course (every three weeks)

- 2 reflections related to group discussions

In total, the portfolios contained 275 journal entries and 171 writing pieces. Each writing task and each journal entry was "pre-coded". To take a few examples, "Michael 1T1R" refers to Michael's first reflection on his first task; "Michael 1T2" refers to Michael's first attempt to task two; "Michael 2RonC" refers to Michael's second reflection on the course. This type of pre-coding is summarised in Table 4.2. In addition to the individual reflections in the portfolios, group reflections done during group discussions were also collected. Samples of reflection can be seen in Appendix 6 (p. 276). 
Table 4.2 Pre-codes - Tasks and reflection work in order

\begin{tabular}{|l|l|l|l|}
\hline Week & \multicolumn{1}{|c|}{ Sequence of activities } & Task code & Reflection code \\
\hline 1 & $\begin{array}{l}\text { Task one, attempt one + reflection: Convincing } \\
\text { Malagasy young students to become teachers }\end{array}$ & $1 \mathrm{~T} 1$ & $1 \mathrm{~T} 1 \mathrm{R}$ \\
\hline 2 & Task one, attempt two + reflection & $1 \mathrm{~T} 2$ & $1 \mathrm{~T} 2 \mathrm{R}$ \\
\hline 3 & $\begin{array}{l}\text { Task one, attempt three + reflection } \\
\text { First reflection on course }\end{array}$ & $1 \mathrm{~T} 3$ & $\begin{array}{l}\text { 1T3R } \\
\text { 1RonC }\end{array}$ \\
\hline 4 & $\begin{array}{l}\text { Task two, attempt one + reflection: Convincing } \\
\text { tourists to visit Madagascar }\end{array}$ & $2 \mathrm{~T} 1$ & $2 \mathrm{~T} 1 \mathrm{R}$ \\
\hline 5 & Task two, attempt two + reflection & $2 \mathrm{~T} 2$ & $2 \mathrm{~T} 2 \mathrm{R}$ \\
\hline 6 & $\begin{array}{l}\text { Task two, attempt three + reflection } \\
\text { Second reflection on course }\end{array}$ & $\begin{array}{l}\text { 2T3R } \\
\text { 2RonC }\end{array}$ \\
\hline 7 & $\begin{array}{l}\text { Task three, attempt one + reflection: Convincing } \\
\text { Malagasy young people to learn a foreign language }\end{array}$ & $3 \mathrm{~T} 1$ & $3 \mathrm{~T} 1 \mathrm{R}$ \\
\hline 9 & Task three, attempt two + reflection & $3 \mathrm{~T} 2$ & $3 \mathrm{~T} 2 \mathrm{R}$ \\
\hline
\end{tabular}

\subsubsection{The methods}

To address the three research questions of this study, I used both qualitative and quantitative research methods respectively to evaluate the improvement of the students' self-regulation skills and to assess their writing performances. As in phase one, I used thematic analysis for the coding of the students' self-regulation skills and the implications for future teaching that the students saw as a result of their reflective learning experience. To grade their writing, I used a rubric (Table 4.4, p. 109).

\subsubsection{Evaluation of self-regulation skills}

A thematic approach was deemed appropriate because it "reports experiences, meanings and the reality of participants, or [...] examines the ways in which events, realities, meanings, experiences and so on are the effects of a range of discourses operating within society" (Braun \& Clarke, 2006, p. 81). The aim of the journals was, indeed, to enable the students to report their experiences and their "realities" when dealing with their writing tasks, but another aim was also to see the effects of their own reflections and the development of their self-regulation on their experiences and realities, which are in this study, their writing and their learning in general. I followed the phases of thematic analysis suggested by Braun and Clarke (2006), which consist of: 
- familiarising myself with the data by transcribing them (as the portfolios belong to the students, I took pictures of each journal entry when I had them in order to give my feedback; then, I typed them so as to make them easier to code), by reading and re-reading them, and noting down ideas

- generating initial codes

- searching for themes,

- reviewing and reorganising the themes

- defining and naming themes, including compiling and tallying

The phases were done using NVivo and manual calculation.

As in phase one, to establish inter-rater reliability, a trained researcher (the second coder) and I coded independently 28 randomly selected journal entries (which made up $10.18 \%$ of the journal entries). Before coding all the 28 entries, the second coder did a trial coding of 3 entries, after which we had a discussion on the units of analysis (including whether the unit of analysis should be sentential, whether sentences should be split into meaningful units, and identifying examples of sentences that did not need coding). After the trial, both of us coded the rest of the selected sample (25 entries) on our own. After coding all the entries, we discussed and compared our codes until we had satisfactory inter-coder reliability scores, which had been calculated using percentage agreement. Table 4.3 (next page) features the comparison of the two codings. The table includes the number of codes for each entry (each journal entry does not necessarily have the same number of codes, as some students, for instance, may not find any difficulties while doing one task, whereas others may find three types of difficulties), the number of codes we were in agreement with, and the number of codes we were not in agreement with, and the subjects of disagreement that needed to be discussed. An example of subjects of disagreement was whether a goal was considered as broad or not (for example, "I want to convince tourists to come to Madagascar"). The percentage agreement is the sum of the agreement codes, divided by the total number of the codes multiplied by 100 . In this case, the sum of the agreement codes is 126 , and the total number of codes is 150 . The percentage agreement is therefore $126 * 100 / 150=84 \%$. Taking into account the discussions, I coded the rest of the data. A sample of coding for reflections is given in Appendix 9 (p. 280). 
Table 4.3 Sample of inter-coder reliability on reflection entries

\begin{tabular}{|c|c|c|c|c|}
\hline Reflection & $\begin{array}{l}\text { Number } \\
\text { of codes }\end{array}$ & $\begin{array}{l}\text { Agreement on } \\
\text { codes }\end{array}$ & $\begin{array}{l}\text { Disagreement on } \\
\text { codes }\end{array}$ & subject of disagreement \\
\hline 1 & 1 & 3 & 2 & 1 \\
\hline 2 & 2 & 5 & 3 & 2 \\
\hline 3 & 3 & 7 & 6 & 1 \\
\hline 4 & 4 & 4 & 3 & 1 \\
\hline 5 & 5 & 8 & 7 & 1 \\
\hline 6 & 6 & 3 & 2 & 1 \\
\hline 7 & 7 & 8 & 7 & 1 \\
\hline 8 & 8 & 7 & 7 & 0 \\
\hline 9 & 9 & 7 & 6 & 1 \\
\hline 10 & 10 & 7 & 5 & 2 \\
\hline 11 & 11 & 8 & 8 & 0 \\
\hline 12 & 12 & 8 & 7 & 1 \\
\hline 13 & 13 & 5 & 3 & 2 \\
\hline 14 & 14 & 7 & 4 & 3 \\
\hline 15 & 15 & 5 & 4 & 1 \\
\hline 16 & 16 & 4 & 4 & 0 \\
\hline 17 & 17 & 9 & 8 & 1 \\
\hline 18 & 18 & 5 & 3 & 2 \\
\hline 19 & 19 & 3 & 3 & 0 \\
\hline 20 & 20 & 5 & 2 & 3 \\
\hline 21 & 21 & 6 & 6 & 0 \\
\hline 22 & 22 & 4 & 4 & 0 \\
\hline 23 & 23 & 3 & 3 & 0 \\
\hline 24 & 24 & 5 & 5 & 0 \\
\hline 25 & 25 & 4 & 4 & 0 \\
\hline 26 & 26 & 4 & 4 & 0 \\
\hline 27 & 27 & 3 & 3 & 0 \\
\hline 28 & 28 & 3 & 3 & 0 \\
\hline Total & Total & 150 & 126 & 24 \\
\hline
\end{tabular}

\subsubsection{Evaluation of the writing performances}

To evaluate the students' writing, all versions of the three writing tasks collected in the portfolio were graded by using a rubric (see Table 4.4, p. 109). The rubric encompassed four points:

- the structure and style, including paragraphing, flow, and appropriateness to the audience

- clarity, looking at whether the question was answered, the writing easily understood, and the ideas/arguments efficiently communicated;

- the technical writing skills, including grammar, spelling, and punctuation; 
- vocabulary, including appropriate word choice and variety.

Each of the four points was marked as 1 (unsatisfactory), 2 (satisfactory), and 3 (exemplary). Half points (1.5 and 2.5 ) were also possible. The maximum point was, therefore, 12. All the scores of each student were saved in an excel file. To have inter-rater reliability, a second rater, having years of experience in teaching and grading writing, scored eighteen pieces of writing (which made up $10.52 \%$ of the writing pieces). The differences between my total scores (for each task) and the second rater's scores are presented by the standard deviation, shown in Table 4.5 (p. 110). The second rater and I discussed the writing pieces with more than 0.70 score differences. The discussion included looking back at the scores given to each of the four points of writing (in the rubric), and reaching an agreement on the scores to give. Taking the discussion into account, I had to look at the other writing pieces again and adjust scores. 
Table 4.4 Writing rubric

\begin{tabular}{|c|c|c|c|}
\hline Aspects & Exemplary & Satisfactory & Unsatisfactory \\
\hline $\begin{array}{l}\text { Structure and style: paragraph } \\
\text { and sentence structure, flow, } \\
\text { appropriate to audience }\end{array}$ & $\begin{array}{l}\text { Variety of sentence construction; logical } \\
\text { flow, style and structure appropriate for task } \\
\text { and audience; thoughtful presentation }\end{array}$ & $\begin{array}{l}\text { Not overly repetitive; some variety in sentence } \\
\text { construction; generally flows well; some } \\
\text { awareness of audience }\end{array}$ & $\begin{array}{l}\text { Overly repetitive or simplistic sentence } \\
\text { structure; lack of flow; style and structure } \\
\text { inappropriate for audience }\end{array}$ \\
\hline $\begin{array}{l}\text { Clarity and conciseness: } \\
\text { Answers the question, } \\
\text { succinct, appropriate }\end{array}$ & $\begin{array}{l}\text { Argument effectively and efficiently } \\
\text { conveyed; highly focused on the question; } \\
\text { easily understood. }\end{array}$ & $\begin{array}{l}\text { Argument reasonably clear; occasionally } \\
\text { misses the point but answers the question; not } \\
\text { over-elaborate or over-complicated. }\end{array}$ & $\begin{array}{l}\text { Main point and/or arguments } \\
\text { confused/unclear. } \\
\text { Irrelevant information, no transition between } \\
\text { ideas. Unclear conclusion. }\end{array}$ \\
\hline $\begin{array}{l}\text { Technical writing skills: } \\
\text { spelling, capitalization, } \\
\text { punctuation, grammar. }\end{array}$ & $\begin{array}{l}\text { Very few spelling errors, correct punctuation, } \\
\text { grammatically correct, complete sentences. }\end{array}$ & $\begin{array}{l}\text { Occasional lapses in spelling, punctuation, } \\
\text { grammar, but not enough to seriously distract } \\
\text { the reader. }\end{array}$ & $\begin{array}{l}\text { Numerous spelling errors, non-existent or } \\
\text { incorrect punctuation, and/or severe errors in } \\
\text { grammar that interfere with understanding. }\end{array}$ \\
\hline $\begin{array}{l}\text { Vocabulary: originality, } \\
\text { breadth, appropriateness, } \\
\text { variety }\end{array}$ & $\begin{array}{l}\text { Highly appropriate, well chosen, precise and } \\
\text { varied vocabulary. Consistently uses correct } \\
\text { word choice. }\end{array}$ & $\begin{array}{l}\text { Generally appropriate vocabulary; not overly } \\
\text { repetitive. Generally uses correct word choice. }\end{array}$ & $\begin{array}{l}\text { Excessively limited or inappropriate or } \\
\text { repetitive vocabulary. Misuse of words. }\end{array}$ \\
\hline
\end{tabular}

Adapted from Victoria Business School 
Table 4.5 A sample of reliability data for rating students' writing

\begin{tabular}{|l|r|r|r|}
\hline Writing & Coder 1 & Coder 2 & $\begin{array}{r}\text { Standard } \\
\text { deviation }\end{array}$ \\
\hline 1 & 4 & 5 & 0.70 \\
\hline 2 & 4 & 5 & 0.70 \\
\hline 3 & 10 & 10 & 0 \\
\hline 4 & 8 & 8 & 0 \\
\hline 5 & 8 & 7 & 0.70 \\
\hline 6 & 8 & 8 & 0 \\
\hline 7 & 7.5 & 7 & 0.35 \\
\hline 8 & 10 & 8 & 1.41 \\
\hline 9 & 10 & 9 & 0.70 \\
\hline 10 & 4 & 5 & 0.70 \\
\hline 11 & 5.5 & 6 & 0.35 \\
\hline 12 & 4 & 5 & 0.70 \\
\hline 13 & 7 & 7 & 0 \\
\hline 14 & 4 & 6 & 1.41 \\
\hline 15 & 7 & 7 & 0 \\
\hline 16 & 7 & 8 & 0.70 \\
\hline 17 & 7 & 8 & 0.70 \\
\hline 18 & 6 & 7 & 0.70 \\
\hline
\end{tabular}

\subsection{Findings}

This second part of the chapter looks at the impacts of reflective learning on the student teachers' self-regulation skills and on their writing performances. As this study focuses especially on self-regulation, this section will put more emphasis on the effects of reflective learning on the development of self-regulation skills, including the students' perceptions of their reflective learning experience. Thus, it discusses their views on how reflective learning affected their ways of dealing with their writing and learning in general, and how they considered implementing reflective learning, or some aspects of it, in their own future classes.

Before dealing with the student teachers' development of self-regulation in detail, I will give some remarks regarding the choice of languages for the reflection, and a common difficulty throughout the reflective learning. These are worth pointing out because they might have had impacts on the quality of reflection. 


\subsubsection{Language used and common difficulties}

As stated earlier, it is crucial that learners feel comfortable expressing themselves when reflecting. Therefore, the use of the first language should be encouraged (Yamashita, 2015). Despite the choice of languages given to the students (Malagasy, French, and English) and my constant encouragement, they all chose to use English. Only one student used French along with English, but she did it only once at the very beginning. Their choice of using English must be due to their passion for or interest in that language, given that they had all decided to become teachers of that language.

Some common difficulties were perceived throughout the course, both through my observation of the students' behaviours and especially through their thoughts expressed in their reflections. The first common difficulty was the reflection itself. The students involved in this study found it really challenging to reflect on their writing particularly at the beginning due to the novelty of such practice (reflecting about how they are dealing with a task):

I didn't understand what I am expected to do. At that time I feel anxious and confused because it was the first time I did a task like that. (Carrie, 3RonC)

[...] for my first writing, I just answered the questions like I answered a comprehension [question]. I did not really realize that the questions concerned me [...]. But now, I see that every answer has changed. (Linah, 3RonC)

My way of answering the prompts has also changed because at the first time I did it, I did it because I have to but little by little I knew that it helped me a lot. (Noelle, 3RonC)

These are examples of students' answers when asked how they had felt while doing 1T1 and 1T2. Linah and Noelle's statements clearly indicate their not understanding of what the reflection was all about. The students were not accustomed to thinking about their learning or to making any decisions in class. Reflecting on learning process is a difficult task (Little, 1995). Chu (2007) suggests that learners not used to reflection are likely to be uncertain of the ways to organise their own learning. Moon (2013) also states that reflection can be quite difficult especially when its purpose includes behaviour changes, which was the case in this study. Nevertheless, as also indicated in the excerpts above, the students improved 
gradually in terms of reflection, as they understood its usefulness for their writing and learning in general.

More common difficulties were perceived in goal setting, monitoring, and self-evaluating. These difficulties will be discussed when dealing with these themes.

\subsubsection{Developing self-regulation}

The coding and tallying of each student's piece of reflection enabled the extraction of two important themes. The first is awareness of difficulties. The second is the development of a strategic behaviour resulting from such awareness. This second theme encompasses the different strategies the students used throughout the course, including the problems and challenges they encountered regarding these strategies. Some of the students' strategies were part of their prior knowledge, which were brought to mind thanks to reflection (Schön, 1983), while some were learned during the course.

The main type of strategies they used was metacognitive. As they were prompted to reflect on their writing process by planning (including setting goals), monitoring, and selfevaluating, they had to use metacognitive strategies. They were also encouraged to use social strategies through group discussions. Those social strategies along with the awareness of difficulties enabled them to seek and use different types of cognitive strategies. Apart from these strategies, they also used affective strategies. Affect is an important theme revealed in this study, not only regarding strategies per se, but regarding the students' awareness in general.

\subsubsection{Being aware of difficulties - the key to self-regulation}

While producing output through writing raises learners' awareness of their difficulties or gaps in their knowledge (Swain, 1995), noting these difficulties down and reflecting on them enhances the awareness (Boud, 2001). In this study, monitoring and self-evaluating during the tasks, as well as self-evaluating in the reflections on the course, enabled the students to perceive and to reflect on their problems, and in general, to act accordingly. To take an example, this is what Elvine decided to do after realising in $2 T 1 R$ that she did not know some useful terms related to tourism: "I should learn vocabulary because I don't know the meaning of some words in English. For example, the meaning of "site touristique"". Other students were not as specific as Elvine, but still aware of what language aspect they should focus on improving: "My problem which I do not still resolve is about grammar, I have to 
work on it" (Natasha, 1RonC). That same student added that knowing her weakness helped her pay more and more attention to her writing. She was not the only one who appreciated the awareness of difficulties. Sixteen students (out of the 22) considered the awareness of difficulties or weaknesses as an advantage of the reflection:

I did not even know that I was bad at writing before, but [the reflection] made me realize and now, my writing skills have improved. (Lacha, 3RonC) Using reflection on my own learning has been very useful because it has helped me to be aware of my difficulties and to be focused on my goal while working. (Noelle, 3RonC)

"[The reflection] helps us find [...] what our real weaknesses are." (TJ, 3RonC)

While specific difficulties are not identified in the excerpts above, these student comments show their awareness of difficulty, which triggered change in their way of writing and in their learning attitudes.

The students did perceive difficulties while doing the first task (1T1). Thirteen students had difficulties related to lack of ideas, nine to vocabulary, six to time management, five to focus and the uncertainty of the relevance of the ideas to the topic (referred to as "others"), four to expression of ideas, four to writing structure, and two to grammar (see Figure 4.1, p. 116). The first two most cited difficulties were easy to notice as they directly hindered the writing. It was more difficult for them to identify other types of difficulty (for example, related to grammar, to audience awareness), until they received feedback from the teacher (me) or until they exchanged ideas in group discussions. After noticing their difficulties, the students - especially, those who had tended to have high self-confidence at the beginning realised that there was room for improvement; and for that purpose, they needed to make an effort. Though the awareness of difficulties may have decreased their self-confidence, it was indispensable, as it enabled them to set specific goals, and therefore to make improvement. This is why it is said that the awareness of difficulties is part of the awareness of learning goals (Porto, 2007).

Figure 4.1 (p. 116) shows that the number of students having difficulty decreased with the repetition of the tasks. By repeating the same task, the students did not have to produce completely new ideas, and think of the entire organisation of those ideas. Furthermore, with the teacher's feedback and the group discussions, they had an idea of what they should 
improve. They also started to notice and expressed their difficulties in more detail, especially from the first reflection on the course (1RonC) on, as exemplified in the excerpts below. Reviewing what they had done for three weeks (along with the teacher's feedback) in the reflections on the course enabled them to see what their difficulties consisted of, which were not always obvious while they were doing the tasks. That is why the difficulties they perceived during the tasks and in the reflections on the course were not the same, as seen in Figure 4.1 (p. 116) and Figure 4.2 (p. 117).

While doing this writing my difficulty is about how to arrange my ideas clearly and what tense of verb I have to use. (Carrie, 2T1R) I had difficulty with the introduction because I don't know how to start with and break the ice, and I almost didn't finish the conclusion. (Nary, 2T2R)

Regarding writing, I can give many ideas or arguments. I can also be aware of my grammar and vocabulary skills. However, when I do a writing, I am not patient and sometimes don't put everything I know on it. (Vetso, 1RonC)

Vetso's statement above demonstrates self-awareness. She understood that what she was lacking was not knowledge about the writing topic or knowledge about language. She has all the writing components at her disposal. The problem was that she was not able to use them due to her impatience and lack of effort. She was one of the sixteen students who expressed the importance of being aware of their difficulties:

The reflective journal [...] helped me because it teaches me that there still a lot of hard work that I must do to have a better writing. (Vetso, 2RonC). I learnt that $[\ldots]$ I should be careful in whatever I write to avoid making mistakes whether it is about grammar or word choice. (Fidy, 1T3R)

The students also talked about their awareness of the connection between difficulties and goals:

The reflective journals helped me attain my goals because through the question "what didn't work", it showed me [...] my own mistakes, and especially dealing with my difficulties and trying to find [...] solutions. (Narindra, 2RonC) 
The reflective journals really helped me attain my goals because I could be aware of my difficulties and I could easily find solutions from them. (Rose, 2RonC)

This statement from Rose was worth citing not only because it shows the link between the attainment of goals and the awareness of difficulties, but also, it reveals the change of her views on journal writing. In 1RonC (the first reflection on the course), she did not find any advantages of journal writing: "For the reflective journals, I think it didn't really help me to attain my goal since I could not really find what I get from it, sometimes I'm confused." Like Rose, three other students expressed their uncertainty about the usefulness of reflection in the first reflection on the course, but changed their mind later. The change of mind was also related to the change of affect, which will be discussed further later in this chapter.

Apart from the difficulties related to ideas, writing structure, grammar, and vocabulary, three students talked about their awareness of knowledge gap regarding general knowledge. To take an example, when dealing with task two about Madagascar, a student stated almost regretfully, "I realize that I don't know much about my country" (Lacha, 2T1R).

In brief, it would not have been possible for the students to progress without being aware of their difficulties. The following statement can serve as the best summary of the link between the awareness of difficulties, and the transformation of the response to such difficulties into goals:

From everything I've seen, I can say that when you clearly find what your weaknesses, you can do everything you can to beat them if you really want to. Fix a goal and strive to achievement. (TJ, 1RonC) 

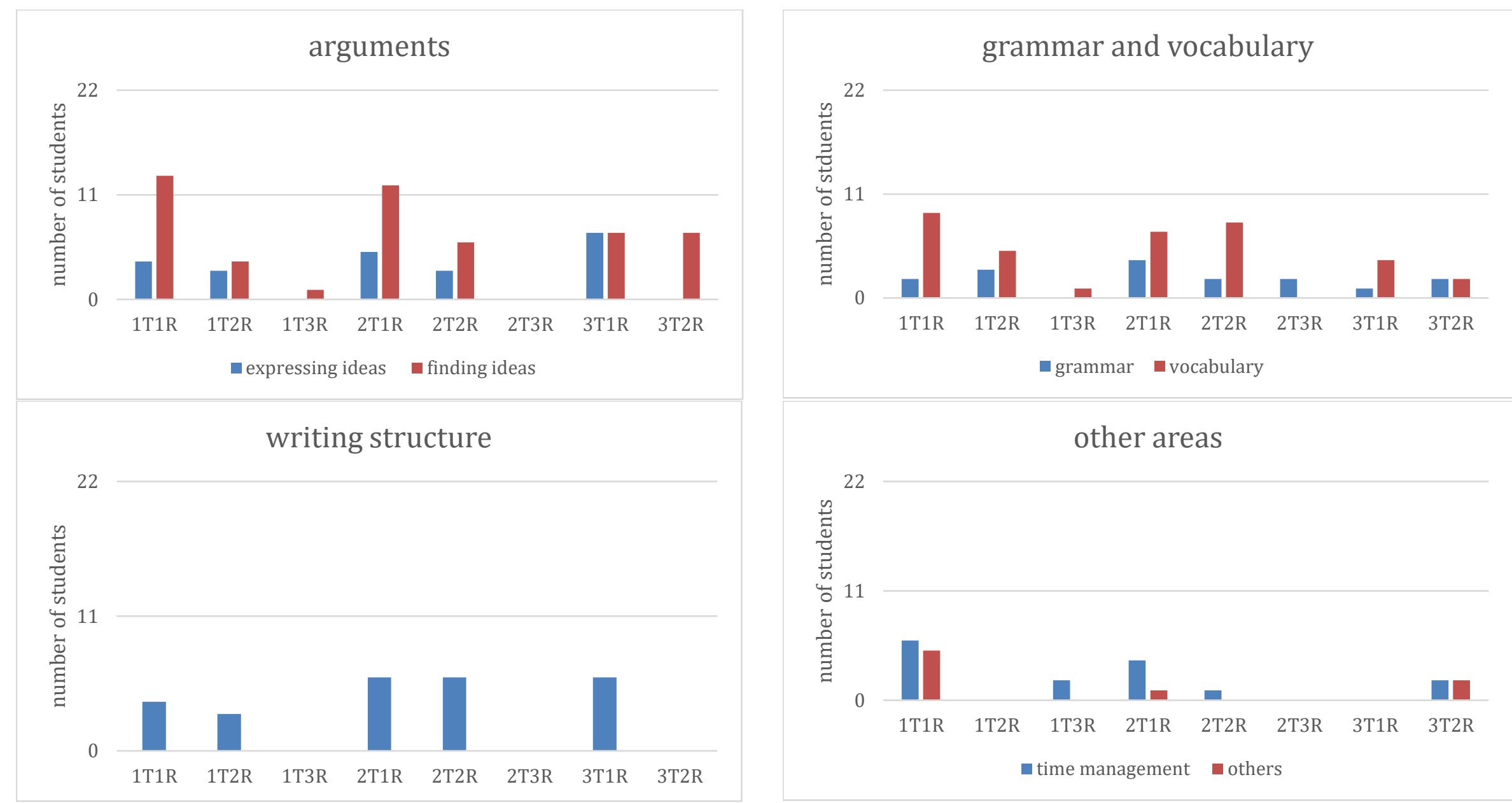

Figure 4.1 Areas of difficulties perceived by the students during and after tasks 


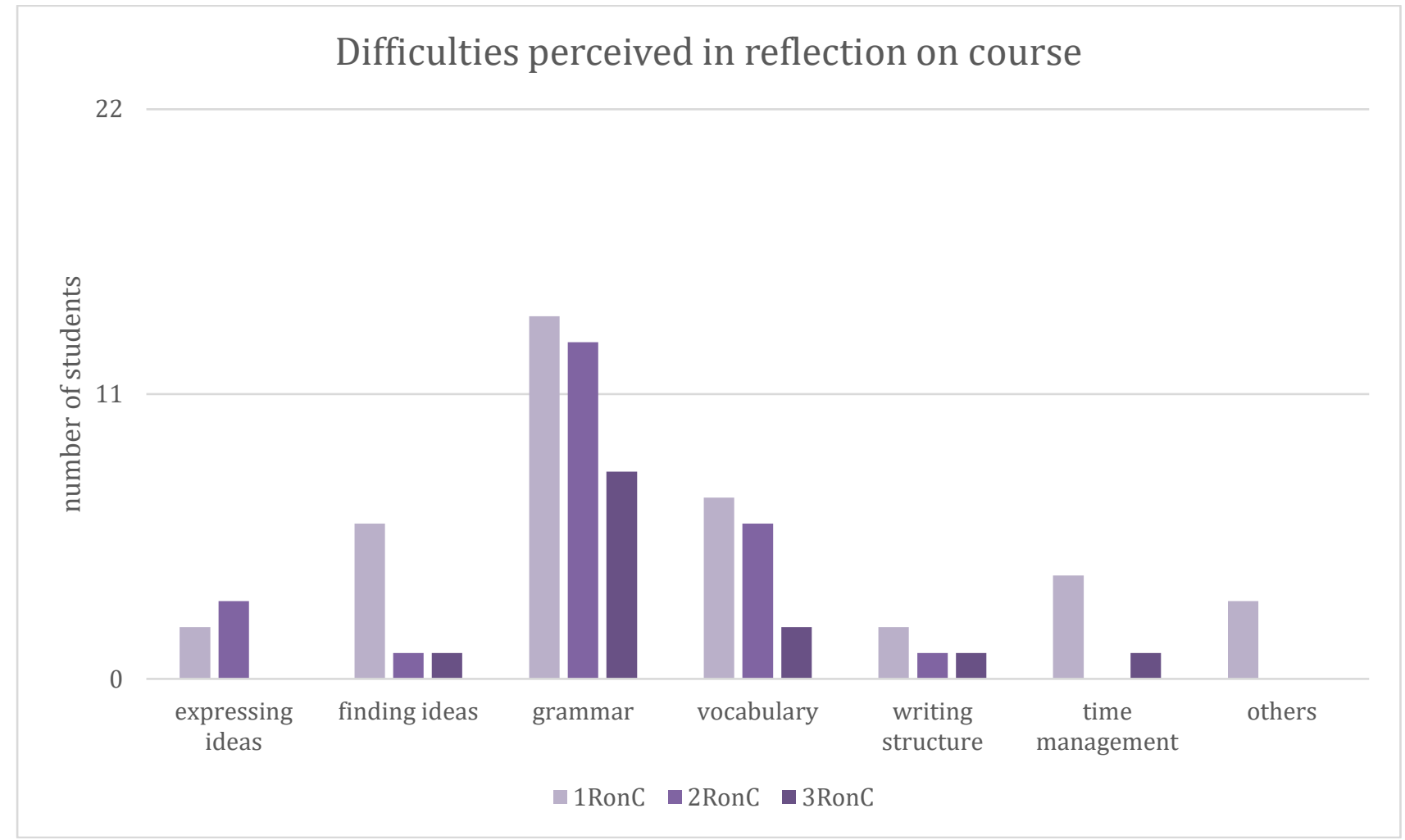

Figure 4.2 Areas of difficulties perceived by the students in reflection on the course

With the practice of reflection, the students were all aware they had difficulties at some point. However, identifying those difficulties was not always obvious to them, especially to the students with lower levels of English (4 in total). To take an example, Naly's main difficulties throughout the study consisted of the lack of vocabulary and knowledge of grammar according to her. Despite the importance of such awareness, those difficulties were not specific enough to help her efficiently focus on finding adequate solutions. An example of strategy she received from her peers is stated in 4.3.2.2.6 (p. 153).

Students like Naly, who could not clearly identify their difficulties had problems developing other components of self-regulation and failed to develop fully strategic behaviour like the other students did. Developing strategic behaviour and the problems with finding strategies are discussed in the following section.

\subsubsection{Developing strategic behaviour}

The awareness of difficulties enabled the students to think strategically. They understood the necessity for them to solve their problems, and thus, to use different strategies they had 
at their disposal, and to look for others. Among the strategies they used, the metacognitive ones were the most common, which is not surprising, as the reflection prompts strongly encouraged them to.

This section discusses how the students developed strategic behaviour. However, it focuses not only on the strategies they used but also on the problems related to those strategies, which were traced in their reflections. Moreover, it discusses the impact of these strategies (and reflection in general) on their perceptions of writing and learning.

\subsection{Metacognitive strategies}

The reflection prompted the students to think consciously of their learning process by planning (including setting goals), monitoring, and self-evaluating. Before discussing how the students dealt with these three components, it is worth noting that the use of metacognitive strategies was not limited to direct responses to the prompts. The students also used these strategies while monitoring, when they were enumerating their writing steps, and while self-evaluating, when they were reflecting on how they had dealt with their difficulties:

Now, I am taking a draft to organize the plan of my writing. I am collecting all ideas related to the topic. (Naia, 1T1R)

I continue to read my writing when I have finished it to check my mistake and especially the spelling. (Vanina, 1T2R)

With my difficulty, I just made a plan in my draft. Then I re-organized my ideas. (Carrie, 2T1R)

These excerpts show planning, organizing, monitoring mistakes, which are all metacognitive strategies (Oxford, 2003b). Another strategy that eight students used was to focus. Focusing can be considered as a metacognitive strategy, as it was part of their management of learning process. Two of these students explicitly stated their focus on their goals while writing. The ability to focus was an aspect of improvement that these students considered important in their writing, as demonstrated in the excerpts in the section on awareness of improvement.

Some writing strategies that the students used - such as checking grammar or proofreading - may appear basic, but they may not have used these strategies without the 
cyclical pattern of reflective learning. Twelve students wrote that they were monitoring their mistakes by proofreading and paying more attention to grammar and vocabulary. Two of these students explicitly stated their habit of checking mistakes as they had become aware of their tendency to make grammar mistakes: "Today I learnt that we should never neglect anything, I mean, when you've finished something you should check for mistakes instead of "I've finished, now I have to go" (TJ, 3T2R). This excerpt demonstrates monitoring of mistakes, and a growth of sense of responsibility.

\section{Setting goals}

The ability to set goals is a crucial element in self-regulation (Locke \& Latham, 2006). For students who had not been accustomed to setting goals, setting goals itself presented some difficulty. The two main difficulties were confusion about the link between goals and writing tasks, and having simplistic goals.

\section{Difficulties in setting goals}

In 1T1R (the first reflection on the first task), eighteen students had their goal related to audience awareness: convincing the readers (Malagasy young people) to choose teaching as a career. They chose that goal because it was clearly included in the instruction (see Table 4.2 , p. 105). I had also suggested audience awareness as a focus for that first task, but they were welcome to add or choose other goals. The choice of that goal was therefore influenced by my suggestion and the instructions; and there was no sign they had difficulty with setting goals. However, when discussing their goals in groups in the first group discussion (reflection after group discussion after 1T1R), a common difficulty was perceived (the key words were bolded to highlight the similarity of their responses):

[Our goals when doing the first writing task were:] Doing what the topic wanted us to do, trying to express our ideas about the topic and finishing the writing until the end without mistakes, especially about the explanations. (Group 1)

"To finish the task until the end and on time, without mistakes; and give the best arguments." (Group 2)

These are excerpts from reflections of two different groups, who did not discuss together. Yet, the similarity of the goals is striking. Not only do these goals have very general 
characteristics, but they also explicitly show the students' 'obedience' towards the task given by the teacher. They aimed only to complete the task - because they were asked to without mistakes, which they had probably done every time they had had writing in secondary school. In fact, it must have been the first time they were asked to think of goals before writing, which explains their unawareness and confusion about the place of goals in writing, as shown in the excerpts below:

For today, I have learnt about what "essay" is and when I do a writing task I have to make a goal [...]" (Soraya, reflection after group discussion after $1 T 1 R)$

[...] with the first reflection, there was something I couldn't answer and I didn't understand like the goal, for example." (Vanina, 3RonC)

Vanina knew what the word "goal" means literally, but what she did not understand was the connection between a goal and a writing task. Even when the students knew they had to set goals, they had little idea of what goals to choose. This explains why their goals were sometimes very broad. The definition and examples of broad goals can be seen on page 123 . While awareness of difficulties helped students narrow down their goals in general, four students still had mostly very vague goals very vague throughout the course regardless of their proficiency levels.

Some goals were specific, but too simplistic. This was due to the task repetition. Though the latter had tremendous effects on affect and the development of a self-evaluation skill (which will be discussed further later), it was not always positive regarding goal setting. Because of the task repetition, students (nine in total, at different points in the course) tended to simply define their goals as correcting the mistakes they had made in the previous writing as demonstrated in the excerpts below:

My goals regarding this final task are to correct my grammar and misspellings mistakes. (TJ, 3T2R)

I did not have difficulties when doing this one because I only did the correction. (Lacha, 1T3R, 3T2R)

My goal was just correcting the mistakes you've underlined but I didn't add anything else in my writing, because if I re-write other things about this topic, I mean if I change it again, I won't never know what I did wrong 
and what should I improve. It's why I've just correct[ed] my mistakes.

(Cassy, 1T3R)

For weaker students, correcting mistakes might be challenging. Therefore, it might be understandable that their goals may only be to correct mistakes. However, for students with higher levels like Lacha and TJ, simply correcting their mistakes prevented them from challenging themselves and from improving more.

\section{Development of a goal setting skill}

Despite the problems described above, the students' abilities to set goals developed gradually thanks to the awareness of their difficulties (related to writing). Generally, they started to set more specific goals from 1T2R. They began linking their goals to the difficulties they had encountered in their previous writing. Goals, thus, varied from one student to another, and from one task to another. The goals the students set throughout the course can be divided into four groups: broad, audience awareness-related, person-related, and language-related goals. The occurrence of the variety of goals with the number of students is presented in Figure 4.3 below. One student may have two or more different goals for one task. Figure 4.3 shows that language-related goals are the ones that were mostly set from $1 T 2 R$ on.

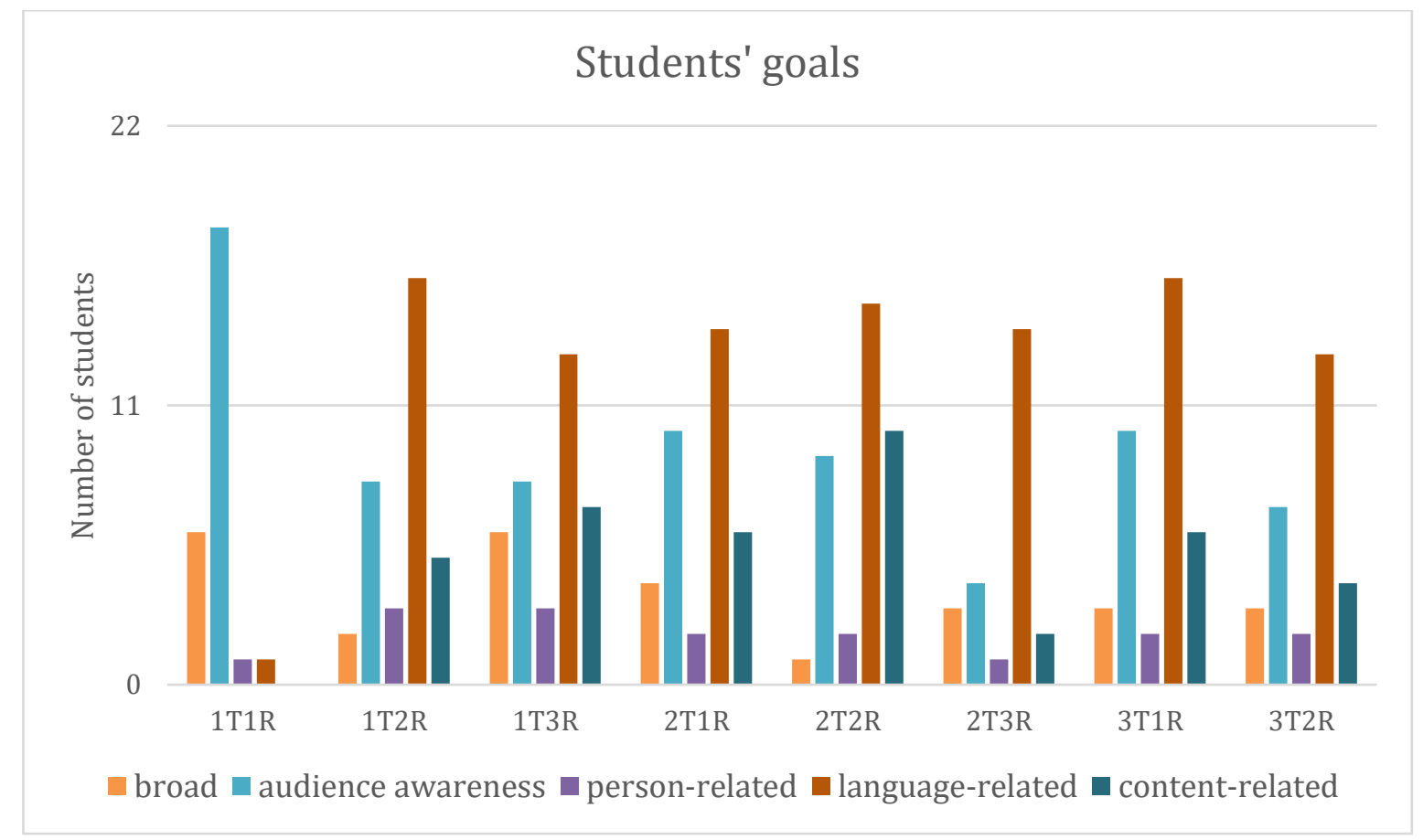

Figure 4.3. Students' different types of goals 


\section{Broad goals}

In this study, some goals that students set were not specifically related to any particular aspects of language (such as grammar and vocabulary) or any other aspects of writing (such as content and audience awareness). The goals might have some links with these aspects, but the links were not clear enough for the goals to be categorised in the other types of goals. Those goals are referred to as "broad goals". As shown in figure 4.3 (previous page), not many students had broad goals throughout the course. However, they tended to be set by the same students: Elvine (62.5\% of the time), Lacha (50\%), Carrie (50\%), Cassy (25\%), Vetso (25\%), Vanina (25\%). The following excerpts are examples of broad goals:

My goals regarding this writing task is to improve my essay in order to make it better. (Elvine, 1T2R)

My goal is to make [the writing] interesting. (Vanina, 1T2R, 1T3R)

\section{Audience awareness-related goals}

Goals related to audience awareness show the aim to communicate with and to convince the reader. As stated earlier, eighteen students chose goals related to audience awareness in $1 T 1 R$ because of the writing instructions and my suggestion. In $1 T 2 R$ and $1 T 3 R$, only eight students related their goals to audience awareness, as they tended to focus more on the mistakes and problems they had had in 1T1, which made their goals more language-related (see Figure 4.4, p.127). In 2T1R and 3T1R, goals related to audience awareness increased (45\%) and decreased again in $2 \mathrm{~T} 2 \mathrm{R}(41 \%)$ and in $3 \mathrm{~T} 2 \mathrm{R}(32 \%)$. The lowest rate was in $2 \mathrm{~T} 3 \mathrm{R}$ (18\%). This shows that the tendency to set goals connected to audience awareness was higher when the students dealt with a task for the first time. The probable reason is that they might be influenced by the instruction (assigning them to convince), or dealing with a new task led them to concentrate more on communicating with the audience. Then, when repeating the same task, they put less emphasis on the audience and put most of their effort on correcting mistakes (from the language feedback I provided) and improving their previous writing.

Nine students chose a goal related to audience awareness for at least $50 \%$ of the time throughout the course. One of them was Nary, who mainly focused his goals on the persuasion of the audience from $2 \mathrm{~T} 1 \mathrm{R}$ on. His writing did have a problem of audience 
awareness from $1 T 1 R$ to $1 T 3 R$, but it was not the leading reason for him to keep his goals related to audience awareness for all the next writing tasks. The reason was the drive he gained from the topics in tasks 2 and 3 . As he felt personally connected to the topics (task 2 about Madagascar, and task 3 about the importance of learning foreign languages), he genuinely wanted to convince foreigners to come and visit Madagascar in task 2, and to persuade Malagasy young people to learn foreign languages in task 3 . In fact, he wanted to "impress" his audience (stated from $2 T 1 R$ to $3 T 2 R$ ). This shows the impact of tasks or topics on the goals students set. This is also evidence that the choice of tasks does matter with regard to the extent to which they motivate the writers to communicate with a specific audience. Therefore, though Nary's goals were not a response to his main difficulties, his goals were not randomly set. They were evidence that he was engaged and felt involved with the topics (Raimes, 2002; Zamel, 1982). The impact of the topics on the students' affect will be further discussed in section 4.3.2.2.3 (p. 142).

Another student, Natasha, also focused her goals three times on audience awareness. Like Nary, she aimed to persuade her readers; this was perceived not only in her goal setting, but also in other areas. For instance, in 2T1R, she wrote:

I am planning to introduce my essay with the reality in Madagascar in order to show the positive points here in my country after that even if there were some problems which happened last year (safety and health problems). For leading the tourists' attention, I am organizing to put some good ideas to compliment Madagascar and to sum up after that.

It is a little bit difficult to choose the right ideas of convincing the readers of my essay. Maybe, my opinions were not convincing at all. (Natasha)

These statements show how she was linking her goals and her writing plan, and then, how she was referring to her goals when monitoring and evaluating her writing. She kept her goal of persuading the audience in $2 \mathrm{~T} 2 \mathrm{R}$, in which she stated her uncertainty about the attainment of her goal, and the necessity for her to "research" ways to convince people.

The following are more examples of goals related to audience awareness:

My goal regarding this writing task is to convince these Malagasy young people who do not know what career to choose after graduating from high school, that teaching is the best option. (Aniel, 1T1R) 
My goals regarding this writing task is to do my best to convince the tourists to come to Madagascar and also to give examples to support all of my ideas. (Nirina, 2T1R)

Throughout the course, only two students did not have any goals related to audience awareness at all. They were among the students who had the greater number of broad goals.

\section{Person-related goals}

Person-related goals are linked to the improvement of some personal features required while writing, such as the ability to focus and to manage time. Person-related goals also include goals that are connected to the improvement of writing, but not specifically related to the writing task being dealt with. These types of goals are future-oriented or long-term.

As shown in Figure 4.3 (p. 121), person-related goals were rare, compared to the other types of goals. This is not surprising, as they were prompted especially to think about their goals for the writing task they were doing. From those rare person-related goals, $75 \%$ were about time management, and they were set mainly by three students. The other goals (25\%) can be viewed as rather unique and exceptional:

My goal regarding this writing task is the improvement of my capacity on writing an essay, especially about some topics concerning education; that is to say: to be aware of my weaknesses on that subject and to be able show [...] my point of view. (Natasha, 1T1R)

Regarding this writing task, except trying to convince and so on, I want to really improve my focus. I really have problems on focusing so this time I hope I will progress. I will give it my best shot. (TJ, 1T2R) My goal is also to be fluent in writing so that I can get high mark at the exam and in the future I will write properly. (Vetso, 1T3R) My goal is thinking in English. (Linah, 2T2R)

Natasha's goal was exceptional indeed, especially considering that it was included in her 1T1R. Thinking about the awareness of her weaknesses as a goal at that stage was not expected. While TJ and Linah's goals were responses to their difficulties (Linah's problem was her tendency to think in French and translate everything in English), Vetso's was future- 
oriented. She did have other language-related goals for that particular task, but she wanted to state that long-term goal because it was important for her. Indeed, she started to understand the importance of writing practice: "I have learnt also that even though I don't want to do my writing in class, I need to because during the exam, I have to do my writing in class, so I need to be patient" (Vetso, reflection after group discussion after 1T1R).

\section{Language-related goals}

Figure 4.3 (p. 121) shows that except for 1T1R, many students (sixteen in $1 T 2 R$ and 3T1R, thirteen in $2 T 2 R$, fourteen in $2 T 1 R$ and $2 T 3 R$, thirteen in $1 T 3 R$ and $3 T 2 R$ ) set languagerelated goals. The latter are especially linked to particular language difficulties or weaknesses, noticed in the previous writing(s). Indeed, reflecting on their difficulties in 1T1 and later made the students realise they had problems to solve, and the solution to such problems became their goals for the next writing. Thus, the awareness of difficulties or the dissatisfaction with the current ability or knowledge triggers the decision over what goals to focus on (Locke \& Latham, 2006). The language-related goals can be divided into 3 types: related to vocabulary, grammar, and writing structure (see Figure 4.4, p. 127).

The most common language-related goal was improving grammar (including spelling). Nineteen students set goals related to the improvement of grammar at least once throughout the course. That was probably due, firstly, to the mistakes I underlined on their writing, which were mostly grammatical. While monitoring and self-evaluating (right after a task), only a few students perceived grammar as a problem, as shown in Figure 4.1 (p. 116). However, while reviewing their writing pieces and their task reflections in the reflections on the course, more students noticed that grammar was part of their weaknesses (see Figure 4.2 , p. 117). Secondly, students tend to notice difficulties with language form more than other aspects when producing output (Fotos, 2001; Izumi, 2002). Thirdly, as the students in this study had been accustomed to grammar instruction, not having grammar mistakes was important to them. Only $9 \%$ of the goals related to grammar were specific, as exemplified in the three excerpts below. The other $91 \%$ were basically to improve grammar and spelling, and to correct grammar mistakes made in previous writings.

I'll be careful with singular and plural words. (Noelle, 3T2R)

I'll try not to have more than 5 mistakes. (Vetso, 1T3R)

[...] to pay more attention to some grammar mistakes such as plurals and 
the use of articles. (Fidy, 2T1R)

The goals related to vocabulary were generally vague. Only $9 \%$ of the time were the goals more specific than just to "improve vocabulary", as shown in this example: "My goals regarding this writing task are improving my arguments [...]; trying to find another word to avoid repetition [...]" (Linah, 1T3R).

Thirteen students set goals related to vocabulary at least once. Two of these students kept such goals for more than $75 \%$ of the time throughout the course, essentially because they were not able to solve their problems with vocabulary. A matching (though not always consistent) between difficulty in vocabulary perceived by the students (in the previous writing) and the goals (in the current writing) can be found, as shown in table 4.6 below.

Table 4.6. Matching of difficulties and goals on vocabulary

\begin{tabular}{|c|c|c|c|c|c|c|c|c|}
\hline $\begin{array}{l}\text { Difficulties/goals } \\
\text { on vocabulary }\end{array}$ & 1T1R & 1T2R & 1T3R & 2T1R & 2T2R & 2T3R & 3T1R & 3T2R \\
\hline Difficulties & 9 & 5 & 1 & 7 & 8 & 0 & 4 & 2 \\
\hline Goals & 1 & 9 & 6 & 3 & 4 & 3 & 4 & 3 \\
\hline
\end{tabular}

The goals related to writing structure were about (re)organisation of ideas, sentence structure, building a paragraph, forming the introduction, and the conclusion. Except for $1 T 2 R$, few students aimed to improve their writing structure (see Figure 4.4, p. 127), though six of them claimed to have difficulty with writing structure in $2 T 1 R, 2 T 2 R$, and 3T1R. A probable reason for the higher number of students (seven) choosing that goal in 1T2R was that it was one of the examples of goals I mentioned. As it was their second time to do the reflection, they still needed to be provided with examples and modelling. However, that cannot be the only reason. Two of the students, that is, half of those who chose a goal related to writing structure in $1 T 2 R$, had mentioned their weaknesses in organisation of ideas and forming the introduction. Therefore, it can be said that they were turning their difficulties into goals. An example of writing structure goals is "[My goal is] to well organize my ideas in a plan that is structured [...]" (Fidy, 2T1R). 


\section{Language-related goals}

22

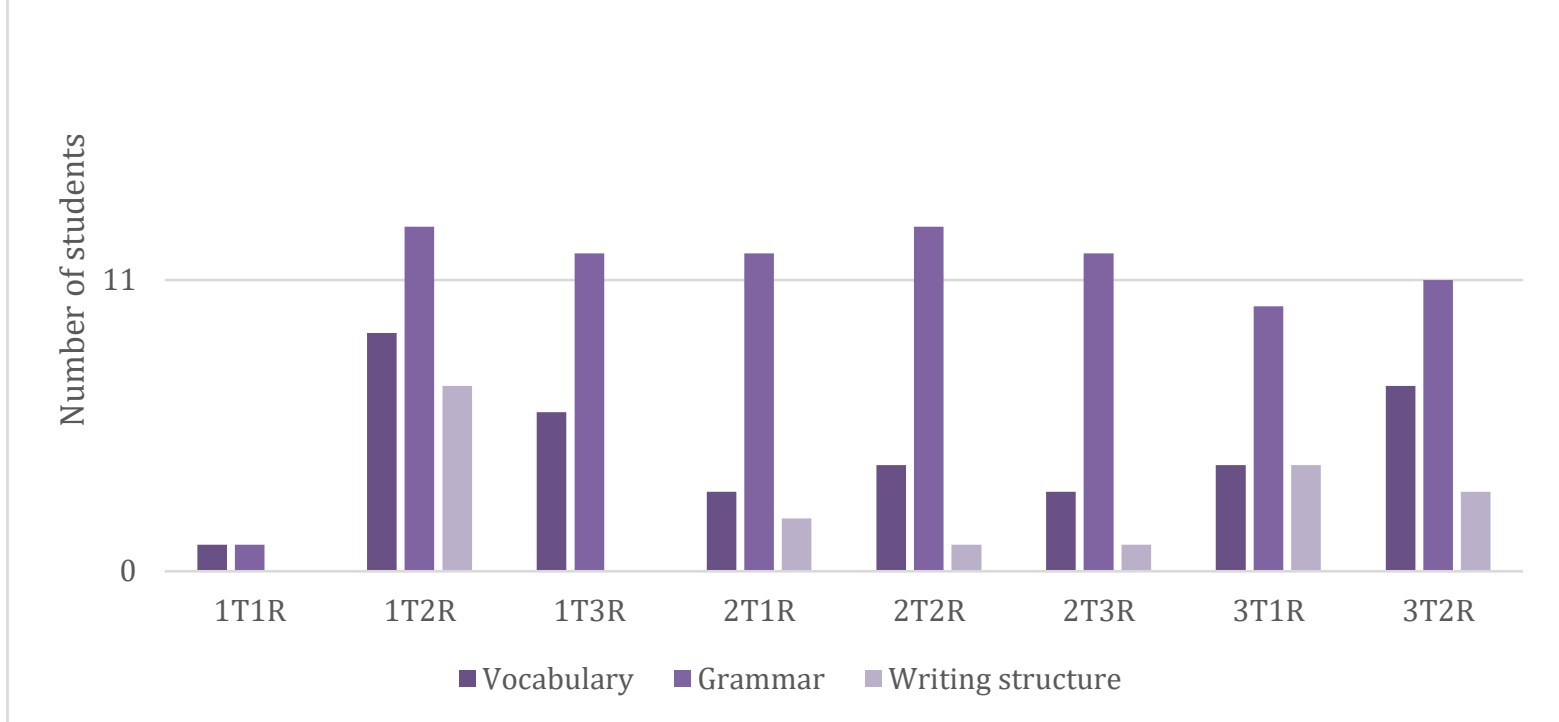

Figure 4.4. Types of language-related goals

\section{Content-related goals}

Content-related goals are related to improvement of ideas. It was at its highest in $2 \mathrm{~T} 2 \mathrm{R}$, in which ten students aimed to improve their ideas. The main reason was that they thought their arguments in 2T1 were not convincing enough due to their lack of knowledge about Madagascar (the topic was to convince tourists to come to Madagascar), as exemplified in the excerpts below. Indeed, the most cited difficulty (twelve students) in 2T1R was to find ideas (see Figure 4.1, p. 116), which shows the matching of the perceived difficulties and the goals set.

I think it's quite difficult to search for arguments. (Carrie, 2T1R)

My difficulty was about finding strong ideas to convince foreigners (about

my last writing task) because I had lack of information concerning

Madagascar. (Natasha, reflection after group discussion after 2T1R)

\section{Awareness of the importance of goal setting}

The importance of goals was expressed by the students, especially (but not only) in their reflections on the course. For instance, when answering what particularly worked when doing the writing task in $3 \mathrm{~T} 2 \mathrm{R}$, a student wrote, "Pre-task prompts worked because [they] [led] my writing" (Soraya, 3T2R). Pre-task prompts included goals and the planning of the 
writing. The students came to the understanding that goals are like clear directions or guidance for them to follow while they write, and are a source of motivation. The excerpts below are examples of the students' awareness of the importance and the usefulness of having goals.

Using reflection on my learning has been useful for me. In fact it [has led] me to have a clear plan when writing and to drive me not to stop until I reach my goals on writing. It really improved my way of doing a writing task. (Natasha, 3RonC)

I think learning with [the] use of reflection has been useful for it helped me to focus on all my goals so as to accomplish the task in a better way.[...] I have learnt also that to set a goal is very important before writing anything on paper, because that is useful to carry out the task well. (Fidy, 3RonC) Before, I didn't really care about my goal but I just focused on my ideas and explanation. But during this writing, I tried to reach my goals with all my ideas. (Aniel, 1T1R)

The last excerpt shows Aniel's awareness of her goals when doing her writing as early as 1T1. She viewed focusing on her goals as a strategy for improvement: "I dealt with my difficulties by being focused on the goal. So that I can find clear and meaningful ideas" (1T1R). She reiterated in her last reflection (3RonC) that from what she had learned from the course, the most important was the indispensability of having goals. Another student, Fidy showed his awareness of the links between his difficulties, his goals, and his evaluation of the attainment of such goals:

My goals were to improve paragraphing, which was attained partially, not to the full (some ideas were not well organized); to take care of my grammar mistakes, which I still need to improve; and to manage the time, about which I have to train myself. (Fidy, 2RonC)

\section{Monitoring}

The during-task prompts encouraged the students to monitor their writing. The aim was to have them reflect on their writing steps, their difficulties, their feelings, and their goals 
while doing the writing task. The simultaneity of writing and monitoring posed a problem to the students, especially at the beginning of the course.

\section{Difficulty with monitoring}

Focusing on the content and the structure of the writing, reflecting about it and their feelings simultaneously, and writing down the reflection can be quite challenging. Eight students expressed the difficulty of doing the task and the reflection at the same time.

The reflective journal didn't help me because when writing it, it takes me [a lot of] time, so, I don't have enough time to do my writing task. (Carrie, 2RonC)

It was difficult to do the reflective journal and the writing at the same time as the reflective journal took all the time. (Katherine, 1RonC)

Though what Carrie and Katherine (both were weaker students) meant was not only about monitoring but with the journal writing in general, they had more difficulty with monitoring than planning and self-evaluating. With their lower level of proficiency, expressing their ideas in the writing task was already a struggle. Furthermore, time was limited. Therefore, it is understandable that adding the reflection was a burden to them. Students with higher levels also felt the difficulty caused by the simultaneity of writing and (especially) monitoring.

The difficult was the during task prompts because we do the writing and the reflective journal at the same time and I feel nervous about the time. (Aniel, 2RonC)

My difficulty was the planning between the [journal] writing and the task. I have to write down in the draft and I think about my writing at the same time. (Cassy, 1T2R)

In order not to discourage the students, I made some adjustment. It was optional for them to answer the during-task prompts every third week, that is, when they dealt with 1T3R and 2T3R. This adjustment can be seen as a type of negotiation, consideration of individual choices, and fostering reflection "in the right dose" (Tassinari, 2018, p. 407). Time for the completion of the writing task and the reflection was also extended from 50 minutes to 1 hour and 45 minutes. 


\section{Feeling and thinking through monitoring}

When monitoring, the students enumerated their writing steps as well as their feelings. While eleven students mentioned what they were doing briefly (see the first excerpt below), the other eleven took the time to describe the steps in detail, as shown in the second excerpt below:

Now, I am writing all my ideas in a draft. I finish building the body, I am doing the introduction. I am writing the body; now I do the conclusion. (Lacha, 3T1R)

I'm thinking about how I should introduce this topic. I think that if I begin it with some ideas about the development of a developing country, it would give more attraction to the reader. Now I move on the 1st argument: I am going to talk about the importance of knowing a foreign language regarding to the dependence on the foreign developed countries to help us to develop. Then I want to talk about how not knowing a foreign language can be a hindrance not to get a job. Then I go on to introduce my third argument talking about how knowing foreign language can help a person to make enough money to feed the family, and how it can give a person oral profit to this one. Finally, I sum up my ideas and I [incite young] people to learn foreign languages. I am rereading my writing to check whether there are some grammar mistakes that I can correct before moving to the post-task prompt. (Fidy, 3T1R)

While it is true that students with lower levels tended to keep the descriptions of their writing steps short, the authors of the excerpts above had both higher levels of proficiency, and both excerpts were from 3T1R. This implies that the way they expressed themselves in the journal did not always depend on their level of proficiency, and that the "quality" of the content of their reflection may not evolve with time. It can be said that some students may be simply more expressive than others. Another possibility is that the "mood" to express oneself depends on the task and on the spontaneity of ideas. In other words, students tended to be more expressive in their journals when they encountered difficulties or they had to take some time to think of what they should do, or they noticed a change in their plans, as exemplified in the excerpts below: 
I don't know if there is [a] translation for the Malagasy word "fihavanana", peace doesn't define it exactly. (Lacha, 2T2R)

Now, I am thinking about what [I] should write in this paper and how to do this task: shall I put an introduction or I just write what I think in my mind.

[...] Now, I am thinking about a translation of "baggage", I mean "une bonne baggage" but I forget the word. (Linah, 1T1R)

I think that I don't follow my plan because while I was writing, another idea came into my mind. (Cassy, 1T1R)

On the other hand, when the students had their total focus on the task or they had many ideas to write, they did not want to lose their flow of ideas by expressing their thoughts and feelings in their journals. This is related to the problem of simultaneity stated in the last section. This is demonstrated in the following excerpts:

I don't notice any feelings, I'm just focused on my task. (Aniel, 2T2R)

Now I am very concentrated and I want to forget the journal a little while.

(Fidy, 2T2R).

The students' expressions of feelings will be discussed later in this chapter when talking about affective strategies.

\section{Self-evaluating}

The post-task prompts encouraged the students to evaluate their own writing performance, to look back at their difficulties, their improvement, their strategies, and to appraise whether they attained their goals or not. As with monitoring, they also encountered some problems when self-evaluating. However, with practice, they learned how to self-evaluate and appreciated the usefulness of self-evaluation, and the empowerment resulting from it.

\section{Problems with self-evaluation}

Self-evaluation was challenging for the students. It was not always obvious for them to identify their strengths, to gauge whether they had achieved their goals or not, or whether the strategies they had used worked or not. Sometimes, even figuring out exactly what strategies they had used was difficult. Six students expressed their difficulty related to selfevaluation: 
It was sometimes difficult to know if I am attaining my goals or not, and [what] will be the [score] I will give my task. Also, it is not easy to know and to write the strategies and solutions we did [...] come up with. (Naia, 1RonC)

It was a little bit difficult for me to answer the third question in the posttask prompts because most of the time, I am not really sure of the achievement of my goals and I always hesitate. (Natasha, 2RonC) Regarding my writing, my strength is not identified clearly up to now. It is up to the topic that I can judge what my strength regarding it [...]. (Fidy, 2RonC)

Apart from the achievement of goals and the usefulness of strategies, it was difficult for some students (three of them mentioned it) to correct their mistakes, as they did not understand the nature of the mistakes. Narindra's statement illustrates this inability to correct mistakes: "When doing the task, I feel a bit confused because there are some mistakes in my last writing that I could not really correct" (3T2R).

The difficulty in appraising the attainment of goals was also shown in some of the students' misjudgement. They sometimes claimed to have achieved their goals, which was not the case. For instance, Carrie stated she attained her goals of convincing young people to choose teaching as a career in 1T3R. Yet, her introduction seemed to do the opposite by stating an important disadvantage of teaching in Madagascar. Likewise, Soraya was persuaded that her goal of organising ideas better was achieved in 2T3R. Yet, there was still a lack of flow and of smooth transitions between her arguments.

\section{Developing self-evaluation skills}

Despite the challenge of self-evaluation, the students built some self-evaluation skills gradually. They learned to identify their difficulties (as seen earlier in this chapter). They became aware of improvement not only in their writing, but also in their learning attitudes. The reflection did generate such awareness, but the teacher's as well as the peers' feedback (discussed later in social strategies) also contributed to it. 


\section{Awareness of improvement related to writing}

When asked their opinions on reflective journals (in the reflections on the course), eleven students claimed the helpfulness of reflection, specifically because it enabled them to perceive their improvement:

I think that every student has to practice the reflective journals because it is very helpful, especially [for] me. I can see my improvement about what I write. (Linah, 3RonC)

[Reflection] helped me to do a writing task in a more efficient way. (Nirina, 3RonC)

The students became aware of their improvement by answering the post-task prompts (for each task) and a question on improvement in the reflections on the course. Perceiving and elaborating on improvement were easier for them than identifying difficulties. The repetition of the same tasks gave them the opportunity to review their writing pieces and to compare them with the ones they were writing. Therefore, the task repetitions assisted their improvement, especially in grammar, finding and expressing ideas, and writing structure stand out, as can be seen in Figure 4.6 (p. 137) and later in Figure 4.7 (p. 146), and shown in the excerpts below.

If compared with my last writing, I noticed that I could find more arguments than the last one. (Rose, $2 \mathrm{~T} 1 \mathrm{R}$ )

Compared with my last writing in this one, I separated clearly the introduction, the body and the conclusion of my work and also grammar is improved, and I noticed my audience. (Carrie, 2T2R)

I found new technical vocabulary. Grammatically, my sentences are better. I found new ideas about the topic. (Cathy, 2RonC)

The students also noticed improvement in other aspects not related to language or writing content, such as focus and time management.

I learned to manage time while doing writing; I must not spend a lot of time [o]n one idea or [...] thinking. (Aniel, 2RonC)

I finished my writing and successfully focused without getting stuck. (TJ, $1 \mathrm{~T} 2 \mathrm{R})$ 
TJ was not the only student who perceived improvement in focus. Ten other students did as well. Two of them considered the ability to focus on their goals as a positive feature they gained from reflection:

[...] the reflective journals always remind me what my goals are so I am not out of subject. (Aniel, 1RonC)

From this course, I learned that using a reflective journal when working is very useful as it helps to be more focused on what you do. (Noelle, 3RonC)

The students showed not only their perception of improvement, but also their awareness of their goals and the strategies they had used, which resulted in the improvement (referred to as "others" Figure 4.5 (p. 136) and Figure 4.6 (p. 137) :

My strengths regarding writing is the fact that I really am focused when doing it, and I never lack time because I use the draft only for the ideas that come $[. .$.$] in my mind; all the rest is in the copy. (Nirina, 1RonC)$ From this course, I have learned to manage time, to arrange my ideas and the most important is to have a goal so that I can improve my writing because, before, I did not [have] that in mind. (Aniel, 3RonC)

Four students expressed their observation that improvement happens gradually. Though such an observation did not make them entirely satisfied with their work, it enabled them to see their ability to improve, and thus, to appreciate the progress they had made. At the same time, it allowed them to realise that there is room for improvement in a positive way:

I noticed that there is a little improvement in the last three works because my first writing is different from the 2 others, but it's not satisfying yet. It may go [...] step by step. (Nary, 1RonC)

I learned also that more I do writing, more my skills are improved. (Aniel, 3RonC)

Personally, doing a writing task is no easy but I noticed that I made less and less mistakes. Also, what I noticed is that my knowledge increased one bit. [...] In the last three weeks, my main goal was to improve my grammar and to improve my knowledge of course. I think I'm not far from attaining them if this keeps up... (Nirina, 1RonC) 
Nirina's excerpt shows that the reflection (and the writing task) also helped him acquire more knowledge. Though he did not specify what he meant by knowledge, from what he had written previously (in 1T2R), "knowledge" can refer to the ideas and the strategy he came up with. 

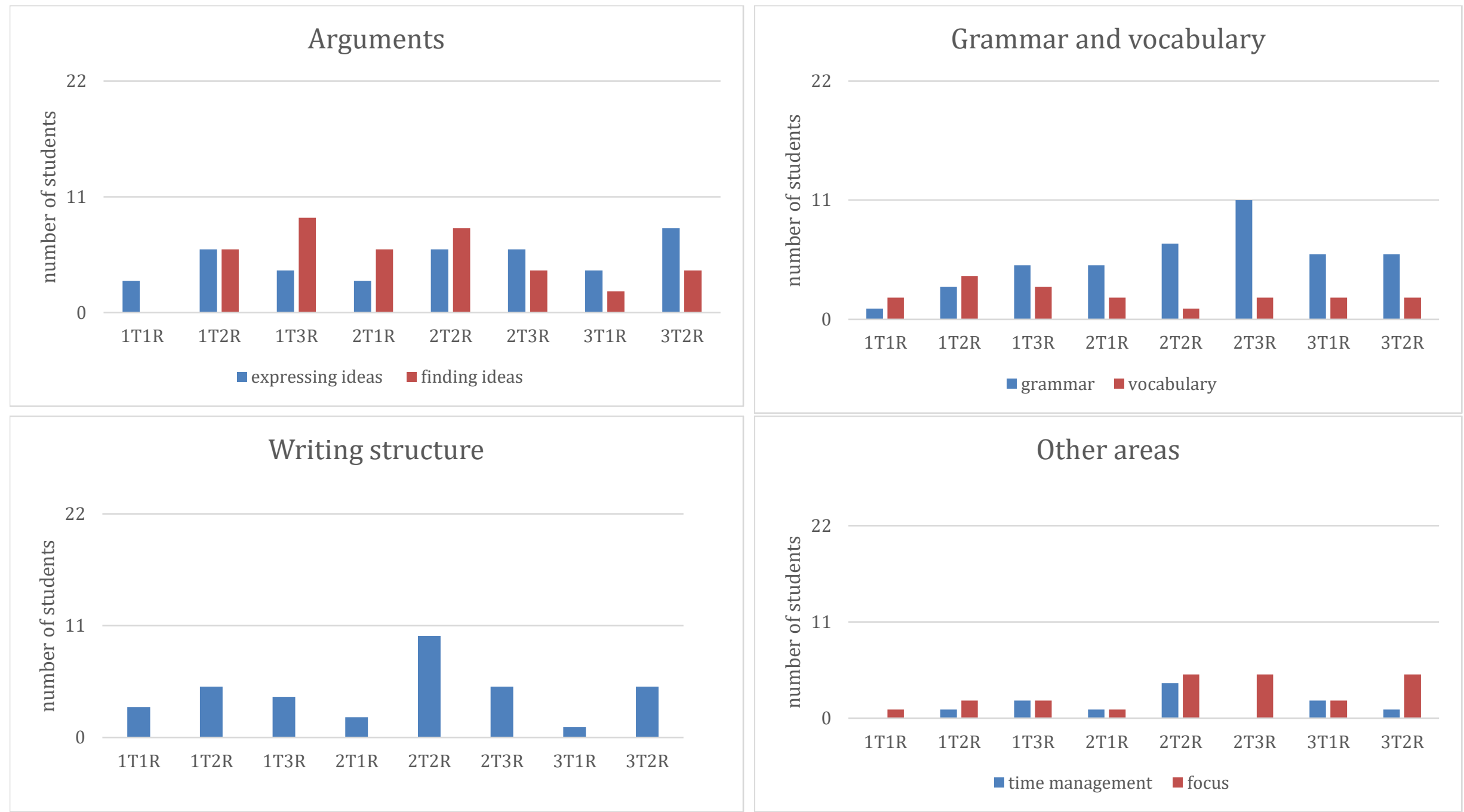

Figure 4.5. Areas of improvement perceived by the students during and after tasks 


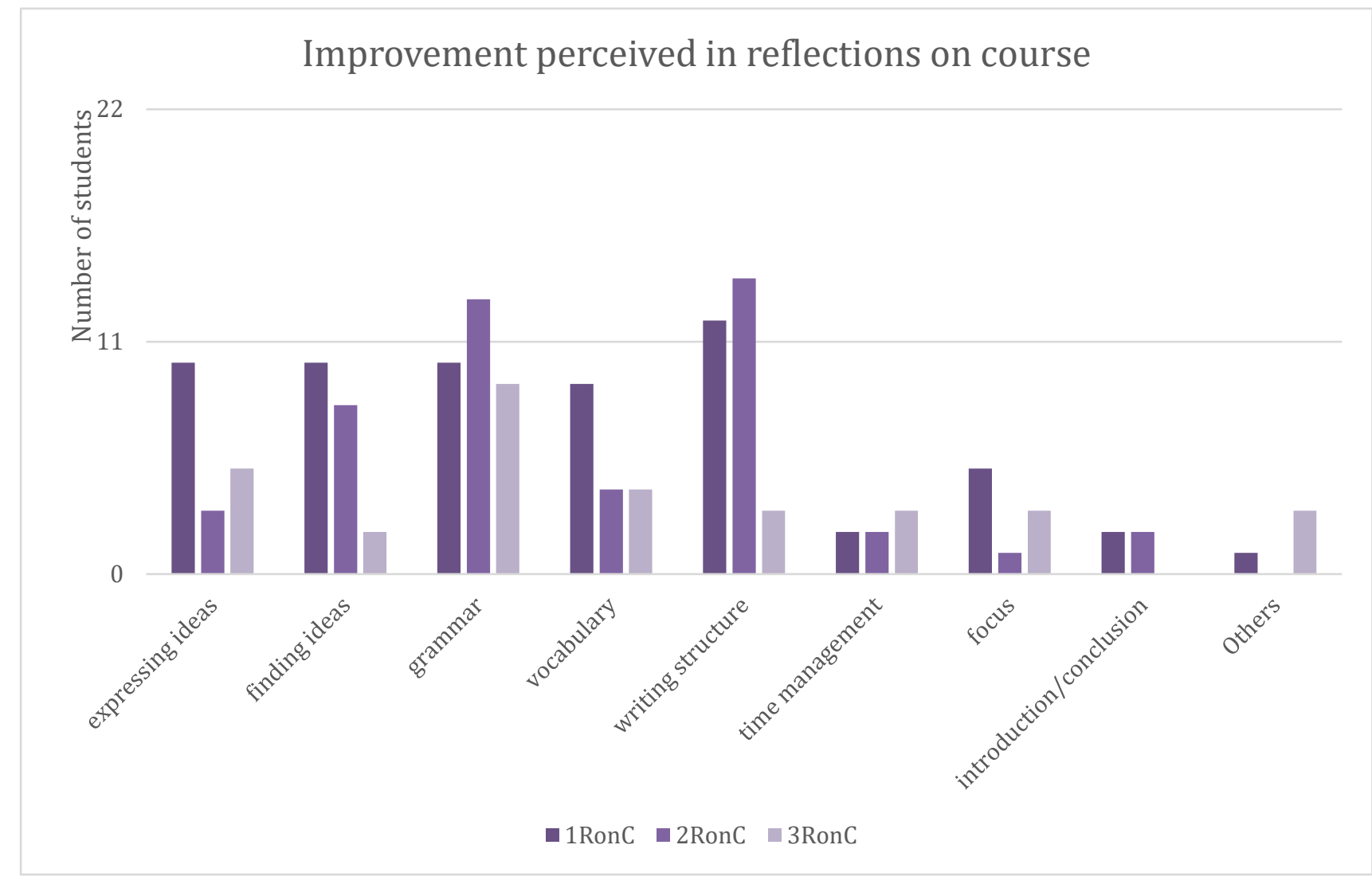

Figure 4.6. Areas of improvement perceived by the students in reflections on course

As shown in the figure above, the improvement the students perceived the most throughout the nine weeks was the improvement related to grammar. The probable reason is that they were able to see that their number of grammar mistakes had reduced from my feedback (underlined mistakes). In 1RonC and 2RonC, more than half of the class noticed improvement in their writing structure. The repetition of the writing tasks enabled them to reorganise their ideas and make their writing more coherent, and such coherence was easier to perceive than other aspects.

\section{Awareness of the necessity of responsibility towards learning}

The reflection work raised the students' awareness on the significance of goal setting, of knowing their difficulties and their improvement in writing. Such awareness resulted in a feeling of being empowered, as they became conscious of what they were capable of doing by themselves. Lacha's statement says it all: "I have learned how to improve myself on my own" (3RonC). 
Fourteen students expressed their appreciation of their ability to correct themselves, which they had gained through the reflection:

Using reflection on my learning has been useful because I, myself am aware of my own mistakes. I think it is more helpful than being taught by others because in this way, I always remember my mistakes and can avoid them [...]. (Aniel, 3RonC)

[...] I could find my usual mistakes and I started to avoid those kind of mistakes. (Nary, 3RonC)

[...] correcting my own mistake is very useful rather than having it corrected by the teacher. (Noelle, 3RonC)

Though the students were helped with the identification of their mistakes (as I underlined them in their writing), the first two excerpts above show that they had developed the ability to identify and avoid their common mistakes.

The feeling of empowerment was accompanied by the awareness of the necessity of responsibility towards writing and learning in general, as exemplified in the excerpts below. It also increased the students' motivation, which will be discussed further later in section 4.3.2.2.3 (p. 142).

[...] now I know that when I have a writing task, I will have to think about what I am going to write before doing it and after that, I analyze my writing if what I wrote is correct or not. (Linah, 3RonC)

The reflective journals and the group discussions helped me because they could give me suggestions that I needed to improve my writing. But there are still problems that need to be resolved by myself. (Fidy, 1RonC) I have learnt that before doing task, I have to have a goal. Then, I should recognize my difficulties and find solution[s] for them in order to improve my study. (Elvine, 3RonC)

\subsection{Social strategies}

By encountering different difficulties, the students expanded their strategy repertoires by looking for strategies on their own and by using peer collaboration through group discussions. Using peer collaboration is a strategy in itself, which is included in social 
strategies (Oxford, 2002, 2003b). Peer collaboration led to exchange and help, peer evaluation, and awareness of more responsibility. It also had some affective impacts, which will be discussed in section 4.3.2.2.3 (p. 142).

\section{Exchange and help}

All the students used social strategies while doing the group discussions (as they were prompted to do). Eleven of them mentioned their use of (or at least the intention to use) strategies they learned from the group discussions, as exemplified in the following excerpts:

During this group discussion I received some solutions for my problems. I know at the moment that I should spend more time on reading English books than on watching English films, because I am not good at grammar. I also need to read some specific books which talk about various topic to extend my knowledge. I also learnt that I should not focus on one point to care about, concerning things that need to be improved, when I do my writing, but should try to have every thing in mind. I just hope to be able to deal with this topic next time by following those solutions." (Fidy, reflection after group discussion after 2T1R)

One of my big difficulties is translation. I mean I translate French to English but I know that I shouldn't. I translate word by word and finally I've got a nonsense sentence. Today I learned about how to solve it: first, I must read articles, magazines, books, revue in English and watch news, movies, documentary in English too. After that, it should be better if I use monolingual dictionary instead of bilingual dictionary. Finally, I should use English as more as I can in my whole life: changing language of my facebook account in English. (Cathy, reflection after group discussion after 2T1R)

Today, from the discussion, I learn how to organize my writing. Exactly, I learn that I must emphasize the introduction, the body and the conclusion so that my task has a structure. (Carrie, reflection after group discussion after $2 \mathrm{~T} 1 \mathrm{R})$ 
From $1 \mathrm{~T} 1$ to $2 \mathrm{~T} 1$, Carrie had only one paragraph containing the introduction, the body, and the conclusion. After that group discussion, she had three paragraphs each time, which she was aware of in $2 \mathrm{~T} 2 \mathrm{R}$ : "Compared with my last writing in this one, I separated clearly the introduction, the body and the conclusion of my work [...]".

Though some of the strategies the students learned from the group discussions seemed basic and lacked specification, they were useful. The students may not have been able to understand the importance of using monolingual instead of bilingual dictionaries, for example, if they had not had group discussions. They may not have thought of reading materials in English and listening to English songs, as shown in the excerpts below:

I've learnt from our discussion that everyone needs to improve their knowledge by reading books, essay, magazine,... (Vetso, reflection after group discussion after 2T1R)

During the discussion, I have learnt that I am supposed to read more books and listen to English song and watch English movies so that I will have more expressed ideas while writing. (Noelle, reflection after group discussion after 1T1R)

The students noticed this usefulness and expressed the appreciation of peer collaboration in their reflections after the group discussions and in their reflections on the course:

The group discussions allowed me to find things and manner of works that I never thought about before, so it helped a lot too, especially in terms of new vocabulary. (TJ, 1RonC)

From our discussion, I learn that working together can bring many ideas about all questions and we can share what we think without judging [one] another." (Linah, reflection after group discussion after 1T1R)

The group discussing [...] allowed us to share our ideas and our ways to do things, and that really helped in the improvement of my writing skills, and even of myself. (TJ, 2RonC)

The last part of TJ's statement has been bolded to emphasise the fact that reflective learning was not all about writing. Though he did not specify what improvement "of himself" he had perceived, his statement indicates that peer collaboration had helped him grow to some extent. In his reflections and discussions in class, he alluded to his becoming 
more focused on his writing and more attentive to details. He also mentioned the power of willingness along with goal setting. All these combined must be what he saw as selfimprovement here.

The students appreciated not only the help they received from peer collaboration, but also the help they were able to give: "From the discussion [...], I could learn how to explain ideas to my friends" (Rose, reflection after group discussion after 1T1R).

\section{Peer evaluation}

Peer collaboration allowed comparisons, resulting in both peer evaluation and selfevaluation. The students were able to help their peers identify mistakes and find appropriate strategies, and at the same time, evaluated themselves in relation to their peers' strengths and weaknesses. Peer collaboration also provided reassurance as they came to understand that their peers had the same problems as theirs. Moreover, they became aware of mistakes that their peers had made, which would enable them to avoid such mistakes in their own writing in the future.

From this group discussion, I've learnt that my problem with finding clear ideas was common. According to that, I think we can all find solutions helping each other, and also four people in one group have their own ideas [...]. (Narindra, reflection after group discussion on 1T1R) During the discussing group, I learnt to exchange my ideas with the others. I also reached some advices and solutions to my mistakes from the others. In addition, I knew from the discussions [...] some mistakes that may happen while writing so that I can avoid them. (Aniel, reflection after group discussion after 1T1R)

\section{Fostering responsibility}

The roles assigned to each group member during the discussions (time keeping, note taking, presenting) helped them not only to focus on the questions, but also to build a sense of responsibility, which they had not been used to necessarily. This was shown in the reflections of two students:

From the group discussions, I have learned about keeping time, I did not really have an habit to keep time when doing something, but there, I was 
used to take a responsibility as a time keeper and it helped me a lot.

(Natasha, 1RonC) (still reiterated in 3RonC)

I also learn that when we have to work together, we should focus on our

task. (Linah, reflection after group discussion after 1T1R)

What Linah referred to by "our task" here is their individual roles while discussing.

Despite the advantages of peer collaboration perceived by the students, a student pointed out what she found as a negative aspect of the group discussions: "During our discussion, I have learnt that working with friends in the same group is a little bit difficult because we have always the intention to laugh, not to concentrate..." (Vetso, reflection after group discussion after $1 T 1 R$, reiterated in 1 RonC). The distraction made her conclude that the group discussions were not really helpful. As a solution, she suggested that they should not stay in the same groups each time. Though distraction might be negative, laughters and humour can also create stronger relationships among peers.

\subsection{Affective strategies}

This section discusses affective strategies used by the students, but it especially focuses on how reflective learning impacted the students affectively. The students' awareness of their feelings about writing started from answering the reflection prompts. They did not find it easy at first to talk about their feelings, but then it came more naturally, when they were facing difficulties or when they were noticing the progress they had made.

\section{Difficulty talking about affect}

The students found it hard to talk about their feelings towards their learning, especially at the beginning. Some of them chose not to mention about their feelings at all. The highest number of students talking about feelings was seventeen in 1T1R and 3T1R. The lowest was in $2 \mathrm{~T} 3 \mathrm{R}, 2 \mathrm{RonC}$ (only one student), and $2 \mathrm{~T} 3 \mathrm{R}$ (only two students). The reason why very few students expressed their feelings in $1 T 3 R$ and $2 T 3 R$ was that, answering the during-task prompts (including the question on feelings) was optional in those two sessions, as explained in section 4.3.2.2.1 on difficulties with monitoring.

When the students answered the prompt on feelings, they could not always elaborate. Firstly, they were not accustomed to talking about their feelings as doing so is not really part 
of the Malagasy education system. Generally, Madagascar is one of the countries where "expressing feelings about their learning is not something that learners do habitually" (Yamashita, 2015, p. 69). Secondly, concentrating on the task may prevent the students from thinking about feelings or anything else, as exemplified earlier. Thirdly, the fact of not being used to exposing feelings made them hesitate what and how much to say:

At the beginning it was difficult to write down all my feelings. I was afraid and I didn't know what should I write down. (Cathy, 1RonC)

It was difficult to write how I really felt, should I be honest or not really, because there are times where I feel very proud of myself but I don't want to seem narcissistic. (Lacha, 1RonC)

It was difficult to express some feeling while doing the reflective journal [...]. (Fidy, 2RonC)

\section{Using affective strategies}

Six students used affective strategies. Three of them realised that in order to write more effectively or to deal with their difficulties, they needed to be calm and relaxed. Two of them mentioned doing their best to have self-confidence, and one of them stated the following as a way to do so: "I tried [...] to ignore my difficulties and think about my positive points" (Noelle, 3T2R). Two of them clearly praised themselves for the good writing they had produced: "I would give 6 out of 10 because I think it is worth it. I am also a little bit kind with myself (-)" (Fidy, 2T2R). Three of them treated journal writing as a strategy in itself, as it helped them pour out their feelings, as shown in the excerpts below. This is what Boud (2001) refers to as using journal writing as a form of therapy.

All thing[s] were easy while writing the reflective journals because I write there my feelings and the thing I'm going to do (all things were about me). (Noelle, 1RonC \& 2RonC)

[...] in the reflective journals, I could write everything I felt and so on, and that was really funny but helping too. [...] Using the reflective journals is really helpful, I mean, when you write on your journal, it's like you are talking to someone. It's like a way to feel free when you are overwhelmed by the works. (TJ, 1RonC) 
YES, using the reflection on my learning has been really useful because it

helps us talking about everything we want to, without offending anyone.

[...] And in the end, it's like a friend to talk too, a confident. (TJ, 3RonC)

Though the other students did not explicitly report the use of affective strategies to solve their problems or to tackle their writing, it does not mean necessarily that they did not. Their reflections did show some positive affective impacts thanks to reflective learning, which will be discussed in the next sections.

\section{Fluctuating feelings}

The students' feelings fluctuated, as shown in Figure 4.7 (p. 146) and Figure 4.8 (p. 146). Negative feelings were at their highest in $1 T 1 R$ (expressed by seventeen students) due to the unfamiliarity of the writing task, and especially, of the reflection work (see Figure 4.7, p. 146 and Figure 4.10, p. 147). Writing for the first time after a long holiday period made the students feel lazy and bored (five of them). They were also worried about the quality of their writing, about time management (six of them), and confused by the task and the reflection to be done at the same time (four of them). The negative feelings decreased in $1 T 2 R$ (from seventeen to ten students), though five of them were still worried either about time management or about not making any improvement. While the negative feelings decreased, positive feelings slightly increased (see Figure 4.7, p. 146). In 1T3R, only two students expressed their feelings, which were both positive.

Figure 4.7 (p. 146) shows that dealing with a new task (in 1T1, 2T1, and 3T1) increased the students' negative feelings. This is probably because they had to come up with the whole writing content and pay attention to all the writing aspects such as grammar and the organisation of ideas into paragraphs. When doing the same task for the second or third time, they had most of the content already. Moreover, they had received teacher's feedback, and help from peers to "fix" their writing. As they noticed their improvement thanks to the corrections they had done, they became more satisfied, motivated, comfortable, and reassured (see Figure 4.9, p. 147):

I feel reassured because I have arguments to support my writing task [...] I think that it is becoming easy to explain and to give illustration about the arguments I gave. (Rose, 2T2R) 
I think there is not a big difficulty while doing the task because I have already the idea but I just need to improve. (Vetso, 1T2R) Now that I'm doing this task for the second time, I feel really happy because I found new ideas to introduce. (Nirina, 1T2R)

It can be said then that although there was fluctuation in the students' feelings, there is a pattern of increased positivity as each task progresses and over the three tasks. The latter is reflected in Figure 4.7 (р. 146) and in Figure 4.8 (p. 146).

In the reflections on the course, the students were not asked about their feelings directly, but were encouraged to reflect on what they had gained from the reflections and to add any comments they may have. That is why they did not necessarily talk about their feelings, as shown in Figure 4.8 (p. 146). However, Figure 4.8. also shows that twelve students did mention their feelings, and most of their comments were about having more comfort, satisfaction, motivation, and self-confidence. The increase of motivation and selfconfidence will be discussed further in the next section:

From the reflective journals, I gain my self-confidence again because it taught me that I can [do] more than I did yesterday. (Vetso, 1RonC) About the feeling, I am a little bit relieved for there are [fewer] mistakes, and it gives me [re]assurance that I did some improvements. (Fidy, 3RonC)

A feature on which the students' feelings also depended was the topic: "[The] feelings I have when I do this [writing] step depend on the topic" (Katherine, 1T1R). Twelve students expressed their appreciation of the topics chosen and the affective impact of the latter. They were motivated to write, as they were able to relate to the topics, and therefore, to feel involved in the task (Raimes, 2002; Zamel, 1982), as exemplified in the excerpts below. Only three students found the first topic (on teaching) difficult or boring.

About the topic, I know that here in Madagascar, many people have difficulty to manage a foreign language and for me, it's a pleasure to write an essay just to convince them [about] learning a foreign language. [...] When doing the task, I feel a little bit pleased and jubilant just enumerating the opportunities I may have because I'm learning [the] English language. (Narindra, 3T1R) When doing the task, I am excited, it is exciting because I love talking 
about my country. (Jerry, 2T2R)

I'm feeling very excited because I love this kind of topic that talks about

tourism. [...] this topic is fantastically exciting. (Nirina, 2T1R, 2T2R)

\section{Students' feelings during task}

22

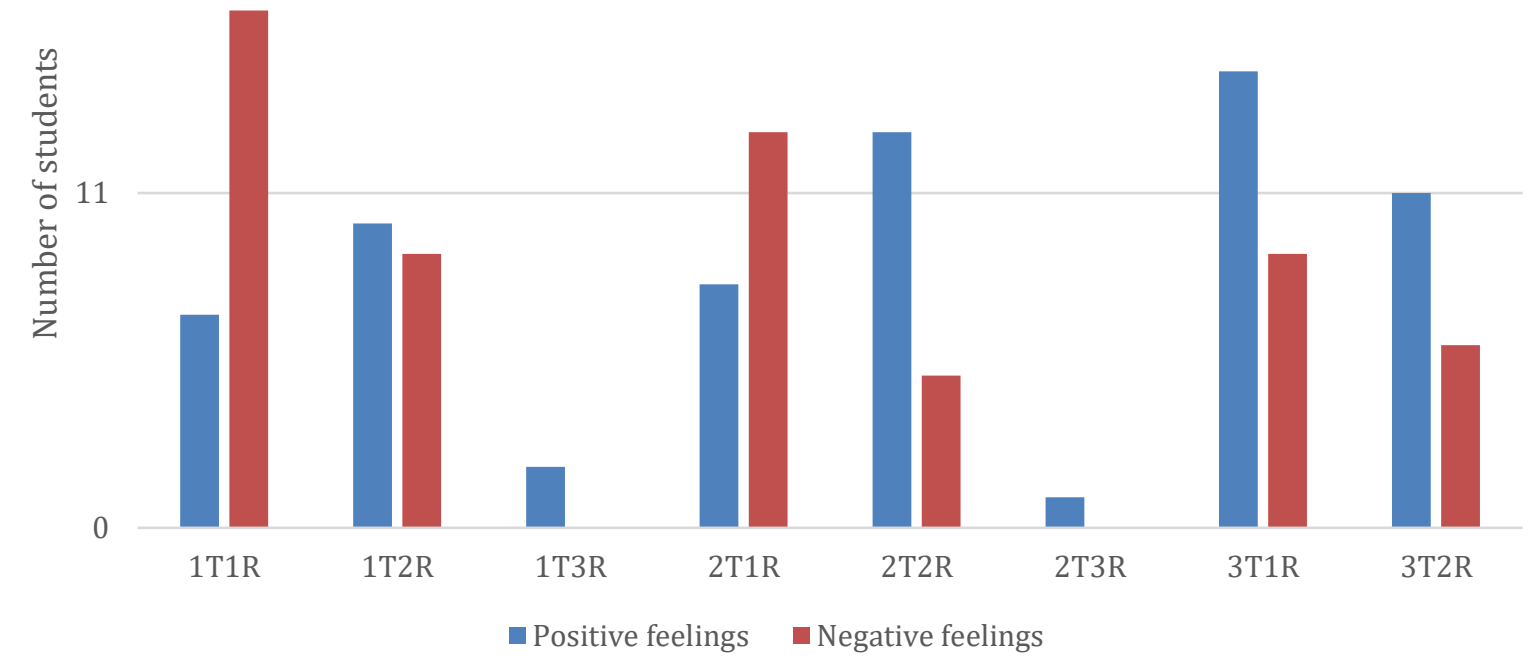

Figure 4.7 Students' expressed feelings during tasks

Students' feelings in reflections on course

22

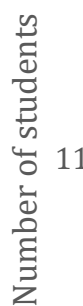

0

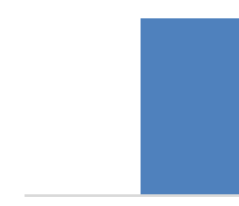

1RonC

2RonC

3RonC

घ Positive feelings $\quad$ Negative feelinlgs

Figure 4.8 Students' expressed feelings during reflections on course 


\section{Students' positive feelings}

$\square$ reassured $\boldsymbol{\square}$ inspired $\square$ happy/excited/satisfied $\square$ self-confident $\square$ calm/comfortable $\square$ motivated $\square$ proud 22

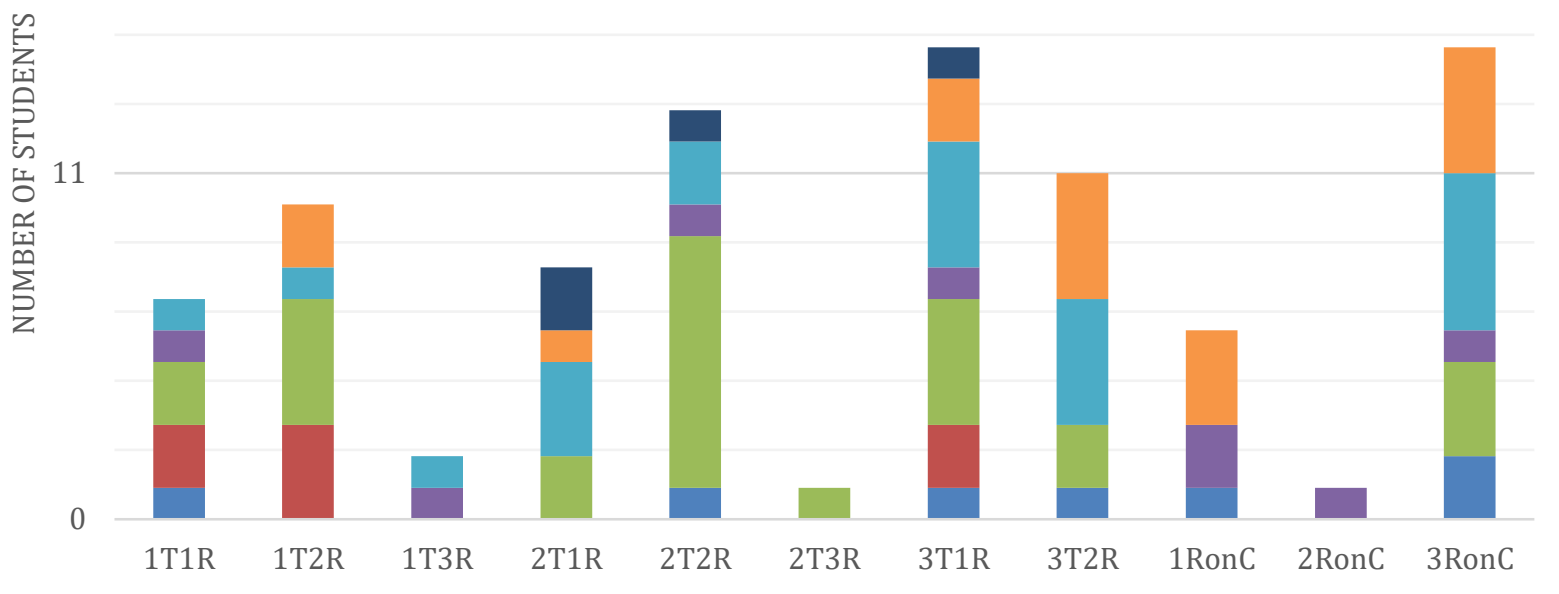

Figure 4.9 Students' positive feelings during tasks and reflections

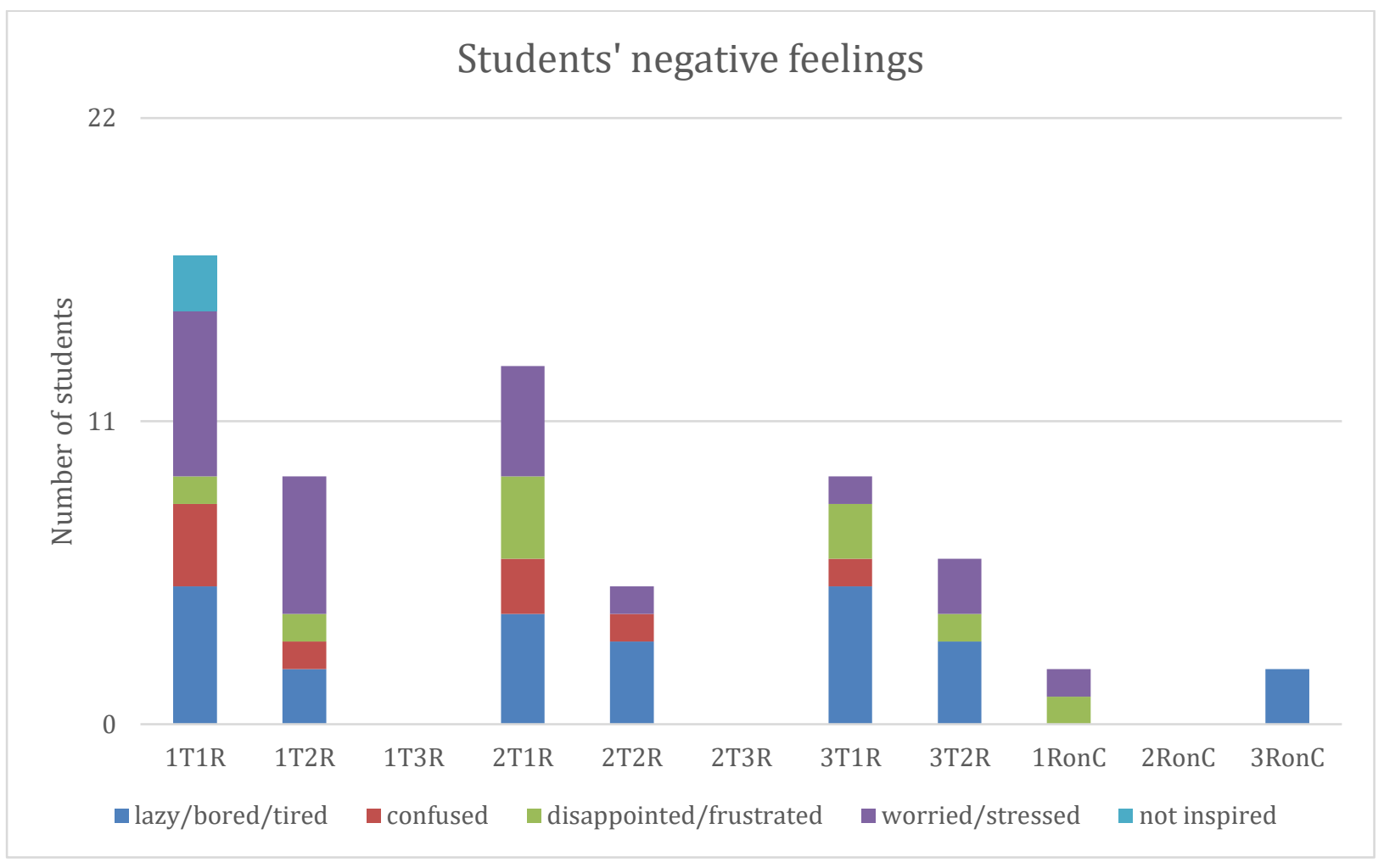

Figure 4.10 Students' negative feelings during tasks and reflections on course 


\subsection{Increasing positive feelings such as motivation and self-confidence}

As shown in Figure 4.9 (p. 147), the students expressed different types of positive feelings. The realisation of the capability to improve themselves with little help from others made the students feel empowered and responsible towards their learning. It also boosted their motivation, self-confidence, and satisfaction with their work. To take an example, Nary had a self-confidence issue from 1T1R to 1T3R: "I always think too much of what I'm going to write. And sometimes, I am not self-confident of my ideas, [whether] [they] positively affect the reader. I sometimes think negatively, a bit pessimistic" (1RonC). Thanks to the perception of his improvement and the understanding that progress occurs gradually, he managed to build more confidence. Although he did not talk about the increase of selfconfidence explicitly, it can be perceived in his reflection. His statement in $2 \mathrm{~T} 2 \mathrm{R}$, for instance, implied certainty and satisfaction with what he had written: "I think it was full of convincing ideas, wasn't it?"

The students gained more motivation and self-confidence from peer collaboration as well. Firstly, it helped them build individual self-confidence, as it enabled double-checking:

What I have learned from our group discussion is that doing a work per group is better than an individual one. First, because, you will combine your ideas and all that has been said. After combining, you will immediately see what should be written or told because you will be more sure of yourself that it's right or wrong. (Nirina, reflection after group discussion after 1T1R)

In the second reflection on the course, he reiterated the link between peer collaboration and self-confidence: "working in group gives you more self-confidence" (2RonC).

Secondly, an aspect that peer collaboration is likely to trigger, but not often emphasised, is the interpersonal relation among the group members. Six students mentioned it and considered it as an advantage of the group discussions:

From the group discussion, I could make new friends [...]. (Carrie, 2RonC)

[...] thanks to the group discussion[s], I could improve my communication with my classmates [...]. (Natasha, 2RonC) 
Group discussion is not to be neglected because it [is] a way to receive help from others, and it makes everybody [more] friendly than before. (Fidy, 2RonC)

Another advantage of collaboration is its contribution to affect as it may increase comfort and motivation. Discussing problems with friends is more comfortable than with strangers; and knowing that one has friends to help with difficulties is comforting: "I [...] gained support from others to resolve my problems, and that is such a relief, is it not?" (Fidy, 2RonC). On the other hand, being able to help friends can raise awareness on one's own abilities and usefulness, and therefore, can generate motivation as well. Thus, motivation does result from the team spirit and interdependence built through peer collaboration.

The friendliness Fidy referred to in the excerpt above must have also been the result of the team spirit they had developed, which triggered trust and the ability to listen to one another:

What I have learnt from my discussion with our group is we have to pay attention to each other even if the other idea does not belong to [us], listening is so important if we want to catch the right idea from each of us. (Natasha, reflection after group discussion after 1T1R)

What I have learnt from our discussions is that I could learn from someone else, and I also know how to work in a group or a team. In addition, I can express myself without hesitation. Even I made some mistakes, we corrected one another. (Nary, reflection after group discussion after 1T1R)

\section{Changing behaviour}

Along with motivation and self-confidence, reflective learning enabled the students to develop other positive features towards learning, such as persistence and focus. They understood the necessity to change their attitudes:

I learnt that a thing (a task or whatever) can look hard in the beginning, but if you concentrate and persevere, you can make it out. (TJ, 2T2R) I learnt from the task that when I try to concentrate and think positively, I can do good things. (Vetso, 2T2R)

At that time [in $1 T 1 R$ and $1 T 2 R$ ], I felt unworthy regarding writing task[s]. 
But that feeling did not refrain myself from thinking I can make an effort to make it better. (Fidy, 3T1R)

Furthermore, reflective learning made the students pay more attention to details: The way I do my writing didn't really change but I'd say I really improved my way of doing "things", like I don't neglect anything anymore. (TJ, 3RonC)

I tried to pay more attention [to] my grammar, I'm aware that paying more attention in everything we do is the best. (Vetso, 2T3R)

Vetso (excerpt above) did change her attitude towards writing. In $1 T 1 R$, she expressed her not liking doing writing tasks in class. However, after the first group discussion (reflection after group discussion after 1T1R), she realised the importance of writing practice, and stated, "my behaviour has changed, now, I like and don't have any problem of doing writing task[s] in class" (3RonC). Other students also mentioned about their change of attitudes not only towards writing, but also towards reflection:

[...] the first time I wrote in this class, I was so lazy and I could not reflect as well as I had to; I just wrote what came in my mind. However, [in] the last writing, I really improved, I was excited to do the writing task and I paid attention [to] my words. (Natasha, 3RonC)

In the beginning, I didn't have any motivation to [answer] the prompts. For me, it was just a waste of time, but after, I realized that it is very helpful because I can see my improvement by setting a main goal in each writing. (Cassy, 3RonC)

\section{Exposing deeper feelings}

It was stated earlier that the students did not always elaborate on their feelings, and five of them chose not to mention feelings at all. Five students were exceptions. While four of them treated their journals as confidants, one student used her journal to communicate her worries to the teacher, especially at the beginning:

I am a little bit afraid to write something wrong and I think too much about your reaction when you [...] read my journal. There is a lot of question in my mind: is it right or wrong? Have I made any mistakes? What will my 
teacher say about it? (Cathy, 1T1R)

I am confused and I am tired. I am afraid too. I used to do this topic many times and what [will] happen if I write something wrong? (Cathy, 3T1R)

These excerpts show Cathy's communication of her apprehension of making mistakes, and of the reactions of the teacher because of these mistakes. These excerpts reveal the anxiety that some students have when dealing with tasks, of which teachers may not be aware. Indeed, it can be inferred from these excerpts and Cathy's suggestion on what to implement in her future classes in both 2RonC and 3RonC (see the excerpt below), that her learning/classroom experience or her communications with former teachers had not always been smooth. From the course, she seemed to discover new attributes that teachers can have, which she would like to have, once she exerts the profession: "Lessons that I can draw from the course: To listen and understand the student[s] instead of punishing them; to be kind and funny [,] so [that] student[s] won't be afraid of us" (Cathy, 2RonC). In 3RonC, Cathy reiterated her statement and her appreciation of the teacher being "kind and funny".

Cathy's statements show how journals can be used as a means for teachers to know and understand how their students actually feel when doing a task, and therefore, to adjust their attitudes towards the students. These statements demonstrate the importance of considering affect when teaching, which will be further discussed in chapter 7.

\subsection{Cognitive strategies}

Sixteen students used cognitive strategies throughout the course. The strategies were mainly about making a rough draft of ideas in order to organise them better. Drafting ideas may be seen as a simple strategy, but it was not always easy for the students to manage it. For instance, Naia tried the strategy of making a rough draft in $1 \mathrm{T1R}$ and realised that it took too much of her time. Therefore, she decided to do her writing directly on the writing paper in $1 T 2 R$. Then, she was not satisfied with her writing because it lacked planning. Thus, she decided to make a rough draft again from 1T3R on. However, she used the draft not to write down the entire writing any longer. She used it to organise ideas, to note down difficult words (or words she did not know in English), and to write down the mistakes she had made in the previous writing in order to figure out why they were mistakes. She stated in 3T1R, "Arranging paragraphs needs draft. I write in a draft some ideas, then I arrange them in order not to repeat the same ideas to put them in order". She, thus, came back to a 
modified form of her strategy. Naia's example illustrates that when students are given freedom to find their way to a goal, they can develop strategic competence through a formative process. Naia was not the only one who considered making a rough draft as a useful strategy:

In the last two weeks, I noticed that in terms of paragraphing and sentence construction, I made some real progress. Now I work longer in the draft before doing the writing in a clear sheet of paper, and the result is wonderful, now my arguments are well presented compared to my old writings. (TJ, 2RonC)

Other cognitive strategies used by the students were related to practice outside class, such as reviewing grammar lessons, learning vocabulary related to the topic, and applying what has been learned in the writing. Two students demonstrated reasoning and analysis of their own mistakes (in the previous writing) and word choice:

I rewrite the mistakes and I try many possibilities to correct [them]. I explain to myself why it is true or not, what are the reasons or justification. [...] After rewriting, I realize why they are false. (Naia, 2T3R) I tried to focus on the meaning of my sentences in order to find the best choice of word. (Fidy, 3T2R)

Eleven students used other cognitive strategies, which can be referred to as "compensatory strategies" (Oxford, 2002) or "cover strategy" (Cohen \& Weaver, 1998). These strategies were solutions to manage time better, and responses to a lack of vocabulary and of ideas that these students were facing.

[...] when I don't have many ideas, I can express the few ideas that I have in the best way. I mean, I should have a better choice of word to make it more formal. I should not be focused on the lack of ideas, I just express them stronger even [though] they are not many. (Naia, reflection after group discussion after 2T1R) I changed the way to express something when I can't find the appropriate word. (Lacha, 2T3R) 


\subsection{Difficulty finding appropriate strategies}

"I learned that even if a task seems hard or impossible, it's just like that until you find what your problems are. "Fix" them and persevere to achievement" (TJ, 3RonC). TJ's statement confirms what was stated about the importance of awareness of difficulties in the sections earlier. However, not all students were clear about their difficulties. Especially, students with lower levels found it difficult to name their problems specifically, and this made it hard for them to look for the suitable solutions. When they did ask for help, for instance, the suggestions they received also lacked specification. This is shown in the second case study (in the next chapter), and in the following excerpt: "During the discussion, I've learned how to solve my difficulties when doing writing task such as I have difficulties [with] vocabulary so they advice me to read some books in English" (Naly, reflection after group discussion after 1T1R). While reading books is indeed a good strategy to expand vocabulary, it can be overwhelming for students with low levels like Naly. She would need to know some reading strategies and the types of books she should start with.

The difficulty with finding strategies was clearly expressed by four students in their reflections, and also, in one of the presentations after a group discussion:

[...] giving strong solutions to my difficulties was a little bit hard for me. (Narindra, 2RonC)

I think that I couldn't actually find any solutions my difficulty, but I know that I should have given more information about the importance of learning foreign language. (Rose, 3T1R)

With my difficulties, I have tried to do an effort in my argument to make sure that it is good. Solutions are still up in the air now. (Vetso, 1T1R)

Consequently, the students did not always use the appropriate strategies to solve their problems. They sometimes stated they had found solutions to their problems during the group discussions, but they did not seem to apply them (most of the time, the solutions were not specified). For instance, Vanina's main difficulty was to express her ideas throughout the course because she did not have enough vocabulary (according to her). In 
the reflections after the group discussions and the reflection on the course, she claimed to have found solutions to her problem. Yet, her problem persisted. The strategy she used was mainly proofreading to check grammar and misspelling mistakes.

\subsubsection{Summary of the development of self-regulation}

Generally, reflective learning helped the students develop their self-regulation, which started with the awareness of weaknesses or difficulties. Such awareness became a drive, enabling them to develop strategic behaviour. Thus, they used different types of strategies to solve their problems, but also to tackle the writing tasks in general. They were prompted to use metacognitive strategies through the reflection. They learned to set goals, which they related to the solution to their problems. They gradually understood the importance of having goals. Though they were not always able to attain their goals, the awareness of working towards the attainment of goals had helped them decide where to put their effort, and had become a source of motivation and persistence:

[...] students should have goals before writing so that they can be more motivated when doing the task. [...] students should understand if they attain their goals or not since they can still use them in the [next] writing especially when it is challenging for them to attain it. (Rose, 2RonC)

From this course, I have learned to manage time, to arrange my ideas and the most important thing is to have a goal so that I can improve my writing because, before, I did not [have] that in mind. I learned also that more I do writing, more my skills are improved. (Aniel, 3RonC)

Rose's statement above refers to motivation and persistence, which were part of the positive affective impacts of reflective learning on the students (according to them). Her statement also alludes to the importance of the responsibility to self-evaluate. The students did develop a sense of responsibility thanks to goal setting, and especially thanks to their awareness of improvement, which developed through monitoring and self-evaluating. As they noticed their progress in writing, they realised their capability of improving on their own. Furthermore, instead of feeling content with the improvement and positive feelings they had built, they understood the indispensability of making the effort to improve more, as exemplified in Vetso's statement in 3RonC below. This is evidence of what T. Lamb (2009) 
refers to when he says, "the more motivated the learners, the more they appeared to be willing to accept that their success or failure may be related to their own behaviours" ( $p$. 76). Accepting the responsibility for their own learning indicates the development of their learner autonomy (Little, 1995).

I think having a reflective journal is [the] best thing because we can see our improvement in what we do, and it pushes us to do more. (Vetso, 1RonC)

It was useful to reflect on my own learning because it helped me to evaluate my improvement and to see my value about writing task. (Carrie, 3RonC)

[The reflection] has helped me so much in improving my writing. It has also given back to me my self-confidence that I lost somewhere. This course has also taught me that I need to improve in everything I do, and there are still a lot of things that I do not know. (Vetso, 3RonC)

Besides the advantages of reflection, the students also expressed their appreciation of the peer collaboration through group discussions. They realised the importance of working in groups in order to help one another find solutions to their writing problems. Such collaborations enabled them to (re)discover some cognitive strategies.

The degree to which self-regulation developed varied from one student to another. Students with lower levels found it more challenging to identify their difficulties, and thus, to look for adequate strategies. Therefore, they were not able to solve their problems with writing within the time of the research. Nonetheless, they were engaged in doing so, and they were able to notice some improvement, which provided them with more motivation.

\subsubsection{Reflective learning and writing performance}

This section discusses the evolution of the students' writing performance throughout the nine-week course. It talks about the difficulties and the improvement that I (the teacher) saw, based on assessing the writing against the four main aspects in the writing rubric (see Table 4.4, p. 109): structure and style, clarity and conciseness, technical writing skills, and vocabulary. Finally, this section includes a comparison between the students' perceptions 
and the teacher's perceptions in terms of difficulties and improvement in the students' writing.

\subsubsection{Writing task one}

The first writing task (1T1) was challenging for all the students, firstly because of the simultaneity of the writing and the reflection. Secondly, it was their first writing argumentative task in English since they had left senior secondary school, which means that they had not had any assigned writing for four months. For these two reasons, there were negative feelings such as worries, stress, laziness, and confusion (see Figure 4.10, p. 147) as well as difficulty in finding ideas and in vocabulary (see Figure 4.1, p. 116). These are also the probable reasons why fourteen students did not get the passing score, as presented in Figure 4.11 (p.157), and why a large number of students had more difficulty in all the four areas of writing in 1T1R than in the other stages, as shown in Figure 4.2 (p. 117). Cathy explained the problems clearly:

I had a lot of difficulties when I do this writing task: I didn't do a writing exercise a long time and I forgot every step for doing that. I was on holiday four month, I didn't practice English anymore so I didn't remember many of vocabulary. (1T1R)

The area that posed a problem to the students the most was technical writing skills, mainly grammar and spelling (see Figure 4.12, p. 158) in 1T1. They did not notice this problem until they received my feedback. They perceived difficulty related to finding and expressing arguments and to vocabulary more than any other areas at that stage (see Figure 4.1, p. 116), as these types of difficulty presented direct obstacles to their writing. However, as a result of my feedback and the group discussions, they realised that they had difficulty in grammar (14 of them stated it in 1RonC, see Figure 4.2, p. 117), and that is why a high number of students ( 13 of them in $1 T 2 R$ ) chose the improvement of grammar as a goal from 1T2R on (see Figure 4.4, p. 127).

In 1T1, another area which students (15 of them) had problems with was structure and style. Some difficulties were related to lack of awareness of the audience, while some were about organisation of ideas. This is not surprising, given they had not had a writing exercise for four months. It is not surprising either that they did not perceive structure and style as a 
problem at that stage (only two of them mentioned about it), as their attention was on ideas and vocabulary.

As an outcome of task repetition, the exchange during the group discussions, and the teacher's feedback, the students were able to correct some of their mistakes, especially in terms of technical writing skills, including grammar and spelling. Though they were still struggling with the clarity and the organisation of their arguments, as well as with vocabulary, in 1T3, their structure and style, including audience awareness improved. There was also improvement in the other areas: fewer grammar and spelling mistakes, slightly better word choice, and better expression and organisation of ideas.

\section{$1 \mathrm{~T} 1$ scores}

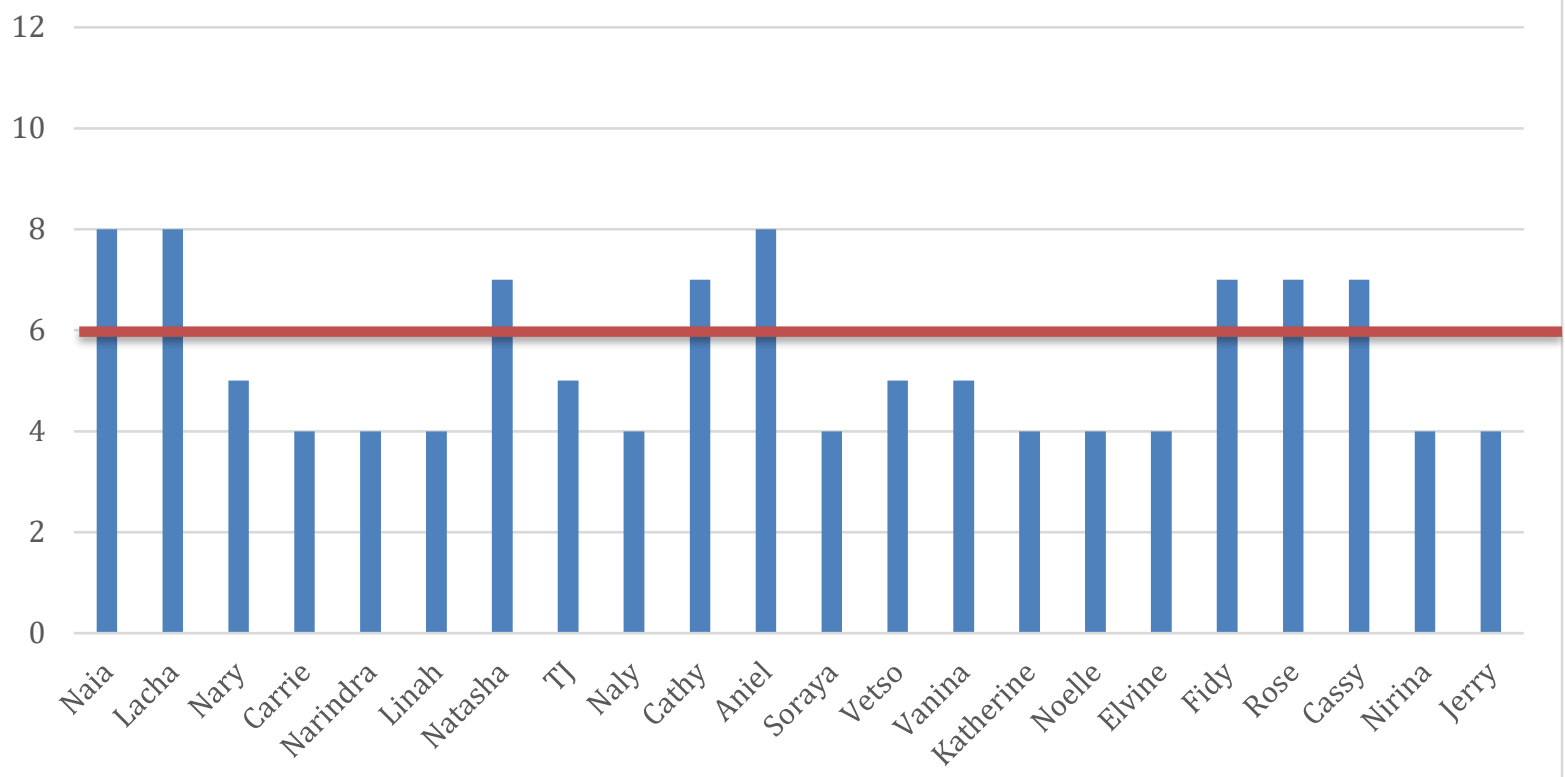

Figure 4.11 Students' scores in $1 \mathrm{~T} 1$ (out of 12) 


\section{Students' difficulties}

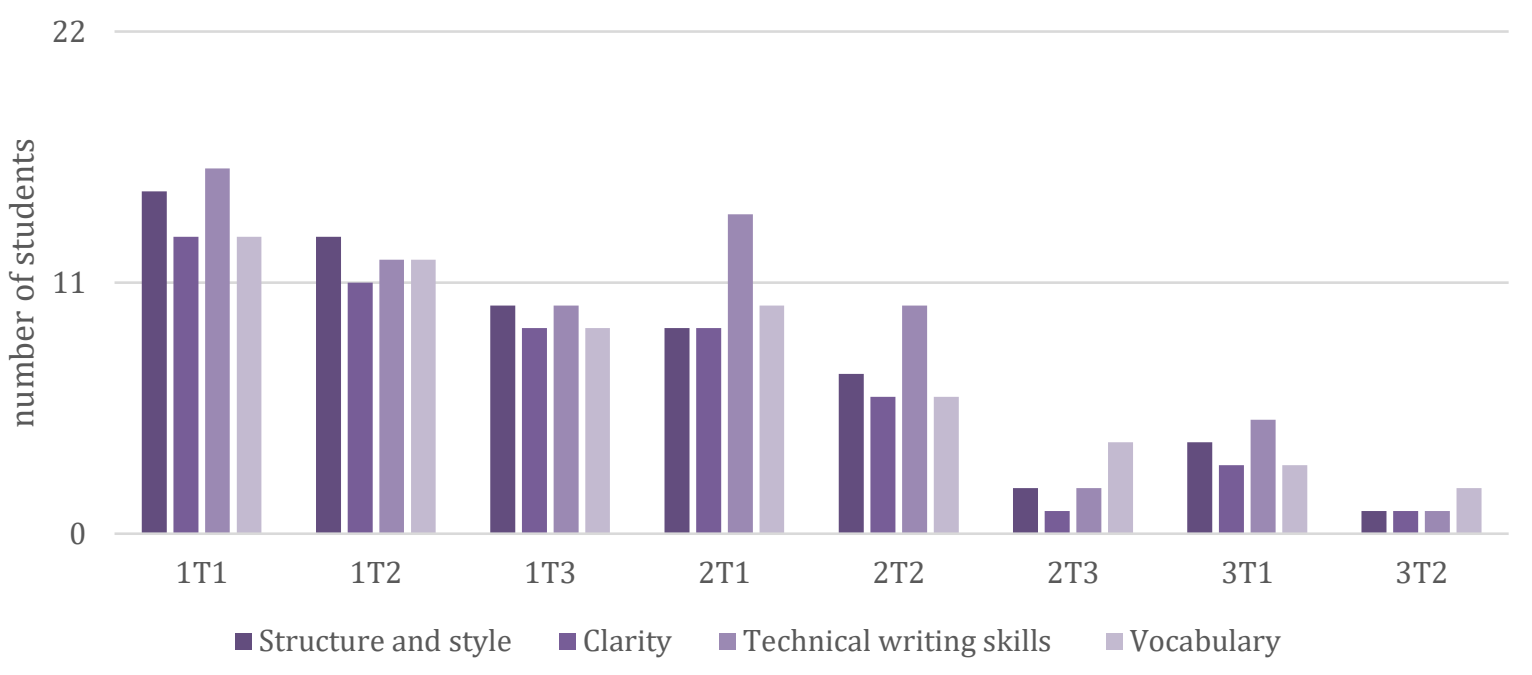

Figure 4.12 Students' difficulties perceived by the teacher

\subsubsection{Writing task two}

Eleven students' overall scores decreased in 2T1 if compared with 1T3, as shown in Figure 4.13 (p. 159). This decrease matches the increase of difficulties in 2T1 shown in Figure 4.12 (p. 158). The main reason was that, in $1 T 3$, it was the third time they dealt with task one, and the latter was therefore refined, whereas $2 \mathrm{~T} 1$ was a first attempt at a new task. In other words, in 1T3, they had improved their piece of writing through correction of mistakes and the use of strategies from peers and themselves. The perception of the improvement had built up their motivation and self-confidence, which must have helped them as well. However, their self-confidence dropped in $2 \mathrm{~T} 1 \mathrm{R}$ when they realised that they still had many difficulties when writing about a new topic, which explains the increase of negative feelings (see Figure 4.10, p. 147). A group mentioned this problem in the group discussions after 2T1R: "When we worked on the same topic again and again, we learnt from our mistakes and corrected them, but when the topic has been changed, the same problems appear". As the topic was new, they had to find new arguments, which constituted the main difficulty they perceived in $2 \mathrm{~T} 1 \mathrm{R}$ (see Figure 4.1, p. 116). The focus on arguments resulted in a decrease of attention in technical writing skills (grammar, spelling, and punctuation) especially, but also in the other areas (see Figure 4.12, p. 158).

As in task one, task repetition, group discussions, and teacher's feedback helped the students refine and improve their writing in $2 \mathrm{~T} 2$ and $2 \mathrm{~T} 3$ (see Figure 4.12, p. 158). In 
addition to correcting grammar mistakes, they looked for more arguments, and better ways to express, to develop, and to organize these arguments. They also eliminated irrelevant ideas. The combination of these content-focussed strategies improved the structure and the clarity of their writing. To take an example of improvement, in 2T1, eight students had problems related to ideas (five needed to develop their ideas, and three included irrelevant ideas). In $2 \mathrm{~T} 2$ and $2 \mathrm{~T} 3$, only one student still had irrelevant ideas, and two did not develop their ideas sufficiently.

\section{$1 \mathrm{~T} 3$ and $2 \mathrm{~T} 1$ scores}

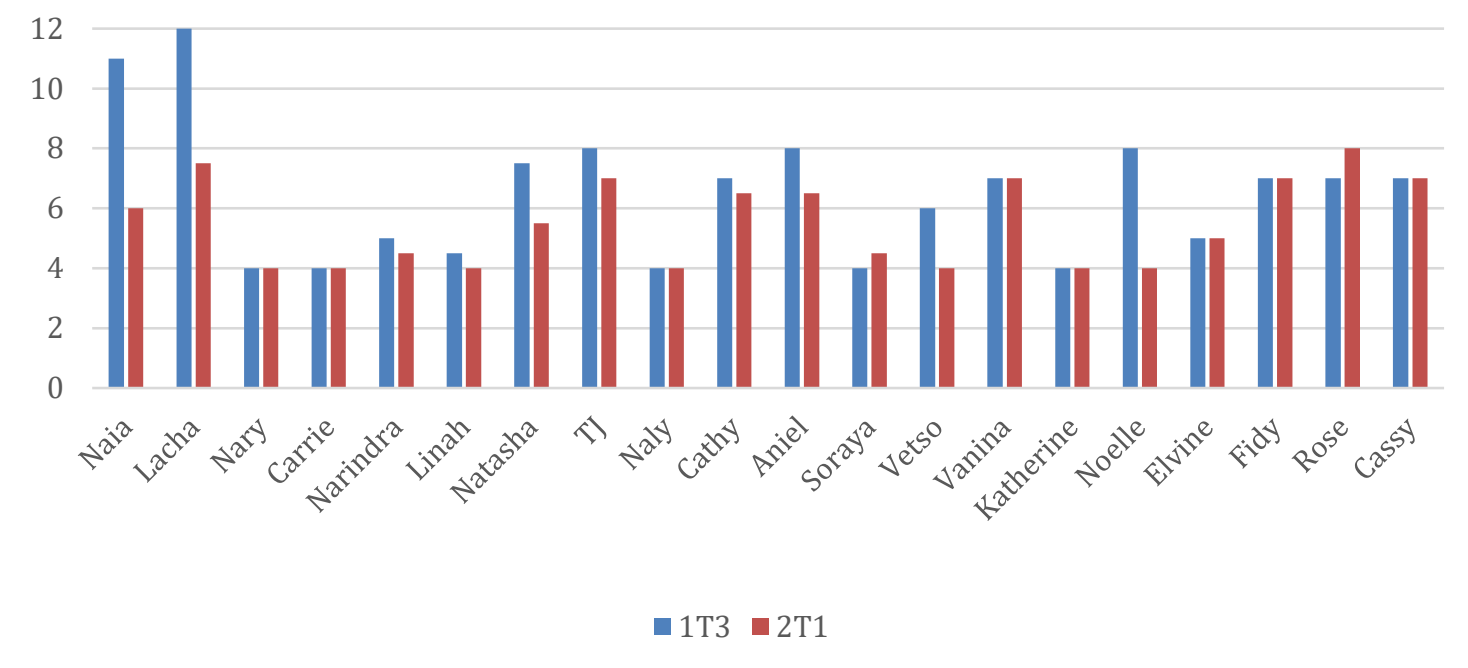

Figure 4.13 Comparison of $1 \mathrm{~T} 3$ and $2 \mathrm{~T} 1$ scores (out of 12)

\subsubsection{Writing task three}

When doing task three for the first time (3T1), the students had the same problem as they had had in $2 \mathrm{~T} 1$, probably due to the same reason. As the topic was new, they had to come up with all the writing components, such as appropriate and convincing ideas, vocabulary to express these ideas, writing structure and grammar. Consequently, the scores of fifteen students dropped in 3T1, as shown in Figure 4.14 (next page). This might suggest that more students had difficulty with $3 T 1$ than $2 T 1$. However, if compared to Figure 4.13 (p. 159), Figure 4.14 shows a general increase in scores. Also, the number of students having difficulty in writing in general in 3T1 is much lower than in 2T1. Only five students had major problems with technical writing skills, mainly grammar and punctuation, and four of them had problems with paragraph structure, incoherence, and lack of audience awareness. 
Three of them had difficulty with relevance of information and used inappropriate words. Therefore, it can be said that the general decrease in the students' scores in 3T1 does not mean necessarily a regression as such. The newness of the task surely impacted their performances if compared with $2 \mathrm{~T} 3$, but generally, they managed to pay attention to the four writing aspects (which was not the case in $2 \mathrm{~T} 1$ when they dealt with task 2 for the first time).

In 3T2, only three students had major problems, which consisted of wrong word choice, irrelevant information, and grammar mistakes. This explains their low scores (see Figure 4.15 on the next page). The other students' writing pieces were not flawless (as demonstrated in the scores in Figure 4.15), but there was a noticeable improvement, if compared with their first writing.

\section{$2 \mathrm{~T} 3$ and $3 \mathrm{~T} 1$ scores}

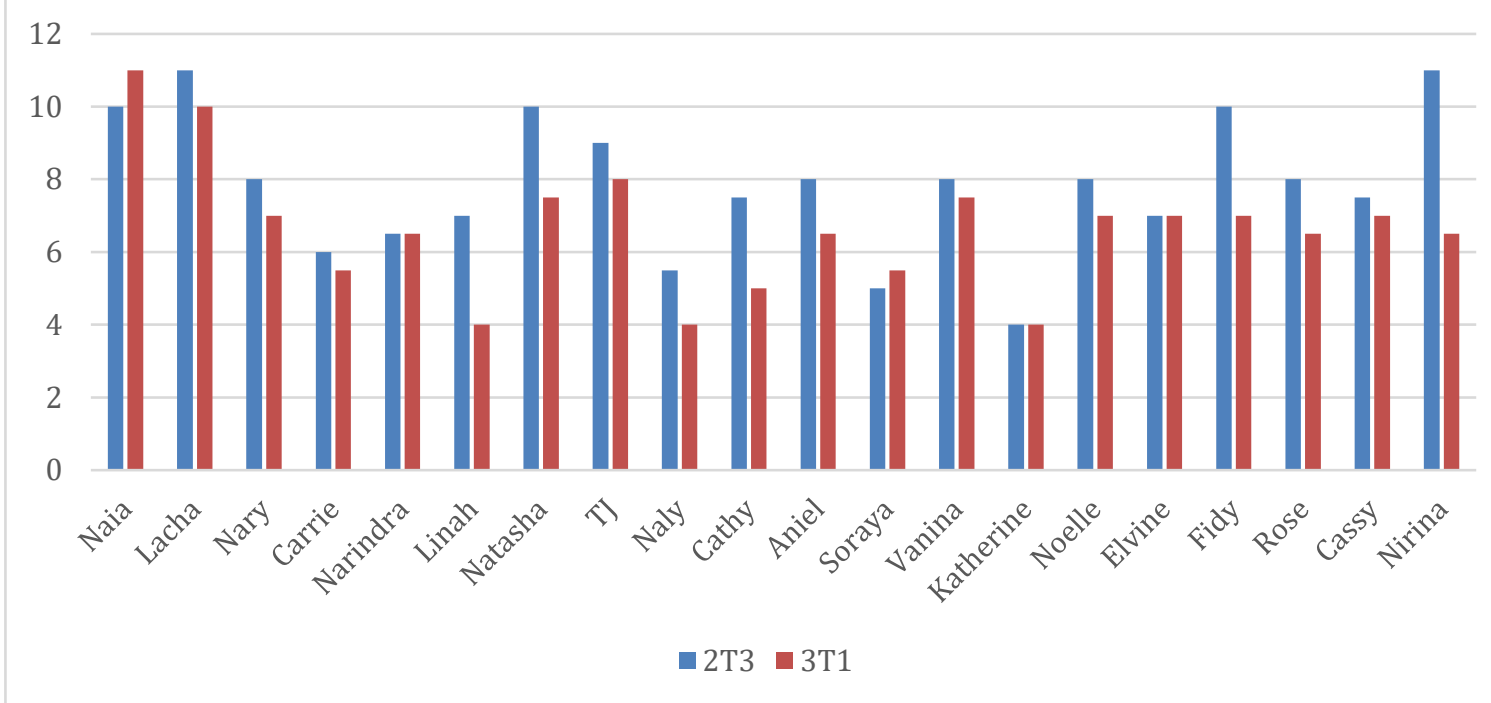

Figure 4.14 Comparison of $2 \mathrm{~T} 3$ and $3 \mathrm{~T} 1$ (out of 12) 


\section{T2 scores}

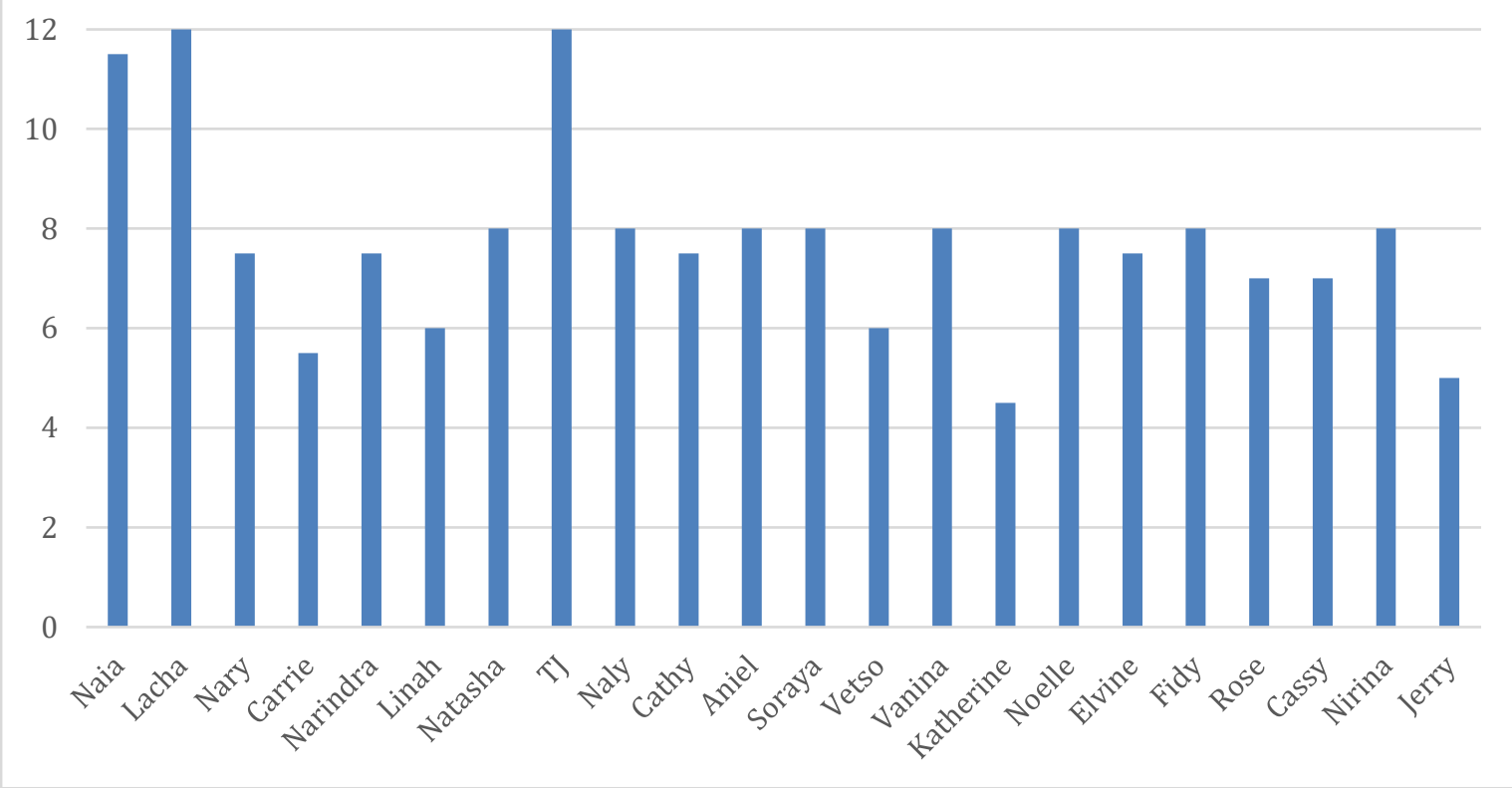

Figure 4.15 Students' scores in 3T2R (out of 12)

\subsubsection{Difficulties seen by the teacher versus improvement perceived by the students}

Though the students' perceptions of difficulty did not always match the teacher's perceptions of performance (see Figure 4.1, p. 116), it does not necessarily mean that the students did not self-evaluate correctly. Evaluating completed writing pieces for a teacher is not as difficult as self-evaluating is for a student. Firstly, students tended to notice difficulties that hinder their writing directly, such as those related to finding and expressing ideas (included in "clarity and conciseness") than other areas. Secondly, they had other aspects to deal with when writing, such as time management and focus, which were not noticeable by the teacher. Thirdly, due to time management or other reasons, the students may not have expressed all their difficulties.

On the other hand, Figure 4.16 (p. 163) shows that when the number of students having difficulty in a given area was high (as evaluated by the teacher) at a certain stage, the number of students perceiving improvement in that area is low. It was the case, for example, in $1 \mathrm{~T} 2$ in all areas, except clarity. Similarly, the lower the number of students having difficulty as seen by the teacher, the higher the number of students noticing improvement, for instance, in clarity in $2 \mathrm{~T} 2$, and in technical writing skills in $2 \mathrm{~T} 3$. Though such patterns were not always consistent in terms of numbers, they reveal some correspondence between the teacher's evaluation and the students' self-evaluation. This 
shows that students' self-evaluation can be accurate and effective. They were able to identify their areas of difficulties and improvement thanks to the reflection. 

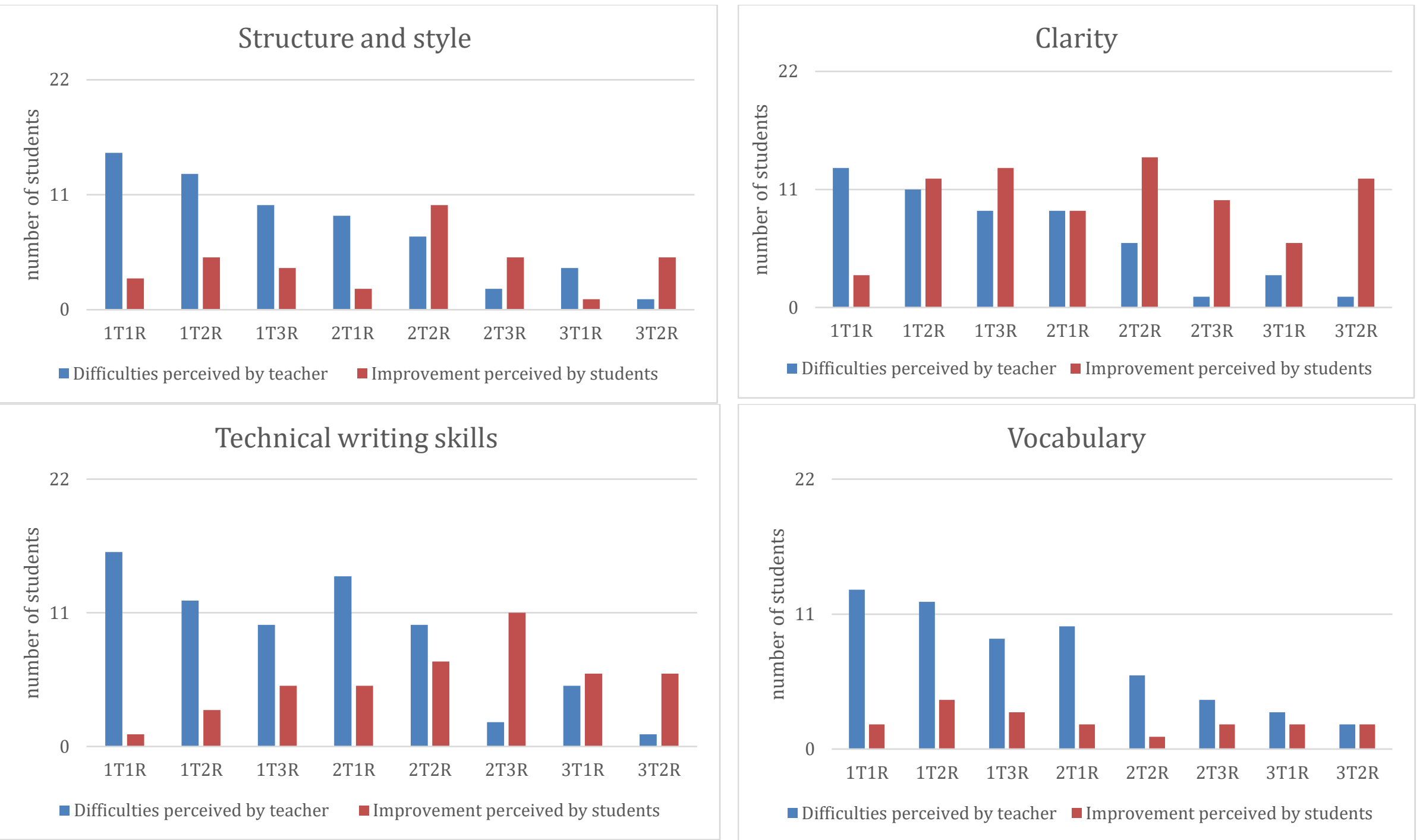

Figure 4.16 Comparison of difficulties perceived by the teacher and improvement perceived by the students 


\subsubsection{Summary of reflective learning and writing performance}

This section revealed that the students improved their general writing performance throughout the course. The task repetition surely contributed to the improvement, as their scores tended to increase when doing the same task for the second and third times, and to drop when doing a new task. This was logical and expected. However, the task repetition was not the only factor that led to the improvement. This was proved in 3T1, when the students did a new task. Although their scores dropped in general, they did not struggle too much with finding the right vocabulary, or with other issues, such as time management any longer (see Figure 4.1, p. 116). With practice, writing became easier. The other reason, which can be related to practice as well, is the reflective learning, encompassing their own reflections while monitoring and self-evaluating, accompanied by the teacher's feedback and the exchange of strategies with peers. Reflective learning was highly likely to play a considerable part in the improvement of their writing performances, as it drew their attention on their difficulties, drove them to look for strategies, and enabled them to pay more attention to the four aspects of writing. The improvement of the students' writing performance as measured by the teacher showed some correspondence with the teacher's evaluation and the students' self-evaluation, thus indicating an ability in the learners to determine areas of weakness and strength.

\subsubsection{Potential impacts on future teaching}

The goals of this study were to help the student teachers develop their self-regulation skills, and to enable them to see the benefits of such a development on their writing and learning in general. The next goal was to enable them, having realised such benefits, to reflect on the possible implementation of reflective learning (or some aspects of it) in their future teaching. Thus, the last two reflections on the course (2RonC and 3RonC) included a prompt asking them to think about such implementation. The students suggested the use of reflection in general, but also some specific aspects such as goal setting, self-evaluation, and peer collaboration. In addition to aspects of reflective learning, they recommended writing practice opportunities, explicit teaching, and some assets teachers should have. Their suggestions are presented in Figure 4.17 (p. 165).

It is worth pointing out that the students did not discuss the reflection prompts in groups before the reflections on the course (which was also the case for the reflections on tasks). 
Thus, their answers to the prompts were their own, and were not influenced by any opinions of their peers. Each of the types of implementation is discussed in the following sections.

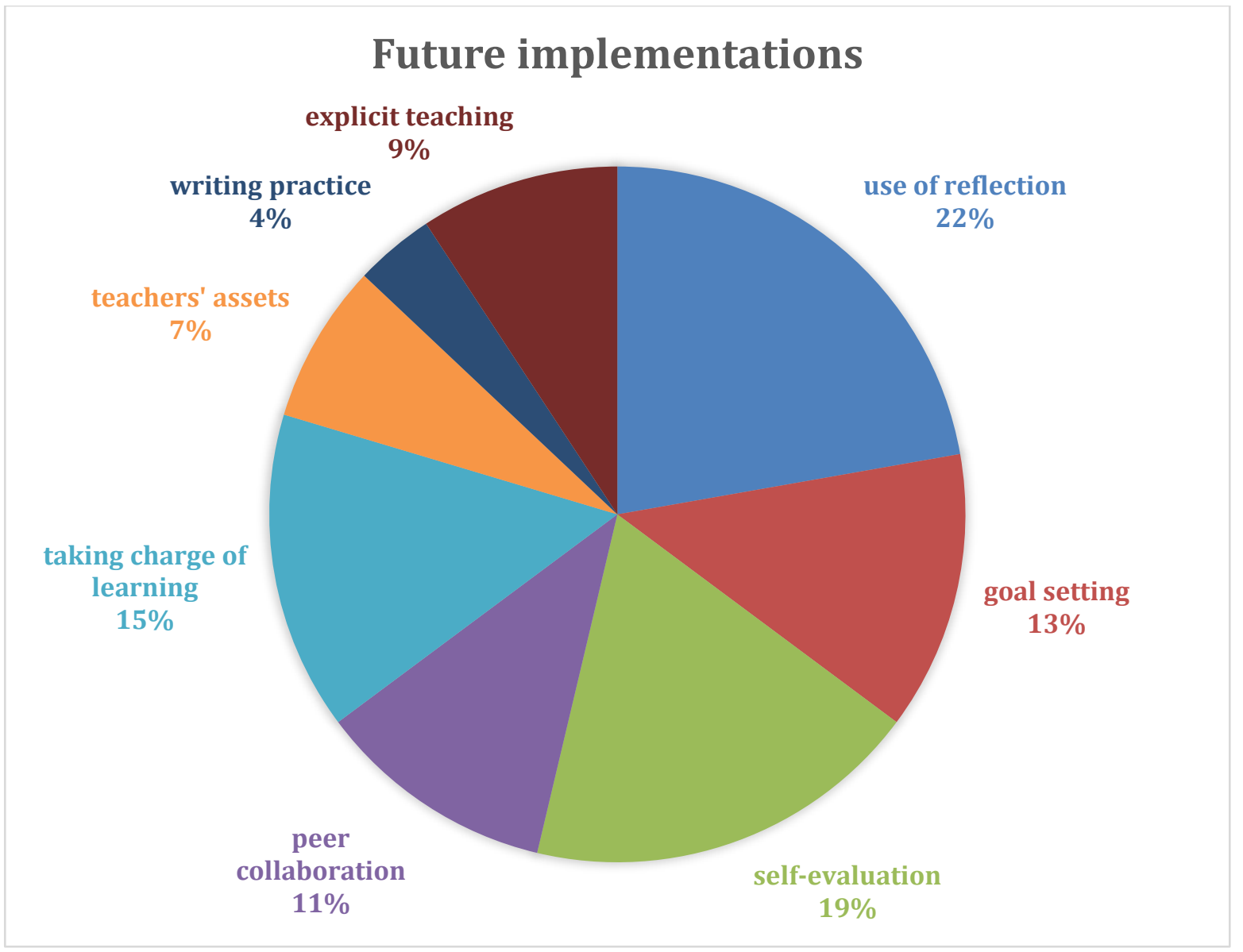

Figure 4.17 Implementations in students' own future classes

\subsubsection{Use of reflection}

The usefulness of reflection (in journals) in their writing and learning in general triggered the intention of twelve students to use it in their future classes. According to them, reflection was useful because it enabled them to identify goals and difficulties, and to respond strategically to these difficulties:

To my future students, l'd make them use a reflective journal as well. That would be the first thing, since it really helps. (TJ, 3RonC)

I will teach them that it is a good idea to reflect before writing an essay because it really helps situating the difficulties and finding solutions. (Narindra, 3RonC)

If I were a (writing) teacher, I would incite my students to write journals because it is very helping, especially in identifying the goals. (Aniel, 2RonC) 
In fact, four of these students used, or planned to use journal writing for their learning in other subjects or for other types of writing outside class:

I could use [the reflective journal] as the lead of my work, not only when doing the writing task here but it helps me [with] my personal writing at home. (Natasha, 2RonC)

I think [journal writing] should be used in every subject. Every teacher should recognize its importance. (TJ, 3RonC)

\subsubsection{Taking charge of their own learning}

The reflection raised the students' awareness of the importance of responsibility towards their learning. They became aware that they should find solutions to their own problems, enlarge their knowledge, pay attention to details, in other words, do their best to improve their writing by themselves. Eight students stated the necessity to give their students opportunities to take charge of their learning regarding writing:

Lessons that I can draw from the course are that when student[s] do writing, they should know how to organize ideas and paragraph[s]. Students should pay attention to every word they write such as their grammar, vocabulary, sentence structure. (Vetso, 2RonC)

I have learned that before we do something we have to set a goal, have a good plan and aware of difficulties and mistakes and must come up with solutions. (Soraya, 3RonC)

The reflective journal [...] makes students aware of their weakness and their strength, and that help[s] them to react and to improve themselves regarding their strength and weakness. (Fidy, 3RonC)

What I can draw from this course is that, self-teaching is really necessary. You can learn many things by yourself and not rely too much on others. (Nirina, 2RonC)

\subsubsection{Goal setting and self-evaluation}

Convinced about the importance of goals, seven students expressed their intention to encourage their students to set goals when writing:

I would suggest my students [...] have goal each time they do something 
because their goals will motivate them. (Elvine, 3RonC)

I plan to make my students understand that writing is not to be done without goal. (Fidy, 2RonC)

I can implement with my future student that we learn from our mistakes to improvement and even [...] when we do writing we must set a goal.

(Soraya, 3RonC)

Ten students considered self-correction and identifying mistakes in particular as an important practice they would like to implement in their future classes:

I think that the lesson is that with effort and learning, students can progress and correct themselves when doing exercise or similar task so that they can evaluate if there is improvement or not. (Carrie, 2RonC) [...] let the student [correct] their own mistake because it is the best way to be perfect [...] (Noelle, 2RonC)

[...] it is essential to know one's difficulty in order to correct oneself. (Rose, 2RonC)

With my future students, I will try to help them to look at what was wrong with their writing and to correct it by themselves. (Carrie, 3RonC)

\subsubsection{Peer collaboration}

Peer collaboration was greatly appreciated by the students. The exchange, the help, and the positive interpersonal relation they gained through peer collaboration motivated six of them to intend to use it in their future classes:

I can apply also the group discussion with my future students to help them understand how we can trust in one another when having difficulties. (Fidy, 3RonC)

I would [...] make them work in group; it helps a lot and it allows them to share their knowledge and their ways of working. (TJ, 2RonC)

With my future students, l'll make them do many group discussions so that they will progress their knowledge and to help each other. (Noelle, 3RonC) 


\subsubsection{Teacher's qualities}

Apart from the aspects of reflective learning enumerated above, four students emphasised qualities that a teacher should have. These qualities encompassed kindness, understanding, and the ability to listen to students. These observations by the students are worth noting because they have an affective impact on students, as shown earlier by Cathy's statement (see section 4.3.2.2.3, p. 142), and therefore on the practice of self-regulation.

Another quality that one student would like teachers to have was patience. Her reflective learning experience made her realise that improvement could happen, but did gradually: "From this course, I [learned that] we need a big patience when teaching and waiting for the students' improvement" (Natasha, 2RonC).

\subsubsection{Writing practice and explicit teaching}

The reflection and the writing practice enabled the students to understand that, firstly, frequent writing tasks helped them to solve their own writing problems, and thus, to improve their writing skills. Secondly, they allowed the students to understand that writing does not only involve building sentences and paragraphs:

I plan to make my students understand that writing is not to be done without goal; nor it is a matter of just combining words to become sentences, then sentences to be[come] paragraphs; nor it is a matter of challenging with the number of words which are recommended. I want to imitate this method of writing that my writing teacher exerces me to apply. (Fidy, 2RonC)

I will teach them that doing a writing task is not just thinking about the topic, but doing a writing task is also thinking about a plan which helps you to write easily and taking care the grammar." (Linah, 3RonC)

Five students expressed their intention to teach writing in an explicit way. They would like to teach what an essay is composed of, and what each part of the essay should encompass. Their intention may reflect their difficulties and their need of more guidance: "If I were a (writing) teacher, I would give a lesson about how to build an attractive introduction and conclusion, then, the best way to [put] ideas in order" (Narindra, 2RonC). 


\subsubsection{Summary of potential impacts on future teaching}

The student teachers were in their first trimester, in which they do not normally have courses related to teaching yet. Therefore, they were not yet familiar with any theories about teaching approaches and methods. The only teaching methods they knew were the ones used by their teachers in primary and secondary school. A goal of this study was to start their teacher training by drawing their attention to their own experience throughout the course in order for them to reflect on what they will do in their future teaching. The students expressed their intentions to use reflective learning or some aspects of it that they considered useful, such as goal setting, self-evaluation, and peer collaboration. They also mentioned the importance of nurturing students' sense of responsibility, and of providing students with frequent writing practice. Some of them also talked about explicit teaching and certain traits teachers should have, such as patience and understanding.

\subsubsection{Summary of chapter 4}

This study focused on the development of student teachers' self-regulation by means of reflection. The study tried to capture the process and the dynamic of movement regarding this development over the nine-week period. Thus, it emphasised the impact of reflection on self-regulation skills and the way the students approached writing. As students became better at self-regulated learning, their writing improved. They also became aware of the importance of fostering strategic learner behaviour in their future roles.

A key word which can summarize this study is "awareness", as the study raised the students' awareness of their responsibilities for their learning, and of their abilities to improve their writing (and learning in general) with limited help from the teacher. The different foci of awareness (awareness of language, self-awareness, awareness of learning goals, awareness of learning strategies) required for the students to be able to take control over their learning (Porto, 2007) seem to have developed, and with them, their selfregulation. Firstly, by trying to understand the nature of their mistakes before correcting them, and by seeking solutions to solve their problems, the students became more aware of how English works. Secondly, by monitoring and self-evaluating, they came to notice their attitudes towards writing and English in general, which were part of their self-awareness. Through their encounters with their difficulties and their improvement, they became aware of their feelings, which fluctuated. Positive feelings became the drive to work towards more progress and to attain goals, but negative feelings also pushed them to look for solutions, 
and therefore, to develop strategic behaviour. Thus, the awareness of difficulties and of improvement triggered the awareness of learning goals and learning strategies.

Along with reflection, task repetition helped the students improve their writing in a way that enabled them to notice and correct their mistakes, and also to perceive their improvement. It may be logical that task repetition results in refinement and improvement, as the students became familiar with the topics, which explains the increase of the students' scores each time they repeat the tasks, and the drop of scores in 2T1 and 3T1. Nevertheless, the improvement the students made throughout the course was not only due to the familiarity with the topic resulting from the task repetition. The improvement also stemmed from the writing practice, the habit of paying more attention to details, the feedback from the teacher and peers, the positive affect emanating from the awareness of the capability to improve, and the awareness of responsibility towards learning. Though the improvement was not outstanding for each student, it can be said that the combination of these factors had affected positively the way the students dealt with writing. Also, learning from one task was transferred in part to the next task, even though performance dropped when starting a new task.

The last section of this chapter demonstrated that reflective learning influenced not only the students' learning. It also impacted their perception of what teaching should involve. They understood that students should take charge of their own learning. This understanding triggered their intention to use reflective learning or some aspects of it with their future students.

The next chapter gives more insights into reflective learning. It gives an in-depth look on the impact of reflective learning on the development of self-regulation and on writing performances by focusing on two particular cases. 


\section{Phase two - case studies}

The previous chapter demonstrated the impact of reflective learning on the student teachers' self-regulation in the process of writing and on their writing performance. It showed that all the student teachers had developed their self-regulation skills, though the degree of development differed from one student to another. It also revealed different levels of improvement in their writing, and provoked ideas on what aspects of their reflective learning experience they would like to implement in their future teaching. However, as that chapter focused on the cohort study, it relied mainly on results from the coding and tallying of the data from the reflections of all the 22 student teachers'. Therefore, it did not allow a more comprehensive study of the processes by which the self-regulation skills evolved, and their writing improved. A more comprehensive study in the form of two case studies is presented in this chapter.

\subsection{Methodology}

\subsubsection{Research method and research goals}

In order to illustrate in detail how self-regulation and writing developed through the reflective learning course, this chapter takes a case study approach and reports on the findings from two the 22 student teachers discussed in the previous chapter. Case study research is said to "provide a concrete illustration of findings" (Chapelle \& Duff, 2003, p. 164) because it focuses on process, and therefore, enables deep insights into the students' behaviours, feelings, intentions, perceptions, and interpretations of their actions (Gillham, 2000; Woodside, 2010). Concentrating on a small number of participants, case study research generates in-depth examination, contextualization, and also singularity and particularity (Duff, 2008). Therefore, it allows the dynamism and the connections of behaviours, performance, and perspectives to unfold, which can be hidden when analysing larger data. By doing so, it sheds lights on the impact of the learning development on the learners (Duff, 2012). Though the focus is on particularity, the findings can "then yield insights of potentially wider relevance and theoretical significance" (Duff, 2012, p. 96).

This chapter addresses the same research questions as the previous chapter, but with the focus on the two students. It aims to look at:

- how reflective learning helped these two participants develop their self-regulation skills - in goal setting, monitoring, and self-evaluation. Included in this is a closer look 
at how their affect changed over time when dealing with the writing tasks, and how that change impacted their self-regulation and writing, and vice versa. This also encompasses how they responded strategically to their difficulties.

- how reflective learning and the development of the self-regulation skills impacted the quality of their writing.

- what implications on their future teaching they see as a result of their reflective learning experience.

\subsubsection{The two participants}

A recommended option to choose participants in case studies is to sample extreme cases (Duff, 2012). For this research, the two students, who will be called Naia and Katherine, were extreme cases among the cohort regarding the development of self-regulation and the improvement of writing. While Naia demonstrated a growth of self-regulation in her reflection, along with improvement in her writing performance, Katherine showed very little improvement regarding both self-regulation and writing performance. Like most of the other students, both had just graduated from senior secondary school, and had studied English (as a school subject) for seven years. Again, it is worth mentioning that in spite of the seven years' study, students' English proficiency is pre-intermediate or lower most of the time.

Apart from being an extreme case, Naia was selected, partly because she stated her lack of confidence and her difficulty with writing at the beginning of the course, which she recalled in her last reflection on the course:

I did not like writing, and I did not know how to translate some French words in English. [...] It took a long time [for me] to think [...] about what I am going to write about the topic. [...] I felt frustrated because I just [knew] few grammar rules, and I was not used to writing in English. (3R on C)

That was how she felt while doing the first writing in class. Nonetheless, she showed readiness to explore the "reflection approach" and to make the most of it for all her learning the very first day of class by asking if the approach could be used to improve other language skills as well (after the introduction and the explanation of the objectives of the course on the first day of class). Equipped with such readiness and willingness, Naia started to "regulate" her writing by answering the reflection prompts. By doing so, she seemed to understand the importance of self-regulation and the responsibility for her own learning. Naia's case is a demonstration that self-regulation can develop through reflection. 
On the other hand, Katherine was chosen because she was relatively weak in writing if compared with the others, and in terms of self-regulation throughout the course. Despite her weaknesses, she demonstrated optimism regarding the improvement of her writing. However, unlike Naia, her monitoring and self-evaluation skills did not develop sufficiently to enable her to identify her difficulties and to seek strategies, thus hindering her progress. Katherine is a case that shows that, like any pedagogical tool, reflection cannot always be 'successful' in helping learners develop self-regulation skills. Her case has led to more reflection on the implications for teaching, that is, on what should be done to help learners make the most of the reflection work or, more precisely, to help them reflect more effectively.

\subsubsection{Reflective learning course}

Both students did the same writing tasks and reflection work as the other students in the reflective learning course: three writing tasks (200-word argumentative essays) over nine weeks (task 1 and task 2 three times, and task 3 twice) along with journal reflections triggered by answering pre-task, during-task, and post-task prompts. Apart from these reflections on tasks, they also wrote reflections on the course (or reflections on reflection), every three weeks, and short reflections on what they had learned in group discussions (mainly after $1 T 1 R$ and $2 T 1 R$ ). All the writing tasks and the journal entries were included in their respective portfolios. The course structure is presented in Table 4.1 (p. 98).

The two students took part in every group discussion, in which they shared their reflective experience, their problems with writing, their ideas and strategies. They never belonged to the same group in those discussions.

Like the rest of the cohort, the two students received feedback from me (the teacher) for each writing piece they had produced. The feedback encompassed underlined mistakes, some remarks (mainly about recurrent mistakes), and encouragement.

\subsubsection{Data analysis}

The data collected for the case studies are composed of the portfolios of the two students, which contained their writing tasks and journal entries described earlier. Like in the previous chapter, each piece of reflection was pre-coded according to the student's name, the writing task and/or the reflection. The type of pre-coding is in Table 4.2 (p. 105). 
The focus on cases implies more qualitative than quantitative data analysis, though grading the writing tasks by using a rubric (see Table 4.3, p. 107) was also part of the analysis. The grades were, indeed, used to gauge the improvement of the two students' writing performances through reflective learning. However, they were not the only factors that were taken into consideration for that purpose. For each writing task, the goals set and their attainment (or not) according to the students and the teacher (myself) were important factors determining improvement regarding the quality of the writing. Solely using the rubric may overlook any particular progress the students had aimed for and achieved. Thus, each writing piece was scrutinised along with the goals and the strategies used to attain the goals.

As with the cohort data, a thematic approach involving NVivo coding was used to analyse each journal entry. Themes were extracted, reviewed, reorganised and compiled. Nevertheless, more time was spent on data reading and re-reading as well as noting down ideas while comparing, which are part of what Braun and Clarke (2006) refer to as familiarisation with data. Apart from familiarisation at the beginning, these were used through the analysis to capture the dynamism involving different aspects such as the students' perspectives, affect, and decisions. In other words, much more focus was placed on the process, the evolution, the connections between these aspects, and the conditions under which these aspects emerged.

\subsection{Naia}

\subsubsection{Developing self-regulation}

This section describes how Naia's self-regulation developed throughout the nine weeks. It discusses how her awareness of difficulties, triggered by her developing monitoring and selfevaluation skills, enabled her to set specific goals and to do her best to attain these goals by responding strategically to her difficulties. Her development of self-regulation can be presented in a cyclical pattern (see Figure 5.1, p. 175). Affect, which is a component of selfregulation (Zimmerman, 2000), is located in the middle of the circle because of its importance. Naia's affect impacted the development of the other components of selfregulation, and her attitudes towards writing and learning in general. 


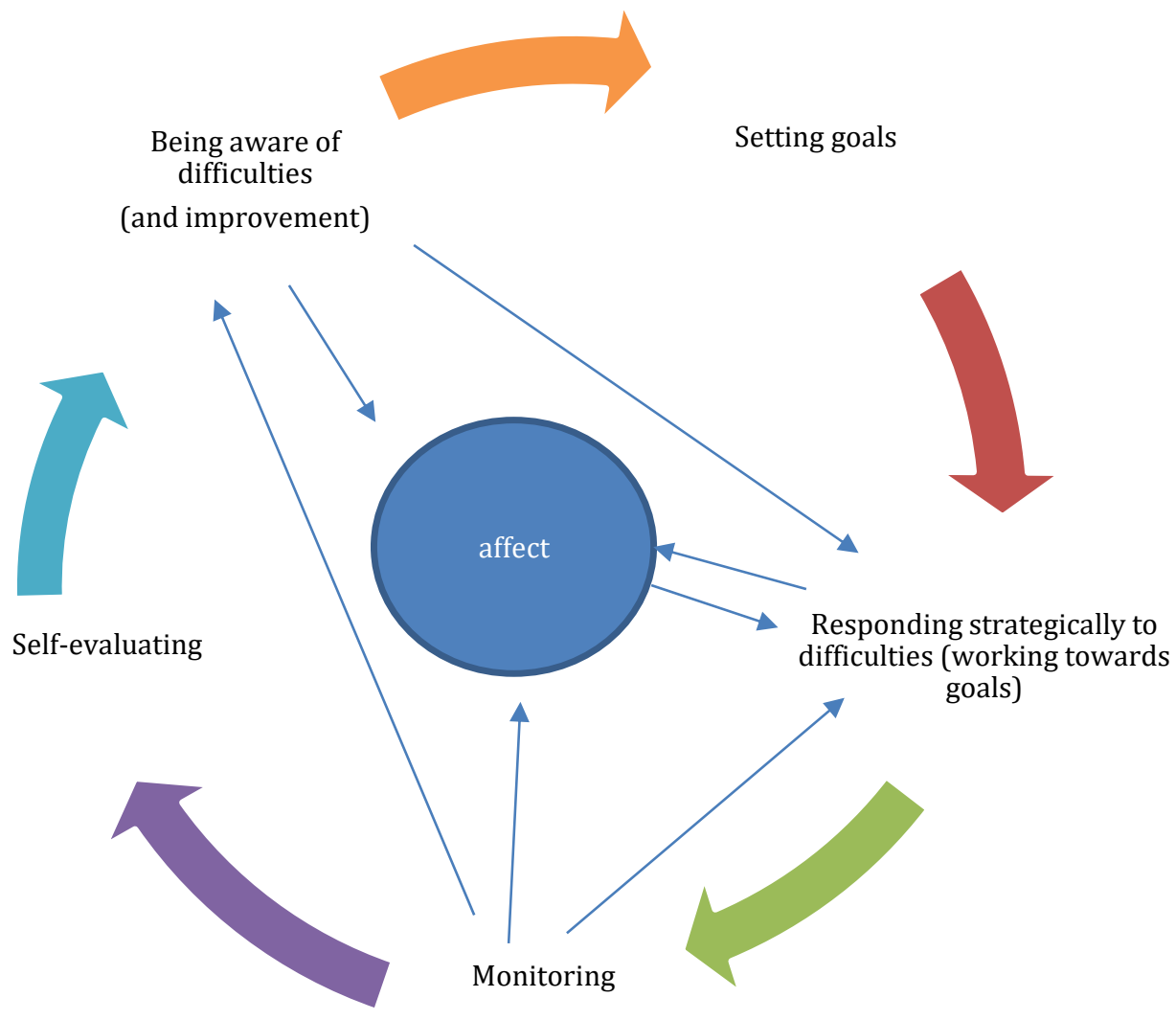

Figure 5.1 Naia's cyclical pattern

\subsubsection{Being aware of difficulties}

Through monitoring, Naia demonstrated her awareness of her difficulties from the first task and first reflection. In 1T1R, she felt and expressed her lack of confidence, her frustration, and her worries about not having enough time to finish her task and to proofread, which would lead to misspellings and grammar mistakes. She also stated her difficulty with organisation of ideas and English vocabulary. Because of the realisation of these problems, she was able to conclude that she needed to manage time better, to be more careful so as not to make spelling and grammar mistakes, to be more self-confident, to improve her writing style, to find adequate vocabulary to better express and organise her ideas. Thus, she turned these necessities into goals for the next two pieces of writing.

What distinguished Naia from the other students was her clear ideas about what her difficulties were, and therefore, what aspects of writing/language to work on. For example, in $2 \mathrm{~T} 2 \mathrm{R}$, she realised that she should work more on relative pronouns and the use of punctuation. In $3 \mathrm{~T} 2 \mathrm{R}$, she stated she needed to learn more about subordinators: "I learn that 
I need to learn about complex sentences using of "conjunctions of subordination" like "as" because I do not know to use them". Such awareness of weaknesses is one of the first steps towards self-regulation and autonomy (Porto, 2007). It is this awareness, triggered by doing the writing task, by reflection, and by the teacher's feedback (the underlined mistakes mainly) that pushed her into thinking about goals. In fact, she transformed these specific weaknesses into goals to achieve. Thus, the connection between difficulties/weaknesses and goals is clear, as far as Naia is concerned. This connection is further explained in the next section below.

\subsubsection{Setting goals}

Naia's goals for her first writing task (in 1T1R) were broad: "My goals regarding this writing task are many. Firstly, I want it be a success when I will finish doing it. Secondly, I plan to make it really attractive for the readers." Despite the lack of precision, her second goal shows audience awareness, and this was perceived through the language she used in her writing, which will be described further later in this chapter.

From the second reflection on, her goals were related to her difficulties. These goals were person-related as well as task-related. In the second reflection on the first task (1T2R), she decided to focus her goals on improving sentence structure and grammar in general. This shift was on account of her difficulties in 1T1R, of the feedback from the teacher (the underlined mistakes) and of what she had learned from the first group discussion. In the third reflection (1T3R), her goals were to manage time, to improve grammar, and to have other "smart" ideas. She chose these goals in that she recognized that she had not yet succeeded in managing her time yet, and that she still made a few grammar mistakes in the previous writing, but being persuaded that her writing would improve if she had better ideas.

Naia's first goals for the second writing task (2T1R) focused on improving spelling and specific grammar points: not to make mistakes on singular versus plural and the use of articles. She kept the same goals in $2 \mathrm{~T} 2 \mathrm{R}$ and $2 \mathrm{~T} 3 \mathrm{R}$ because she did not attain them in $2 \mathrm{~T} 1 \mathrm{R}$ : “[...] the same as my preceding goals because I did not attain my goals. I [won't] change my goals until I attain them and I improve on [them]". This statement shows not only her considerable awareness of the goals that she set, but also her persistence and determination to reach them. In 3T1R, Naia's goals were to improve grammar, sentence structure, and 
paragraphing. In $3 \mathrm{~T} 2 \mathrm{R}$, she still aimed to improve her grammar by correcting the mistakes she had made in $3 T 1 R$, and to add some "strengthening" words in her writing.

It can be concluded that due to reflective learning, Naia was aware of the importance of setting goals, which is a huge step in self-regulation development. From 1T2R, though her goals were mainly grammar-oriented, they were related to what she considered as difficulties in her previous writing. She did take her goals very seriously and she seemed to embrace the challenge of trying to attain them. Though sometimes she felt disappointed that she did not reach them, she did not give up on them. She was constantly seeking strategies to reach her goals. After each task, she gauged carefully whether her goals had been attained or not. To take an example, in 3T1R, she stated, "I think yes [I attained my goals] about paragraphing, but I hesitate a little bit about the grammar and sentence structure". She also showed such awareness of goals in her reflection on the course: "I think, I attained the goal to convince the reader and having self-confidence, but I need to learn more grammar and practise reading, and learn how to make a good sentence structure" (1RonC). Then, when she noticed that her goals were attained, her aim was still towards more and more improvement. Thus it could be said that she had a strong goal orientation which contributed to her self-regulation: she did set her own goals according to her learning needs.

\subsubsection{Responding strategically to difficulties}

The identification of difficulties, turned into goals, pushed Naia to continuously look for solutions, both instantly (during the task, while a problem appeared) and later (on her own and during the group discussions). She further expressed her realisation of the importance of using strategies while writing:

The reflective journal [...] helped me to remember all my weaknesses because they were [written] down, like thatl try to improve and to find solutions [to] my problems and obstacles. Also it helps me to have strategies while writing, before I just did writing like I felt, now I know everything should be learnt and if I want to be really good I should have some tips to fight against hindrances when writing. The group discussions help to think about my problems as well, and to get solutions from my classmates who have already experienced them and share them to me, I find that really helpful. (1RonC) 
Throughout the nine weeks, the reflective learning course induced Naia to set goals according to her learning needs, to monitor her writing by keeping track of her progress, and to evaluate her own writing, which are all strategies in themselves. However, from the beginning (1T1R), she demonstrated knowledge of other strategies, such as organising the plan of her writing in a draft, collecting all the ideas related to the topic, proofreading, then, editing by correcting misspellings and grammar mistakes, and changing irrelevant sentences. Another strategy she used in 1T1R was taking risks. Though she was not certain about the relevance of her ideas, she "took the risk" of writing them down. This strategy may be considered as a compensatory strategy (Oxford, 2002, 2003b) or cover strategy (Cohen \& Weaver, 1998), which attempts to fill the gaps in the knowledge of the target language by pretending, oversimplifying, or using what one knows even though it might not be appropriate. Once she used this strategy, many "smart ideas" came along, which shows that the strategy worked to some extent.

The clear identification of difficulties thanks to the reflective journal (stated in 2RonC) helped Naia strategically respond to them and build persistence. In $1 T 2 R$, for instance, to solve her time management problem in the previous writing, she came up with the strategy of not using drafts, and directly doing the writing on the writing paper. The strategy did work because she managed her time better and therefore finished her writing the way she had planned to. However, she adjusted that strategy later (from 2T1R on) when she realised that she needed drafts to better organise her ideas: "Arranging paragraphs needs draft. I write in a draft some ideas, then I arrange them in order not to repeat the same ideas to put them in order" (3T1R).

In response to her lack of self-confidence, Naia came up with an original strategy in 1T3R, which can be considered as affective: "I try to be in the place of a magazine writer, like that, just to be at ease to write, and to be more confident." In 2T1R and 2T2R, regarding her specific difficulties about finding vocabulary, time management, organisation, spelling and grammar, she found the following specific strategies:

For spelling, I rewrite [the word] in a draft to see if it is like that that it is spelled. (2T1R)

If [there was] some lack of vocabulary, skip it, I didn't focus on problems, I made blanks and carry on writing then after, I remembered them automatically, but when I could not remember, I changed them another word. That helped me [a lot] to manage time. I also thought before writing, 
really took care what I am writing to avoid stupid and disorganized sentence. I wrote in a draft the complex sentences in order to check and see if [they were] logical or not, then I change if they are not. I took note all confusing words or grammar rule, then I was trying to remember if I have already known about them before or if they were already corrected during my preceding writing. It was helpful also to see the list of mistakes I had before [in order] not to make them again; like that, I am reassured that I improve. $(2 \mathrm{~T} 2 \mathrm{R})$

Her description shows that the strategies she used involved looking back at her previous writings. Doing so enabled her not only to avoid making the same mistakes but also to compare her pieces of writing, and then to evaluate her own progress.

After the group discussion after 2T1R, in which the students were asked to discuss solutions to some selected difficulties, Naia recognised that there were still many points she should work on to master English. For each of these points, she came up with detailed strategies. For instance, to deal with difficulties with vocabulary, she wrote:

With problems of vocabulary or lack of vocabulary, I should anticipate, take one topic for example "education" or "health" or "discrimination", then I try to find all vocabulary or words related to it, like that, when I need to state or to assert about this topic, I have many things to say, also, it avoids nonsense words or French domination.

Another way too is to take one new word, and to find the noun of this word, the adjective related to it as much as possible. Ex: "to assert": verb / "assertion": noun. That mean[s], to know the part of speech.

To solve the problem of lacking ideas, her strategy was to make the few ideas she had stand out, by supporting them with strong arguments:

[...] when I don't have many ideas, I can express the few ideas that I have in the best way. I mean, I should have a better choice of word to make it more formal. I should not be focused on the lack of ideas, I just express them stronger even [though] they are not many. (reflection after the group discussion on $2 \mathrm{~T} 1 \mathrm{R})$

Correcting the underlined mistakes in the previous writing was a strategy to improve the next writing, and all the students did their best to do such corrections, on their own and/or 
using peer collaboration during group discussions. Naia tried to figure out the reasons why they were mistakes before correcting (stated in $2 \mathrm{~T} 2 \mathrm{R}$ ). Her strategy was to rewrite the mistakes and try "many possibilities to correct" them, then, to explain to herself why they were mistakes. This shows deeper reflection, with the aim of understanding the root of problems, instead of simply trying to solve them in the surface level.

In 3T1R, Naia's goals were to improve sentence structure and paragraphing. With these goals in mind, she used the following strategies: writing all the ideas related to the topic in a draft, then, organising them into different paragraphs, writing the introduction (including the general facts about the topic) directly on the writing paper, making sure to make a smooth transition between paragraphs, and finally, summarising all the ideas in the conclusion. She emphasised the significance of organising ideas in a draft so as not to repeat the same ideas. She also employed a new strategy to save time and not to lose her ideas: using a pencil to write the body of the writing, then, erasing the mistakes and writing the correct version with a pen afterwards.

Naia came up with the strategies cited above mostly on her own. In 2RonC (second reflection on the course), she mentioned that she gained more strategies from writing the reflective journals than from the group discussions. Nevertheless, she found the exchange of problems and solutions during group discussions helpful both for her and her group members. As they had more or less the same problems, finding the solutions together was not difficult. She suggested that the group discussions should be carried on outside class, as time in class is not enough to share all their problems. It can be said, then, that she also used social strategies (Cohen \& Weaver, 1998) through peer collaboration. She stated, however, that she was aware that she must solve some of her problems on her own, and it may take time to solve them completely. From these statements, Naia seems to recognise the importance of independence and interdependence in learning, which are both considered essential for the development of learner autonomy (Little, 2011).

Thinking strategically or matching strategies to goals/obstacles is an important feature of learner autonomy (Wenden, 1991). The impact of learning strategy instruction has been confirmed by literature and research on strategies (Cohen \& Weaver, 1998; Gu, 2019; McDonough, 1999; Nguyen \& Gu, 2013). In this study, strategies were not "taught" so much as fostered. In Naia's case, her awareness of the strategies she was using and of the necessity of looking for others increased through her planning, monitoring, and evaluating. 
This awareness of strategies and their use to respond to difficulties imply a growth of metacognition and/or self-regulation.

\subsubsection{Monitoring and self-evaluating}

Answering the reflection prompts helped Naia develop not only her goal setting ability, but also her monitoring and her self-evaluation abilities. Actually, her awareness of difficulties described earlier, to which she responded strategically, was the result of her monitoring and self-evaluation. She monitored her writing by observing and taking note of her difficulties while enumerating each step she was taking while doing the task. She also jotted down the strategies she was using as well as her affect, and how the latter changed overtime.

After each task, she evaluated her performance by noting down her scores, giving reasons for the scores, stating what she considered as improvement, and difficulties (what she should work on for the next writing and in general). What distinguished her from the other students was that she sometimes went beyond answering the prompts. She expressed herself more freely, especially when she started to treat her reflective journal as a confidant: "It was easy to express all my feelings and difficulties [in the journal], I felt like if I share my problems to someone who will try his best to help me, so I felt relieved from all my frustrations" (1RonC).

It can be concluded that from monitoring her writing task while it was in progress, Naia developed a better understanding of herself (Chu, 2007) or her self-knowledge. She became aware of her feelings and her writing steps. It is especially from the awareness that she was able to self-evaluate, as she discovered her difficulties, which she came to perceive in a detailed and precise way. The more detailed her awareness of difficulties (which she turned into goals) was, the better her strategic thinking became, as demonstrated in the examples of statements she gave. As well as noting her difficulties, she noticed her improvement and her changing affect.

\subsubsection{Being aware of improvement}

Reflection should enable learners to focus not only on their weaknesses, but also on their strengths (Chu, 2007). The reflective prompts did encourage Naia to observe her improvement in the quality of her writing and the way she dealt with writing, while monitoring and self-evaluating. 
Though Naia was not always able to identify what her improvement was at the beginning $(1 \mathrm{~T} 2 \mathrm{R})$, she was aware of the connection between the improvement in her writing, or the management of her writing, and the strategies she was using. For example, in 1T2R, she realised that she managed her time better thanks to the strategy consisting of writing directly without using a draft. Better time management enabled her to do proofreading, which helped her edit and revise her writing piece, and therefore, made it better than the previous one. She developed this habit of proofreading (stated in 3RonC), which, with some grammar rules learning (stated in $2 \mathrm{~T} 2 \mathrm{R}$ ), made her accustomed to identifying her own mistakes (the improvement she noticed in 3T1R): "I am rereading, and checking mistakes especially about definite or indefinite articles, and plural and singular. [...] I can find some mistakes easily compared to my preceding writings". As shown in the this statement, she was looking at specific mistakes, which had been present in her previous writings. This example clearly reveals her awareness of her problem, and the implementation of a strategy to solve the problem in order to improve. Indeed, she stated it herself that her mistakes helped her develop her self-evaluation skills: "before, my mistakes did not have much effect on me, but now, I evaluate myself related to them" (2RonC). Naia did make constant comparisons between her writing pieces to make sure improvement occurred (see her statement in $2 \mathrm{~T} 2 \mathrm{R}$ above).

Naia viewed having strategies as an improvement in itself. In 3RonC, when asked what her difficulties were at the beginning of the course, she mentioned the lack of strategies. Over time and responding to her difficulties, she accumulated different strategies as explained in the previous section.

In $1 T 3 R$ and 1 RonC, she noticed some progress and less difficulty regarding the expression of ideas. In $2 \mathrm{~T} 2 \mathrm{R}$, she felt that her writing was better organised, her introduction better "structured" and that she managed time better, and again, had time to proofread. In 3RonC, she pointed out her improvement regarding specific grammar points, paragraphing, translation and vocabulary.

Despite the improvement she made, she was aware of the necessity of the effort she should still make, thanks to reflection:

[The reflective journals] encourage me to learn more than I did, because they teach me that there [is] always something to improve in my English. They are like a portfolio, so I am able to [have] a look at them to remember what I did to deal with my difficulties, my feelings and why I feel like that. 
They record everything to be useful for the next [writing] I will write [...] (3RonC).

Naia's statements above, together with her statement that she had begun using a reflective journal in other courses (stated in 1RonC) because of its problem-solving principle, obviously demonstrate her comprehension of the objective of reflective learning. She understood the significance of being aware of problems in order to make progress. On the other hand, Naia also learned to appreciate the progress she had made, even though she was not completely satisfied with her writing performances. She was aware of her becoming more patient with herself and came to understand that progress was happening gradually. This can be viewed as an improvement given that she tended to be perfectionist: the highest score ( 6.75 out of 10 ) she gave was on her last piece of writing, for which she clearly stated that her goals had been attained. The improvement of her affect will be discussed further in the next section.

\subsubsection{Changing affect}

The improvement that Naia became aware of was not only in the quality of her writing but also in her affect. As shown in Figure 5.1 (p. 175), Naia's affect had been changing through her monitoring, her awareness of difficulties and improvement, and her pathway towards her goals. This changing affect played an important role in the development of her selfregulation, and vice versa.

Naia felt that she lacked self-confidence and expressed her frustration due to what she considered as her difficulties (for example, lack of vocabulary, dissatisfaction with her writing style), at the beginning of the course (1T1R and 1T2R). In 1T3R, however, she started to understand that improvement was possible, and more importantly, noticeable. Even though she did not perform as well as she had wanted to in that session, she did not feel frustrated any longer because she began to appreciate the improvement she was perceiving. That perception turned into her "present" motivation, keeping her desire to learn on a dayto-day basis (Yamashita, 2015).

Though having self-confidence was not one of the explicit goals she set in 1T1R - 1T3R, it was among the aspects she knew she should work on (stated in 1T1R). In 1RonC, she reported that she attained the goal of having self-confidence when writing. The perception of improvement, the feeling of attainment of goals, and the increasing self-confidence aroused her interest in writing: "I can remark that I begin to be interested in writing, before I 
used to not like it very much, now I would like to be really good at it" (1RonC). Moreover, it was at that stage that she began to treat her reflective journal like a confident. Sharing her problems and feelings with the journal relieved her frustrations. This is a clear example of what Boud (2001) refers to as using a journal as a form of therapy. Actually, Naia found the use of reflective journal so useful that she started to use it in other courses as well (stated in 1RonC). This clearly shows the development of her self-regulation, her understanding of the problem-solving process presented by reflection (Silver, 2013), and it is an evidence of transfer of learning (Cotterall, 2009):

I gain many things [from the course]. First, I apply [the reflective journal] for other courses, I wrote down my problems with [other] courses, and now I cannot stop thinking about solutions if there are problems. It helped me to know that we should always progress, and never repeat mistakes we have [made] before. (1RonC)

Despite a feeling of disappointment in 2T1R, Naia became more and more relaxed. For instance, in $2 \mathrm{~T} 2 \mathrm{R}$, she expressed her uncertainty whether her arguments are convincing or not, but in a relaxing way, as she added a laughing sound imitation. In $2 \mathrm{~T} 2 \mathrm{R}$, overcoming her frustration seemed to be confirmed, and her self-confidence increased more and more because of her awareness that she was able and ready to find solutions to any problems: "I feel confident this time. I like that. That helps me very well, because I will always want to bring solutions if problems happen." In 3T2R, Naia stated that she felt comfortable and her love for English had grown thanks to the writing task (as the topic was to persuade young people to learn a foreign language). In 3RonC, she confirmed her love for English, not owing to the writing this time, but to reflective learning: "The reflective journal] helps me to love English more than before and to persist on what I [want to attain]".

\subsubsection{Summary of Naia's development of self-regulation}

Through reflective learning, Naia gained insights on the importance of setting goals and the awareness of such goals while writing. The goals that she set from her second writing on were related to what she felt as her weaknesses, implying that they were genuine goals. When the goals were not attained, she kept them for the following writing task. However, even when they were reached, she understood that there was always room for improvement. 
From monitoring and evaluating her writing task, Naia became aware of her writing steps, her feelings, her difficulties, and her improvement. She came to perceive these difficulties and improvement in a detailed and precise way. While the perception of difficulties pushed her to find strategies, her perception of improvement gave her more self-confidence and motivation. She did point out her readiness for the writing tasks and her constant desire to improve (stated in 3RonC).

Naia found it crucial that students must be given opportunities to find the solutions to their problems themselves. This may include asking their peers for help, but she stressed the necessity of looking for solutions on their own, and of patience and perseverance, as finding solutions may take a long time, and improvement may not take place immediately. She found different types of strategies by herself and from the group discussions, which demonstrates the development of her strategy knowledge, which is a significant part of metacognition and self-regulation. The best summary of Naia's perception of learning and goals can be the following:

I learned that learning is not just to receive something from the teacher; it is especially to learn by ourselves. Also, [the reflective learning course] taught me that everything is possible; every goal is attainable with great strategies and persistence. (3RonC)

These statements clearly show that she understood the importance of learning autonomously, of having goals and strategies, which indicates the acceptance and enjoyment of the responsibility for or control over her learning.

\subsubsection{Improving writing performance}

Each of Naia's writing pieces was scored following the writing rubric (see Table 4.4, p. 109). Her scores are presented in Figure 5.2 (p. 188), which shows that her writing fluctuated in quality, like most of the other students'. Despite the importance of these summative results, they were not the only aspects taken into account when measuring the impact of reflective learning on Naia's writing performance. The goals that Naia had set for each piece of writing and the attainment (or not) of these goals (according to the teacher) as well as Naia's selfevaluation were also considered. As Little (2011) states, self-assessment is reliable if constantly accompanied by evidence.

One of the goals that Naia set in $1 T 1 R$ was to make the writing attractive to the readers. This goal seemed to be attained (though she was not certain about its attainment), as her 
writing included an engaging introduction, eight convincing arguments, and a conclusion that summarised the ideas. She did address the audience (the Malagasy young people) directly by using the personal pronoun "you". She engaged them by asking a question right at the beginning of the introduction: "Are you still hesitating where to study after graduating secondary school?" The negative points about the writing in 1T1 was the lack of organisation of the ideas, which she was aware of in her self-evaluation. Also, she made some grammar mistakes and misspellings, which she predicted, as she did not have time to proofread.

In $1 \mathrm{~T} 2$, she improved in terms of organization of ideas by reducing the number of ideas and putting similar ones together, instead of randomly listing them. She noticed the improvement as she stated that her sentence structure and her paragraphs looked better. Moreover, the number of spelling and grammar mistakes reduced. However, she was not satisfied with her topic sentences and stated that her goal on improving grammar was not reached.

In 1T3, she used more sophisticated vocabulary. For instance, instead of stating "Teaching is the basis of development" (1T1R and 1T2R), she wrote "Education is the most powerful weapon to make a better world", which contributed to her writing being more attractive and convincing. She found it easier to express her ideas, she claimed. She even found so many ideas in $1 T 3$ that she did not have time to write all of them down.

In 2T1R, Naia's goals were clearer and more specific, as stated earlier. She focused on avoiding mistakes on singular and plural, articles, and misspellings. According to her, as she did not have time to proofread, her goals were not attained. This was evidenced by the rather sub-standard quality of her writing, if compared to the previous one (in 1T3). Some of the French words (which she put first before the English words came to her mind) remained untranslated. Furthermore, there were many grammar mistakes, such as the misplacement of adjectives, misuse of personal pronouns, of articles, of singular and plural, and a problem of grammatical agreement. Moreover, the ideas needed reorganising, as a lack of flow was easily noticed. This decline in quality (if compared with 1T3) was probably due to the fact that in $1 T 3$, it was the third time she dealt with the same task: through repetition, she had collected enough ideas, tried to improve how to express and organise them, and corrected her mistakes. In $2 \mathrm{~T} 1$, because of the newness of the task, she still had to think of all the ideas related to the topic.

Because of the failure of achieving her goals in $2 T 1 R$, she was determined to keep the same goals in $2 \mathrm{~T} 2 \mathrm{R}$. The number of her grammar mistakes and misspellings did reduce. She 
did not use any more French words. Her arguments were well organised, making the transitions of ideas smoother, and the writing clearer. She was aware of these improvements and felt satisfied with her writing. In $2 \mathrm{~T} 3$, she kept the same arguments, and did her best to correct all her mistakes (the ones underlined by the teacher). Compared to the writing in 2T1, the one in 2T3 had fewer but better-developed and organised arguments.

The description above seems to imply that Naia's writing improved only because of the repetition of tasks and that whenever she faced a new task, she struggled. However, it was not the case for the third (new) task. In 3T1R, firstly, she reported she was comfortable and relaxed while doing the writing. Secondly, her writing was well presented with strong arguments. She implemented the strategy of having fewer well-defended ideas instead of having many in a form of a list. Her misspellings and grammar mistakes reduced again, as she knew how to identify mistakes by herself when proofreading (without the teacher underlining them). Her goals in 3T1R of improving grammar and paragraphing seemed to be attained, though she was not certain about grammar. In $3 \mathrm{~T} 2 \mathrm{R}$, her goals were to correct all her grammar mistakes and to add new ideas with convincing words, which she found easy to do (according to her). The writing contained no more misspellings and very few grammar mistakes. It had the same arguments, but the latter were better presented and defended. It can be concluded, thus, that her goals in 3T2R were attained, which she was aware of.

Throughout the course, Naia mainly aimed to improve her grammar and vocabulary. This must be due, at least partly, to the education background. In Madagascar, these two language aspects are still mostly what is emphasised in secondary school and below regarding foreign language learning (whether English or French). Other aspects such as audience awareness when writing (except if it is clearly letter writing) seem to be neglected. Nevertheless, Naia showed in her writing that she was appropriately addressing her audience by engaging them with questions and by persuading them with strong arguments, which became better and better organized.

The summaries of Naia's performances in each task are presented in Table 5.1 (p. 188). 
Table 5.2 (p. 189), and Table 5.3 (p. 189).

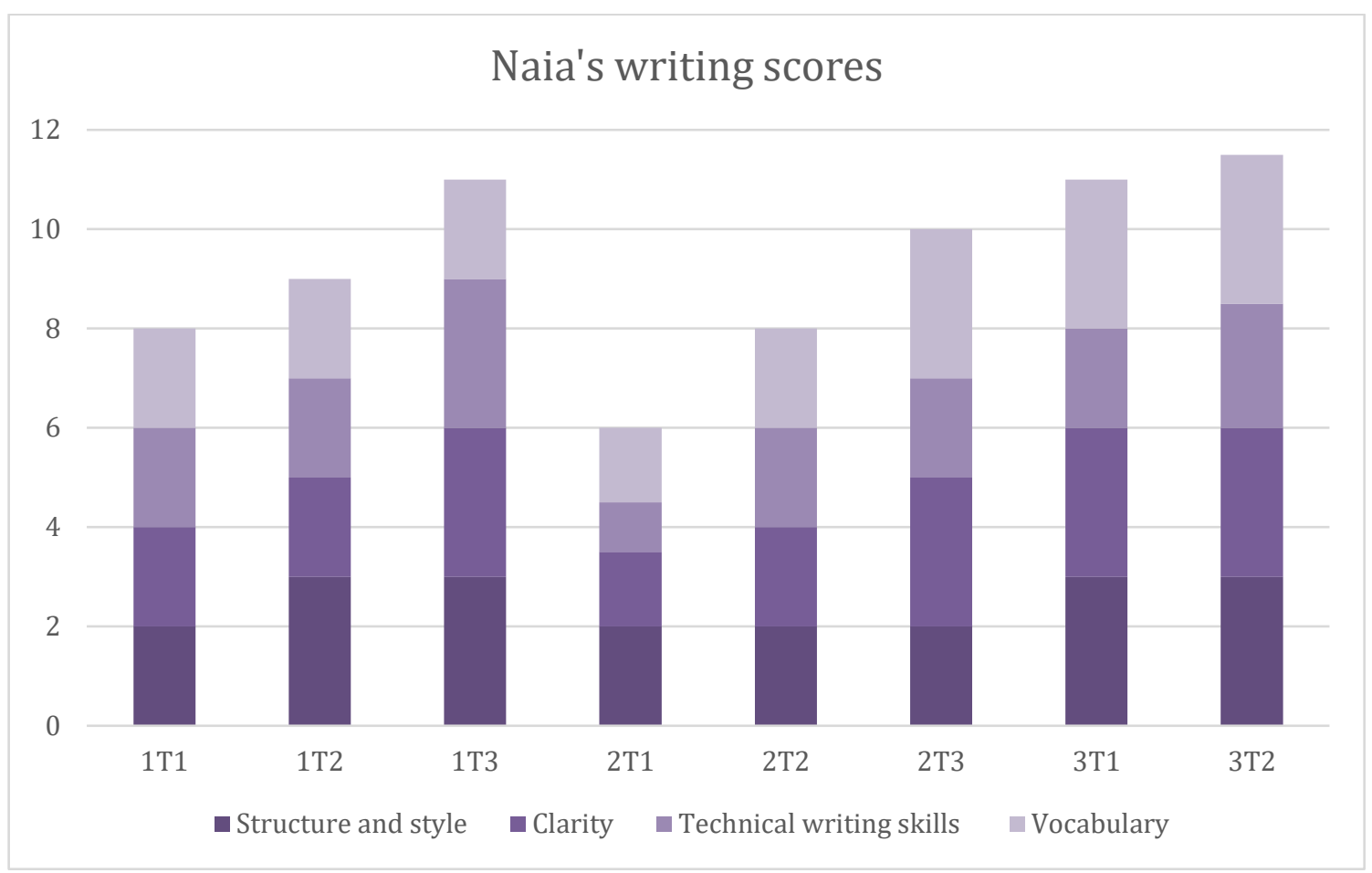

Figure 5.2 Naia's scores throughout the course

Table 5.1 Impacts of reflective learning on Naia's performance - task 1

\begin{tabular}{|c|c|c|c|c|c|c|}
\hline & \multicolumn{2}{|l|}{ Reflection 1} & \multicolumn{2}{|l|}{ Reflection 2} & \multicolumn{2}{|l|}{ Reflection 3} \\
\hline$\underline{\text { Task } 1}$ & $\begin{array}{l}\text { Problems: } \\
\text {-Grammar } \\
\text {-Misspellings } \\
\text {-Organization of } \\
\text { ideas } \\
\text {-Expression of ideas } \\
\text {-Irrelevance of ideas } \\
\text {-Vocabulary } \\
\text {-Time management } \\
\text {-Self-confidence }\end{array}$ & $\begin{array}{l}\text { Improvement / } \\
\text { strength: } \\
\text { Audience } \\
\text { awareness }\end{array}$ & $\begin{array}{l}\text { Problems: } \\
\text {-Vocabulary } \\
\text {-Time } \\
\text { management }\end{array}$ & $\begin{array}{l}\text { Strategies: } \\
\text {-Not using draft } \\
\text { Improvement: } \\
\text {-Fewer grammar } \\
\text { and spelling } \\
\text { mistakes } \\
\text {-Fewer } \\
\text { arguments but } \\
\text { better developed } \\
\text {-No more } \\
\text { irrelevant ideas }\end{array}$ & $\begin{array}{l}\text { Problems: } \\
\text {-Time } \\
\text { management }\end{array}$ & $\begin{array}{l}\text { Strategies: } \\
\text {-Trying to be in the place } \\
\text { of a magazine writer to } \\
\text { be at ease, to write, and } \\
\text { to be more confident } \\
\text {-Collecting ideas before } \\
\text { writing } \\
\text { Improvement: } \\
\text {-Fewer grammar and } \\
\text { spelling mistakes } \\
\text {-Better expression of } \\
\text { ideas: use of more } \\
\text { appropriate vocabulary } \\
\text {-Self-confidence }\end{array}$ \\
\hline
\end{tabular}


Table 5.2 Impacts of reflective learning on Naia's performance - task 2

\begin{tabular}{|c|c|c|c|c|c|c|}
\hline & \multicolumn{2}{|l|}{ Reflection 1} & \multicolumn{2}{|l|}{ Reflection 2} & \multicolumn{2}{|c|}{ Reflection 3} \\
\hline Task 2 & $\begin{array}{l}\text { Problems: } \\
\text {-Grammar - } \\
\text { Misspellings } \\
\text {-Vocabulary } \\
\text {-Organization of } \\
\text { ideas } \\
\text {-Time management }\end{array}$ & $\begin{array}{l}\text { Strategies: } \\
\text {-Putting French } \\
\text { words for } \\
\text { unknown } \\
\text { vocabulary first, } \\
\text { then, translating } \\
\text { them later } \\
\text {-Writing topic } \\
\text { sentences for } \\
\text { each paragraph, } \\
\text { and finding } \\
\text { smooth } \\
\text { transitions } \\
\text { Improvement / } \\
\text { strength: } \\
\text { Audience } \\
\text { awareness }\end{array}$ & $\begin{array}{l}\text { Problems: } \\
\text {-Use of } \\
\text { inappropriate } \\
\text { words } \\
\text {-A few } \\
\text { grammar } \\
\text { mistakes }\end{array}$ & $\begin{array}{l}\text { Strategies: } \\
\text {-Putting similar ideas } \\
\text { together } \\
\text {-Proofreading and self- } \\
\text { correcting } \\
\text {-Skipping unknown } \\
\text { vocabulary, then, going } \\
\text { back later } \\
\text { Improvement: } \\
\text {-Fewer grammar mistakes } \\
\text {-Better organization of } \\
\text { ideas } \\
\text {-Better time management } \\
\text {-Self-confidence => } \\
\text { satisfaction }\end{array}$ & $\begin{array}{l}\text { Problems: } \\
\text {-A few } \\
\text { grammar } \\
\text { mistakes }\end{array}$ & $\begin{array}{l}\text { Strategies: } \\
\text {-Understanding why } \\
\text { mistakes are mistakes: } \\
\text { rewriting and trying } \\
\text { "many possibilities" to } \\
\text { correct them } \\
\text { Improvement: } \\
\text {-Fewer grammar } \\
\text { mistakes }\end{array}$ \\
\hline
\end{tabular}

Table 5.3 Impacts of reflective learning on Naia's performance - task 3

\begin{tabular}{|c|c|c|c|c|}
\hline & \multicolumn{2}{|l|}{ Reflection 1} & \multicolumn{2}{|l|}{ Reflection 2} \\
\hline Task 3 & $\begin{array}{l}\text { Problems: } \\
\text {-A few } \\
\text { misspellings }\end{array}$ & $\begin{array}{l}\text { Strategies: } \\
\text {-Writing with a pencil, then, erasing } \\
\text { mistakes afterwards } \\
\text {-Arranging ideas in a draft "to have a } \\
\text { clear plan" } \\
\text { Improvement: } \\
\text {-Self-confidence } \\
\text {-Easiness to identify mistakes } \\
\text {-Well-presented and strong } \\
\text { arguments } \\
\text {-Audience awareness }\end{array}$ & $\begin{array}{l}\text { Problems: } \\
\text {-Use of } 2 \text { non- } \\
\text { existent words }\end{array}$ & $\begin{array}{l}\text { Strategies: } \\
\text {-Correcting mistakes from previous } \\
\text { writing } \\
\text {-Adding more "strengthening" words } \\
\text {-Writing difficult words or some } \\
\text { sentence structures to be sure how to } \\
\text { write them correctly } \\
\text { Improvement: } \\
\text {-Self-confidence } \\
\text {-Better expression of ideas } \\
\text {-No more misspellings }\end{array}$ \\
\hline
\end{tabular}




\subsubsection{Potential impact on future teaching}

The reflective learning experience raised Naia's awareness of the importance of interdependence and independence. She found group discussions useful to find solutions, which made her suggest extending the time for such discussions. On the other hand, she understood that it required effort on her own. In other words, she came to the understanding that she should take charge of her own learning, which implies trying to solve her own problems both by herself and by using peer collaboration. Thus, she was aware that she should take advantage of peer collaboration, but she should not be over-reliant on it. When asked directly what (from the reflective learning experience) she might implement in her future classes, her answers emphasised the importance of giving students the opportunity to set their own goals, to figure out themselves how to attain them, to find the solutions to their problems on their own and in groups. The benefits she gained from the reflective journal, not only in the course but for other subjects as well (stated in 1RonC), made her want to implement its use in her future classes:

If I were a writing teacher, I would use the reflective journal sometimes for my students. I would tell them that learning by themselves is really important because when we are just given lessons, we forget them after few times and we do not really understand why they are like that, but when we have to find solutions and lessons by ourselves, we never forget them. I would let them [set] clear goals and challenge themselves to attain them. (2RonC)

I will use this method of reflective journals. I will not just a teacher who correct mistakes, but I ask them to correct together their mistakes. I will [...] sometimes [...] put them in groups to help one another because it is important to work together solving others' difficulties. And I urge them to use reflective journal[s] for other subjects. (3RonC)

In brief, Naia became aware of her responsibility towards her learning as a result of the reflective learning, and she wanted to develop the same awareness in her own students.

\subsubsection{Summary of Naia's story}

Naia's case illustrated growth in self-regulatory abilities. Through reflective learning, she learned how to set goals and to plan for her writing, to monitor her writing while doing it, 
and to evaluate it once it was completed. She demonstrated awareness of the importance of her learning goals, which she had chosen according to her difficulties. She had what Locke and Latham (2002, p. 707) call "goal commitment". That commitment was triggered by her consideration of the achievement of her goals as important, and by her belief that she could attain her goals.

Naia developed her monitoring and self-evaluation skills, as she was able to observe and attend to her difficulties, her progress, and her feelings while and after they occurred. These resulted in awareness of weaknesses and strengths/improvement, which indicates that her self-awareness had increased. The awareness of weaknesses pushed her to increase her strategy knowledge: she was persistently looking for strategies to solve her problems, and she did find some through personal endeavour and group discussions. The awareness of improvement aroused her self-confidence, her "love", and her interest in writing and English in general. These aspects are encompassed by self-regulation, as the latter includes not only metacognition, but also affective reactions and self-belief (Zimmerman, 2000).

Along with the development of self-regulation came the gradual improvement of Naia's writing. As she understood that it was not all about doing the writing itself, that she needed to work on her weaknesses, among which were different aspects of language such as particular grammar points, vocabulary, spellings, and expression of ideas, she did her best to master such aspects. Though she did not completely master them by the end of the course, the effort and its consequence could be seen in her writing: reduction of grammar mistakes, use of more appropriate vocabulary, use of strong arguments to support ideas, better engagement of the audience, and time management. Furthermore, the quality of her writing in 3T1 clearly indicates that though the task was new, she managed to clearly express and support her ideas well. She made minimal mistakes, and addressed the audience appropriately, thanks to her familiarity with different strategies. She used these strategies effectively. Also, on account of the repetition of (the type of) tasks, her familiarity with them grew, which helped her plan her writing better and avoid recurring mistakes. It can be said, thus, that her task knowledge as well as her language awareness developed.

To summarise, Naia's active engagement in the process of her learning led to her awareness of responsibility for her learning. This awareness pushed her to appreciate her learning process in return, including the discovery of problems, the challenge and the eagerness to find solutions to the problems, but also the patience and perseverance required for these problems to be solved. Her self-confidence increased with the awareness 
of her ability to continuously improve and eventually attain her goals. The combination of all these changes seems to correspond to what Moon (1999) labels as "transformative learning", which results from persistent work and the emergence of a new view on learning.

\subsection{Katherine}

\subsubsection{Developing self-regulation}

This section describes the development of Katherine's self-regulation in writing throughout the reflective learning course. More precisely, it will discuss how her self-regulation did not really grow despite her awareness of the importance of setting goals resulting from the reflection work. The main reason was the lack of awareness of difficulties, which prevented her from responding to those difficulties strategically.

\subsubsection{Lacking awareness of specific difficulties}

Difficulties related to ideas are obvious: without ideas and/or without the ability or words to express them, writing is not possible. That is why such difficulties are easy to notice; and these were mainly the problems Katherine perceived throughout the nine weeks. In 1T1R and $1 T 2 R$, she thought the problem of finding arguments was due to the topic. Yet, when answering the prompt (pre-task) on her knowledge about the topic, she stated she did not need to know more information about the topic. Her statement was the same for the second task (2T1) despite her persistent problem with finding ideas. Expressing ideas remained her major issue till the last writing (3T2).

Apart from the problems with finding and expressing ideas, Katherine did not seem to know exactly what her difficulties were. With my feedback, she came to know she had made mistakes, but she was unable to name what types of mistakes they were, unless I identified them (I had to point out mistakes such as incomplete sentences and too short paragraphs). In her self-evaluation in $1 T 2 R$ and $1 T 3 R$, she wrote that the reason why she gave her writing the score of 6 out of 10 was that she had made mistakes in her writing. However, she did not mention what types of mistakes. Furthermore, if she had really been aware of the mistakes, she could have corrected them.

In brief, Katherine noticed only difficulties related to ideas and vocabulary that directly impeded her writing. To perceive other difficulties, she needed feedback that needed to be more specific than mere underlined sentences. 


\subsubsection{Setting goals}

Katherine's goal for her first writing task (1T1R) was to convince young people to choose teaching as a career. At first sight, this can be seen as related to audience awareness, but it should be pointed out that this was part of the writing instruction. Also, as it was the first reflection, it was not surprising that she (and most of the other students) was not able to think about any other specific goals. She kept the same goal in $1 T 2 R$, but this time, she added two specific others: to finish in time and to give clear arguments. She chose these two because they were related to her difficulties in 1T1R, which shows that she understood the connection between goals and difficulties. She still aimed to manage her time well in 1T3R and in $2 \mathrm{~T} 1 \mathrm{R}$, as she had not attained that goal yet in $1 \mathrm{~T} 2 \mathrm{R}$. The other goals that she set in $1 T 3 R$, in $2 T 1 R$ and $2 T 2 R$ were mainly to improve her previous writing and grammar and to make fewer mistakes. The reasons behind these goals must have been my feedback, which consisted mostly of numerous underlined mistakes. In 3T1R and 3T2R, her goal was to improve paragraphing, again because I pointed out that her paragraphs were too short (containing only one sentence each). Therefore, it can be said that Katherine set her goals according to her previous difficulties, which can be the beginning of the development of selfregulation.

\subsubsection{Monitoring and self-evaluation - Lacking strategic responses to difficulties}

Katherine monitored her writing by stating her writing plan (focusing on the content of the different parts of the writing), sometimes enumerating a few steps of her writing (such as writing the introduction in a draft first, then, copying it in the paper), and her difficulties briefly. After each task, she evaluated her performance by noting down her scores, giving reasons for the scores, and stating what she viewed as improvement and difficulties. Unlike Naia, she did not often take notes of her affect, though the reflection prompts addressed that subject.

Throughout the course, Katherine used strategies, which were part of her prior knowledge. When reflecting on the first task (1T1R and 1T2R), Katherine demonstrated some knowledge of strategies, such as writing ideas in a draft first before building sentences about the ideas, and then connecting similar ideas into paragraphs. These were mainly the strategies that she used throughout the course.

On account of the superficial awareness of her difficulties, Katherine was not able to seek adequate strategies on her own or with peer collaboration. She did use social strategies as 
she exposed her difficulties during group discussions, and she mentioned that the latter helped her find solutions to her difficulties and attain her goals (stated in the three reflections on the course). However, the advice she took from group discussions was vague. For instance, after the group discussion after 1T1R, she wrote, "This group discussion helped me to get other students' ideas. They advised me to think and write quickly". To deal with her vocabulary problem, the suggestion she received was to read books and use English as much as possible.

Whenever asked how she dealt with her difficulties, she would simply answer that she was thinking deeply and did her best to focus on the writing. Moreover, she herself stated that even though she was aware of her difficulty of finding ideas, she was too lazy to make the effort to seek some. In $2 T 2 R$, for example, despite the repetition of the task, she still could not find better ideas because she had not looked for some: "I didn't look for ideas about the topic yet so I didn't give more ideas".

Through monitoring and evaluating, Katherine noticed some progress in her writing. She saw improvement in terms of numbers of ideas as well as expressing them in $1 T 2 R$ and 1RonC. She also noticed that she became more focused and therefore quicker in thinking when writing. In 2RonC, she noticed some improvement in grammar, and she particularly mentioned the "avoidance" of incomplete sentences, which she managed to do in 2T3. In general her perceived improvement from $2 T 1 R$ to $3 T 2 R$ was avoiding incomplete sentences and mistakes. In 3RonC, the last reflection, the improvement she stated was general: "Yes, my writing [greatly] improved, as my difficulties decreased writing after writing. I improved also my way of writing and I made little mistakes".

\subsubsection{Changing affect}

Katherine mentioned in $1 \mathrm{~T} 1 \mathrm{R}$ and in 1 RonC that her feelings, especially motivation depended on the topic, or more precisely, on the knowledge of the topic. When reflecting on the first task and the second task (1T1R to $2 T 3 R$ ), she did not add how exactly she felt before talking about her difficulty of finding ideas. However, she stated in 3RonC (the last reflection on the course) that she felt discouraged when doing the first writing due to the difficulties of finding and expressing ideas. When reflecting on the third task (3T1R and $3 T 2 R)$, she said she was motivated because she liked the topic and she perceived improvement over time. She also stated that her motivation and her willingness to improve her writing was raised by the journal writing and the group discussions (stated in 1RonC), 
and by the goals she set (stated in 3RonC). Her increase of motivation towards the end of the course was also due to her knowing more about her difficulties:

On the two last writings, I only had difficulty in paragraphing. I noticed that I made improvement; I mean, I made [fewer] grammatical mistakes. On the last writing, I was so motivated as I knew what my mistakes were and I felt motivated to avoid them and to improve my writing. (3RonC)

Indeed, seeing that her writing contained fewer mistakes (from my feedback) raised Katherine's satisfaction, which was a positive outcome. Nevertheless, her satisfaction seemed to become a hindrance to further personal effort. Once she perceived that her goals were attained (mainly correcting mistakes), she seemed to feel reassured, and the effort she would make for the next writing would be limited to avoiding those mistakes.

\subsubsection{Summary of Katherine's development of self-regulation}

Reflective learning did raise Katherine's awareness of her difficulties and improvement. It also allowed her to know the significance of having goals, and to change her affect towards writing positively. These changes could be seen to contribute to the development of selfregulation but to a limited extent.

From monitoring her task, Katherine became aware of some of her difficulties. She did turn these difficulties into goals, and this can be viewed as the beginning of the development of self-regulation. Moreover, she viewed goals as contributing to motivation and she recognised the importance of awareness of difficulties in the last reflection (3RonC):

Using reflection has been useful on my own learning as it helped me to think deeply, to know what my difficulties were and especially to motivate myself by imposing a goal in each writing task. In other terms it helped me to improve my writing.

However, she did not always demonstrate strong willingness to make a self-directed effort to solve her perceived problems. This might be a reason why her problems of finding and expressing ideas persisted until the end of the course. Apart from these obvious problems, she was not able to clearly identify other problems she had, which did not enable her to respond strategically to them. As represented in Figure 5.3 on the next page, she seemed to have a cyclical pattern, in which her awareness of other difficulties were triggered only by my feedback. These difficulties were basically seen by Katherine as mistakes to be corrected. Because of that, she simply tried to correct them but did not go 
beyond correction. Once she thought her mistakes were fixed (which was not always the case), she was satisfied and persuaded that her goals were attained. Actually, she stated it clearly when asked what she learned from the course in the last reflection (3RonC): "From this course, I learned to know what my mistakes were and to avoid them when doing the next similar writing task". The awareness of learning strategies, which is crucial in the development of learner autonomy was not apparent.

According to Katherine in 3RonC, her affect changed from discouragement to motivation throughout the course. Motivation was generated by the topic (in the third task) and the improvement she had noticed in her writing. Increase of motivation is important as it is part of the affective reactions included in self-regulation (Zimmerman, 2000) and in selfawareness, which is one of the aspects that constitute learner autonomy (Porto, 2007). Nonetheless, Katherine's tendency to overestimate her improvement limited her effort in working towards more progress.

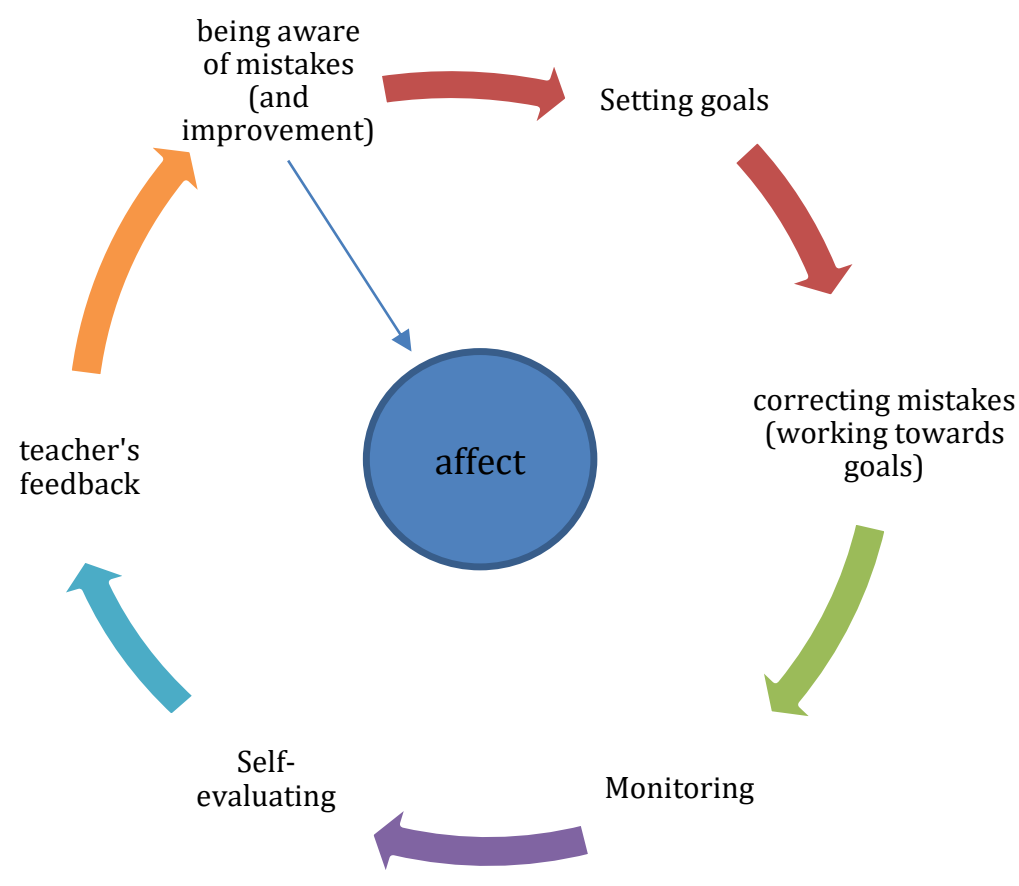

Figure 5.3 Katherine's cyclical pattern

\subsubsection{Improving writing performance}

Katherine's writing scores presented in Figure 5.4 (p. 198) show that her writing performance did not really improve throughout the nine weeks' course. However, as in Naia's case, the evaluation of the impact of reflective learning on Katherine's writing is not only based on her scores, but also on the goals she had set, on the attainment (or not) of the 
goals according to the teacher (me), and on Katherine's self-evaluation. Thus, this section will discuss whether her goals were attained or not while doing the three tasks.

As stated earlier, Katherine's goal expressed in 1T1R seemed to be related to audience awareness, as she aimed to convince the young people to choose teaching as a career. In her writing, however, she did not properly address the young people, though she mentioned the advantages of teaching. She did not state whether she had attained her goal or not. Nevertheless, the difficulty of finding arguments that she observed indicated that she was not satisfied with the content of her writing, which implies that her goal had not been attained according to her: "Here, giving argument is the most difficult as "Teaching is the best option" is not very convincing for me [...]". In 1T2R, she clearly stated that her goal about time management was not attained. Though she was aware that she had more ideas than in $1 T 1 R$, she was not very satisfied with them. Actually, she did provide more arguments, but they were not used effectively. Instead of supporting her arguments on the advantages of teaching, she took three examples of jobs and mentioned a disadvantage for each. The idea of doing so may not be wrong, but the advantages of these jobs were not integrated into an argument for teaching. To take an example, the following sentence was at the beginning of her second paragraph (after the introduction) in 1T2R: "Being judge is a very well paid job, but sometimes if a judge don't accept corruption he or she will be murdered." She kept the goal about time management in 1T3R, which she felt that she did not attain. She also aimed to improve her writing, which she felt she had managed to do, as she noticed that "she wrote in a better way". However, neither of the four points (structure and style, clarity, technical writing skills, vocabulary) had improved.

In $2 \mathrm{~T} 1 \mathrm{R}$ and $2 \mathrm{~T} 2 \mathrm{R}$, she found that her goals of improving grammar, making fewer mistakes, presenting clear ideas, and managing time were achieved. Yet, her writing lacked organisation of ideas and included incomplete sentences. Though there were fewer mistakes in terms of word choice and misspellings, it cannot be said that her grammar really improved. On the other hand, her goal in 2T3R consisting in writing complete sentences was attained. Both she and I noticed the attainment of this goal.

Viewing paragraphing as her main weakness (stated in 2RonC, as I pointed out that her paragraphs were too short in $2 \mathrm{~T} 2 \mathrm{R}$ and $2 \mathrm{~T} 3 \mathrm{R}$ ), her goal in $3 \mathrm{~T} 1 \mathrm{R}$ was to improve paragraphing. According to her self-evaluation, she attained her goal. However, her writing contained seven paragraphs, three of which contained only one sentence each. As that was emphasised in my feedback, she kept the same goal in 3T2R. The goal was attained, 
according to both of us. She did put sentences together to form paragraphs. Thus, instead of seven paragraphs, she had five.

The summary of Katherine's performances in each task are presented in tables 5.4, 5.5, and 5.6. (below and on the next page).

\section{Katherine's writing scores}

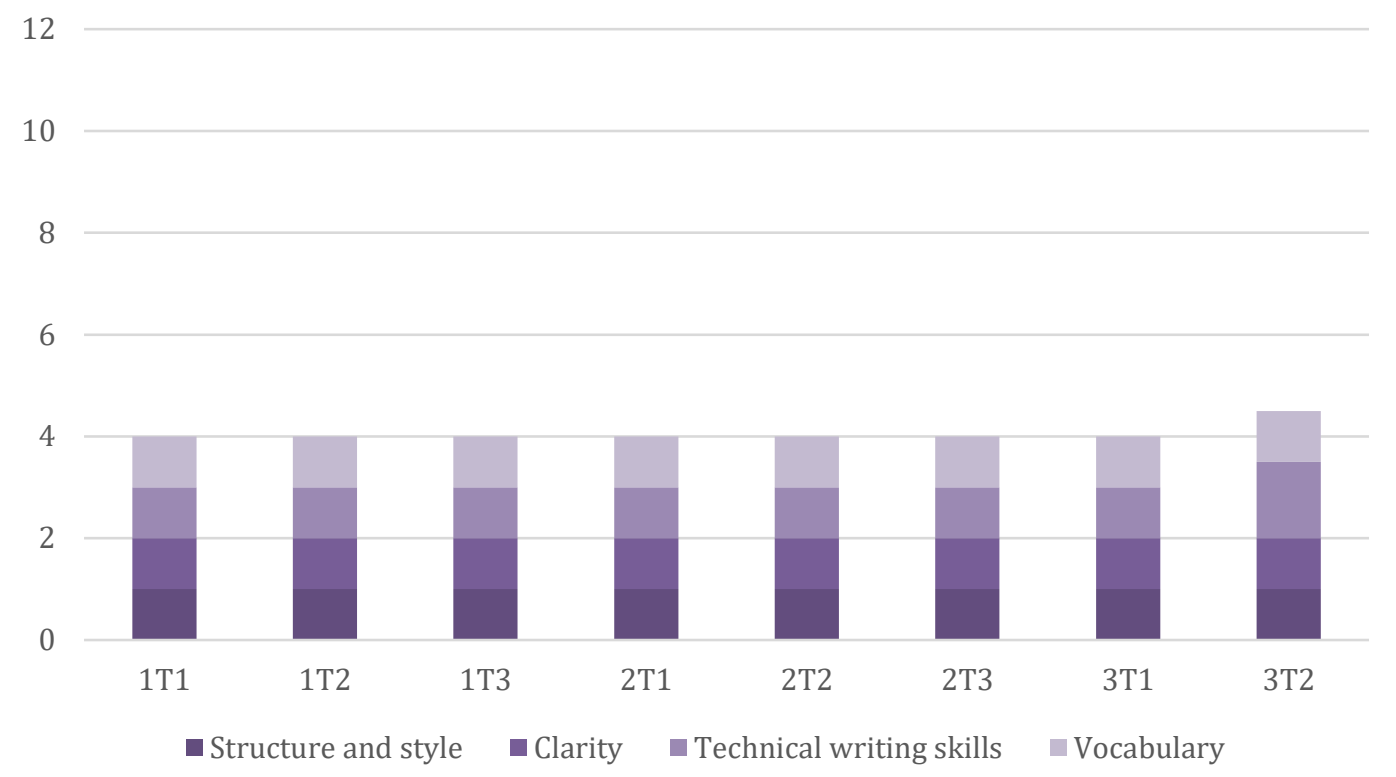

Figure 5.4 Katherine's scores throughout the course

Table 5.4 Impacts of reflective learning on Katherine's performance - task 1

\begin{tabular}{|c|c|c|c|c|c|c|}
\hline & \multicolumn{2}{|l|}{$\underline{\text { Reflection } 1}$} & \multicolumn{2}{|l|}{$\underline{\text { Reflection } 2}$} & \multicolumn{2}{|l|}{ Reflection 3} \\
\hline Task 1 & $\begin{array}{ll}\text { Problems: } \\
\text { - } & \text { Grammar: } \\
& \text { singular/plural, } \\
& \text { prepositions } \\
\text { - } & \text { Misuse of } \\
\text { words } & \text { Lack of ideas } \\
\text { - } & \text { Ideas not } \\
\text { developed } \\
\text { enough }\end{array}$ & $\begin{array}{l}\text { Improvement / } \\
\text { strength: }\end{array}$ & $\begin{array}{l}\text { Problems: } \\
\text { - Grammar: } \\
\text { singular/plural, } \\
\text { prepositions, } \\
\text { accord, articles } \\
\text { - Misuse of } \\
\text { words } \\
\text { - Inappropriate } \\
\text { ideas }\end{array}$ & Improvement & $\begin{array}{l}\text { Problems: } \\
\text { - Paragraphing } \\
\text { - Grammar: } \\
\text { sentence } \\
\text { structure, } \\
\text { singular/plural, } \\
\text { prepositions } \\
\text { - Misuse of } \\
\text { words } \\
\text { - Organisation of } \\
\text { ideas }\end{array}$ & $\begin{array}{l}\text { Improvement } \\
\text { Better ideas }\end{array}$ \\
\hline
\end{tabular}


Table 5.5 Impacts of reflective learning on Katherine's performance - task 2

\begin{tabular}{|c|c|c|c|c|c|c|}
\hline \multirow[b]{2}{*}{ Task 2} & \multicolumn{2}{|l|}{ Reflection 1} & \multicolumn{2}{|l|}{ Reflection 2} & \multicolumn{2}{|l|}{ Reflection 3} \\
\hline & $\begin{array}{l}\text { Problems: } \\
\text { - Grammar, } \\
\text { including } \\
\text { incomplete } \\
\text { sentences } \\
\text { - Misuse of words } \\
\text { - Misspellings } \\
\text { - Punctuation } \\
\text { - Inappropriate } \\
\text { ideas }\end{array}$ & $\begin{array}{l}\text { Improvement / } \\
\text { strength: } \\
\text { Slight } \\
\text { improvement in } \\
\text { grammar }\end{array}$ & $\begin{array}{l}\text { Problems: } \\
\text { - Incomplete } \\
\text { sentences } \\
\text { - Paragraphing } \\
\text { - Misspellings } \\
\text { - Capitalization } \\
\text { - Choice of } \\
\text { words / use of } \\
\text { non-existent } \\
\text { words } \\
\text { - Organization of } \\
\text { ideas } \\
\text { - Inappropriate } \\
\text { ideas }\end{array}$ & 更 & $\begin{array}{l}\text { Problems: } \\
\text { - Misuse of } \\
\text { words } \\
\text { - } \text { Count/uncount } \\
\text { nouns } \\
\text { - Paragraphing } \\
\text { - Organization of } \\
\text { ideas }\end{array}$ & $\begin{array}{l}\text { Improvement: } \\
\text { No more incomplete } \\
\text { sentences }\end{array}$ \\
\hline
\end{tabular}

Table 5.6 Impacts of reflective learning on Katherine's performance - task 3

\begin{tabular}{|c|c|c|c|c|}
\hline & Reflection 1 & & Reflection 2 & \\
\hline Task 3 & $\begin{array}{l}\text { Problems: } \\
\text { - Word choice } \\
\text { - Paragraphing } \\
\text { - Grammar: } \\
\text { singular/plural, } \\
\text { articles, } \\
\text { capitalization, } \\
\text { accord }\end{array}$ & $\begin{array}{l}\text { Improvement: } \\
\text { Appropriate ideas }\end{array}$ & $\begin{array}{l}\text { Problems: } \\
\text { - Word choice / Use of } \\
\text { non-existent words } \\
\text { - Grammar: word choice, } \\
\text { count/uncount nouns, } \\
\text { articles } \\
\text { - Paragraphing }\end{array}$ & $\begin{array}{l}\text { Improvement: } \\
\text { - Capitalization } \\
\text { - Accord } \\
\text { - Better expression of ideas }\end{array}$ \\
\hline
\end{tabular}

\subsubsection{Potential impact on future teaching}

Katherine found the reflective learning course helpful. She stated that both the reflective journals and the group discussions had enabled her to improve her writing. Thus, she would be willing to implement such practice in her future teaching:

I will use this way of writing. I mean I ask my students to do the reflective journals as it helped me to improve my writing. I will ask them to discuss in 
group too. (2RonC)

From what I have learned from this course, I will apply the reflection technic to my students and also the group discussion as [...] both helped me to improve my writing. (3RonC)

These statements are not specific in terms of how journal writing and peer collaboration helped and what improvement they had brought. Though Katherine was basically aware that reflective learning allowed her to solve her problems in writing to some extent, she seemed to continue to see reflection as a classroom technique rather than a tool that develops a more generic awareness of skills and strategies. Like some other students, Katherine thought that despite its usefulness, journal writing is considerably time-consuming (stated in 3RonC).

\subsubsection{Summary of Katherine's story}

Some aspects of self-regulation were perceived to develop in Katherine as a result of reflective learning. She became aware of her goals, which were clearly related to her previous difficulties. Having these goals was one of the factors that increased her motivation. Attaining the goals and perceiving her improvement were other sources of motivation. Some of her goals were indeed attained, and some slight improvement could be seen in her writing. Therefore, it can be said that she understood that reflection facilitated problem-solving. However, her awareness of specifi, personal learning goals did not fully develop, as she was not able to identify most of her difficulties. This inability did not allow her to look for appropriate strategies or to use peer collaboration effectively. Indeed, her awareness of difficulties was mainly triggered by my feedback. She treated these difficulties as mistakes, and she aimed to correct them in the next writing task, without seeking strategies that could serve as long-term solutions. Thus, her awareness of learning strategies did not grow.

Katherine's story implies that turning difficulties into goals is not enough to develop selfregulation. The development of self-regulation and learner autonomy requires actions towards the goals, and these actions do not consist merely in correcting mistakes. The actions are what are referred to as engagement in the learning. For students like Katherine, these actions seem to need prompting by means of more than reflection and group discussions. Discussions about such prompts will be dealt with in the last chapter of this thesis. 


\subsection{Summary and conclusions of the two case studies}

This section attempts to summarise the two case studies and explain why reflective learning did not have the same impact on the development of the two students' self-regulation or on their writing performances. Two possible reasons will be presented.

The first possibility is the difference of proficiency levels. It is undeniable that the two students' language proficiency levels were different from the beginning. As Naia's English was definitely better than Katherine's, it can be assumed that Naia was able to express herself more easily in her journal. However, the difference of proficiency levels could not be the principal cause of the disparity of the impacts. Firstly, the students were encouraged to use any language they were comfortable with when writing the journal, but both Naia and Katherine chose to use English. Secondly, the measurement of the improvement of writing performances took into account the students' proficiency levels at the beginning. In other words, no matter what their starting levels were, improvement (from these levels) was possible. Moreover, it was seen in the previous chapter that even students with low proficiency levels were able to develop their self-regulation and to improve their writing in a gradual way. Indeed, $30 \%$ of the students had approximately the same level as Katherine at the beginning.

The second possibility is the depth of reflection. Naia's reflection had the characteristics of what Moon (2013) refers to as deep reflection, as Naia described her learning progress very clearly. She often looked back at her previous reflections in order to compare her feelings, difficulties, and improvement. That helped her perceive the links between her prior experience and her present behaviour. That also made her aware of the importance of feelings in learning: "It is important to feel comfortable and relaxed while writing" (3T1R). Furthermore, she understood that learning is built through experience and perseverance, and that she was continuously able to improve. Through her deep reflection, her difficulties and goals became clear and specific, which made them easier to focus on and to respond to. On the other hand, Katherine's reflection tended to be superficial. Though, like Naia, she understood the importance of setting goals and was aware of such goals while writing, she was not always able to specify her difficulties. This inability made it difficult for her to develop strategic thinking. Instead of figuring out her specific difficulties, she mainly concentrated her effort on correcting the mistakes pointed out (by me) in her writing. It can be said, therefore, that her independence did not really evolve. Furthermore, she also had 
weak self-initiation because even when she was able to define her difficulties, she did not demonstrate strong willingness to solve them. More possible reasons why self-regulation learning is not always efficient will be discussed in the last chapter of this thesis.

In brief, the difference between the two cases mainly lies in learning engagement, more precisely, on the effort to find and then implement strategies in order to solve problems. While Naia embraced the problem-solving opportunities presented through the reflection, and viewed reflection as a powerful tool for her learning, Katherine seemed to consider reflection as a classroom technique rather than a tool. Though Katherine's awareness increased, it did not suffice to push her to explore more and to take charge of her learning fully. 


\section{Discussion}

This research aimed to bring insights into the relevance and the implementation of LA in a Malagasy EFL context. To attain such a goal, it followed a few necessary steps. The first step was to study the context by investigating the contextual affordances and the constraints regarding the dimensions of LA in a Malagasy rural school (phase one). The second step was to use the knowledge of the affordances and the constraints to decide what dimension of LA needs focusing on. In the Malagasy context, self-regulation was the dimension mostly and purposefully promoted partly because of the constraints perceived in phase one. The third step consisted of the implementation (phase two), that is fostering self-regulation with student teachers by highlighting the affordances and providing the students assistance and guidance with regard to the constraints. The students were guided by means of journal reflection prompts. As a result of the reflection, their self-regulatory skills did develop. This development enabled them to engage in strategic behaviour, which in turn, increased their self-initiation. The growth of self-regulation and self-initiation triggered their awareness of their responsibilities towards their learning, which generated independence. The awareness also impacted their writing performances as well as their perspectives and beliefs on teacher and learner roles. Figure 6.1 (p. 204) shows the steps taken in the research and their results.

This chapter highlights four main points, which are interconnected, based on the findings from the steps. Firstly, it talks about the importance of understanding the context when promoting LA. This includes the contextual constraints and the affordances perceived and developed in the two studies. Secondly, it discusses the dynamic interrelation of the three dimensions of LA, as observed in the two studies. Thirdly, it looks at the link between the development of LA and language proficiency. Finally, it discusses why experiencing LA on

their own learning is strongly recommended for pre-service and in-service teachers. This encompasses the link between LA and teacher autonomy. 


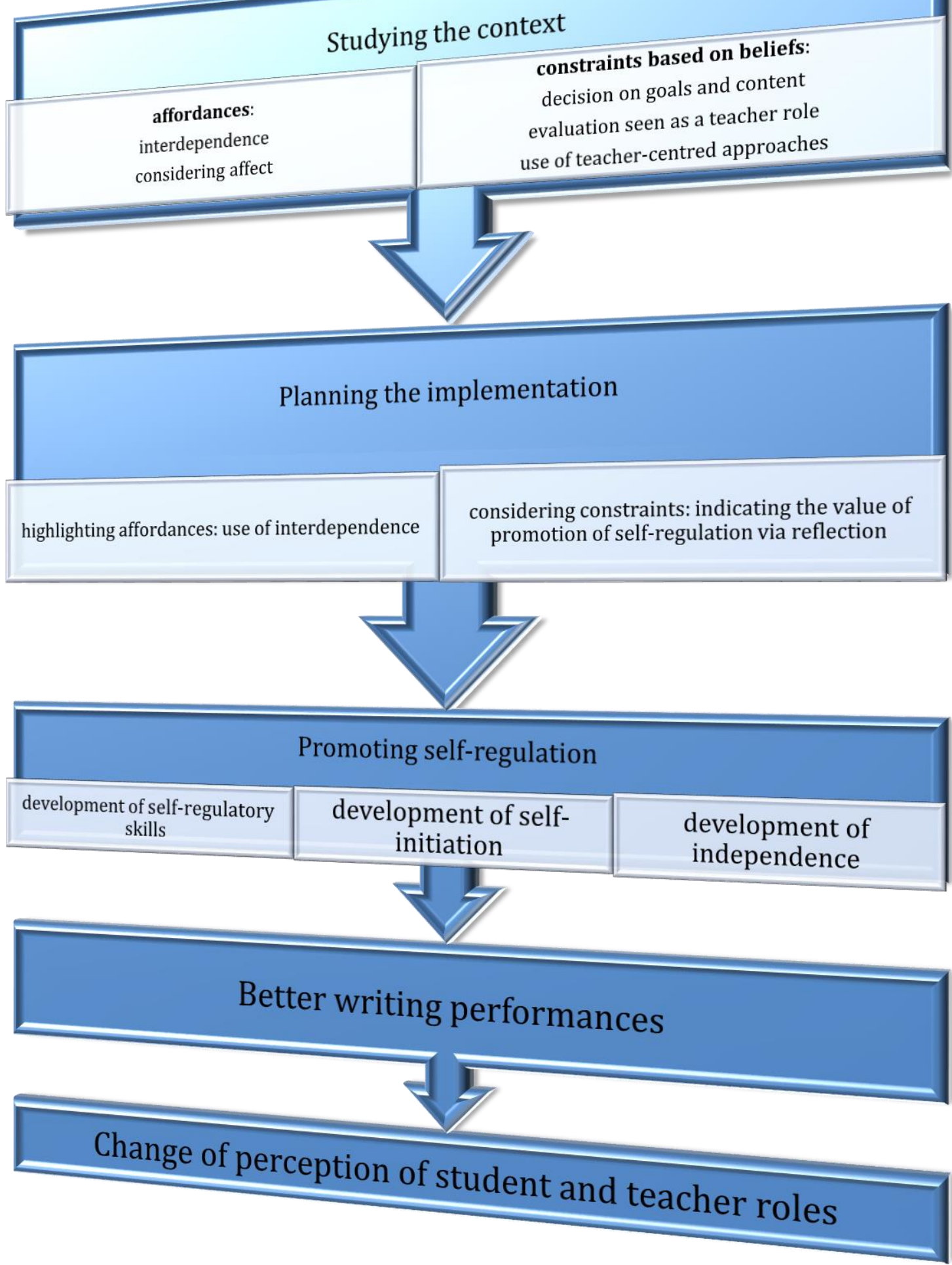

Figure 6.1 Summary of the findings of the two phases 


\subsection{Taking the context into account when implementing autonomy}

This research started with the belief that LA is a relevant goal for any age group, and in any setting (Ryan \& Deci, 2017). However, the socio-cultural factors in the setting should be taken into account (Little, 1999) because "[t]he learner and the context of the learning experience cannot be separated" (O'Leary, 2014, p. 18). That is why phase one aimed to study the context. More specifically, it intended to detect affordances or elements that can be used and/or related to the development of the three dimensions of LA. For this purpose, the study investigated (1) the teachers' beliefs on what language learning and teaching entail, reflecting the socio-cultural context and the teaching conditions they were in, and (2) their practices in class and out of class. The findings included affordances for autonomy as well as constraints on exercising it. Phase two made full use of those affordances and took the constraints into consideration, when implementing LA with student teachers. This section emphasises the affordances in phase one, and how they were used in phase two, but before that, it will discuss some constraints found in both studies, and discuss why recognising the contextual constraints is significant when aiming to implement autonomy.

\subsubsection{Identifying constraints}

Any educational context has its constraints regarding the promotion of LA; and these constraints are often related to institutional factors (Palfreyman, 2018). In Madagascar, these factors can include the curricula (the content of which do not always match the levels of the students in rural areas, according to the teachers in phase one) and the national examinations. Additionally, there is the lack of resources and the "difficult circumstances" (Smith et al., 2018) Malagasy rural settings generally face. All these factors, together with the Malagasy students being 'concrete-sequential' (accustomed to having an authoritative figure as a teacher) (Oxford, 2003b) can be easily seen as constraints on LA. Except for the last point, it would be hard to avoid these constraints.

In this section, I focus on constraints that can be altered. They are linked to teachers' beliefs and perceptions, based on the findings in both studies of the research. These beliefs, including expectations about what learning and teaching involve, had been built through the teachers' own learning and teaching experiences (de los Angeles Clemente, 2001; Prabhu, 1992). The beliefs and perceptions concern decision-making (particularly goal setting), evaluation, and teacher-centred approaches. 


\subsubsection{Decisions regarding goals and content}

The teachers firmly believed that goal setting was a role exclusively allocated to teachers. This is a belief that is shared with teachers in other studies on teacher autonomy/education in different countries, such as Japan, Hong Kong, Oman, and Saudi Arabia (Al-Rabai, 2017; S. Borg \& Al-Busaidi, 2012; Chan, 2003; Nakata, 2011). As in some of those studies, the teachers in phase one believed that students may be involved in choosing in-class activities from time to time, but definitely not in methodological decision-making involving goals or teaching content. Therefore, they did not give any opportunities at all to their students to think about their own goals while doing tasks.

The experience of having goals and content always set by teachers was also an issue for the students in phase two at the beginning. They did not understand the reason for having goals before doing a task, and the exact link between a goal and a task. Therefore, they had no idea what their goals for their writing task should be, and tended to have broad goals, or to define their goal as merely finishing the writing task on time. As Macaro (2006) states, having clear goals is not always evident for learners. In addition to goals, the wish for more explicit teaching about writing was reflected in some of the students' reflections, implying they were expecting the teacher to provide the learning content and to guide them more on how they should proceed with writing. This is in line with EFL Turkish university students' perception of LA revealed in the research conducted by Dişlen (2011). In that study, though the students were aware of their responsibility towards learning, they felt that teachers should be in charge of making decisions regarding content. They believed that, as students, they were not sufficiently knowledgeable to make any decisions. They did expect their teachers to give them room for independent learning, but also to be the providers of motivation and guidance; and part of the guidance is the determination of the learning content.

\subsubsection{Evaluation seen as a teacher responsibility}

Like goal setting, the evaluation of learning seemed to be seen as the teacher's responsibility in this research (in phase one and at the beginning for phase two), given the very few cases of self-evaluation in phase one and the difficulties in self-evaluating expressed by the students in phase two. In phase one, apart from the self-evaluation triggered by peer evaluation through comparisons (only done intentionally by one teacher), the teachers did not provide their students with opportunities to self-evaluate. It is true that peer evaluation 
constantly occurred in class due to the wide promotion of peer collaboration, and it is one of the affordances found in the study (discussed further in the next section). However, the teachers (two of them in particular) believed that peer evaluation and self-evaluation can be done only with tasks related to grammar, that is, with concrete rules that can be checked. They did not think their students were capable of evaluating any subjective tasks, such as the content of writing, for instance. This may be related to what de los Angeles Clemente (2001) refers to as "distrust of students" (p. 50); and this is why teachers tend to perceive any decisions and performances regarding evaluation as an exclusive teacher role (S. Borg \& AlBusaidi, 2012; Chan, 2003). This perception is not only from teachers but also from learners with an educational background that views teachers as authority figures (Littlewood, 1999), as is the case in Madagascar.

Though the students in phase two did not mention this perception explicitly, their unfamiliarity with self-evaluation was implied in their reflections when they talked about their difficulty in evaluating whether their goals were achieved, or whether their strategies were efficient or not. It was also implied in their reflections on what they had learned from the reflective learning course, when they stated their realisation of the importance of selfevaluation, and their change of perceptions on teacher and learner roles, which will be discussed in the section on affordances.

\subsubsection{Use of teacher-centred approaches}

Teacher-centred approaches in the Malagasy rural context were expected in phase one, given the high degree of authority allocated to teachers in the Malagasy education system. Some approaches, such as rote learning, choral repetition, and memorisation, which are often considered as typical in developing countries (Westbrook et al., 2014), were seen during the class observations. The teachers probably used those approaches because they were repeating practices of their former teachers (Mulkeen et al., 2007), which can be the result of lack of teacher training. They may not merely imitating their teachers. It may also be due to the fact that they had found those practices useful in their own learning and teaching, and they became part of their beliefs regarding language learning. This is in keeping with what Nakata (2011) states about the use of the grammar-translation method used by EFL Japanese teachers. Nakata says that the teachers' use of this method should not necessarily be seen as a characteristic against the promotion of LA "because that method could be the outcome of their self-regulated thoughts and reflective practice" (p. 907). 


\subsection{Recognising constraints to better implement LA}

Recognising the contextual constraints is one step in the promotion of LA. In fact, constraints on promoting autonomy will always exist in educational contexts, as total freedom is not possible, but the promotion of LA relies on the management of these constraints and the emphasis on the affordances for promoting autonomy:

In educational contexts, formal curricula (including materials, planned activities or assessments of all kinds) may or may not support learning and autonomy, depending on the discussion that goes on around them and the use that is made of them by the teacher and learners for promoting reflection, awareness, responsibility, informed choice and so on. (Palfreyman, 2018, p. 54).

Phase one included the discussions Palfreyman refers to. The discussions between the teachers and me enabled the knowledge of the constraints described above. Identifying the constraints, firstly, confirmed a need for awareness raising about the value of goal setting and self-evaluation, implying that self-regulation is one of the dimensions of LA to promote. Considering the newness in this context of self-regulation and reflection on learning, its promotion should include maximum guidance. As Moon (2013) states, reflecting purposefully needs coaching. Therefore, using reflective journal writing with clear and detailed prompts seemed to be the ideal option.

Apart from providing a knowledge of the constraints, the interviews with the teachers in phase one also enabled me to perceive that simply discussing aspects of teaching and learning, including the constraints (not presented as "constraints" to them), led teachers to reflect on and even to question their practices. That will be included and discussed in the next section on affordances.

\subsection{Highlighting affordances}

Despite the existence of the constraints, phase one showed a number of affordances for autonomy, which are also crucial when considering implementing LA (Allwright, 1988; Smith et al., 2018). The affordances that stood out the most were interdependence through peer collaboration and the consideration of affect. Those affordances were highlighted in phase two, contributing to the positive results regarding the development of self-regulatory skills in the participants. What can be considered as affordances were also the ability to self- 
evaluate and the change (or disposition for change) observed in the teachers (phase one) and the student teachers (phase two) regarding beliefs and attitudes towards learning, including a new perception on teacher and learner roles.

\subsubsection{Using interdependence to develop autonomy}

Interdependence through peer collaboration was the most prevalent affordance perceived in phase one, and it was promoted in both studies because it triggers independence, as explained in 6.4.2.1 (p. 223). Interdependence was not only seen as an efficient social strategy (Oxford, 2002, 2003a) by both the teachers in phase one and the students in phase two, but also as a key to learning and well-being in the Malagasy context. This section discusses the reasons for the wide promotion of interdependence found in phase one, the impacts of such a promotion in both studies, including the link between interdependence and the development of LA.

\subsubsection{A suitable approach to the context}

The first reason for the wide promotion of interdependence in phase one may be strongly related to the cultural context. Madagascar is known for its community-oriented culture, emphasising the value of "fihavanana", which can be translated into "kinship". For the Malagasy people, kinship is a concept incorporating moral ties and obligations to relatives and the surrounding society, and "is at the core of what it means to be a human being" (Keller, 2009, pp. 83-84). Thus, the Malagasy people are one of the societies inclined to collectivism, valuing interdependence, and considering society as an indispensable factor of a sense of belonging (Ferraro, 2002; Littlewood, 1999). This is reflected in everyday life, including at school, as Littlewood (1999) puts it:

[...] it should not be surprising if, when [the members of a culture] enter formal education, their values and perceptions of learning have been influenced to a considerable extent by the values and perceptions that they have commonly experienced within their sociocultural group. (p. 78)

Thus, seeing interdependence as a prerequisite for the balance of social beings' independence (Little, 1991) and developing "autonomous interdependence" (Ryan, 1991, p. 227) or the social dimensions of autonomy (Murray, 2014a; Tassinari, 2012) would not be difficult in the Malagasy context. Malagasy teachers and learners would believe that "our ability to learn is dependent upon our participation in social life and our membership of 
communities of learning" (Esch, 2009, p. 34). This was shown in the students' reflections in phase two, when they expressed their appreciation of and the necessity for the group discussions. They valued the help they received and provided, and also the interpersonal relations they had built with their peers. The interpersonal relations will be discussed further later in this chapter.

Another reason for the promotion of interdependence is still linked to the context but is more related to conscious implementation rather than a natural cultural tendency. The teachers encouraged group work because they were implementing a suitable approach to the local context (Wills et al., 2014). They used an appropriate way to face the challenges of the rural situation (Westbrook et al., 2014) they and their students are in. As Wills et al. (2014) puts it, "where resources are lacking, teachers can make student learning more enriching in different ways, both inside and outside the classroom. For example, they could promote cooperative learning [...]" (pp. 128-129). Based on their own experience, both in language learning and teaching, the teachers in phase one were aware of the insufficiency of resources due to the setting they were in, and the lack of ability to self-evaluate. Thus, they considered peer collaboration as the key to solve their problems regarding language and to acquire more knowledge about teaching, and they wanted their students to do the same.

\subsubsection{Social mediation}

Another reason why the teachers in phase one promoted interdependence is related to its being a forerunner to independence. The teachers explicitly stated that they wanted stronger students to help the weaker ones. The teachers stated that such peer assistance is not only beneficial for the receivers of the help, but also for the providers of the help. The latter would not only feel useful, but would also be aware of their knowledge, which would give them self-confidence, motivation, and a sense of responsibility. The teachers' statements are in line with Kao's (2011) findings in his research on peer tutoring, which demonstrated that, among other positive aspects, peer tutoring resulted in the development of a sense of responsibility and motivation as well as an enhancement of their confidence in English learning. Assisting peers resulting in the affective factors mentioned above was also perceived in phase two. Though the students tended to focus more on the assistance they gained rather than what they gave, they also mentioned their appreciation of peer teaching. Motivation, self-confidence, and responsibility as a result of peer collaboration will be discussed in the following sections. Having stronger students help weaker ones is connected 
to social constructivism or what is referred to as "social mediation" (Palfreyman, 2018, p. 57).

\subsubsection{Boosting motivation and self-confidence}

In phase two, peer collaboration helped boost the students' motivation, as stated in the literature: " [a way of promoting motivation is] [i]nvolving the learners more actively in the classroom process in activities that demand inter-student communication and co-operative efforts on their part" (Wright, 1987, p. 53). It also enhanced their self-confidence. Four aspects, nurtured through interdependence, were the main reasons why peer collaboration fostered motivation and self-confidence, according to the findings in phase two: peer assistance, "safe" opportunities to talk, reassurance via double-checking, and interpersonal relations.

The students were motivated by the peer assistance they received in relation to writing content, which is in keeping with the study involving peer writing discussions conducted by Neumann and McDonough (2015). In addition to writing content, they also had useful exchanges on writing structure, other areas of writing, and other aspects of language they had difficulty with. As stated earlier, they learned different strategies, which they implemented in their writing.

The students did express their appreciation of the opportunities to discuss their difficulties without shame or fear of being judged. Therefore, they felt comfortable exposing their problems to their peers and looked forward to working on finding solutions together. Discussing their problems with their peers also enabled them to realise that their problems regarding writing were common, giving them reassurance.

Still related to reassurance, discussing with peers allowed the students to double-check their knowledge in different aspects of writing/language in general. The fact that it had been double-checked with others suppressed doubts and therefore resulted in better selfconfidence when writing.

Peer collaboration built agreeable interpersonal relations among the students, which is in keeping with what Kagan (1994) states about the benefit of cooperative learning. The interpersonal relations triggered a team spirit and enabled the students to "grow" socially in a way that they developed their ability to listen, and therefore, became more open to new ideas and more aware of the necessity of collaboration. One of the students even mentioned 
his appreciation of the increase of his humility, which resulted from not being "stuck to his self-opinions".

The four aspects reflect what Ryan (1991) suggests should be included in an environment conducive to the development of self-regulation:

The facilitating environment of self-regulation is one that includes the affordance of choice and an empathic, perspective-taking stance with respect to the actor by important others, as well as concrete support, involvement, and concern. Thus, autonomy is nurtured by attunement in interpersonal relationships. [...] [S]elf-development [...] depends on specific qualities in the interpersonal sphere and social context of development. (p. 221)

\subsubsection{Peer evaluation and self-evaluation}

The two studies demonstrated that peer collaboration led to both peer evaluation and selfevaluation. In phase one, through the habit of collaboration, it became natural for the students to spontaneously correct one another and, in certain cases, to give constructive feedback to one another. In phase two, peer evaluation was triggered by the group discussions, which was not surprising, as they had to expose their difficulties to one another in order to find solutions together. Through the exchanges, they discovered their peers' difficulties as well as strengths.

Such instances of peer evaluation (in both studies) generated incidental comparisons to their own strengths and weaknesses, implying that peer evaluation does result in selfevaluation. As a result of evaluating others, the students became more aware of their own learning. This is in agreement with Kao's (2011) findings revealing that peer tutoring reinforces peer tutors' critical awareness of their own learning. It is understandable that such an ability to self-evaluate evolved in phase two because peer collaboration was used with individual reflection. However, self-evaluation was also perceived in phase one (particularly in John's classes) when the students were looking at one another's sentences and drawings and would remark, for instance, "Our sentence is not as long as theirs".

\subsubsection{Leading to self-regulation}

As described above, the more the students were able to evaluate themselves, the more likely they self-regulated, as self-evaluation results in setting clearer goals. For instance, the 
goal of the students making the remark above would be to write a longer sentence next time they do the same task. They may not have thought of such a goal if they had not compared their work to their peers'. Thus, interdependence enabled the students in the research to improve their metacognitive skills and their self-awareness.

Self-awareness associated with interdependence was especially perceived in phase two. The students in phase two understood that they were responsible for their learning, and a huge part of the responsibility is to solve their own problems. They were aware that a way to solve their problems is through interdependence, but they are still the ones in control of their learning. In other words, they knew peer collaboration was conducive to their learning, and could be used as a strategy to find other strategies or solutions to their problems and to enlarge their knowledge. Equipped with those strategies and solutions, they were more able to attain their goals and to improve in different aspects of their learning. This is what Palfreyman (2018) refers to when stating, "the social element of autonomy can be viewed in terms of the individual learner's critical adaptive ability and capacity for making the most of interactions for learning purposes" (p. 55). Also, this is why interdependence does have a role in the development of self-regulation, as advocated by Zimmerman (2002): “[...] selfregulated students seek out help from others to improve their learning. What defines them as "self-regulated" is not their reliance on socially isolated methods of learning, but rather their personal initiative, perseverance, and adoptive skill" (pp. 69-70).

In addition to self-awareness, the interpersonal relations built through peer collaboration contributed to the development of self-regulation in that they fostered motivation and selfconfidence, as explained earlier.

\subsubsection{Highlighting affect to promote autonomy}

Affect was one of the aspects closely examined and highlighted in both studies of this research, as affective factors constitute an essential component of self-regulation (Zimmerman, 2000). Moreover, motivation is part of self-initiation (Nguyen, 2008). The findings in both studies confirmed the importance of affective factors, including motivation, in the development of LA advocated by many researchers (P. Benson, 2007; Littlewood, 1996; Martinez, 2008; Tassinari, 2012; Yamashita, 2015). Firstly, this section looks at the links between affect and the dimensions of autonomy, as perceived in the two studies. Then, it discusses how realistic goal setting can sustain motivation. 


\subsubsection{Evident links between affect, self-initiation, and self-regulation}

Affect and self-initiation are strongly connected, as demonstrated in phase one. The findings revealed the strong motivation that the four teachers had. Driven by their passion, their interests in English, and the fear to lose or decrease the quality of their English, they had developed both their LA and teacher autonomy through independent work, including "creation of personal learning contexts" (Littlewood, 1996, p. 432). They would make the best of any opportunities to learn more, for example, by practising their speaking with me during lunchtime, by asking me to conduct a workshop including some "teaching tips" at the end of my stay. They would also create opportunities by holding regular speaking meetings, by exchanging teaching approaches and methods with colleagues in the school and teachers from other schools. With their awareness of the significance of affect in their own learning, the teachers did their best to motivate their students. They encouraged their students by promoting peer collaboration (Wright, 1987) and by using positive interpersonal interactions (Ryan, 1991), hence creating a pleasant atmosphere and building students' self-confidence (Littlewood, 1996).

The findings from phase two showed evident connections between affective factors and the development of self-regulation. Firstly, simply being aware of feelings constituted a step towards self-regulation in a way that identifying the feelings as well as analysing their causes allowed the students to perceive the connection between their feelings and their learning experiences (Yamashita, 2015). That perception enabled them to understand themselves better, and then to advance by sharing those feelings, or seeking advice from their peers, or adjusting their ways of learning on their own. That was how the feelings (both positive and negative), triggered by the awareness of weaknesses resulted in specific goal setting and the development of strategic behaviour, as shown in Figure 6.2 (p. 223). With the use of strategies that they learned or that were brought to their consciousness, they were able to improve their writing and their knowledge (regarding language, writing, and the topic).

In addition, the perception of improvement increased motivation and self-confidence, and thus, raised the students' awareness of their capability and their responsibility to take charge of their learning. This is in line with what Littlewood (1996) states about the link between ability and willingness, which are two components of LA:

[...] the more knowledge and skills the students possess, the more confident they are likely to feel when asked to perform independently; the more confident they feel, the more they are likely to be able to mobilise 
their knowledge and skills in order to perform effectively [...]. (p. 428)

Additionally, the students appreciated the interpersonal relations they had built throughout the course, which is related to interdependence, as explained earlier.

It is worth mentioning that the students found it difficult to talk about their feelings at first, which was not surprising, given that their traditional educational background did not encourage them to do so. Other research, such as Yamashita's (2015) also demonstrates that expressing feelings can be challenging for students with such background. However, in this research, following the repeated reflection prompts, the students' habit of expressing feelings built up gradually. The habit enabled the exposition of fluctuating feelings, the increase of motivation and self-confidence triggered by the awareness of improvement, and a positive change of behaviour and attitudes towards learning. Thus, the connection between these affective factors and the development of self-regulation was evident.

\subsubsection{Sustainable motivation through realistic goal setting}

Nurturing motivation is one of the teacher's key roles (Wright, 1987). This role is not easy, especially in an education system tending to put emphasis on students' rankings in class (the first having the highest average scores in all subjects, and the last having the lowest), as in the Malagasy education system. Despite the prominence of interdependence in class, rankings based on individual scores still tend to constitute the only learning evidence that parents and heads of schools take into account. The consequence of the emphasis is the students' tendency to aim only to have good scores, and in this way, to prove to their teachers (and parents) that they have succeeded. Having such goals is not always negative and can be a source of motivation. In fact, it is considered as part of instrumental motivation (Gardner \& Lambert, 1972). However, having only such motivation is not sufficient. It can be even detrimental for weaker students, as they know they would never be the best in the class. It is, thus, necessary to nurture their motivation by raising their awareness of their individual progress, rather than by highlighting their scores and their rankings in class. In other words, they should be encouraged to think more about the learning process rather than focusing solely on the learning product. This implies the importance of developing metacognition, including goal setting, as demonstrated in phase two.

In phase two, the students were able to cultivate intrinsic motivation. They came to the understanding that they did the reflection and the tasks with the aim to improve themselves, but not to "get things right" in order to please the teacher, or only to have the 
best scores. They were surely motivated by their perceived improvement, but it was more than the improvement itself. What motivated them the most seemed to be the awareness of the strategic behaviour they were developing. In other words, they understood that solving their problems should become their goals, as suggested by Locke and Latham (2006). They set goals that were more individualised, more specific and thus, more efficient (Locke \& Latham, 2002). They did "monitor their behavior in terms of their goals and self-reflect on their increasing effectiveness" (Zimmerman, 2002, p. 66). They understood their capability of reaching their goals eventually, as the goals were more realistic and attainable than the goal of having the best score in class. Furthermore, they were aware that they may keep the same goals until they were reached, as solving problems happens gradually. Therefore, they were the decision-makers regarding their goals, and that engaged them in their writing and learning in general, which is in line with what Chu (2007) stated about the impact of decision making on learning. Additionally, they were embracing small progress, having in mind their capability of improving more and more with practice and individual effort. The understanding of the efficiency of their effort gave them a sense of being in control of their learning (Dickinson, 1995). In brief, the students became aware of their ability to attain their goals through their effort, which pushed them to become (and accept to be) more and more autonomous. That awareness constituted the dynamic and "present" motivation keeping their yearning for learning on a daily basis (Dörnyei and Otto, 1998; Dörnyei, 2009; Ushioda, 2009; Yamashita, 2005), and also enabling them to "view their futures optimistically" (Zimmerman, 2002, p. 66). Phase two, thus, demonstrates the strong link between LA and motivation, and is in keeping with Ushioda's (1996) definition: "autonomous language learners are by definition motivated learners" (p. 2). It also confirms that high motivation tends to result in learners' acceptance of their responsibility for their learning, as they see the connection between their behaviours and their learning outcomes (T. Lamb, 2009).

In phase one, though the teachers did not particularly foster metacognitive skills in class, one of them stressed the importance of students' having realistic goals. The example of goals he gave was for the students to be able to communicate with their foreign pen pals independently. That goal became an incentive to the students. Despite their young age, they knew the significance of the ability to communicate with foreign people and, more importantly, of the friendship they were going to build or to keep with these pen pals. Though such a goal is long-term, the students knew that it was realistic, and that their working towards the improvement of their English would not be vain. 


\subsubsection{Self-evaluation}

The ability to self-evaluate was an affordance perceived in the student teachers in phase two. As self-evaluation was fostered through reflection in phase two, it is not surprising that the students developed their self-evaluation skills. They did have difficulty with selfevaluation, especially at the beginning. However, with practice, more specific goals, and the understanding of the efficiency of the problem-solving process that the reflection work involved them in, the majority of the students were able to evaluate their own writing and their learning process critically.

In phase one, the teachers also showed or implied that they evaluated their own teaching. Though only one of the teachers linked the evaluation of his teaching with his goals, the other teachers talked about adjustment of teaching approaches because of observations they had made on the efficiency of their teaching on their students. One of them also expressed her awareness of her difficulties involving lack of self-confidence. It can be said, thus, that one of the affordances found in phase one is related to teachers' selfregulation, and thus, to teacher autonomy, or more specifically, self-directed teaching.

\subsubsection{Change of perceptions on teacher and learner roles}

This research showed that the key to change is awareness. Thanks to awareness, the teachers and the student teachers in both studies were able to change their perceptions and beliefs about teaching and learning, despite their traditional educational background.

It has been suggested that changing beliefs and practice is required for teachers to be able to foster LA (Tütüniş, 2011). That is challenging because beliefs built through years of learning and teaching experience cannot be dismantled by "new" theories or short training (de los Angeles Clemente, 2001; Wallace, 1991). This is what Prabhu (1992) refers to as the teachers' "loyalty to [their] past" (p. 103), making them reluctant to change or innovate in terms of teaching approaches. The teachers' reluctance is understandable in a way because it is much easier to believe in approaches they have used many times and they find successful than in an approach they have not experienced and they may even see as a threat (de los Angeles Clemente, 2001; Wallace, 1991). Apart from teaching and learning experiences, the socio-cultural factors also influence teachers' perceptions of language learning and teaching (Littlewood, 1999), resulting in the constraints described in the last section. However, Littlewood adds that influence does not occur in a passive way. Despite their beliefs and perceptions, learners and teachers can still have flexibility vis-à-vis these 
perceptions. This implies that they can have the ability to reconsider and analyse the basis of these perceptions as well as the ability to be open and receptive to other aspects unrelated to these perceptions, provided that they are introduced to these aspects. These abilities were shown in both studies: in teachers' beliefs and practices, and in the student teachers' changing attitudes towards learning, which are considered as affordances.

The teachers in phase one started to question their perceptions regarding teaching and learning after the first interview. During informal interactions, a question about goals arose. One teacher asked whether goals should be stated clearly before starting each task. During the interviews, the way the teachers answered some questions also implied their willingness to include some practices mentioned in the questions. For instance, when asked whether they ask students' opinions on teaching materials and teaching content, and student feedback on their teaching, they said no but would consider doing so, and even stated some benefits that asking students would bring. They believed that it would motivate their students, and at the same time, it would allow the teachers to evaluate their teaching. Some change was also perceived, particularly in one of the teachers' classes. She made sure she stated and explained the goal before each task, which she had not done before the first interview.

In their reflections on the course, the students in phase two expressed the realisation and the acceptance of their responsibilities as learners, as described earlier (see Figure 6.2, p. 223). They became aware that they needed to identify their own problems in order to be able to solve them. This acceptance implies their realisation of what teaching and learning entail, including a drastic change of perception of student and teacher roles. Such change of perception is considerably significant not only for their learning but also for their future teaching.

\subsubsection{Summary of autonomy in the Malagasy context}

This section discussed the importance of studying contextual affordances and constraints when planning to promote LA. Knowing them results in more understanding of the people directly concerned (Breen, 1992), their beliefs, and their perceptions, and from that knowledge, a better analysis of how LA can be implemented in the context.

The constraints found in the Malagasy context (in phase one) were linked to the teachers' beliefs and perceptions on language learning and teaching, shaped by their own learning and the context they had been in. Their educational background made them believe that 
teachers are the ones in charge of goal setting, decision making about learning content, as well as evaluation. Likewise, their experiences in both learning and teaching may have encouraged them to use teacher-centred approaches, which are not likely to be conducive to their students' LA. Recognising those constraints considerably helped with the decision on what dimension of LA to focus on in such a context, and how to promote that dimension.

To implement LA in the Malagasy context, this research suggests that promoting interdependence is indispensable. Interdependence was, indeed, the most predominant affordance perceived in phase one. It was essentially promoted since it generates exchanges, peer evaluation, and even self-evaluation at times, which are reasons in line with the benefits stated in research on teacher collaboration (Dunn \& Shriner, 1999; Meirink, Imants, Meijer, \& Verloop, 2010). For these reasons, it was fostered in phase two, which further demonstrated that interdependence also resulted in the development of independence, self-regulation, as well as motivation and self-confidence. In addition to interdependence, one of the affordances found in both studies was the importance of the consideration of affect, including the increase of motivation through realistic goal setting. The findings in both phases also revealed the teachers' and the student teachers' abilities to self-evaluate and to change their perceptions on teaching and learning.

In brief, recognising the constraints and highlighting the affordances in phase one led to a better implementation of LA in phase two. Also, it can be said that the affordances outweighed the constraints. Furthermore, with the increase of awareness on the part of the teachers and the student teachers, the constraints tended to decrease.

\subsection{Dynamic interrelation of three dimensions of LA}

As the constraints were related to the beliefs that goal setting and evaluation are teachers' responsibilities, and to teacher-centred approaches, the dimension of LA that was not a natural part of Malagasy classroom practice was self-regulation. Because self-regulation encompasses students' taking charge of setting their own goals and self-evaluating, an approach aiming at the development of self-regulation is learner-centred. Self-regulation was promoted through reflective journal writing in phase two, resulting in the student teachers' development of the self-regulatory skills of goal setting, monitoring, and selfevaluation. The development of self-regulation generated the development of the other two dimensions, demonstrating a dynamic interrelation across the three dimensions. 


\subsubsection{A strong connection between self-regulation and self-initiation}

The findings from phase two particularly demonstrated a strong connection between selfregulation and self-initiation, implying the importance of promoting self-regulation. Before discussing the connection, I talk about evidence from phase one confirming that students do monitor and evaluate themselves in a regular basis, but just doing so does not necessarily help them unless it is done consciously. Therefore, students should be provided with help so that they become aware of their practices of monitoring and self-evaluating. The awareness will turn these practices into strategies, as shown in phase two.

\subsubsection{Necessity of promoting self-regulation}

Students practise monitoring and self-evaluation every time they deal with a task (they may also have an unspoken goal), but not in a conscious way. This was demonstrated by a student, Jenny, I overheard in phase one. She was talking to a classmate and to herself while and after doing a task. She expressed a feeling of loss when talking about her difficulties in the task she was doing and the homework she was given. She was, thus, aware of her problems. However, she did not find the solutions to these problems (at least, not during that class), or allude to an attempt to find solutions outside class. She seemed to accept and be convinced that she was "not good enough" for the tasks, which led to a feeling of discouragement and surrender. Encouragement to reflect more on her difficulties and on possible solutions may have changed her feeling and may have encouraged her to be more willing to make an effort to solve her problems. Jenny's case demonstrated the need to help students reflect consciously on their learning so that they turn their monitoring and their self-evaluation into strategies, as demonstrated in phase two.

By promoting conscious reflection, phase two raised the students' awareness of their capabilities of taking charge of their learning by nurturing reflection, coupled with peer collaboration, as the literature recommends (Allwright, 1990; Holec, 1981). The impacts were positive in terms of self-regulation, writing performances and attitudes towards learning in general. These impacts are in line with Candy's (1991) statement about the use of journals and group discussions resulting in learners' increasing control of their learning:

If people are to develop a sense of personal control, they need to recognize a contingent relationship between the strategies they use and their learning outcomes, and this may well involve having learners maintaining learning journals, analysing their own approaches to learning and 
discussing their beliefs and approaches to learning in groups or with a facilitator or counsellor (p. 389).

\subsubsection{Development of self-regulation through reflective journal writing}

Phase two enabled the conclusion that reflective journal writing enabled the students to use metacognitive strategies encompassing goal setting, monitoring, and self-evaluation (B. Sinclair, 2009). The use of the metacognitive strategies (1) raised their awareness of their process of learning, including their difficulties and improvement, (2) allowed them to have goals to work towards, and therefore, (3) enabled them to be proactive. Then, those three points led to more metacognitive strategies.

Monitoring and self-evaluation allowed the students to become aware of their difficulties and their improvement. Reflecting (and writing down their reflections) while doing the task helped them identify their difficulties. The awareness of difficulties, considered as a step towards LA (Porto, 2007), encouraged them to use prior strategies and knowledge or to seek new ones. They, thus, developed strategic behaviour, defined as "some kind of consistent response to problems that arise" (McDonough, 1999, p. 57), a prerequisite in the development of LA (Oxford, 2013). The awareness of their improvement and strengths, on the other hand, boosted their motivation and their self-confidence. Perceiving their own progress and highlighting what they were capable of doing made them believe in themselves and built pride. This research, then, suggests that monitoring and self-evaluation through reflective journal writing enabled the students to be conscious about both their learning process and the feelings related to the process. This research, thus, supports the claim made by Hurd (2011) stating that reflection leads to awareness of not only the learning process but also sources of motivation and demotivation.

Another source of motivation for the majority of the students in phase two was the goals they were working towards. Turning their difficulties into goals to attain, they made sense of what learning really entails, and realised the importance of taking the responsibility for their learning. The goals they set themselves, in parallel with their awareness of their strengths and weaknesses triggered what Zimmerman (2002) refers to as "proactiveness": "[The] learners are proactive in their efforts to learn because they are aware of their strengths and limitations and because they are guided by personally set goals and task-related strategies [...]." (pp. 65-66). The students, thus, developed their proactive autonomy, as they were "able to take charge of their own learning, determine their objectives, select methods and 
techniques and evaluate what has been acquired" (Littlewood, 1999). The link between goals and motivation is discussed in 6.3.2.2 (p. 215).

\subsubsection{Self-initiation as a result of self-regulation}

The proactiveness described above encompasses not only self-regulation but also selfinitiation. The two dimensions developed together and were clearly linked in phase two (see Figure 6.3, p. 229) , implying that self-regulation leads to self-initiation.

The link consisted mainly of the strategic behaviour the students developed as a result of the awareness of difficulties through monitoring and self-evaluating. Identifying their difficulties helped them set specific goals. Having specific goals gave them motivation, as explained earlier. Then, the motivation triggered effort. On the other hand, the awareness of their improvement, also from monitoring and self-evaluating, appeared to trigger awareness of their capability to improve. Such awareness gave them more motivation to set other goals or to keep the goals they had not reached yet, and again to make effort to attain those goals. The importance of motivation related to goal setting is discussed further in 6.3.2.2 ( $p$. 215).

Phase two showed that the combination of self-regulation and self-initiation enabled the students to develop a sense of responsibility, which they expressed in their reflections. They took charge of their writing and their learning in general. It was that sense of responsibility that encouraged them to find strategies to solve their problems or to attain their goals, and to persist until the achievement of their goals. That is why it is often said that the acceptance of responsibility is the foundation of self-regulation and LA:

This acceptance of responsibility has both socio-affective and cognitive implications: it entails at once a positive attitude to learning and the development of a capacity to reflect on the content and process of learning with a view to bringing them as far as possible under conscious control. (Little, 1995, p. 175)

Self-regulated learning can occur only when the ability to control strategic thinking processes is accompanied by the wish to do so. (Ushioda, 2007, p. 15)

Thus, it can be concluded from this study that the development of self-regulation triggers that of self-initiation, and vice versa. This is in line with what Nguyen (2008) states: "if learners take their own initiative, make an effort to learn, and they know how to manage 
and regulate their own learning, they should achieve good results in whatever they learn, including a foreign language" (p. 68).

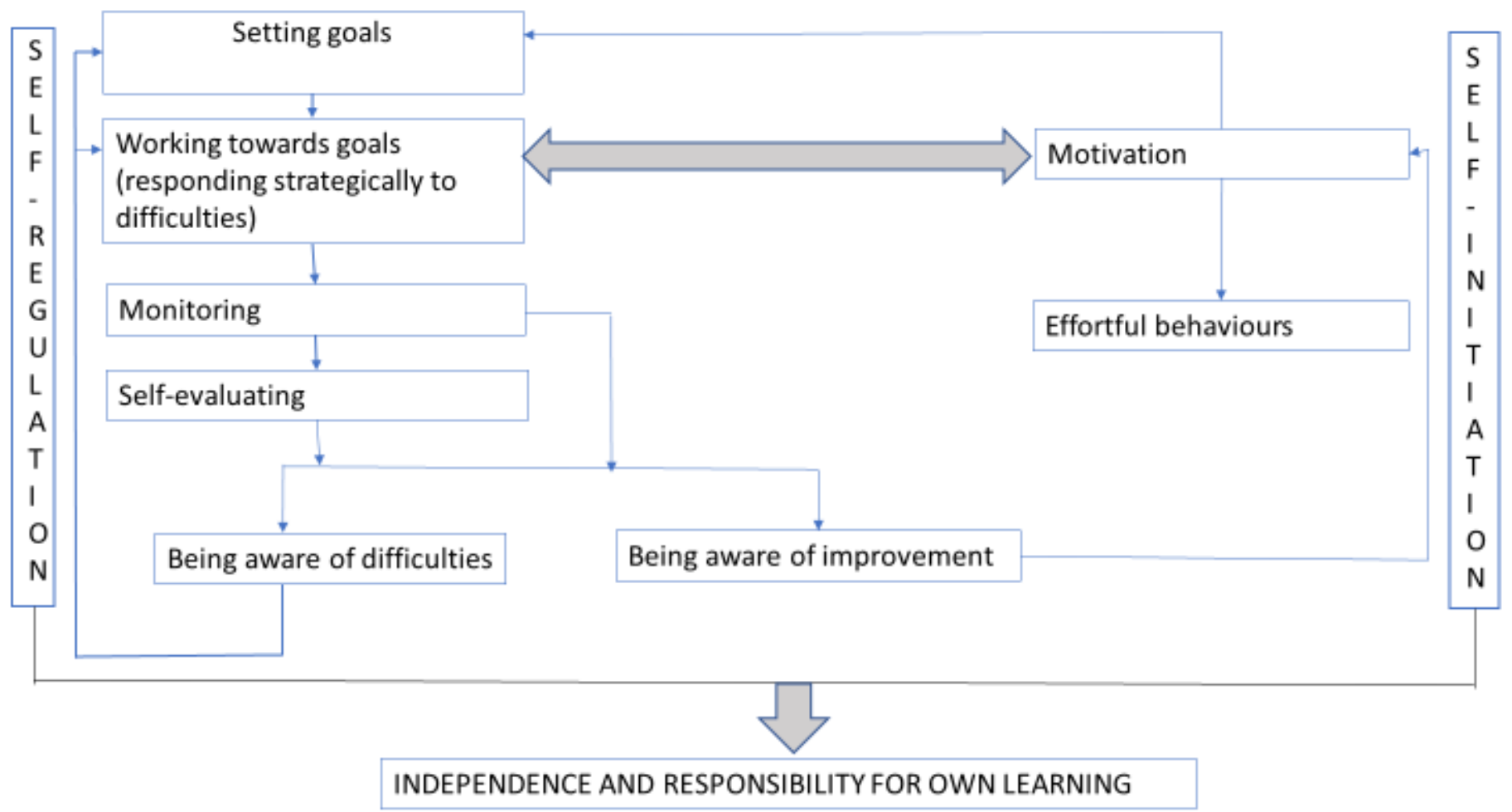

Figure 6.2 Interrelation between self-regulation and self-initiation

\subsubsection{Independence as a result of interdependence, self-regulation and self-initiation}

It was found in this study that the increasing sense of responsibility for learning, resulting from the development of self-regulation and of self-initiation, developed both students' interdependence and independence, two interconnected aspects that were promoted in both studies. Before discussing the link between independence and the sense of responsibility triggered by the development of self-regulation and self-initiation, this section first looks at how independence was triggered through interdependence in the two studies, and the caution to be considered regarding interdependence.

\subsubsection{Interdependence leading to independence}

The teachers in phase one promoted independence through interdependence. They explicitly stated that one of the reasons why they fostered peer collaboration in class (and out of class) was that they wanted to train their students not to rely on teachers. They used peer collaboration as a social mediation, as stated earlier. They encouraged their students, 
for example, to find answers to their own questions in pairs or in groups. In senior secondary classes, the students were given small group projects, in which they had to make decisions on content as groups, not depending on their teacher in any way. As a result of the constant encouragement of peer collaboration, the students would consult one another when having questions or even evaluated one another's work without being asked by the teacher. This clearly shows that interdependence does generate independence from teachers gradually, as advocated by the literature (P. Benson, 2011; Scharle \& Szabó, 2000).

For the same reason, peer collaboration was used in phase two. The student teachers were assigned to discuss their difficulties with writing in groups in order to find appropriate solutions. In addition, they were presented with difficulties that some of their peers (anonymously) had had, to which they also had to suggest solutions. Thus, peer collaboration clearly allowed them to "broaden[...] their use of English learning strategies" (Kao, 2011, p. 134), which made them aware of the power of interdependence and of their independence from the teacher.

\subsubsection{Caution with interdependence}

Undeniably, interdependence is conducive to autonomy (Dam, 2011; Kao, 2011; Palfreyman, 2018; Ryan, 1991; Tassinari, 2012). Moreover, interdependent skills need developing at school, as they are considerably important for the students' social life and their future, regardless of the jobs they will have (Kagan, 1994). However, advocates of cooperative learning like Kagan also made it clear that the use of cooperative learning should be limited. In other words, there must be time allocated to cooperative learning, but also to individual learning. In phase one in the rural setting, the latter seemed to be neglected on account of the dominance of peer collaboration. Interdependence seemed to overrule independence.

The neglect of independence is a concern because the students in this context have to sit for national examinations, which requires them to work alone. Though the focus should not be put on summative examinations, the latter need considering, as they are still the gateways towards further education and career opportunities in Madagascar (and in most parts of the world). In addition to examinations, preparing students for the "dynamics of working alone" (Crabbe, 1993, p. 447) is necessary for the "private domain", that is, their learning outside the classroom, and in their life in general. 


\subsubsection{Promoting independence through the promotion of self-regulation}

Considering the importance of independence described above, it needs promoting, especially in the Malagasy context, where interdependence seems to predominate. A promising way, as demonstrated in phase two, is to promote independence through the promotion of self-regulation via reflection. This seems to work in two ways.

Firstly, during the writing tasks and the reflections, independence was fostered as the students had to work on their own. They had to set their own goals, to evaluate their own strengths, progress, weaknesses, and the impacts of the reflective learning course on their writing/learning without any assistance from their peers or their teacher. They were, thus, developing their abilities to take charge of their own learning, as they were actively engaged in their learning process (Holec, 1981, 1990; Scharle \& Szabó, 2000).

Secondly, the students' independence resulted from the interdependence fostered through the group discussions, as stated above. The exchanges of ideas and strategies during the group discussions enabled them to develop independence in general in a way that they found out how to deal with some writing issues or how to tackle their next writing tasks on their own. In their reflections, they did express their understanding of the benefits of interdependence, but they also mentioned their awareness that it was their individual responsibility to use or adapt these strategies for the attainment of their individual writing/learning goals.

\subsubsection{Summary of dimensions}

Promoting self-regulation results in the promotion of self-initiation and independence, as phase two demonstrated. The self-regulatory skills of goal setting, monitoring, and selfevaluation can be developed through reflection. The awareness of difficulties caused by the monitoring and self-evaluation triggers strategic behaviour, resulting in the development of self-initiation. The strategic behaviour pushes learners to find ways to attain their goals both using interdependence and individual work, raising their awareness on their responsibility towards their learning. Their independence, then, increases, through the individual work, the reflection on their own learning, and the application of the strategies they have learned from their peers. 


\subsection{LA and language proficiency}

The preceding two sections discussed the importance of recognising the contextual constraints and of highlighting the affordances when implementing LA, as well as the interrelation between the three dimensions of LA, according to the findings from this research. The development of LA was a goal in its own right. However, it was also, and more importantly, a means to an end, that of better writing performances. This section discusses the impact of the development of the dimensions of LA on English proficiency. While the teachers in phase one acknowledged that their English was at the level it was thanks to their self-initiation, the student teachers in phase two could perceive the improvement in their writing thanks to the self-regulatory skills they had developed.

\subsubsection{Self-initiation and self-regulatory skills lead to better English proficiency in general}

Though phase one did not attempt to assess the teachers' language proficiency as a result of their LA, their beliefs based on their own learning experiences can be viewed as evidence. Intrinsically motivated, they made all possible effort to improve their English, implying their strong self-initiation. Related to their self-initiation were some self-regulatory skills. They did set goals, though the latter may not have been very specific. A clear example was Norah's case. Two years before the interview, she had had "zero English", and had not dared even to read in English in front of her colleagues, according to her. However, once she had set her goal of becoming a teacher of English, she did her best to improve her English, and she was persuaded that attending English courses would not suffice. The teachers also did some selfevaluation, though the latter may also have lacked specificity. They talked about their awareness that their English had improved through the years, and that they became teachers of English mostly due to their own effort outside class. They mentioned different strategies (including peer collaboration, which was seen during the three-week stay) and/or activities they had used outside class, which they thought, contributed to the improvement of their English.

Thus, it can be said that the teachers had improved their English proficiency at least partly because of their LA, which is in line with the literature advocating the essentiality of LA in language learning (e.g., Benson, 2001; Little, 1991). Though they may not have known what LA was, they were implementing it in their English language learning, and they clearly accepted to take charge of their own learning. 
Self-initiation, therefore, does result in a better language proficiency. As long as learners have motivation to push themselves to make an effort, they are likely to improve. However, the degree of improvement varies, and is likely to depend on whether they know exactly what they should improve, that is, whether, their goals are sufficiently clear or not. If their goals are clear, it will be easier for them to find the right strategies and to evaluate themselves. Otherwise, they may make an effort to do many activities without seeing any improvement, which may result in gradual demotivation. That argument justifies the development of self-regulatory or metacognitive skills of goal setting, monitoring, and selfevaluation, along with self-initiation.

\subsubsection{Self-regulation results in better writing performances}

In phase two, along with the development of self-regulation and self-initiation was the improvement of the students' writing, which was perceived by both the students and me.

The improvement resulted mostly from the acceptance of responsibility for their writing due to the reflection work, as stated earlier.

Monitoring and evaluating their own writing helped the students identify their difficulties, enabling them to look for appropriate strategies, as shown in Figure 6.2 (p. 223). Monitoring and self-evaluation also allowed them to perceive their progress and improvement, providing them with more motivation to work towards their goals. Through their selfevaluation and my feedback (mostly underlined mistakes and comments encouraging them to pay attention to some aspects of writing), they became more alert to the four aspects of writing (structure and style, clarity and conciseness, technical writing skills, and vocabulary), and developed a habit of editing their own writing. Self-editing was not limited to correcting mistakes. It encompassed deeper analyses, as some of the students' reflections showed (an example is included in Naia's case study, when she stated that she did her best to understand her mistakes). Self-editing helped them understand the nature of their mistakes and how the latter impacted the reader's understanding (Ferris, 2002). The habit of selfediting enhanced their evaluation skills (Nguyen \& Gu, 2013) and enabled them to help their peers edit their writing as well (Ferris, 2002). It can be concluded, thus, that the development of self-regulation did result in the improvement of the writing performances, which is in line with Nguyen's (2008) findings on the important correlation of writing scores with self-regulatory skills, especially monitoring. The process of the development of selfregulation resulting in the improvement of writing is shown in Figure 6.3 (p. 229). 
The results in both self-regulation and writing were not the same for every student in phase two, as evidenced by the students' scores, the difficulties they still had at the end of the course, and the improvement they had throughout the course. This is not surprising, as students differ from one another in terms of learning capacity, intelligence, cognitive strategies, and learning styles (P. Benson, 2007; Nguyen, 2008).

Self-regulation and writing performances are related respectively to what Little (1995) refers to as pedagogical autonomy and communicative autonomy. Little states that though these two dimensions are interdependent, they do not necessarily develop at the same pace. According to him, "we may successfully practise pedagogical autonomy from the first language lesson onwards, but it will be some time before our learners can venture forth as autonomous language users in the target language community" (p. 176). Every learner does not necessarily reach the same level of autonomy (Little, 1999). Moreover, they may not develop the self-regulatory or metacognitive skills (goal setting, monitoring, and selfevaluation) in an equal way: their ability in goal setting may improve in a period of nine weeks, but not their monitoring or self-evaluation ability, or vice versa. In addition, they may resist new approaches, and may consider it as a waste of time (cited in Yannick's 3RonC: her thought at the beginning). Also, some of them may have developed their self-regulatory skills, but the results of this development may not have been visible in their writing performances immediately. 


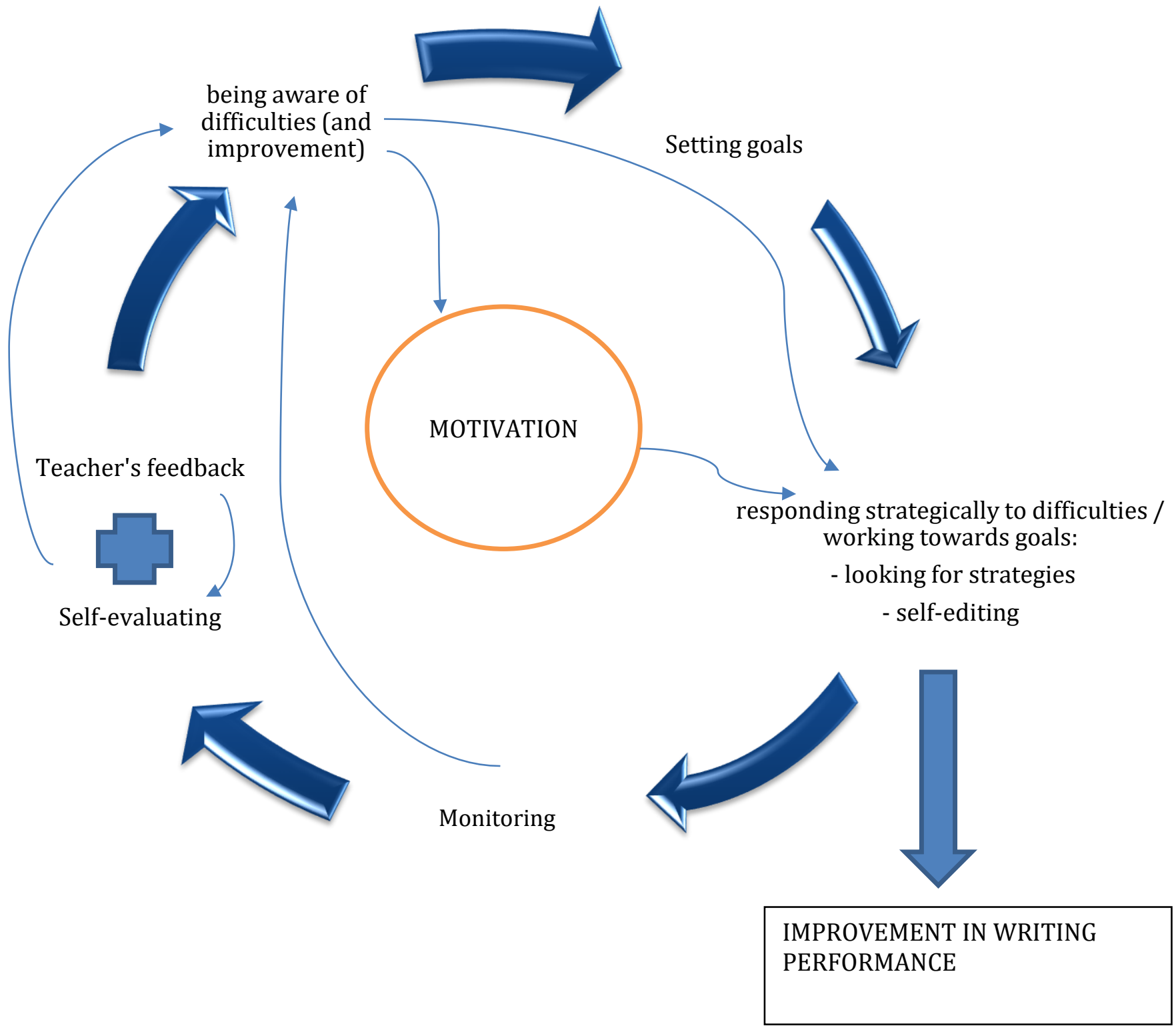

Figure 6.3 Development of self-regulation and improvement in writing

\subsubsection{Summary of LA and language proficiency}

This research has shown that the development of self-initiation and that of self-regulation resulted in the acceptance of responsibility towards learning. Once learners take charge of their learning and work towards their goals consciously, they are bound to do their best. The more specific their goals are, and the better monitoring and self-evaluation skills they have, the more likely it is for them to enhance their language proficiency, as demonstrated in phase two. The latter showed that the development of self-evaluation skills, constituted by the habit of self-editing together with the ability to identify their difficulties, gradually improved the students' writing performances. 


\subsection{Promoting LA to (student) teachers}

The positive impacts of LA on language proficiency indicates that its expanded promotion would be beneficial to language learning. This expansion is more likely to occur if teachers know how to foster LA in their students. The best way for teachers to have this knowledge is through experiencing LA in their own education (Little, 1995). Thus, LA should be included in teacher training. This is the claim this section will discuss, based on the findings of this research. This section also considers teacher autonomy as a goal in itself.

\subsubsection{Developing teacher-learner autonomy}

One of the reasons for the lack of affordances for self-regulation in the Malagasy rural setting (phase one) was the teachers' unfamiliarity with self-regulation. That was shown through their surprise during the interviews, when asked about students' setting goals for a task for example, and through their remarks and questions during informal interactions (for instance, when Christina asked me if the students should have goals each time then). The unfamiliarity with self-regulation was also noticed in phase two. Most of the student teachers were confused and did not understand why they had to answer the reflection prompts and why they should have goals for a task at the beginning. These findings indicate that the reason why teachers are not promoting LA may be because of their unawareness, not because of their unwillingness. As Nakata (2011) states, "reluctance to engage in attempts to promote LA should not be simply interpreted as lack of motivation to do so" ( $p$. 907). Therefore, it would be logical to suggest that the promotion of LA should start with teacher training: "If we are to achieve large-scale progress in the promotion of LA we must now bring our focus of concern back to the teacher, and especially to the way in which we organize and mediate teacher education" (Little, 1995, p. 180).

Two ways can be suggested to enable teachers to know about and to experience the promotion of LA. Giving training workshops and seminars on LA to in-service teachers as suggested by Al-Rabai (2017) is one of them. However, given that in-service teachers have already formed their beliefs through their experience in both learning and teaching (de los Angeles Clemente, 2011), it would be better if the promotion of autonomy were given before they become teachers, that is, during their teacher training, a learning experience. Thus, student teachers should be "taught" about LA. However, providing them with basic theories would not be sufficient to convince them about the importance of LA (Smith, 2003b). The "gap between their knowledge and practice" should be filled (Tütüniş, 2011, p. 
162) by practice itself. Furthermore, though they have not had any teaching experience yet, they have their learning experience, which must have formed some beliefs about what teaching and learning involve (de los Angeles Clemente, 2001; Prabhu, 1992). Thus, giving them opportunities to experience ways of promoting their own LA is much more powerful (Smith, 2003b; Smith \& Erdoğan, 2008), which phase two demonstrated.

In phase two, the students found it challenging to reflect, involving the setting of goals, monitoring, and self-evaluating, especially at the beginning. However, they quickly perceived the usefulness and efficiency of reflection (and the development of their self-regulation) on their writing and learning in general. Through the reflection, they understood the value of correcting their own mistakes, having goals, and taking charge of their learning. This understanding led them to revisit their expectations of teacher and students' roles, as described earlier. As they were gradually accepting their responsibility for their learning, they became more self-reliant. Though they still expected the teacher to give some feedback, they knew that the feedback would give them only ideas on what to improve, instead of providing them with correct words or grammar, for example. Therefore, they understood that the teacher role is to facilitate and to give some guidance (when needed), and to empower the students with self-awareness, leading to self-regulation:

If a student fails to understand some aspect of a lesson in class, he or she must possess the self-awareness and strategic knowledge to take corrective action. Even if it were possible for teachers to accommodate every student's limitation at any point during the school day, their assistance could undermine the most important aspect of this learning - a student's development of a capability to self-regulate. (Zimmerman, 2002, p. 65)

Seeing the benefits of the self-regulation they were developing via reflection made the students think of implementing reflection in their future teaching. This shows how important it is not only to raise teachers' awareness about LA, but also, to give (future) teachers opportunities to develop their own LA:

[...] learner autonomy becomes a matter for teacher education in two separate but related senses. We must provide trainee teachers with the skills to develop autonomy in the learners who will be given into their charge, but we must also give them a first-hand experience of LA in their training (Little, 1995, pp. 179-180). 


\subsubsection{Teacher autonomy as a goal in itself}

Teacher autonomy, defined as the capacity of self-directed teaching may not necessarily result in the capacity to promote LA (Nakata, 2011). Nevertheless, it should be seen as a goal, due to its leading to thriving professional development (Smith \& Erdogan, 2008).

Considering themselves as permanent learners, the teachers in phase one knew the effort they should make (and have made) to improve their language, as explained earlier. Thus, they were considerably aware of the importance of self-initiation, which they had maintained for further improvement of their language and for professional development. Coupled with and pushed by self-initiation was peer collaboration. They did use peer collaboration as a strategy to practise their speaking and to receive some peer evaluation. The combination of self-initiation and peer collaboration seems to be included in what Smith (2003b) defines as teacher-learner autonomy: "the ability to develop appropriate skills, knowledge and attitudes for oneself as a teacher, in cooperation with others" (p. 1).

In phase two, though the main goals were to help the student teachers develop their selfregulation of writing (and learning), and to encourage them to encourage the use of reflective journal writing with their future students, it also aimed to help them build the habit of reflecting to develop self-regulation in their future teaching. In other words, the aim was for them to transform "reflective learning" into "reflective teaching", given that reflection on their teaching is crucial for their professional development (Ambler, 2012; Larrivee, 2008; Smith, 2000), and that reflection enables them to evaluate their past teaching in order to make decisions for future planning (Endo, 2011). The habit of reflecting when learning and the awareness of the benefits of such reflection work on their learning would make it easier for them to accept (and hopefully to realise by themselves) the necessity of reflection on their teaching. Likewise, the responsibility, involving reflection, that the students had developed, for their learning may be transferrable to their future teaching, making them autonomous teachers:

Genuinely successful teachers with autonomy have a strong sense of personal responsibility for their teaching, exercising via continuous reflection and analysis the highest possible degree of affective and cognitive control of teaching process, and exploring the freedom that this confers (Little, 1995, p. 179). 
As Hacker and Barkhuizen (2008) demonstrate, it is hard to inculcate reflection with inservice teachers. The teachers in their study found it too time-consuming, and some of the teachers felt reflective journal writing did not really enable them to develop their metacognition. However, the overall findings revealed that, at the end of the study, the teachers appreciated reflective journal writing, as they realised its benefits on their teaching, with time and practice. Therefore, to save time, it would be ideal to integrate reflection in pre-service training.

\subsubsection{Summary of promoting LA to (student) teachers}

Promoting LA in an educational context starts with and depends on teachers to a large extent. Teachers' own education should allow the development of LA, if they are expected to help their own students develop their LA (Little, 1995). That is why including LA in teacher training curricula is likely to have a significant impact, and that is what phase two did. The students' experience developing their self-regulation provided them with an understanding and approach to their own learning that is likely to be transferred to their future teaching contexts. At the same time, they had developed a habit of reflection, an essential element for their future professional development or their self-directed teaching, which should be considered as a goal in its own right. It can be concluded, thus, that both teacher-learner autonomy and self-directed teaching were developed in phase two. As Smith (2003b) puts it: "After all, if teachers do not know how to / are not willing to engage in self-directed teaching and teacher-learning for their own benefit and that of their students, they are, of necessity, the 'victims' of received ideas" (p. 8).

\subsection{Summary of the chapter}

Four major points are discussed in this chapter. Firstly, LA is likely to flourish if the educational environment allows it to, as autonomy is an asset that learners own already (P. Benson, 2009; Holliday, 2003; Smith, 2003a), or at least they can reach (Little, 1999) . This research showed that autonomy does have its relevance in developing country contexts (Smith et al., 2018) like Madagascar. However, investigating the affordances and the constraints should be the first step before any implementation in any contexts. The affordances should then be highlighted and the constraints considered in the implementation. In the Malagasy context, as one of the most important affordances found in phase one was interdependence, it was promoted in phase two. On the other hand, as the 
constraints consisted of beliefs related to viewing goal setting and evaluation as exclusive teacher roles, phase two attempted to demonstrate that goal setting and evaluation can and should be conducted by students. That is why the dimension chosen to focus on was selfregulation.

Secondly, this research confirmed that self-regulation can be promoted by teachers and peers in classrooms (Zimmerman, 2002). It further demonstrated that the development of self-regulation through reflection results in the development of self-initiation and that of independence. With the awareness of difficulties, strategic behaviour develops, facilitating the independent search for strategies and using interdependence. Also, with realistic goals, motivation tends to be maintained.

Thirdly, this research showed that self-regulation and self-initiation are associated with the improvement of language proficiency. Since autonomous learners feel responsible for their learning, they make an effort to improve it in every way, as the teachers in phase one did. Additionally, learners equipped with self-regulatory skills can identify their difficulties more easily, helping them look for adequate solutions, as demonstrated by the students in phase two.

Finally, this research supports the promotion of LA to teachers and especially student teachers, in order for them to be able to promote it to their future students. Phase two particularly showed that experiencing the advantages of the development of LA on their own learning is highly likely to encourage student teachers to foster LA in their own students. As Little (2000) states, "It is unreasonable to expect teachers to foster the growth of autonomy in their learners if they themselves do not know what it is to be an autonomous learner". 


\section{Conclusion}

This research first studied the affordances for autonomy in a rural setting in Madagascar. That phase one revealed some "seeds" of autonomy that were incorporated in the teachers' beliefs and their practices in class and out of class. The absence of affordances for selfregulation found in phase one supported my initial intention to focus on self-regulation in phase two. The latter attempted to develop self-regulation through reflection among firstyear student teachers at a Malagasy university. The findings showed that reflection enhanced the students' LA in that it raised their awareness on every aspect of their writing and learning. Evidence from both studies demonstrated the relevance of LA in the EFL Malagasy context. It can be said that both studies have made theoretical, methodological, and pedagogical contributions to the field of LA in general, and in the Malagasy context in particular. This chapter discusses these specific contributions. Then, it outlines the limitations of the study. Finally, it draws some conclusions and recommends some directions for future research.

\subsection{Theoretical contributions}

The theoretical contributions provided by this research can be divided into four categories. Firstly, the research has conceptualised LA as having three dimensions: self-regulation, selfinitiation, and independence. Secondly, the research has demonstrated the importance of peer collaboration and affective factors in the development of LA. Thirdly, the research has confirmed the significance of LA in language learning by demonstrating the positive impacts of the development of self-regulation through reflection on the students' writing performances and their attitudes towards language learning. Lastly, the research has given insights into the promotion of LA in developing countries, especially in Madagascar. It also contributes to research on tertiary education in Madagascar.

\subsubsection{The three dimensions}

This research recognises self-regulation, self-initiation, and independence as a set of dimensions of LA. They are triggered by affordances such as peer collaboration and the consideration of affect. They are interrelated because the development of self-regulation results in the development of self-initiation and of independence.

According to the findings of phase two, the components of self-regulation, which are selfmanagement learning skills or metacognitive skills of planning, monitoring, and evaluating, 
along with affective factors, such as confidence, comfort, self-satisfaction, and negative feelings, such as disappointment and frustration, fosters strategic behaviour. The strategic behaviour results in the development of self-initiation, which comprises effortful behaviour pushed by motivation and volition. Effortful behaviour consists of making the most of any opportunities and creating opportunities to practise and to learn English, especially outside class. Effortful behaviour involves a sense of responsibility and persistence. Therefore, it may incorporate finding strategies, figuring out (alone or asking for help) how language works, including but not limited to grammar rules, the meaning of new words, formulation of sentences, reading more to know more vocabulary, listening more in order to improve pronunciation.

Phase two also showed that independence can be the result of self-regulation and selfinitiation. Once learners are motivated and adopt strategic behaviour, they are likely to be able to work alone, without the help of others. Although learning in isolation from other people' s support is not the ultimate goal of developing LA, the ability to work alone is as significant as the ability to work collaboratively, not only regarding language learning, but also with regard to the preparation of the learners for their future jobs and responsibilities in the future.

The interrelation found between the three dimensions confirms the indispensability of self-regulation and its inclusion in the development of LA. Learners may be motivated to learn, but they may not make sufficient effort. They may only focus on overt learning in class, but they do not make any extra effort to learn more (Nguyen, 2008). Another possibility is, learners may have self-initiation, in other words, they have the motivation and make all possible effort to learn, but they may not have specific goals. The absence of specific goals, firstly, implies the unawareness of difficulties. Therefore, not having specific goals can lead to a feeling of being overwhelmed, as there are so many different aspects of the language to learn. Secondly, it makes it difficult for learners to perceive improvement, which can lead to demotivation. As shown in phase two, the students really appreciated and understood the importance of seeing their improvement in relation to their goals.

\subsubsection{Key affordances for autonomy}

This research has confirmed the importance of social interactions in the development of autonomy (Aoki \& Smith, 1999; Kuchah \& Smith, 2011; Murase, 2015; Palfreyman, 2018). Indeed, peer collaboration was the most ubiquitous of the affordances for autonomy 
discovered in phase one. The teachers' promotion of peer collaboration was so frequent that the students tended to collaborate even without being asked to. The collaboration helped them become more and more independent from their teachers and accustomed to peer evaluation. Peer collaboration through group discussions was also promoted in phase two. Peer collaboration was considerably appreciated by the students on account of the learning through the exchanges it generated. As it allowed them to solve some of their problems or simply to know that their peers have the same problems as theirs, it gave them motivation, contributing to the development of both their self-regulation and self-initiation.

The research also showed the significance of affect, another prevalent affordance found in both studies, and advocated to play an important role in the development of autonomy by theorists and researchers in LA. Aware of the importance of affective factors, especially, motivation in language learning from their own learning experience, the teachers in phase one clearly endeavoured to increase their students' motivation through positive feedback and the promotion of peer collaboration. On the other hand, the student teachers in phase two gained motivation and self-confidence not only from peer collaboration but also from the realisation of their capability to improve with a little help from others. This realisation made them feel empowered and encouraged them to do their best to achieve their goals or to set other goals (if their previous goals had been achieved).

\subsubsection{Self-regulation and language learning}

It was evident in phase two of this research that a positive link between the development of self-regulation (connected with that of self-initiation) and language learning exists. Firstly, the research showed that the development of self-regulation resulted in the improvement of the students' writing performances. Though the results for each student in phase two were not the same, there was evidence showing that the awareness raised by the reflection, related to the development of the metacognitive skills, considerably helped the students detect their weaknesses and act accordingly. As stated above, the awareness of their weaknesses enabled them to have clear and specific goals. The more specific their goals were, the easier it was for them to seek strategies. From monitoring and self-evaluation, they learned to identify and correct their own mistakes, which explains the improvement perceived in their writing.

Secondly, their attitudes towards language learning changed. With the sense of responsibility and the awareness of capability (described above), their perception of what 
their role should be as learners shifted. They realised the importance of evaluating their own work, of setting and attempting to attain their own goals. This realisation made a few of them use (or think of using) reflection in other subjects related to English. Thus, they gradually took charge of their learning.

\subsubsection{LA in developing countries}

This research has brought insights into the potential and relevance of the implementation of LA in developing countries. Phase one showed the existence of affordances for autonomy, such as the promotion of peer collaboration, of peer evaluation, of self-evaluation, consideration of affect, not only in a developing country context, but also in a rural setting having rather "difficult circumstances" (Smith et al., 2018). Phase two demonstrated a way of implementing LA, or more specifically, a way of developing self-regulation in class among Malagasy EFL student teachers, which brought positive results. Findings from both studies confirmed that LA can have its place and constitute an educational goal in any setting as long as the context is well understood (Little, 1999; O'Leary, 2014) and the dimensions or elements of autonomy to focus on are well defined. This research has demonstrated that considering LA as a western concept is a misconception.

To date, this research seems to be the first to investigate LA in Madagascar. It not only examined affordances for autonomy, but it also implemented autonomy in a country where the term "learner autonomy" is not seen in any of the curricula designed by the Ministry of Education, and is often misinterpreted as self-instruction by Malagasy teachers and other people in the field of education. In this sense, this research can be considered as pioneer research with regard to LA in the Malagasy context.

Research on Malagasy tertiary education in general is scarce (Venart \& Reuter, 2014), hence the necessity of research such as the present one. One of the contributions of this research is the systemic understanding that the implementation of LA for teachers in training at tertiary level in Madagascar can be the best starting point to further implement LA at lower levels. By introducing and fostering LA in the tertiary students involved in the study, they saw for themselves the positive impacts of the development of their LA on their writing (and learning in general). In this way, the students will hopefully follow (or adapt) the same procedure of implementation of LA with their own students in the future. The necessity of including the application of LA in teacher education will be discussed further in section 7.3. 


\subsubsection{Summary of theoretical contributions}

The theoretical contributions of this research include the initial conceptualisation of LA into three dimensions and the identification of prevalent affordances that are considered to contribute to those dimensions. The research demonstrated that peer collaboration contributed to the development of self-regulation and self-initiation and that there is a clear connection between self-initiation and self-regulation, highlighting the significance of the latter. Additionally, the research confirmed the importance of LA in language learning by demonstrating the positive impacts of the development of self-regulation through reflection on the students' writing performances. Furthermore, the research has given insights on the promotion of LA in developing countries, like Madagascar.

\subsection{Methodological contributions}

This research has been divided into two phases for the ultimate goal of implementing LA in the Malagasy context. To reach that goal, it aimed first to have an understanding of the contextual affordances and constraints through an ethnographic approach. The contextual understanding reinforced my initial choice of focusing on self-regulation in phase two. The phase two intervention was intended to help students develop their self-regulation and was analysed through practitioner research.

\subsubsection{A rich contextual understanding via an ethnographic approach}

The value of the ethnographic approach used in phase one was that it enabled the discovery of affordances and constraints in a Malagasy EFL context. The approach consisted of interviews, class observations, and informal interactions. The data all contributed to building an understanding of teachers' beliefs and practices, constituting the affordances and constraints for fostering autonomy. At the same time, the interviews seemed to have some influence on the teachers' beliefs. In addition, the three-week "immersion" or stay in the school enabled information to be gathered about the affordances for the teachers' own autonomy as professional learners.

\subsubsection{Discovering affordances via interviews and class observations}

Phase one aimed to study contextual affordances for autonomy in the Malagasy setting. It enabled the knowledge of affordances for autonomy, such as teachers' beliefs including their attitudes towards autonomy (or aspects related to autonomy), which are important for 
two reasons. Firstly, teachers' beliefs are powerful in that they strongly influence their thoughts and behaviours (M. Borg, 2001). Secondly, "[i]ncreased awareness of one's own beliefs about language learning and of one's own understanding of learner autonomy can be considered a prerequisite to fostering learner autonomy" (Martinez, 2008, p. 118).

Furthermore, it is important to know the teachers' feelings and desires that serve as driving forces to them and keep them motivated (Hargreaves, 1994) when the ultimate aim is to introduce an innovative approach (de los Angeles Clemente, 2001). Though the aim of phase one was not to introduce LA overtly to the teachers, the knowledge of their beliefs and feelings related to autonomy was deemed necessary for a better preparation of the practitioner research with student teachers in phase two.

To achieve its aim, phase one used interviews and class observations, which are common tools utilised when intending to know teachers' beliefs and practices. However, the study was different from other studies focusing on teachers' beliefs or perspectives on LA (such as Alrabai (2017) and Nakata (2011)) in a way that it did not aim to address the topic of LA directly with the teachers. In other words, unlike the other studies, it did not intend to ask the teachers directly what they thought of or understood by LA. In fact, the term "learner autonomy" was never used during the interviews or the class observations. Neither were technical terms such as "self-regulation" and "self-initiation". Instead, the teachers were incited to talk about their perspectives, beliefs and their practices regarding elements that may be conducive to autonomy in a subtle way.

The teachers' perspectives and beliefs were compared to their in-class practices via class observations. Though not all the elements in the beliefs were perceivable, the interviews coupled with the class observations had two advantages. Firstly, they enabled some beliefs to be confirmed and some mismatches identified between beliefs and practices. The mismatch implied they were aware of the necessity of the elements, such as effortful behaviour outside class, but they had little knowledge on how to promote them with their students. Secondly, the combination of the interviews and the class observations revealed that the teachers' beliefs and practices had been influenced by the interviews.

Changing teachers' beliefs is not easy, as they have been formed through their own plausible evidence: socio-cultural factors (Littlewood, 1999), learning and teaching experiences (de los Angeles Clemente, 2001; Prabhu, 1992). However, findings in phase one showed the teachers' questioning their beliefs, as described in the discussion chapter (see 6.2.3.4.). Therefore, it can be said that the interviews led to reflection and self-awareness 
(Hurd, 2011). Instead of building resistance, the teachers thought more about their practice while reflecting on the rationale behind the interview questions. This research has therefore demonstrated that, firstly, interviews can be an efficient awareness-raising tool and a subtle way to introduce innovation in teaching and learning; and secondly, that there are underlying dynamics and effects of any "research investigation", implying that researchers using tools such as interviews are also participants in their own research, and that their questions (and even just their presence) surely produce effects on their participants (Gillham, 2000).

\subsubsection{More information through “immersion"}

Another feature that distinguishes phase one from other studies on teachers' beliefs and practices regarding autonomy is the short "immersion" I had in the school. Although phase one lasted only three weeks, staying there during that period of time enabled not only the completion of the interviews and the class observations, but also the possibility of more informal interactions with the teachers as well as the discovery of their practice outside class. These interactions occurred at school at lunchtime, during breaks, just before and after class, and outside school (as they all lived in the village where the school is, we came across each other often, for example, on the street, at church). These informal interactions, though not recordable and not meant to have any relevance to LA, were invaluable, as they built comfort between the teachers and me. The more informal interactions took place, the more relaxed the teachers were during the class observations. It was also thanks to these interactions that the questioning of beliefs described in the previous section was discovered. The interactions also brought about more knowledge about teachers' practice outside class, which are important elements of their teacher-learner autonomy (for example, the weekly meeting for speaking practice). In short, the "immersion" allowed the teachers to see that I was there not only to conduct research but also to socialise, and that I was willing to integrate myself in their community, which enabled them and me to be at ease with one another.

\subsubsection{Using practitioner research to develop self-regulation}

One of the findings in phase one was the absence of affordances for self-regulation. That finding supported my intention to concentrate on self-regulation in phase two, which involved practitioner research. Taking into account the prevalence of peer collaboration and 
its advantages (promotion of motivation, independence from the teacher, exchanges) perceived in phase one, peer collaboration was widely promoted in the practitioner research.

The findings showed positive results regarding the development of self-regulation, of selfinitiation, and the improvement of writing performances. The student teachers realised the importance of taking charge of their own learning and were convinced about the efficiency of reflection on their writing. That conviction made them start to think of implementing reflection with their future students. This shows how practitioner research can be a positively influential tool in terms of promoting LA.

\subsubsection{Summary of methodological contributions}

The more ethnographic approach of phase one combining interviews, the class observations, and the informal interactions made it possible to develop a deeper understanding of affordances for autonomy in the Malagasy context, and therefore suggested the relevance of autonomy in Madagascar. This relevance was further confirmed by the positive results of the practitioner research conducted in phase two. Thus, it can be said that the methods used in this research enabled the attainment of its goals, and emphasises the value of finding out the contextual affordances and constraints regarding autonomy in a Malagasy setting in order to better implement autonomy. More on the implementation of LA in such a context is discussed in the next section.

\subsection{Pedagogical contributions}

This section discusses pedagogical suggestions based on the findings of the research. It talks about what needs to be done to promote LA in a Malagasy context, including implications for classroom teaching. Then, it suggests more general implications on how LA can be fostered in any context.

\subsubsection{Promoting LA in a Malagasy context}

Phase two has shown the impact of reflection on the student teachers' perception of learning and teaching, as they came to understand the importance of being responsible for their learning. As student teachers, they began to make the connection between their learning experience regarding reflection and the development of self-regulation with their future teaching. Therefore, the first pedagogical implication from this research should be the 
necessity to start promoting LA among future teachers. The second implication might be to use reflection as a key operational tool for promoting LA, and the third will be to continue promoting peer collaboration, but with moderation.

\subsubsection{Starting with teacher training}

Phase two gave a specific example of how to promote LA in an EFL teacher training context. Courses such as "reflective learning" are essential at teacher training colleges. The reflective learning course allowed the student teachers to develop not only their LA, but also their ability to reflect on their learning. The use of reflection will be discussed further in the next section.

Though the reflective learning course had its flaws (discussed in the "responding to weaker learners" and the "limitations" sections in this chapter), it can be said that its aim was attained. It enabled the students to change their perspectives of learning and teaching.

As only a minority of future teachers can go to teacher training colleges in Madagascar, it is essential to equip these few people with the best tools. They will hopefully use such tools once they are in their own classrooms and spread the benefits of using the tools to their colleagues who did not have the chance to go to university. Educating one person out of thousands still can make a difference.

\subsubsection{Promoting reflection}

Phase one showed self-initiation including motivation and effortful behaviour in language learning on the part of the teachers. They strongly believed that self-initiation was key to the attainment of the level of their English and to their becoming teachers. They were totally aware of the importance of self-initiation. However, apart from encouraging their students to practise as much as they can, and boosting their motivation with positive feedback, the teachers did not seem to know how to promote self-initiation.

A way to promote self-initiation in a Malagasy context is through the promotion of reflection, as demonstrated in phase two. Firstly, using reflective journals can help develop self-regulation. Monitoring and self-evaluating while and after doing tasks result in the awareness of weaknesses, which develops into a problem-solving attitude or strategic behaviour, and enables the formulation of specific goals. The development of a problemsolving attitude implies self-initiation, as it involves effort. In brief, the use of reflection enables students' development of strategic behaviour, leading them gradually to take charge 
of their learning. Thus, the use of reflective journals is likely to be productive not only in language learning, but in any types of learning.

Perceiving the advantage of reflection on their learning, the students in phase two expressed some potential implementation of reflection in their future teaching, which was another aim of this research. In addition, an expectation from the research was to nurture reflection so that it becomes a habit that the students would keep when they teach, as reflection should be part of teachers' professional development (Tütüniş, 2011). It would help them analyse their own teaching including their difficulties and improvement and think of strategies they may need to apply, which will make their teaching more effective and successful:

Genuinely successful teachers have always been autonomous in the sense of having a strong sense of personal responsibility for their teaching, exercising via continuous reflection and analysis the highest possible degree of affective and cognitive control of the teaching process [...]. (Little, 1995, p. 179)

That is why O'Leary (2014) suggests the following:

Share your teaching 'know how' with your students, including your pedagogy for autonomy, and give them the opportunity to develop themselves (for instance, reflection, needs analysis) and others in terms of cognitive and metacognitive ability (for instance peer feedback, collaborative projects) (p. 35).

The reflective journal prompts can be in Malagasy or French and can be simplified according to the students' levels. For lower-level classes, students may need more help with answering the prompts. Therefore, instead of open questions, multiple choice questions may be more appropriate. To make it even easier for primary school children, the use of smileys may be more helpful and adequate when asking how they find a task, for instance. The use of "reflective learning" with other language skills will be discussed in the section on future research directions.

\subsubsection{Promoting peer collaboration}

The prevalence of peer collaboration in phase one and the advantages that peer collaboration presented in both phases can lead to the conclusion that peer collaboration is certainly a means to foster autonomy in the Malagasy context. As Wills et al. (2014) puts it, 
"where resources are lacking, teachers can make student learning more enriching in different ways, both inside and outside the classroom. For example, they could promote cooperative learning by incorporating group assignments into the syllabus [...]" (pp. 128129). Furthermore, it has been demonstrated in both phases that peer collaboration resulted in motivation, as stated by Wright (1987).

The findings in both phases demonstrated that promotion of peer collaboration led gradually to independence from the teacher, to motivation, to peer evaluation, and to selfevaluation, and that peer collaboration can be fostered at any levels, from primary school students to university students. Despite the advantages of peer collaboration, its use should be moderated and allocated to selected tasks in order not to encourage over-reliance on peers. Individual learning should have its place in the Malagasy context, as discussed in chapter 6 . Interdependence should not overrule independence. There should be a balance between them. As Palfreyman (2018) states, not all social learning contributes to the development of LA. The following are examples of how to make the most of peer collaboration to foster LA.

A clear example of promotion of peer collaboration involving peer evaluation with lower level students was the activity used in John's classes, when the students were asked to look at one another's writing and drawing. When asked which one they found the best, they answered with positive feedback. They also gave constructive feedback to the others (without being asked), which demonstrates the development of critical thinking. From this type of peer evaluation and the developing critical thinking, they were able to evaluate their own work. Although self-evaluating through comparison with others is not ideal as it may cause demotivation (because they may discover their peers' performances are much better than theirs) (Zimmerman, 2002), it may make them realise what their weaknesses are, and to encourage them to make more effort.

Using peer collaboration, coupled with individual reflection (as in the reflective learning course) can be significantly more efficient, as the students have opportunities to work by themselves (while doing the tasks and reflecting at the same time), which helps them develop their independence. Then they are given the opportunity to share their reflections, ideas, difficulties, and advice with their peers, developing their ability to collaborate with others. Also, both in-class and out-of-class tasks should enable individual work as well as collaborative work, and this should be clearly stated in the goals for each task. Group discussions can always be done after individual tasks to instil more reflection and exchange. 
Randomly assigning roles (for example, presenter, time-keeper, simple participant, notetaker) to group members in discussion appears to help students focus, as was done in phase two. The roles enabled the students in the study to discuss more efficiently, as they had to focus on the questions, to do their best to answer them (as one of them would have to present the answers in front of the class), and to finish in the allotted time. Also, the fact that the roles were chosen randomly prevented any group members from dominating the discussions, or from having a "free ride" or totally depending on the others (Palfreyman, 2018 , p. 58). This is related to the findings of Jensen, Johnson, and Johnson (2002), revealing that peer collaboration is more efficient when the members know they will all have the same score, rather than individual scores. In phase two, the groups did not work towards a score but towards a common goal, that of figuring out the best answers possible to the questions. Some of the students expressed their appreciation of the allocation of roles. They stated that having their assigned roles made them feel responsible.

Another way to balance interdependence and independence is allowing students to work collaboratively, and then having them reflect on their use of peer collaboration. This type of reflection is referred to as "metasocial" abilities by Tassinari (2012). It can help students selfevaluate with regard to their need for peer collaboration. They can gauge, for instance, when they feel the necessity to work with their peers, and to what extent they need the help of others (peers or teachers). Such evaluation will prevent them from using peer collaboration in an automatic way and will make them aware of their individual abilities as well as their abilities to work with others.

\subsubsection{General implications for classroom teaching}

In addition to the promotion of reflection and the promotion of peer collaboration with moderation, some practical pedagogical implications could be drawn from the findings of both phases. These include the revision of teacher roles, the choice of tasks and topics, the provision of autonomy-supportive strategies, the development of strategic behaviour through task repetition, ways to respond to weaker learners, and the potential use of thinkaloud protocols as part of reflection. These are the "changes in classroom practices [that] can make a difference" referred to by (T. Lamb, 2009, p. 83). 


\subsubsection{Revising teacher roles}

The aim of phase two encompassed making classes more learner-centred instead of teachercentred, which is a "move" implied by definition in the development of LA (Dam, 2011), and has been part of worldwide recent curriculum reforms (Westbrook et al., 2014). Effectively, it is logical that in order to promote LA, learners should be given the opportunity to feel that they are responsible for their learning, and giving such opportunities should be one of the teacher roles:

In formal educational contexts learners do not automatically accept responsibility for their learning - teachers must help them to do so; and they will not necessarily find it easy to reflect critically on the learning process - teachers must first provide them with appropriate tools and with opportunities to practise using them (Little, 1995, pp. 176-177).

It is, thus, the teacher role to provide what Crabbe $(2003,2007)$ refers to as a "learning opportunity". A learning opportunity is defined as "a specific cognitive or metacognitive activity that a learner can engage in that is likely to lead to learning" (Crabbe, 2007, p. 118). The metacognitive activity provided in phase two was the reflection, "adding value to tasks" (ibid, p. 122). In other words, adding the reflection to the writing tasks made the latter a source of learning and awareness. Among the suggestions Crabbe gave on how to add learning values to tasks were: to give learners opportunities to discuss difficulties encountered when doing the tasks and affective factors such as lack of self-confidence; to include the learning opportunities (the prompts to answer or to follow) explicitly in the teaching materials; and to evaluate the efficiency and the frequency of the "opportunity take-up" (ibid, p. 122) via learning logs. All these suggestions were put into practice in phase two.

Another teacher role is to motivate students by providing them with positive feedback, with meaningful and relevant tasks, with an atmosphere conducive to work, with opportunities to collaborate, and to self-evaluate (Wright, 1987). Phase two also attempted to provide all these points. It demonstrated that it was feasible to provide them all together, and that they did result in motivation and willingness to accept responsibility for learning: "Though learners are equipped with metacognitive strategies, these are vain if they do not feel any willingness to take their learning responsibility [...]" (B. Sinclair, 2009, p. 185). 
In addition to the ways of keeping students motivated above, Wright (1987) states that seeing the teacher motivated also impacts students. Whether teachers like it or not, they usually serve as models to their students. This is in keeping with what Little (1995) says: "[T]he teacher cannot help but teach "herself"" (p. 178), which makes every teacher unique even though they teach the same programme and follow the same curriculum. Therefore, teachers should show their motivation and their interest in what they teach.

\subsubsection{Choosing engaging tasks}

Still related to teacher roles, phase two showed the importance of the choice of the tasks. The students felt involved in the tasks and understood that the tasks were genuine: they engaged with the task "in such a way that they appropriate it to their own purposes." (Cotterall \& Cohen, 2003, p. 160). Indeed, the students knew that it was highly likely that they would be asked the questions included in the task instructions in real life. This explains why the tasks gave them incentives, pride, and even happiness at times, but sometimes disappointment and dissatisfaction with their own knowledge about the topics.

Phase one also demonstrates that when the students are aware that they need the language to really communicate, their willingness to make effort increases. An example was when I was observing one of Norah's classes, and the students wanted to ask me questions in English. They did their best to formulate the questions, as they genuinely wanted me to answer. They did "use the target language for genuinely communicative purposes, [allowing] them an equal share of discourse initiatives" (Little, 1995, p. 179), which should be provided by projects aiming to foster autonomy.

The task about recipes used in one of Christina's classes in phase one also motivated the students because it enabled them to talk about the food they eat and part of the chores they do every day. They felt the direct connection with their daily lives while preparing for the task, which is not the case for other types of homework, such as grammar gap-filling exercises or reading comprehension.

\subsubsection{Providing autonomy-supportive strategies}

Phase two did not aim to teach strategies explicitly. Though it enabled the students to use metacognitive strategies consisting of planning, monitoring and self-evaluating, the aim was for them to see the benefits of such strategies for their own learning, rather than "teaching" them. The other strategies that the students came up with were from their individual 
strategy research, group discussions, and presentations (after group discussions). In the group discussions, the students were prompted to reflect on strategies to tackle particular difficulties that some students had had when doing their writing. After the presentations, all the suggested strategies were wrapped up; and if there were some unsolved problems, the students were asked to think more about any possible strategies.

Overall, the aim of the study was to provide the students with autonomy-supportive strategies. As Ryan and Deci (2017) puts it, "autonomy-supportive versus controlling teaching strategies foster more autonomous forms of motivation in students and the higher quality engagement, performance, and the positive experience associated with it" (p. 351).

\subsubsection{Developing strategic behaviour through repetition}

Instead of overt strategy instructions, repetition - of both writing tasks and reflection prompts - was emphasised in phase two, as the objective was to raise students' awareness of their own difficulties and to encourage them to seek appropriate strategies. Repetition, which is also included in Crabbe's (2007) learning opportunities, raised the students' awareness of strategies they had known before. Bringing known strategies into consciousness is necessary (Leki, 1995) because, firstly, it enables students to use such strategies with awareness and at appropriate times, which is referred to as building their conditional knowledge of strategies (Gu, 2019). Secondly, it allows them to share them with their peers, making peer collaboration more effective. To take an example, the first case study showed that Naia had some metacognitive and cognitive strategies at her disposal from the beginning. However, she was also able to find other different types of strategies through peer collaboration and by persevering with her goals, as clear goals should be the basis of a strategy choice. Macaro (2006) puts it, "a key feature of a strategy should be the explicitness of its goal orientation" (p. 328).

Phase one also showed the importance of repetition. Though repetition did not necessarily develop strategic behaviour in John's students, it enhanced a certain autonomy. The students' familiarity with the stories and the in-class types of tasks grew through repetition. One of those tasks was peer evaluation, including the ability to think critically and give constructive feedback. The students also developed their self-evaluation through the comparison from the peer evaluation. Furthermore, they enhanced their awareness of language (Porto, 2007) by answering the same type of comprehension questions. 


\subsubsection{Responding to weaker learners}

All the students attending the reflective learning course in phase two claimed to notice improvement thanks to the course. They perceived improvement not only in their writing, but also in their behaviour involving self-regulation in writing. Indeed, they all made progress in both the development of self-regulation and writing, but not at the same level, as demonstrated especially in the second case study in chapter 5 (Katherine's case). Weaker learners like Katherine did not show much improvement. They were given the same opportunities as the others, but they did not benefit from them for a number of reasons. Firstly, not all learners are (or become) aware of what they need to learn (in relation to a particular task or in general). This unawareness deters them from using appropriate strategies: "they do not have the capacity to appraise both the demands of the task and their own learning needs in relation to that task in order to select appropriate instruction" (Kirschner \& van Merriënboer, 2013, p. 177).

Secondly, learners like Katherine lacked self-initiation: though they were sometimes aware of some of their difficulties, the willingness to solve these difficulties did not seem to be a priority for them. Therefore, such learners would need more incentives, which could be provided in the form of help and guidance to identify or narrow down their own weaknesses and their goals, to help them with finding strategies. A way to guide them may be to give them more detailed feedback with specific questions or, in case of strategies, they may be given some options to choose from. The appreciation of help with identifying mistakes and the need of more explicit teaching was perceived in two of the weaker learners' reflections.

"Simple" strategies, such as making a rough draft, and using monolingual dictionaries, should not be taken for granted. Thirdly, weaker learners tend to be more easily satisfied with their work. When they perceive a little improvement, they are persuaded that they have attained their goals. Therefore, they need assistance in identifying which goals have been achieved and which have not.

\subsubsection{Using think-aloud protocol as an alternative option}

One of the students with lower levels in phase two complained about journal writing being so time-consuming that it impacted her writing. However, she did acknowledge the usefulness of reflection by stating later that reflecting on her learning helped her evaluate her improvement and see the "value" of writing. Due to this acknowledgement and her awareness of difficulty caused by the simultaneity of the reflection and the writing, she 
suggested writing reflection not at the same time as the writing task. Though her suggestion seems to be a sensible solution, it would avoid capturing the thoughts and feelings as they appear, which was one of the goals of reflective learning.

One solution to that student's (and other students') difficulty would be the use of thinkaloud protocols (TAPs). Instead of writing down their reflection, they could say it aloud, while doing the task. Thinking aloud saves time, and might enable more "natural" descriptions, as it does not require the students to think of the appropriate words or expressions to use that writing requires (even though it is journal writing). Also, it would be easier for the students to use their first language when using TAPs. In fact, Jenny in phase one (chapter 3) was using TAPs in Malagasy when describing what she was doing and what she found difficult when doing her grammar exercise. Thus, one major advantage of TAPs is that they allow participants to voice their feelings about what they are doing while they are actually doing it, rather than retrospectively, as in other methods. Furthermore, TAPs make it possible for the researcher to gain an ethnographic perspective on the influence of context on learners' emotional responses and learning behaviour, including strategy use, as they occur (Hurd, 2011, p. 91). As TAPs enable students to focus more on "online processing" rather than planning and evaluating (Chamot, 2005, p. 114), it would be recommended to use TAPs in monitoring (during the writing task), and still use journal writing for the goal setting (before the task) and the self-evaluation (after the task).

\subsubsection{Summary of pedagogical contributions}

This research has demonstrated that elements of self-initiation and independence were already practised in a Malagasy rural setting. It has also revealed that the third element, self-regulation, which did not appear in phase one, can be enhanced through reflection, implying that the development of self-regulation can be done through training. Therefore, the pedagogical implications of this research strongly indicate the value of incorporating the promotion of LA in teacher education, of using reflective journals, and of promoting peer collaboration with moderation. In particular, this research has given insights into the relevance of peer collaboration to LA, which is still an under-researched area, according to Palfreyman (2018).

Additionally, the implications for classroom teaching encompass some practical aspects that would help with the attempt to foster LA. Apart from the use of reflection and peer collaboration, these aspects focus on the revision of the teacher's role. It has been said that 
teachers should provide their students with learning opportunities, adding value to the tasks they deal with; and the tasks should be engaging in a way that they feel a connection with, an interest in, or a perceived usefulness of the tasks. Teachers should also help students develop strategic behaviour, and a way to do so is through task repetition. Lastly, teachers should attend to weaker learners by giving them more guidance, and by using alternatives such as TAPs for reflections.

\subsection{Limitations}

Both phases in this research have some limitations, including the fact that both are smallscale in terms of numbers of participants and the time limit. Phase one involved only one rural school and focused on four teachers of English. Though the school is located in a rural area, it is in good conditions and has adequate facilities, which is not the case for most Malagasy rural schools. This is due to the aid the school receives from an overseas organization. It has a library with a large number of books, for instance. It also provides lunch to the students and teachers every day, which considerably helps both, given the state of poverty they are in. The time allocated to the study was limited to three weeks, which is rather short for developing an ethnographic account. Phase two involved only one class of twenty-two students. The class served as an experimental group, and there was no possibility of having a control group. Therefore, the study did not enable the comparison of the improvement of writing performances between a group doing the reflection and another one not doing the reflection, for example. The time for the study was also very limited, which explains the limited progress that could be perceived regarding the writing performances.

The findings of phase two relied heavily on the students' reflections, which might not always contain genuine information, and which can be influenced by factors such as the Hawthorne effect. Though the possibility of Hawthorne effect was minimised by constantly encouraging the students to state their sincere thoughts and feelings, and by reassuring them that their reflections would not be graded, it cannot be fully guaranteed that $100 \%$ of the content of their reflections is truthful. However, as Chamot (2005) states, "Although self-report may be inaccurate if learners do not report truthfully or cannot remember their thinking, it is still the only way available to use to develop some understanding of learner's mental processing." (p. 115) 


\subsection{Directions for further research}

The findings and limitations of this thesis suggest areas for future research. The conceptualisation of LA in this thesis can be used to develop more research on LA. Approaches to enhance self-initiation, independence, and self-regulation can be explored. As the focus of phase two is on the development of self-regulation, more directions regarding self-regulation will be suggested.

In phase two, reflective journals were used to help enhance the students' self-regulation of writing. Using TAPs rather than journals as a reflection tool would make for an interesting comparison. TAPs will enable the students to focus more on their writing tasks and to catch their feelings and their monitoring in a more "natural" way. Therefore, the students would not have to worry about doing two different writing "tasks" at the same time.

Another recommendation would be to have a control group in parallel with the experimental group. The control group would be taught writing in the "traditional" way. That is, the teacher would instruct them how to compose an essay, would give them writing tasks, and would provide feedback, including corrections of mistakes and scores. In this approach there would not be any opportunities to discuss the writing with peers. On the other hand, the experimental group would participate in "reflective learning" like the students in phase two. Such an experimental study would be a way to assess the impact of the reflection on the writing performances and thus to provide more quantitative results.

Phase two focused on writing, but "reflective learning" can also be adjusted to fit the other language skills, or other subjects, as a few of the students in the study already did. Having students reflect in a way that they set goals, monitor, and self-evaluate would not be difficult with reading. However, monitoring may be difficult with speaking and listening because of the simultaneity. Therefore, emphasis should be put more on setting goals and self-evaluating when dealing with these two language skills. Also, self-recording (Zimmerman, 2002), encompassed in TAPs, may be a useful way to help more with the selfevaluation of speaking.

The study concentrated on an EFL context with learners speaking the same languages (Malagasy and French). It would be interesting to conduct the same research in multilingual classes in an ESL context like New Zealand. The problems the learners would encounter might differ on account of their different language learning backgrounds, making the group discussions more enriching, as the discovery of new problems may lead to the discovery of 
new strategies and/or bring known strategies into consciousness. For instance, because of their similar backgrounds stressing on accuracy, the learners in the study tended to focus more on grammar mistakes than other aspects of writing. On the other hand, the lack of a shared L1 might inhibit the quality of the peer interaction.

Lastly, more ethnographic research can be conducted in other Malagasy rural schools and in Malagasy urban schools. The findings of such research may confirm some of the findings of this research or may bring other insights in terms of affordances for autonomy in the Malagasy EFL context. Likewise, it would be interesting to do similar research using an ethnographic approach in other developing countries in order to compare the cultural and social influences on the development and exercises of learner autonomy.

\subsection{Conclusion}

The key findings of this research were 1) the existence of affordances for autonomy (both LA and teacher autonomy) in the EFL Malagasy context, and 2) the effectiveness of reflective practice with regard to the development of self-regulation in writing. Phase two has demonstrated that when given opportunities to engage with their own learning processes through reflection, and to prove to themselves that they are able to solve their own problems, learners are likely to build their self-confidence and responsibility for their learning. Their own reflections over time raise their awareness of the importance of taking charge of their own learning. Furthermore, the development of their self-regulation had a positive impact on their writing performances. The study also revealed some potential for the new awareness of the value of self-regulation that was gained through reflection and peer collaboration to influence their practice as future teachers. 


\section{References}

Adams, P. (2006). Exploring social constructivism: theories and practicalities. Education 3-13, 34(3), 243-257. doi:10.1080/03004270600898893

Al-Rabai, F. (2017). Saudi EFL Teachers' Perspectives on Learner Autonomy. International Journal of Linguistics, 9(5), 211-231.

Allwright, D. (1988). Autonomy and individualization in whole-class instruction. In A. Brookes \& P. Grundy (Eds.), Individualization and autonomy in language learning (pp. 35-44). London: Modern English Publications and the British Council.

Allwright, D. (1990). Autonomy in language learning pedagogy. In CRILE Working Paper 6: Centre for Research in Education, University of Lancaster.

Allwright, D. (2003). Exploratory Practice: rethinking practitioner research in language teaching. Language Teaching Research, 7(2), 113-141.

Ambler, T. B. (2012). Autobiographical vignettes: a medium for teachers' professional learning through self-study and reflection. Teacher Development, 16(2), 181-197. doi:10.1080/13664530.2012.679864

Ampiah, J. G. (2008). An investigation of provision of quality basic education in Ghana: A case study of selected schools in the Central Region. Journal of International Cooperation in Education, 11(3), 19-37.

Anderson, N. J. (2012). Metacognition: Awareness of language learning. In S. Mercer, S. Ryan, \& M. Williams (Eds.), Psychology for Language Learning: Insights from research, theory and pedagogy (pp. 169-187). Basingtoke: Palgrave Macmillan.

Aoki, N., \& Smith, R. (1999). Learner autonomy in cultural context: The case of Japan. In S. Cotterall \& D. Crabbe (Eds.), Learner autonomy in language learning: Defining the field and effecting change (pp. 19-27). Frankfurt am Main: Peter Lang GmbH, Internationaler Verlag der Wissenshaften.

Au, K. H. (1998). Social Constructivism and the School Literacy Learning of Students of Diverse Backgrounds. Journal of Literacy Research, 30(2), 297-319. doi:10.1080/10862969809548000

Bartlett, S., \& Burton, D. (2006). Practitioner research or descriptions of classroom practice? A discussion of teachers investigating their classrooms. Educational Action Research, 14(3), 395-405. doi:10.1080/09650790600847735

Bayat, O. (2011). The relationship between autonomy perception and the reading comprehension achievement of English language learners. Eurasian Journal of Educational Research, 42, 15-28.

Bennett, P. A. (2018). Affective factors in learner autonomy. Relay Journal, 1(1), 128-132.

Benson, C. (2004). Do we expect too much of bilingual teachers? Bilingual teaching in developing countries. International Journal of Bilingual Education and Bilingualism, 7(2-3), 204-221.

Benson, P. (2001). Teaching and researching autonomy in language learning. Harlow: Pearson Education.

Benson, P. (2007). Autonomy in language teaching and learning. Language teaching, 40(1), 21-40. doi:10.1017/S0261444806003958

Benson, P. (2009). Making sense of autonomy in language learning. In R. Pemberton, R. Toogood, \& A. Barfield (Eds.), Maintaining control: Autonomy and language learning (pp. 13-26). Aberdeen, Hong Kong: Hong Kong University Press.

Benson, P. (2011). Teaching and researching autonomy (Second ed.). London and New York: Routledge. 
Benson, P., \& Lor, W. (1999). Conceptions of language and language learning. System: An International Journal of Educational Technology and Applied Linguistics: Special Issue on Metacognitive Knowledge and Beliefs in Language Learning, 27(4), 459-472.

Berg, B. L. (2001). Qualitative Research for the Social Sciences (Fourth ed.). Needham Heights, MA: Pearson Education Company.

Borg, M. (2001). Key concepts in ELT. Teachers' beliefs. ELT journal, 55(2), 186-188.

Borg, S., \& Al-Busaidi, S. (2012). Learner autonomy: English language teachers' beliefs and practices. ELT journal, 12(7), 1-45.

Boud, D. (1981). Developing student autonomy in learning. London. UK: Kogan Page.

Boud, D. (1988). Moving toward autonomy. In D. Boud (Ed.), Developing student autonomy in learning (Second ed., pp. 17-39). London and New York: Taylor \& Francis.

Boud, D. (2001). Using journal writing to enhance reflective practice. New directions for adult and continuing education, 2001(90), 9-18.

Boud, D., Keogh, R., \& Walker, D. (1985). Promoting reflection in learning: A model. Reflection: Turning experience into learning, 18-40.

Braun, V., \& Clarke, V. (2006). Using thematic analysis in psychology. Qualitative research in psychology, 3(2), 77-101.

Broady, E. (1996). Learner autonomy: An introduction to the issues. In E. Broady \& K. M.-M. (Eds.), Promoting learner autonomy in university language teaching (pp. 9-21). London: Association for French Language Studies in association with the Centre for Information on Language Teaching and Research.

Caillods, F., \& Postlethwaite, T. (1995). Teaching/learning conditions in developing countries. Educational planning: the international dimension, 3-24.

Candy, P. C. (1991). Self-Direction for Lifelong Learning. A Comprehensive Guide to Theory and Practice: ERIC.

Carson, L., \& Mynard, J. (2012). Introduction. In J. Mynard \& L. Carson (Eds.), Advising in language learning: Dialogs, tools and context. Harlow: Routledge.

Chamot, A. U. (2005). Language learning strategy instruction: Current issues and research. Annual review of applied linguistics, 25, 112-130.

Chan, V. (2003). Autonomous language learning: The teachers' perspectives. Teaching in higher education, 8(1), 33-54.

Chapelle, C. A., \& Duff, P. A. (2003). Some guidelines for conducting quantitative and qualitative research in TESOL. TESOL quarterly, 37(1), 157-178.

Chu, P.-y. (2007). How students react to the power and responsibility of being decision makers in their own learning. Language Teaching Research, 11(2), 225-241.

Cohen, A. D. (1999). Language learning strategies instruction and research. Learner autonomy in language learning: Defining the field and effecting change, 8, 61-68.

Cohen, A. D., \& Weaver, S. J. (1998). Strategies-based instructions for second language learners. ANTHOLOGY SERIES-SEAMEO REGIONAL LANGUAGE CENTRE, 1-25.

Cotterall, S. (1995). Readiness for autonomy: Investigating learner beliefs. System, 23(2), 195-205. doi:https://doi.org/10.1016/0346-251X(95)00008-8

Cotterall, S. (2000). Promoting learner autonomy through the curriculum: principles for designing language courses. ELT journal, 54(2), 109-117. doi:10.1093/elt/54.2.109

Cotterall, S. (2009). Learner autonomy in a mainstream writing course: Articulating learning gains. In R. Pemberton, Toogood, S. \& Barfield, A. (Ed.), Maintaining control: Autonomy and language learning (pp. 87-107). Aberdeen, Hong Kong: Hong Kong University Press.

Cotterall, S. (2017). The pedagogy of learner autonomy: Lessons from the classroom. Studies in Self-Access Learning Journal, 8(2), 102-115. 
Cotterall, S., \& Cohen, R. (2003). Scaffolding for second language writers: producing an academic essay. ELT journal, 57(2), 158-166.

Cotterall, S., \& Crabbe, D. (2008). Learners talking: from problem to solution. In T. Lamb \& H. Reinders (Eds.), Learner and teacher autonomy. Concepts, Realities and Responses (pp. 125-140). Amsterdam: Peter Lang.

Cotterall, S., \& Murray, G. (2009). Enhancing metacognitive knowledge: Structure, affordances and self. System, 37(1), 34-45.

Crabbe, D. (1993). Fostering autonomy from within the classroom: the teacher's responsibility. System, 21(4), 443-452. doi:https://doi.org/10.1016/0346251X(93)90056-M

Crabbe, D. (2003). The quality of language learning opportunities. TESOL quarterly, 37(1), 934.

Crabbe, D. (2007). Learning opportunities: adding learning value to tasks. ELT journal, 61(2), 117-125.

Creswell, J. W. (2009). Research Design - Qualitative, Quantitative, and Mixed Methods Approaches (Third ed.): SAGE Publications, Inc.

Cunningham, J., \& Carlton, W. (2003). Collaborative newsletters. In A. Barfield \& M. Nix (Eds.), Autonomy you ask! (pp. 113-128). Tokyo: Learner Development Special Interest Group of the Japan Association for Language Teaching.

Dadds, M., \& Hart, S. (2001). Doing practitioner research differently. London: Routlege Falmer.

Dam, L. (1995). Learner autonomy: From theory to classroom practice (Vol. 3). Dublin: Authentik Language Learning Resources.

Dam, L. (2009). The use of logbooks-a tool for developing learner autonomy. In R. Pemberton, Toogood, R. \& Barfield, A. (Ed.), Maintaining control: Autonomy and language learning (pp. 125-144). Aberdeen, Hong Kong: Hong Kong University Press.

Dam, L. (2011). Developing learner autonomy with school kids: Principles, practices, results. In D. Gardner (Ed.), Fostering Autonomy in Language Learning (pp. 40-51). Gaziantep: Zirve University: Retrieved from http://ilac2010.zirve.edu.tr.

Dam, L., Eriksson, R., Little, D., Miliander, J., \& Trebbi, T. (1990). Towards a definition of autonomy. Paper presented at the Third Nordic workshop on developing autonomous learning in the FL classroom.

de los Angeles Clemente, M. (2001). Teachers attitudes within a self-directed language learning scheme. System, 29(1), 45-67.

Deci, E. L. (1996). Why we do what we do: The dynamics of personal autonomy. New York: Penguin.

Diab, N. M. (2010). Effects of peer-versus self-editing on students' revision of language errors in revised drafts. System, 38(1), 85-95.

Dickinson, L. (1993). Talking shop: Aspects of autonomous learning. ELT journal, 47(4), 330336.

Dickinson, L. (1995). Autonomy and motivation a literature review. System, 23(2), 165-174.

Dişlen, G. (2011). Exploration of how students perceive autonomous learning in an EFL context. In D. Gardner (Ed.), Fostering Autonomy in Language Learning. Gaziantep : Zirve University: Retrieved from http://ilac2010.zirve.edu.tr.

Dörnyei, Z. (2009). The L2 motivational self system. Motivation, language identity and the L2 self, 36(3), 9-11.

Dörnyei, Z., \& Ottó, I. (1998). Motivation in action: A process model of L2 motivation.

Duff, P. A. (2008). Case study research in applied linguistics. New York: Taylor \& Francis Group. 
Duff, P. A. (2012). How to carry out case study research. Research methods in second language acquisition: A practical guide, 95-116.

Dunn, T. G., \& Shriner, C. (1999). Deliberate practice in teaching: What teachers do for selfimprovement. Teaching and teacher education, 15(6), 631-651.

Endo, Y. (2011). Teacher trainees' autonomous development through reflection. In D. Gardner (Ed.), Fostering Autonomy in Language Learning (pp. 173-184). Gaziantep: Zirve University: Retrieved from http://ilac2010.zirve.edu.tr.

Esch, E. (1996). Promoting learner autonomy: Criteria for the selection of appropriate methods. In R. Pemberton, E. S. L. Li, W. W. F. Or, \& H. D. Pierson (Eds.), Taking control: Autonomy in language learning (pp. 35-48). Hong Kong: Honh Kong University Press.

Esch, E. (2009). Crash or clash? Autonomy 10 years on. Maintaining control: Autonomy and language learning, 27-44.

Ferraro, G. (2002). Global Brains - Knowledge and Competencies for the 21st Century. Charlotte, North Carolina: Intercultural Associates, Inc.

Ferris, D. (2002). Teaching students to self-edit. In J. C. Richards \& W. A. Renandya (Eds.), Methodology in language teaching: An anthology of current practice (pp. 328-334). Cambrdige: Cambridge University Press.

Fonseka, E. G. (2003). Autonomy in a resource-poor setting: Enhancing the carnivalesque. In D. Palfreyman \& R. Smith (Eds.), Learner Autonomy across Cultures - Language Education Perspectives (pp. 147-163). Hampshire, New York: Palgrave Macmillan.

Fotos, S. (2001). Cognitive approaches to grammar instruction. Teaching English as a second or foreign language, 3, 267-283.

Gagne, R. M. (1975). Essentials of learning for instruction: Dryden Press.

Gardner, R. C., \& Lambert, W. E. (1972). Attitudes and Motivation in Second-Language Learning.

Gillham, B. (2000). Case study research methods: Bloomsbury Publishing.

Glewwe, P., \& Kremer, M. (2006). Schools, teachers, and education outcomes in developing countries. Handbook of the Economics of Education, 2, 945-1017.

Graham, S., \& Perin, D. (2007). A meta-analysis of writing instruction for adolescent students. Journal of Educational Psychology, 99, 445-476.

Gu, Y. (2009). [LALS 516 Learner Autonomy and Learning Strategies course notes. School of Linguistics and Applied Language Studies].

Gu, Y. (2019). Approaches to Learning Strategy Instruction In A. U. H. Chamot, V. (Ed.), Learning strategy instruction in the language classroom: Issues and implementation (pp. 22-37). London: Multilingual Matters Ltd.

Hacker, P., \& Barkhuizen, G. (2008). Developing personal theories through reflection in language teacher education. Learner and Teacher Autonomy: Concepts, realities, and response, $1,161-183$

Hargreaves, A. (1994). Changing Teachers, Changing Times. London: Cassell.

Holec, H. (1981). Autonomy and foreign language learning. . In: Oxford: Pegamon Press.

Holec, H. (1990). Qu'est-ce qu'apprendre à apprendre. Mélanges pédagogiques, 1990, 7587.

Holliday, A. (2003). Social autonomy: Addressing the dangers of culturism in TESOL. In D. Palfreyman \& R. Smith (Eds.), Learner autonomy across cultures - Language Education Perspectives (pp. 110-126). Hampshire, New York: Palgrave Macmillan.

Hord, S. M. (1986). A Synthesis of Research on Organizational Collaboration. Educational leadership, 43(5), 22-26. 
Huang, J. P., \& Benson, P. (2013). Autonomy, agency and identity in foreign and second language education. Chinese Journal of Applied Linguistics, 36(1), 7-28.

Hurd, S. (2011). Research methods to investigate emotions in independent language learning: A focus on think-aloud verbal protocols. In B. Morrison (Ed.), Independent Language Learning: Building on Experience, Seeking New Perspectives (pp. 87-100). Aberdeen, Hong Kong: Hong Kong University Press.

Izumi, S. (2002). Output, input enhancement, and the noticing hypothesis: An Experimental Study on ESL Relativization. Studies in second language acquisition, 24(4), 541-577. doi:10.1017/S0272263102004023

Jensen, M., Johnson, D. W., \& Johnson, R. T. (2002). Impact of positive interdependence during electronic quizzes on discourse and achievement. The Journal of Educational Research, 95(3), 161-166.

Kagan, S. (1994). Cooperative Learning. San Clemente: Kagan.

Kao, S.-H. (2011). Developing learner autonomy through peer teaching experiences. In B. Morrison (Ed.), Independent Language Learning: Building on Experience, Seeking New Perspectives (pp. 131-144). Aberdeen, Hong Kong: Hong Kong University Press.

Karlsson, L., Kjisik, F., \& von Boehm, S. (2012). ALMS Counselling: Stories of Research and Practice. In C. Ludwig \& J. Mynard (Eds.), Autonomy in Language Learning: Advising in Action (pp. 28-38). Kent: International Association of Teachers of English as a Foreign Language (IATEFL).

Kato, S., \& Mynard, J. (2016). Reflective dialogue: Advising in language learning. New York: Routledge.

Keller, E. (2009). The danger of misunderstanding 'culture'. Madagascar Conservation \& Development, 4(2), 82-85.

Kemmis, S. (2009). Action research as a practice-based practice. Educational Action Research, 17(3), 463-474. doi:10.1080/09650790903093284

Kirschner, P. A., \& van Merriënboer, J. J. (2013). Do learners really know best? Urban legends in education. Educational psychologist, 48(3), 169-183.

Kojima, H. (2008). A CARL approach to promoting EFL teacher trainees' autonomy in preservice teacher education at a Japanese university. JALT Teacher Education SIG Newsletter Exploration in Teacher Education, 16(3), 3-14.

Kojima, H. (2012). Advising for Teacher Autonomy in the Practice of Collaborative, Autonomous, and Reflective Learning. In L. M. Christian, J. (Ed.), Autonomy in Language Learning: Advising in Action (pp. 84-101). Kent, UK: IATEFL, Darwin College, University of Kent.

Kuchah, K., \& Smith, R. (2011). Pedagogy of autonomy for difficult circumstances: From practice to principles. Innovation in Language Learning and Teaching, 5(2), 119-140.

La Ganza, W. (2008). Learner autonomy-teacher autonomy. In T. Lamb \& H. Reinders (Eds.), Learner and Teacher Autonomy: Concepts, Realities and Responses (pp. 63-79). Amsterdam, Philadelphia: John Benjamins Publiching Company.

Lamb, M. (2007). The impact of school on EFL learning motivation: An Indonesian case study. TESOL quarterly, 41(4), 757-780.

Lamb, T. (2009). Controlling learning: Learners' voices and relationships between motivation and learner autonomy. In R. Pemberton, R. Toogood, \& A. Barfield (Eds.), Maintaining control: Autonomy and language learning (pp. 67-86). Aberdeen, Hong Kong: Hong Kong University Press.

Larrivee, B. (2008). Development of a tool to assess teachers' level of reflective practice.

Reflective practice, 9(3), 341-360.

doi:http://dx.doi.org/10.1080/14623940802207451 
Lassibille, G., Tan, J.-P., Jesse, C., \& Van Nguyen, T. (2010). Managing for results in primary education in Madagascar: Evaluating the impact of selected workflow interventions. The world bank economic review, 24(2), 303-329.

LaVaque-Manty, M., \& Evans, M. (2013). Implementing metacognitive interventions in disciplinary writing classes. In M. Kaplan, D. LaVaque-Manty, \& D. Meizlish (Eds.), Using Reflection and Metacognition to Improve Student Learning: Across the Disciplines, Across the Academy (pp. 122-146). Sterling, Virginia: Stylus Publishing.

Leki, I. (1995). Coping strategies of ESL students in writing tasks across the curriculum. TESOL quarterly, 29(2), 235-260.

Lewis, T. (2013). Between the social and the selfish: learner autonomy in online environments. Innovation in Language Learning and Teaching, 7(3), 198-212. doi:10.1080/17501229.2013.836202

Lie, A. (2007). Education policy and EFL curriculum in Indonesia: Between the commitment to competence and the quest for higher test scores. TEFLIN journal, 18(1), 01-15.

Little, D. (1991). Learner autonomy: Definitions, issues and problems: Authentik Language Learning Resources.

Little, D. (1994). Learner autonomy: A theoertical construct and its practical application. Die Neuren Sprachen, 93(5), 430-442.

Little, D. (1995). Learning as dialogue: The dependence of learner autonomy on teacher autonomy. System, 23(2), 175-181.

Little, D. (1999). Learner autonomy is more than a western cultural construct. In S. Cotterall \& D. Crabbe (Eds.), Learner autonomy in language learning: Defining the field and effecting change (pp. 11-18). Frankfurt am Main: Peter Lang GmbH, Internationaler Verlag der Wissenshaften.

Little, D. (2000). We're all in it together: Exploring the interdependence of teacher and learner autonomy. Paper presented at the Proceeding of the 7th Nordic Conference and Workshop on Autonomous Language Learning, Helsinki.

Little, D. (2003). Tandem language learning and learner autonomy. In T. Lewis \& L. Walker (Eds.), Autonomous language learning in tandem (pp. 37-44). Sheffield: Academy Electronic Publications.

Little, D. (2007). Language learner autonomy: Some fundamental considerations revisited. International Journal of Innovation in Language Learning and Teaching, 1(1), 14-29.

Little, D. (2011). Learner autonomy, self-assessment and language tests: towards a new assessment culture. In B. Morrison (Ed.), Independent Language Learning - Building on Experience, Seeking New Perspectives (pp. 25-39). Aberdeen, Hong Kong: Hong Kong University Press.

Littlejohn, A. (1997). Self-access work and curriculum ideologies. In P. Benson \& P. Voller (Eds.), Autonomy and independence in language learning (pp. 181-191). New York: Longman.

Littlemore, J. (2001). Learner autonomy, self-instruction and new technologies in language learning: current theory and practice in higher education. ICT and language learning: A European perspective, 39-52.

Littlewood, W. (1996). "Autonomy": An anatomy and a framework. System, 24(4), 427-435. Littlewood, W. (1999). Defining and developing autonomy in East Asian contexts. Applied linguistics, 20(1), 71-94.

Locke, E. A., \& Latham, G. P. (2002). Building a practically useful theory of goal setting and task motivation: A 35-year odyssey. American psychologist, 57(9), 705-717. doi:10.1037/0003-066x.57.9.705 
Locke, E. A., \& Latham, G. P. (2006). New directions in goal-setting theory. Current directions in psychological science, 15(5), 265-268.

Macaro, E. (2006). Strategies for language learning and for language use: Revising the theoretical framework. The Modern Language Journal, 90(3), 320-337.

Martinez, H. (2008). The subjective theories of student teachers Implications for teacher education and research on learner autonomy. Learner and teacher autonomy: Concepts, realities, and response, 1, 103-124.

McCambridge, J., Witton, J., \& Elbourne, D. R. (2014). Systematic review of the Hawthorne effect: new concepts are needed to study research participation effects. Journal of clinical epidemiology, 67(3), 267-277.

McDonough, S. H. (1999). Learner strategies. Language teaching, 32(1), 1-18.

McGrath, I. (2000). Teacher autonomy. In B. Sinclair, I. McGrath, \& T. Lamb (Eds.), Learner autonomy, teacher autonomy: Future directions (pp. 100-110). Essex, England: Pearson Education Limited.

Meirink, J. A., Imants, J., Meijer, P. C., \& Verloop, N. (2010). Teacher learning and collaboration in innovative teams. Cambridge Journal of Education, 40(2), 161-181. doi:10.1080/0305764X.2010.481256

Mercer, S., \& Gregersen, T. (2020). Me and my relationships. In S. Mercer \& T. Gregersen (Eds.), Teacher Wellbeing: Oxford University Press.

Mercer, S., MacIntyre, P., Gregersen, T., \& Talbot, K. (2018). Positive Language Education: Combining positive education and language education. Theory and Practice of Second Language Acquisition, 4(2), 11-31.

Ministère de l'Éducation Nationale, M. (2016). Systeme educatif. Retrieved from http://www.education.gov.mg

Moon, J. A. (1999). Reflection in learning and professional development: Theory and practice. London and New York: RoutledgeFalmer.

Moon, J. A. (2013). Reflection in learning and professional development: Theory and practice: Routledge.

Mulkeen, A., Chapman, D. W., DeJaeghere, J. G., \& Leu, E. (2007). Recruiting, Retaining, and Retraining Secondary School Teachers and Principals in Sub-Saharan Africa (Vol. World Bank Working Paper NO. 99). Washington D.C.

Murase, F. (2015). Measuring language learner autonomy: problems and possibilities. In C. J. Everhard \& L. Murphy (Eds.), Assessment and autonomy in language learning (pp. 3563). Hampshire, New York: Palgrave Macmillan.

Murray, G. (2011). Metacognition and imagination in self-access language learning. In D.

Gardner (Ed.), Fostering Autonomy in Language Learning. Gaziantep: Zirve University: Retrieved from http://ilac2010.zirve.edu.tr.

Murray, G. (2014a). Exploring the social dimensions of autonomy in language learning. In G. Murray (Ed.), Social dimensions of autonomy in language learning (pp. 3-11). Hampshire/New York: Springer.

Murray, G. (2014b). The social dimensions of learner autonomy and self-regulated learning.

Mynard, J. (2010). Promoting cognitive and metacognitive awareness through self-study modules: An investigation into advisor comments. Paper presented at the Proceedings of the International Conference CLaSIC 2010 "Individual Characteristics and Subjective Variables in Language Learning", Singapore.

Nakata, Y. (2011). Teachers' readiness for promoting learner autonomy: A study of Japanese EFL high school teachers. Teaching and teacher education, 27(5), 900-910.

Nation, P. (2007). The Four Strands. Innovation in Language Learning and Teaching, 1(1), 213. doi:10.2167/illt039.0 
Natri, T. (2007). Active learnership in continuous self-and peer-evaluation. In Reconstructing autonomy in language education (pp. 108-119): Springer.

Neumann, H., \& McDonough, K. (2015). Exploring student interaction during collaborative prewriting discussions and its relationship to $L 2$ writing. Journal of Second Language Writing, 27, 84-104.

Nguyen, L. T. C. (2008). Learner autonomy and EFL proficiency: A Vietnamese perspective. Asian Journal of English Language Teaching, 18, 67-87.

Nguyen, L. T. C., \& Gu, Y. (2013). Strategy-based instruction: A learner-focused approach to developing learner autonomy. Language Teaching Research, 17(1), 9-30. doi:10.1177/1362168812457528

Nix, M. (2003). Writing autonomy; or 'It's the content, stupid!'. In A. Barfield \& M. Nix (Eds.), Autonomy you ask! (pp. 197-212). Tokyo: Learner Development Special Interest Group of the Japan Association for Language Teaching.

O'Leary, C. (2014). Developing autonomous language learners in HE: A social constructivist perspective. In Social dimensions of autonomy in language learning (pp. 15-36): Springer.

O'Malley, J. M., \& Chamot, A. U. (1990). Learning strategies in second language acquisition. Cambridge: Cambridge University Press.

Osborne, T. (2016). Poverty and employment in Madagascar 2001-2012: A synthesis of recent findings. In Shifting Fortunes and Enduring Poverty in Madagascar: http://documents.worldbank.org/curated/en/413071489776943644/pdf/113582-v2FINAL-PUBLIC-7817-Madagascar-Poverty-Report.pdf.

Oxford, R. L. (2002). Language learning strategies in a nutshell: Update and ESL suggestions. In J. C. Richards \& W. A. Renandya (Eds.), Methodology in language teaching: An anthology of current practice (pp. 124-132). Cambridge: Cambridge University Press.

Oxford, R. L. (2003a). Language learning styles and strategies: An overview. Learning Styles \& Strategies/Oxford, GALA, 2003, 1-25.

Oxford, R. L. (2003b). Toward a more systematic model of L2 learner autonomy. In D. Palfreyman \& R. Smith (Eds.), Learner Autonomy across Cultures - Language Education Perspectives (pp. 75-91). Hampshire, New York: Palgrave Macmillan.

Oxford, R. L. (2013). Teaching \& researching: Language learning strategies: Routledge.

Palfreyman, D. M. (2003). Introduction: Culture and learner autonomy. In D. Palfreyman \& R. C. Smith (Eds.), Learner autonomy across cultures - Language Education Perspectives (pp. 1-19). Hampshire, New York: Palgrave Macmillan.

Palfreyman, D. M. (2018). Learner Autonomy and Groups. In Autonomy in Language Learning and Teaching (pp. 51-72): Springer.

Peña Clavel, M. (2018). Teletandem language learning right out of the box. Paper presented at the 8th Independent Learning Association Conference - Whose Autonomy? Voices and Agency in Language Learning, Kobe, Japan.

Pintrich, P. R. (2000). The role of goal orientation in self-regulated learning. Handbook of self-regulation, 451, 451-502.

Porto, M. (2007). Learning diaries in the English as a foreign language classroom: A tool for accessing learners' perceptions of lessons and developing learner autonomy and reflection. Foreign Language Annals, 40(4), 672-696.

Prabhu, N. (1992). Second Language Pedagogy. Oxford: Oxford University Press.

Raimes, A. (2002). Ten steps in planning a writing course and training teachers of writing. In J. C. Richards \& W. A. Renandya (Eds.), Methodology in language teaching: An anthology of current practice (pp. 306-314). Cambridge: Cambridge University Press. 
Reinders, H., Hacker, P., \& Lewis, M. (2004). The language adviser's role: identifying and responding to needs. The Language Learning Journal, 30(1), 30-34. doi:10.1080/09571730485200201

Richards, J. C., \& Renandya, W. A. (2002). Methodology in language teaching: An anthology of current practice: Cambridge university press.

Rogers, C. R. (1983). Freedom to learn for the 80's. Columbus: Charles E. Merrill Publishing Company.

Rubin, J., \& McCoy, P. (2008). Tasks and good language learners. In C. Griffiths (Ed.), Lessons from good language learners (pp. 294-305). Cambridge: Cambridge University Press.

Ryan, R. M. (1991). The nature of the self in autonomy and relatedness. In The self: Interdisciplinary approaches (pp. 208-238): Springer.

Ryan, R. M., \& Deci, E. L. (2000). Intrinsic and extrinsic motivations: Classic definitions and new directions. Contemporary Educational Psychology, 25(1), 54-67.

Ryan, R. M., \& Deci, E. L. (2017). Self-determination theory: Basic psychological needs in motivation, development, and wellness: Guilford Publications.

Scharle, A., \& Szabó, A. (2000). Learner autonomy: A guide to developing learner responsibility. Cambridge: University Press.

Schmenk, B. (2005). Globalizing learner autonomy. TESOL quarterly, 39(1), 107-118.

Schön, D. A. (1983). The reflective practitionerhow professionals think in action.

Schraw, G. (1998). Promoting general metacognitive awareness. Instructional Science, 26(1), 113-125. doi:10.1023/a:1003044231033

Seow, A. (2002). The writing process and process writing. In J. C. Richards \& W. A. Renandya (Eds.), Methodology in language teaching: An anthology of current practice (pp. 315320). Cambridge: Cambridge University Press.

Sert, N. (2006). EFL student teachers' learning autonomy. The Asian EFL Journal, 8(2), 180201.

Shaw, J. (2008). Teachers working together - What do we talk about when we talk about autonomy? In T. R. Lamb, H. (Ed.), Learner and Teacher Autonomy - Concepts, realities, and responses (pp. 187-203). Amsterdam/Philadelphia: John Benjamins Publishing Company.

Sheerin, S. (1997). An exploration of the relationship between self-access and independent learning. In P. Benson \& P. Voller (Eds.), Autonomy and independence in language learning (pp. 54-65). New York: Longman.

Silver, N. (2013). Reflective pedagogies and the metacognitive turn in college teaching. In M. Kaplan, N. Silver, D. LaVaque-Manty, \& D. Meizlish (Eds.), Using reflection and metacognition to improve student learning: Across the disciplines, across the academy (pp. 1-17). Sterling, Virginia: Stylus Publishing.

Sinclair, B. (2009). The teacher as learner: Developing autonomy in an interactive learning environment. In R. Pemberton, R. Toogood, \& A. Barfield (Eds.), Maintaining control: Autonomy and language learning (pp. 175-198). Aberdeen, Hong Kong: Hong Kong University Press.

Sinclair, J. M., \& Coulthard, M. (1975). Towards an analysis of discourse: The English used by teachers and pupils: Oxford Univ Pr.

Smith, R. (2000). Starting with ourselves: Teacher-learner autonomy in language learning. In B. Sinclair, I. McGrath, \& T. Lamb (Eds.), Learner Autonomy, Teacher Autonomy: Future Directions Essex, England: Pearson Education Limited.

Smith, R. (2001). Learner and teacher development: Connections and constraints. The Language Teacher, 25(6), 43-44. 
Smith, R. (2003a). Pedagogy for autonomy as (becoming-) appropriate methodology. In D. Palfreyman \& R. Smith (Eds.), Learner autonomy across cultures - Language Education Perspectives (pp. 129-146). Hampshire, New York: Palgrave Macmillan.

Smith, R. (2003b). Teacher education for teacher-learner autonomy. Paper presented at the Symposium for Language Teacher Educators: Papers from Three IALS Symposia (CDROM). Edinburgh: IALS, University of Edinburgh. Retrived from: http://www. warwick. ac. uk/ elsdr/Teacher_autonomy. pdf.

Smith, R., \& Erdoğan, S. (2008). Teacher-learner autonomy - Programme goals and studentteacher constructs. In T. Lamb \& H. Reinders (Eds.), Learner and teacher autonomy. Concepts, Realities, and Responses (pp. 83-102). Amsterdam, Philadelphia: John Benjamins Publishing Company.

Smith, R., Kuchah, K., \& Lamb, M. (2018). Learner Autonomy in Developing Countries. In Autonomy in Language Learning and Teaching (pp. 7-27): Springer.

Sonaiya, R. (2002). Autonomous language learning in Africa: A mismatch of cultural assumptions. Language Culture and Curriculum, 15(2), 106-116.

Swain, M. (1995). Three functions of output in second language learning. . In G. Cook \& B. Seidelhofer (Eds.), Principle and Practice in Applied Linguistics: Studies in Honour of H.G. Widdowson (pp. 124-144). Oxford: Oxford University Press.

Tassinari, M. G. (2012). Evaluating learner autonomy: A dynamic model with descriptors. Studies in Self-Access Learning Journal, 3(1), 24-40. doi:10.37237/030103

Tassinari, M. G. (2015). Assessing learner autonomy: A dynamic model. In C. J. M. Everhard, L. (Ed.), Assessment and autonomy in language learning (pp. 64-88). Hampshire, New York: Palgrave, Macmillan.

Tassinari, M. G. (2018). Autonomy and reflection on practice in a self-access language centre: Comparing the manager and the student assistant perspectives. Studies in Self-Access Learning Journal, 9(3), 387-412.

Thornton, K., \& Mynard, J. (2012). Investigating the focus of advisor comments in a written advising dialogue. Autonomy in language learning: Advising in action. Canterbury, UK: IATEFL.

Tütüniş, B. (2011). Changing teacher beliefs and attitudes towards autonomous learning. In D. Gardner (Ed.), Fostering Autonomy in Language Learning (pp. 161-165). Gaziantep: Zirve University: Retrieved from http://ilac2010.zirve.edu.tr.

UNICEF. (2018a). Country Office Annual Report 2018 - Madagascar. Retrieved from https://www.unicef.org/about/annualreport/files/Madagascar 2018 COAR.pdf

UNICEF. (2018b). Defis et Opportunites des Enfants a Madagascar. Retrieved from https://www.unicef.org/madagascar/media/1241/file/Defis\%20et\%20opportunites\% 20des\%20enfants\%20\%C3\%A0\%20Madagascar\%20(FR).pdf

UNICEF. (2019). 1,300,000 children in Madagascar are not enrolled in pre-primary education. Ushioda, E. (1996). The role of motivation: Authentik.

Ushioda, E. (2000). Tandem language learning via e-mail: From motivation to autonomy. ReCALL, 12(2), 121-128.

Ushioda, E. (2007). Motivation, autonomy and sociocultural theory. In P. Benson (Ed.), Learner Autonomy 8: Teacher and learner perspectives (pp. 5-24). Dublin, Ireland: Authentik Language Learning.

Ushioda, E. (2009). A person-in-context relational view of emergent motivation, self and identity. In Z. Dornyei \& E. Ushioda (Eds.), Motivation, language identity and the L2 self (Vol. 215228, pp. 215-228). Bristol, UK: Multilingual Matters.

Ushioda, E. (2014). Motivation, autonomy and metacognition. Motivation and foreign language learning: From theory to practice, 31-49. 
Valdivia, S., McLoughlin, D., \& Mynard, J. (2011). The importance of affective factors in selfaccess language learning courses. Reading.

Venart, L., \& Reuter, K. (2014). Education in Madagascar: A Guide on the State of the Educational System, Needed Reforms and Strategies for Improvement. University of Mauritius Research Journal, 20, 208-247.

Victoria Business School, V. U. o. W. Rubric for Written Communication Skills. from Retrieved from https://www.victoria.ac.nz/ data/assets/pdf file/0007/1095253/LO-2aRubric-for-Written-Communication-Skills.pdf

Vygotsky, L. S. (1978). Mind in society: The development of higher psychological processes. Cambridge: Harvard University Press.

Wallace, M. J. (1991). Training Foreign Language Teachers: A Reflective Approach. Cambridge: Cambridge University Press.

Webb, S. (2005). Receptive and productive vocabulary learning: The Effects of Reading and Writing on Word Knowledge. Studies in second language acquisition, 27(1), 33-52. doi:10.1017/S0272263105050023

Wenden, A. (1991). Learner strategies for learner autonomy: Prentice Hall.

Westbrook, J., Durrani, N., Brown, R., Orr, D., Pryor, J., Boddy, J., \& Salvi, F. (2014). Pedagogy, curriculum, teaching practices and teacher education in developing countries.

White, C. (1995). Autonomy and strategy use in distance foreign language learning: Research findings. System, 23(2), 207-221.

Wills, A. R., Reuter, K. E., Gudiel, A. A., Hessert, B. P., \& Sewall, B. J. (2014). Barriers to Student Success in Madagascar. Global Education Review, 1(4), 114-134.

Woodside, A. G. (2010). Case study research: Theory, methods and practice: Emerald Group Publishing.

Woolfolk, A. (2004). Educational psychology (9th ed.). Boston: Pearson A and B.

Wright, T. (1987). Roles of teachers and learners: Oxford University Press, USA.

Yamashita, H. (2015). Affect and the Development of Learner Autonomy through Advising. Studies in Self-Access Learning Journal, 6(1).

Zamel, V. (1982). Writing: The process of discovering meaning. TESOL quarterly, 16(2), 195209.

Zimmerman, B. J. (1998). Developing self-fulfilling cycles of academic regulation: An analysis of exemplary instructional models. In D. H. Schunk \& B. J. Zimmerman (Eds.), Selfregulated learning: From teaching to self-reflective practice (pp. 1-19). New York: Guilford Press.

Zimmerman, B. J. (2000). Attaining self-regulation: A social cognitive perspective. In Handbook of self-regulation (pp. 13-39): Elsevier.

Zimmerman, B. J. (2002). Becoming a self-regulated learner: An overview. Theory into practice, 41(2), 64-70. doi:10.1207/s15430421tip4102_2 


\section{Appendices}

\subsection{APPENDIX 1. Interview questions}

\section{First interview}

\section{Language learning histories}

a) Which languages do you speak?

b) Think back on your language learning, especially English.

c) What methods, strategies, activities, etc... used by your teacher(s) in class did you find most effective?

d) What strategies, activities, etc... used by yourself in and/or outside class did you find most effective when you were still at school?

e) How did you keep your level of English or how did you improve it after you had graduated from school?

f) What aspects of the language (the 4 skills, vocabulary and grammar) did you spend most of your time on (alone before and/or after graduation)?

g) Why did you decide to become an English teacher?

\section{$\underline{\text { Pedagogical content knowledge }}$}

h) Now, think about your own teaching. What aspects of the language do you think

- are the most important to teach to your students?

- your students find the most difficult? Do you have any tips on how to overcome these difficulties?

- are the most difficult to teach?

- are the easiest to teach?

i) What methods or strategies do you find very useful to help your students improve ... (a particular aspect of the language)?

\section{Promoting learner autonomy}

\section{Promoting self-regulation}

j) Do you help your students set their own learning goals? How?

k) Do you make sure that your students know what specific goal(s) to achieve before each task? How? 
I) Do you encourage your students to refer to the goals when doing a task?

m) Do you ask your students how they feel when or after doing a task?

n) Do you ask your students what they find difficult and/or easy when or right after doing a task?

o) Do you give your students opportunities to evaluate their own learning?

p) Do you ask your students to reflect on what they learned (during a specific duration, for example, the previous week)?

\section{Promoting self-initiation and/or independence (from teacher)}

q) Do you encourage your students to learn or to practice English outside class? How?

r) Do you give your students opportunities to help one another?

s) Do you encourage your students to find their own answers to questions or problems?

\section{Promoting volition}

t) Do you give your students opportunities to choose the teaching materials to use in class?

u) Do you allow your students to give opinions on what to learn in class?

v) Do you encourage your students by giving them positive feedback?

w) Self-directed teaching (teacher autonomy)

\section{Promoting self-regulation}

x) Do you set your own teaching goals?

y) Do you keep a record of your reflection on your teaching: goals, any improvement, any 'failure', any feelings, and any points to work on?

z) Do you evaluate your own teaching? How?

aa) Do you try to identify your problems regarding teaching and find solutions?

bb)

\section{$\underline{\text { Self-initiation }}$}

cc) Do you make an effort to improve your teaching skills? How?

dd) Do you share and exchange ideas about teaching (methods, strategies, activities, etc...) with other teachers?

ee) Do you ask your students for feedback on your teaching? 


\section{Second interview}

Reflection on what the teachers did in class

a) What did you think of your classes this week? Did everything go as you plann do you think it did (not)?

b) If no, what was wrong? Are you planning to do something about it next week

c) What are your plans for next week?

d) Questions related to what has been observed, for example,

e) You asked (name of a student) this question, why did you do so?

f) Why do you think (name of a student) asked this question...?

\section{Questions related to learner autonomy}

g) Which of the following are important to you? Why?

h) Helping students set their own learning goals

i) Making sure they know what the goal is when doing a task?

j) Asking they how they feel and what they find difficult/easy when/after doing

k) Encouraging them to reflect on and to evaluate their own learning?

I) Encouraging them to learn and practice English outside class

m) Giving them opportunities to help one another

n) Encouraging them to find their own answers to questions and/or problems

o) Giving them opportunities to have their say on teaching materials and/or tear content

p) Encouraging them by giving positive feedback

q) Setting your own teaching goals

r) Reflecting on and evaluating your own teaching

s) Making effort to improve your teaching skills.

t) Exchanging ideas about teaching with other teachers.

u) Asking students for feedback on your teaching. 


\subsection{APPENDIX 2. Samples of interview transcripts}

V: Vola (me)

A: Ariane

J: John

Samples from John's second interview

V: Do you think it is important to help students set their own learning goals

$\mathrm{J}$ : Yes. I think it is very important because if they don't have a goal, they cannot evaluate themselves. When they have a goal, they can see if they made some improvement or not. V: I know you're dealing with little children, is it important for them to have learning goals? It depends on the goal. It may not be a very [big] goal, but just, for example, [a goal like], I want to be able to write to my penfriend. If that is their goal, that will help them to make some effort to work hard to reach their goal, and then, they will be able to write to their penfriends.

[...]

V: Do you think it is important to ask students how they feel and what they find difficult/easy when/after doing a task?

J: Yes. Very often, I ask them "how do you find this activity? Is it easy? Why did you make this mistake? Etc...

V: Do you think it's helpful for them?

$\mathrm{J}$ : Yes, because discussing with them the difficulty of doing things helps them. So, it helps them, and it also helps me to know their difficulty, to see what is easy and difficult for them. For example, today, one of them said, it was very difficult to write [the word] "excited". I thought that as we read it many times, they will memorise it, but in fact, they say, it's difficult [to write] "excited". So, I think it's helpful to ask them about their difficulty. $[\ldots]$

V: Do you think it's important to encourage students to reflect on and to evaluate their own learning?

$\mathrm{J}$ : Yes, most of the time, I say yes (laughter). The answer is yes. I think it's very helpful because they need to evaluate not only their own work but also to evaluate [the others' work]. I don't have to evaluate them but they evaluate themselves by saying, "This sentence is good. This sentence is very silly. This is a good picture". I think it helps them, so, evaluating themselves is a good idea. It's very helpful for them. 
V: Helpful in what way (compared to your evaluation)?

$\mathrm{J}$ : I see that when they're between themselves, they are honest to themselves. When they see what the others did, they can think that "maybe next time, I will do better than this one". For example, today they write a short silly sentence, and when they see other pupils writing a very long sentence, they will think of making a longer one next time.

\section{Samples from Ariane's first interview}

V: Do you give your students opportunities to evaluate their own learning?

A: Yes, when we do dictation, or with exercises with concrete answers, it's possible, such as grammar, but not with something creative. I ask them to correct each other. Sometimes, I also give them something to do in groups, and they correct each other. In that case, I really refuse to correct.

V: Do you ask your students to reflect on what they learned (during a specific duration, for example, the previous week)?

A: I used to, but now, I forgot to do it. When checking attendance before, when I called their names, they had to say a vocabulary item we'd learned during the session, at the end of the session. For grades 8 and 9, they have discussions for about 5 minutes on what they learned in the session.

\section{[...]}

\section{V: Do you set your own teaching goals?}

A: I do. When I plan lessons, I don't follow the curriculum set by the ministry, because I think of the level of my students. That's why it's not easy for me to plan lessons. I think about ways how I can make the lesson understood by the students. If I followed the ministry's curriculum, we wouldn't be able to finish it. I try to give my students lots of exercises, oral exercises, writing at the beginning of the year, and I see from there, what their difficulties are. And I set my objectives for the school year from there.

V: Do you make an effort to improve your teaching skills? How?

A: I do. We have training here sometimes, and I have to make the effort to apply what has been taught during the training. The problem of education in Madagascar is that everything is about theory. No practice at all! In the old days - I asked my aunts how they had learned before - for example, when they learned about vegetal planting, they are taken to a planting site, and given explanation and demonstration. When they learned about pollen, they were shown real stuff. We didn't experience that. All we had was 200-page lessons to review, without knowing what we need them for. The effort we should make is then to make the 
class alive. The objective is not to fill in a whole notebook. Students should know why they learn such or such things, and there should be more practice. I improve my teaching skills, then, by applying what I learn in the training.

V: Do you share and exchange ideas about teaching (methods, strategies, activities, etc...) with other teachers?

A: I do, especially with [Norah], and sometimes with other teachers in the secondary school. I find sharing and exchanging ideas very useful. There should be a specific time every week when teachers of the same class should discuss and exchange ideas. 


\subsection{APPENDIX 3. Class observation checklist}

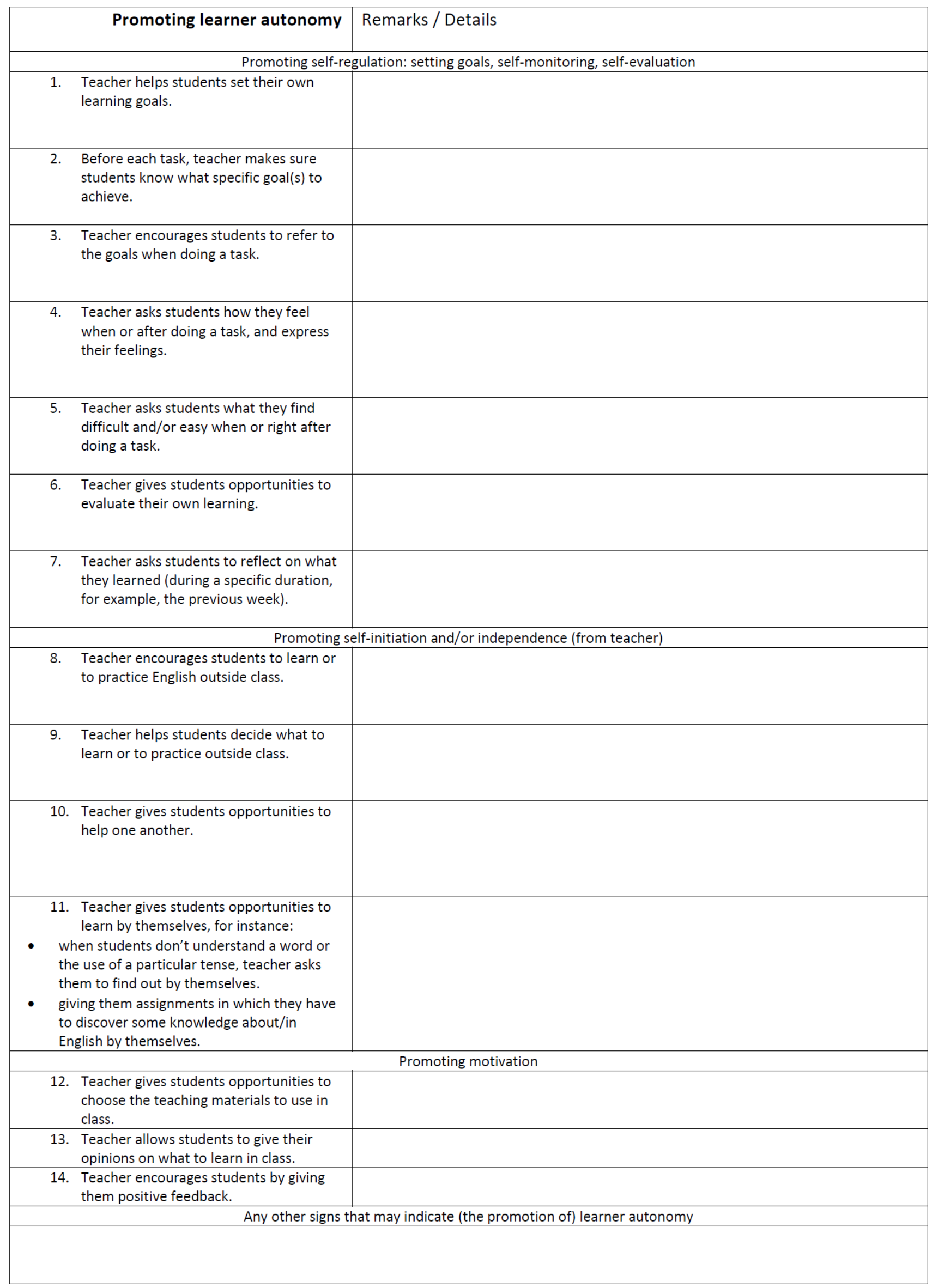




\subsection{APPENDIX 4. Sample of my notes during class observations}

Teacher asks "What's news?", and 3 volunteers raise their hands. They tell some news in the village in Malagasy: a story of a ghost and a story of a pig thief.

Teacher asks 2 volunteers to read aloud the list of intellectual and manual jobs with descriptions on their notebooks.

Teacher gives some pronunciation correction: the letter ending a word in English should be pronounced, like the " $s$ " in "teaches", unlike in French.

Teacher writes the date and the title of the new lesson: Possessive adjective.

Teacher asks them the list of personal subjects, then, the possessive adjectives, then, writes them on the board.

Teacher asks when to use the possessive adjectives, then, explains the use and the rule (that they should be followed by nouns), and gives some examples.

Students also shout some examples: "Her name is Francia." "It is your school bag." "It is my hat."

Students are asked to write 7 sentences with possessive adjectives (individually). T encourages them to use vocabulary they have learned.

Those who have finished go to the teacher's desks to show her their sentences. T corrects their sentences.

Teacher gives some mistakes to avoid, and gives some correct examples (Ex: they learn their lessons, instead of "my lesson").

Teacher erases the board and rewrites the personal subjects and the possessive adjectives (with colored chalk this time), and some examples.

Homework: Build up ten sentences with each possessive adjective.

Elements of learner autonomy

Promoting self-initiation and/or independence (from teacher)

The assignment of building 7 sentences including possessive adjectives gave students opportunities to discover (or at least review) some knowledge in English. While doing the assignment, the students had to find the vocabulary they needed. They did not only use the vocabulary they had already known, but tried to find other new words as well. For that, they had to ask their peers sometimes. The homework also gives them the same opportunity. Other interesting remarks 
While the second volunteer read aloud the list of manual jobs, the other students corrected her pronunciation. As pointed out by J, when students correct (which is part of peer evaluation), they indirectly evaluate themselves (here, they know that they are better than the one they are correcting).

The students shout the examples of sentences including possessive adjectives without being asked to. This is a "seed" of autonomy, as they were somehow using the target language autonomously.

While some students went to show their sentences to the teacher on the teacher's desk, some were comparing their sentences, and correcting one another (without being asked). From this example and the one above, it can be said that the students do have self-initiation, and peer evaluation seems to occur very naturally. 


\subsection{APPENDIX 5. Reflection prompts (phase two)}

\section{Weekly reflective journal prompts (reflection on the task)}

1.1. Pre-task prompts

1.1.1. What are your goal(s) regarding this writing task?

1.1.2. How are you planning to do the task?

1.1.3. What do you know about the topic?

1.1.4. What other information do you need to know about the topic?

\subsection{During-task prompts}

1.2.1. If possible, write down every step you are doing or thinking, for instance, "now, I am thinking of dividing my writing in two main parts", "now, I am proofreading to check grammar and punctuation", etc...

1.2.2. Write down any feelings you have when doing (every step of) the task.

1.2.3. What difficulties are you having while doing this writing task?

1.2.4. What do you think is easy when doing this writing task?

1.2.5. Are you attaining your goal(s)?

\subsection{Post-task prompts}

1.3.1. What score out of 10 would you give to your piece of writing? Why?

1.3.2. Did you notice anything you did better if compared with your last writing?

1.3.3. Did you attain your goal(s)?

1.3.4. Apart from your goal(s), what else did you learn from the task?

1.3.5. How did you deal with your difficulties? Did you come up with solutions?

1.3.6. What worked? What didn't work?

1.3.7. What would you do differently?

1.3.8. What will be your next goal(s) when doing similar tasks?

\section{Reflective journals on the course (every 3 weeks)}

2.1. What progress or improvement related to your writing skills did you notice in the last 3 weeks?

2.2. What are your strengths now regarding writing?

2.3. What are your weaknesses regarding writing that you still have to overcome?

2.4. What were your goals in the last 3 weeks?

2.5. Were they attained? Did you have to reset your goals?

2.6. How did the reflective journals and the in-class discussions help you attain your goals?

2.7. Apart from these goals, what else did you gain from the reflective journals and the discussions?

2.8. What challenges did you face when writing the reflective journals and discussing?

2.9. Do you have any other comments regarding the use of reflective journals and discussions?

2.10. Think of yourself as a (writing) teacher in the future, what lessons can you draw from this course?

(in 2RonC and 3RonC) 


\subsection{APPENDIX 6. Samples of reflection (phase two)}

\section{Sample of reflection on the task}

\section{Pre-task}

My goals regarding this writing task are many. Firstly, I want it will be a success when I will finish doing it. Secondly, I plan to make it really attractive for the readers.

I plan to do so many research about how to write an showcased-essay. Then, I collect all ideas to convince the reader to choose teaching. After [,] I try to write in a draft, rewrite, and reproof, and correct all grammatical errors or spelling, and I will change if there are some sentences which are not very relevant.

I know that teaching is the basis of development. Also, it is so passionating.

I need to know many other interesting and convincing ideas concerning teaching.

During-task

Now, I am taking a draft to organize the plan of my writing. I am collecting all ideas related to the topic. I am writing the general idea about the writing: "to convince young people that teaching is the best option."

I am passing directly in the writing task. I find that the time is not enough for me because I don't really like writing, especially when I am not at home, because I can't use dictionary, books for research or internet for documentation. But I am trying to do it well. There are many vocabularies that I don't know in English, so it is a kind of obstacles.

I don't really have so much ideas for this topic as well, and I don't know how to make a paragraph, how to write an showcased essay! no idea!

Anything doesn't seem easy for me while doing this writing. I am used to being lazy proofreading to check grammar and punctuation... etc.

I think, I am not attaining my goals.

Post-task

$5 / 10$ is the score I would give to my piece of writing. First of all, I didn't make proof-reading after I finished the writing task, so I am sure, there are many mistakes and wrong word spelling. Also, I think I was not very well-organised with my ideas. I think I was out of subject talking about ENS, the school college where students are trained to be a teacher.

I found that my introduction was more captive [catchy] and my last paragraph with the conclusion were more convincing than my last writing.

Sincerely, I am not sure either I attain my goal or not. I think I should have more convincing ideas.

I learnt that I really need to master the time, and to be more careful with mistakes. Maybe I need selfconfidence. I need to improve my style of writing.

I had difficulties with my ideas, I wasnt't sure that they are relevant to the topic,so, I've tried to take risk to write them down. Even if I had difficulties during the writing task, I have tried to do it well as possible I can.

When I took the risk to write all my ideas, many smart ideas came up into my mind, so that worked I suppose. Even if I tried to know the meaning of some French words in English, I didn't find exactly what are they.

I would be more confident when writing; master the time; not making any grammar mistakes or spelling mistakes; I would like having more vocabularies to express better my ideas.

My next goal (s) are:

- Not be afraid to be out of the topic

- To be well organised and having a lot of great ideas

- The writing will be without any mistakes and well written

- The task will be convincing and interesting for the reader as my preceding goals 


\section{Sample of reflection on the course}

My difficulties were that I couldn't manage time, so I just finished the introduction of the writing. But my main difficulty was about focusing; I wasn't able to concentrate without thinking about something else. About the reflective journal, I didn't finish it [either]. At that time, my first feeling was about: "How in the world would I finish all this work in 30 minutes?" And I got easily bored.

During my last 2 writings and reflections, I didn't have the same difficulties and didn't do the same mistakes anymore. I was finally able to correctly manage time, to fully focus on something and not get disturbed by something else anymore. And I wasn't bored or sleepy anymore. The way I do my writing didn't really change but I'd say I really improved my way of doing "things", like [,] I don't neglect anything anymore. The way I answered the prompts? I'd say I have become a bit more talkative.

As I always said, YES, using the reflection on my learning has been really useful because it helps us talk[...] about everything we want to, without offending anyone. It helps us find[...] what our real weaknesses are. And in the end, it's like a friend to talk too, a confident.

From this course, I've learned that we should never neglect anything. I learned that even if a task seems hard or impossible, it's just like that until you find what your problems are. "Fix" them and persevere to achievement.

To my future students, I'd make them use a reflective journal as well. That would be the first thing, since it really helps.

One last thing, as the reflective journal is really helpful, I think it should be used in every subject. Every teacher should recognize its importance. 


\subsection{APPENDIX 7. Sample of coding for interviews (phase one)}

\begin{tabular}{|l|l|l|}
\hline Code names & Files & References \\
\hline experience as former learners & 0 & 0 \\
\hline effective tasks in class & 3 & 3 \\
\hline self-initiation & 4 & 12 \\
\hline experience as teachers & 0 & 0 \\
\hline difficulties of their students & 8 & 12 \\
\hline motivation & 3 & 4 \\
\hline promoting learner autonomy & 0 & 0 \\
\hline asking students their difficulties & 3 & 4 \\
\hline giving positive feedback & 7 & 7 \\
\hline independence from teacher & 5 & 5 \\
\hline interdependence & 8 & 13 \\
\hline letting students express opinions & 6 & 11 \\
\hline peer evaluation & 4 & 5 \\
\hline reflection & 1 & 1 \\
\hline self-evaluation & 6 & 6 \\
\hline self-initiation & 4 & 5 \\
\hline setting goals & 5 & 6 \\
\hline specifying task goals & 5 & 6 \\
\hline strategies used or suggested to students & 4 & 5 \\
\hline taking students' feelings into account & 5 & 7 \\
\hline teacher autonomy & 0 & 0 \\
\hline asking students' feedback & 3 & 3 \\
\hline peer collaboration & 7 & 10 \\
\hline self-evaluation & 7 & 10 \\
\hline awareness of difficulties & 3 & 6 \\
\hline self-initiation for improving language & 5 & 5 \\
\hline self-initiation for improving teaching & 5 & 5 \\
\hline setting goals & 7 & 11 \\
\hline
\end{tabular}




\subsection{APPENDIX 8. Sample of coding for class observations (phase one)}

\begin{tabular}{|l|l|l|}
\hline Name & Files & References \\
\hline independence (learning by themselves) & 3 & 6 \\
\hline monitoring and self-evaluation (overheard) & 1 & 5 \\
\hline Peer collaboration & 0 & 0 \\
\hline decision making & 5 & 7 \\
\hline doing tasks & 8 & 29 \\
\hline solving a problem & 8 & 15 \\
\hline Peer evaluation & 7 & 11 \\
\hline Positive feedback & 10 & 18 \\
\hline promoting responsibility & 4 & 5 \\
\hline reflecting on mistakes & 1 & 1 \\
\hline saying what to do outside class & 5 & 8 \\
\hline Self-evaluation & 4 & 11 \\
\hline specifying goals & 7 & 12 \\
\hline students have their say & 7 & 13 \\
\hline
\end{tabular}




\subsection{APPENDIX 9. Sample of coding for reflections (phase two)}

\begin{tabular}{|c|c|c|}
\hline Name & Files & References \\
\hline evaluation & 0 & 0 \\
\hline on group discussions & 78 & 94 \\
\hline on reflection & 58 & 107 \\
\hline self-regulation & 0 & 0 \\
\hline Goal setting & 0 & 0 \\
\hline audience awareness & 75 & 75 \\
\hline broad & 27 & 28 \\
\hline language-related & 110 & 112 \\
\hline grammar & 79 & 81 \\
\hline idea improvement & 39 & 39 \\
\hline others & 7 & 9 \\
\hline vocabulary & 36 & 36 \\
\hline writing structure & 21 & 21 \\
\hline person-related & 4 & 4 \\
\hline time management & 12 & 12 \\
\hline Monitoring & 4 & 4 \\
\hline difficulties & 1 & 1 \\
\hline expressing ideas & 24 & 26 \\
\hline finding ideas & 53 & 61 \\
\hline focus & 7 & 7 \\
\hline grammar & 36 & 38 \\
\hline others & 13 & 13 \\
\hline self-confidence & 1 & 2 \\
\hline time management & 19 & 21 \\
\hline vocabulary & 53 & 59 \\
\hline writing structure & 28 & 30 \\
\hline enumerating every writing step & 99 & 111 \\
\hline feelings & 0 & 0 \\
\hline negative & 53 & 61 \\
\hline positive & 81 & 102 \\
\hline self-evaluation & 1 & 1 \\
\hline improvement & 194 & 275 \\
\hline negative points & 70 & 85 \\
\hline what has been learned & 90 & 93 \\
\hline what should be done & 43 & 50 \\
\hline strategies & 1 & 1 \\
\hline affective & 14 & 14 \\
\hline cognitive & 65 & 92 \\
\hline analysis & 3 & 4 \\
\hline organization & 22 & 30 \\
\hline practice of what has been learned & 5 & 9 \\
\hline metacognitive & 0 & 0 \\
\hline focus on goals & 13 & 13 \\
\hline monitoring mistakes & 32 & 34 \\
\hline planning & 18 & 23 \\
\hline others & 71 & 74 \\
\hline compensatory & 19 & 20 \\
\hline miscellaneous & 42 & 51 \\
\hline social & 8 & 8 \\
\hline teaching implementation & 36 & 36 \\
\hline explicit teaching & 5 & 5 \\
\hline finding own solutions & 10 & 10 \\
\hline focus & 1 & 1 \\
\hline peer collaboration & 7 & 7 \\
\hline practice & 3 & 3 \\
\hline reflection & 15 & 18 \\
\hline self-evaluation & 11 & 11 \\
\hline setting goals & 10 & 10 \\
\hline teachers' required assets & 4 & 4 \\
\hline
\end{tabular}




\subsection{APPENDIX 10. Ethics approval}

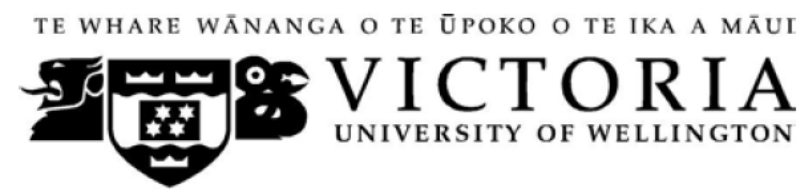

Phone 0-4-463 5480

MEMORANDUM

Email susan.corbett@vuw.ac.nz

\begin{tabular}{|c|c|}
\hline TO & Dominique Vola Ambinintsoa Razafindratsi \\
\hline COPY TO & Dr Peter Gu \\
\hline FROM & AProf Susan Corbett, Convener, Human Ethics Committee \\
\hline DATE & 14 December 2017 \\
\hline PAGES & 1 \\
\hline SUBJECT & $\begin{array}{l}\text { Ethics Approval: } 25387 \\
\text { Promoting learner autonomy in a Malagasy EFL context }\end{array}$ \\
\hline
\end{tabular}

Thank you for your application for ethical approval, which has now been considered by the Standing Committee of the Human Ethics Committee.

Your application has been approved from the above date and this approval continues until14 December 2020. If your data collection is not completed by this date you should apply to the Human Ethics Committee for an extension to this approval.

Best wishes with the research.

Kind regards
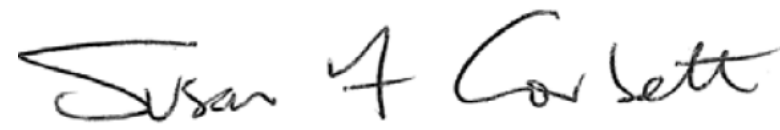

Susan Corbett

Convener, Victoria University Human Ethics Committee 


\title{
9.11 APPENDIX 11. Teachers' information sheet in English (phase one)
}

\author{
TE WHARE WĀNANGA O TE ŪPOKO O TE IKA A MĀUI \\ 59 \\ U UNIV \\ Promoting learner autonomy in a Malagasy EFL context
}

INFORMATION SHEET FOR PARTICIPANTS (Study one)

You are invited to take part in this research. Please read this information before deciding whether or not to take part. If you decide to participate, thank you. If you decide not to participate, thank you for considering this request.

\section{Who am I?}

My name is Dominique Vola Ambinintsoa R. and I am a Doctoral student in the School of Linguistics and Applied Language Studies at Victoria University of Wellington. This research project is work towards my thesis.

\section{What is the aim of the project?}

This project aims to promote learner autonomy via reflection in EFL (English as a Foreign Language) learning in a Malagasy setting.

This research has been approved by the Victoria University of Wellington Human Ethics Committee 0000025387.

\section{How can you help?}

Before conducting an intervention course promoting learner autonomy at the University of Antananarivo, it would be considerably helpful for me if I could do some English class observations in a Malagasy rural area in order to investigate what aspects of autonomy are present already, and also to study the conditions in which teachers work in such an area.

If you accept to participate in the research, you would be agreeing to:

- be interviewed twice or three times: we would discuss your language learning histories, your beliefs and views about English learning and teaching, about learner autonomy, and about the use of reflection in teaching. The interviews will be audio-recorded. Each interview will last about 25 minutes.

- be observed and audio-recorded while teaching between March 1 and 24, 2018.

\section{What will happen to the data?}

This research is confidential. This means that the researcher named below will be aware of your identity but the research data will be combined and neither your identity nor the name or the location of the school will be revealed in any reports, presentations, or public documentation.

Only my supervisors, Dr. Peter Gu, Dr. David Crabbe, and I will have access to the data. The interview transcripts, summaries and any recordings will be kept securely and destroyed two years after the completion of the research.

\section{What will the project produce?}

The information from my research will be used in my PhD thesis, but the participants will not be individually identified in any way in the thesis, which will be publicly available. The research may also 
be presented at academic conferences, and published in academic journals, or books, also without identifying any participants.

\section{What are your rights as a research participant?}

Your participation in the research is voluntary. If you do decide to participate, you have the right to:

- choose not to answer any question during the interview;

- ask for the recorder to be turned off at any time during the interview and during the class observations;

- withdraw from the study before March 14, 2018;

- ask any questions about the study at any time;

- receive a copy of your interview recording;

- receive a copy of your interview transcript;

- be able to read any reports of this research by emailing the research to request a copy.

\section{If you have any questions or problems, who can you contact?}

If you have any questions, or would like to receive further information about the project, please feel free to contact me via the information provided below.

\section{Researcher}

Dominique Vola Ambinintsoa Razafindratsimba

dominique.volaambinintsoa@vuw.ac.nz

School of Linguistics and Applied Language Studies Victoria University of Wellington

PO Box 600, Wellington 6140, New Zealand

Phone: +64 44635233 (ext. 8694)

\section{Supervisors}

Dr. Peter Gu

peter.gu@vuw.ac.nz

School of Linguistics and Applied Language Studies Victoria University of Wellington PO Box 600, Wellington 6140, New Zealand

Phone: +64 44765328 (ext. 5606)

Dr. David Crabbe

david.crabbe@vuw.ac.nz

School of Linguistics and Applied Language Studies Victoria University of Wellington

PO Box 600, Wellington 6140, New Zealand

Phone: +64 44793799 (ext. 5619)

\section{Human Ethics Committee information}

If you have any concerns about the ethical conduct of the research you may contact the Victoria University HEC Convenor: Associate Professor Susan Corbett. Email susan.corbett@vuw.ac.nz or telephone +64-4-463 5480 . 


\title{
9.12 APPENDIX 12. Teachers' information sheet in French (phase one)
}

\author{
TE Whare Wánanga te Opoko o te ika a mãu
Promouvoir l'autonomie de l'apprenant de l'anglais comme langue étrangère dans un contexte malgache

FICHE D'INFORMATION DU PARTICIPANT (Recherche numéro 1)

Vous êtes invité à participer à cette recherche. Veuillez lire ces informations avant de décider de participer. Si vous décidez de participer, je vous remercie. Si vous décidez de ne pas participer, merci d'avoir considéré cette demande.

\section{Qui suis-je?}

Mon nom est Dominique Vola Ambinintsoa R. et je suis étudiante en Doctorat à l'Ecole du Linguistique et Etudes Appliquées de Langue à Victoria University of Wellington. Ce projet de recherche est le travail de ma thèse.

\section{Quel est l'objectif de ce projet?}

Ce projet a pour objectif de promouvoir l'autonomie de l'apprenant via la réflexion dans l'apprentissage de l'anglais comme langue étrangère dans un contexte malgache.

Cette recherche a été approuvée par le Comité de l'Ethique Humaine de Victoria University of Wellington 0000025387.

\section{Comment pourriez-vous aider?}

Avant d'entreprendre des cours d'intervention promouvant l'autonomie à l'université d'Antananarivo, ça m'aiderait considérablement si je pourrais observer des classes d'anglais dans un milieu rural malgache afin d'examiner quels aspects d'autonomie existent déjà, et aussi d'étudier les conditions dans laquelle les enseignants travaillent dans un tel milieu.

Si vous acceptez de participer à la recherche, vous seriez d'accord pour :

- participer à trois interviews: on discutera de vos expériences concernant l'apprentissage de langues, vos opinions à propos de l'apprentissage et l'enseignement de l'anglais, à propos de l'autonomie de l'apprenant, et à propos de l'utilisation de la réflexion en enseignement. Les interviews seront enregistrées. Chaque interview durera à peu près 25 minutes.

- que je vienne observer et enregistrer (audio) vos classes entre le $1^{\text {er }}$ et le 24 Mars 2018. Qu'est-ce qui passera avec les données?

Cette recherche est confidentielle. Cela veut dire que la chercheure dont le nom est mentionné cidessous connaitra votre identité, mais les données de recherche seront combinées et ni votre identité, ni le nom ou l'emplacement de l'école ne sera révélé dans aucun rapport, présentation, ou documentation publique.

Seulement mes superviseurs, Dr. Peter Gu (peter.gu@vuw.ac.nz), Dr. David Crabbe (david.crabbe@vuw.ac.nz), et moi auront accès aux données. Les exercices d'expression écrite, les journaux et tout enregistrement seront gardés en sécurité et seront détruits deux ans après l'achèvement de la recherche. 


\section{Que produira la recherche?}

Les informations émanant de la recherche seront présentés dans ma thèse, mais les participants ne seront pas identifiés individuellement dans la thèse, qui sera disponible publiquement. La recherche pourrait aussi être présentée dans des conférences académiques, et publiées dans des journaux académiques, ou des livres, sans identifier aucun des participants. Deux ans après l'achèvement du projet, toutes les données seront complètement détruites.

\section{Quels sont vos droits en tant que participant ?}

Votre participation à la recherche est volontaire. Si vous décidez de participer, vous avez le droit de :

- ne pas répondre à n'importe quelle question ;

- demander à ce que l'appareil enregistreur soit éteint à n'importe quel moment pendant l'interview et l'observation de classe ;

- vous retirer de la recherche avant le 14 Mars 2018 ;

- recevoir une copie de l'enregistrement de votre interview ;

- demander des questions à propos de la recherche à n'importe quel moment ;

- recevoir une copie de l'enregistrement de votre interview ;

- recevoir une copie de la transcription de votre interview ;

- pouvoir lire les rapports concernant la recherche en envoyant un courriel à la chercheure pour demander une copie.

Si vous avez des questions, ou vous voudriez avoir plus d'informations sur le projet, n'hésitez pas à me contacter via les coordonnées ci-dessous. Merci pour votre coopération.

\section{Chercheure}

Dominique Vola Ambinintsoa Razafindratsimba

dominique.volaambinintsoa@vuw.ac.nz

School of Linguistics and Applied Language Studies Victoria University of Wellington

PO Box 600, Wellington 6140, New Zealand

Phone: +64 44635233 (ext. 8694)

\section{Superviseurs}

Dr. Peter Gu

peter.gu@vuw.ac.nz

School of Linguistics and Applied Language Studies Victoria University of Wellington PO Box 600, Wellington 6140, New Zealand

Phone: +64 44765328 (ext. 5606)

\section{Dr. David Crabbe}

david.crabbe@vuw.ac.nz

School of Linguistics and Applied Language Studies Victoria University of Wellington PO Box 600, Wellington 6140, New Zealand

Phone: +64 44793799 (ext. 5619)

\section{Coordonnées du comité d'éthique humaine}

Si vous avez des préoccupations au sujet de la conduite éthique de la recherche, vous pouvez communiquer avec le coordonnateur HEC de I'Université Victoria : Professeur Agrégé Susan Corbett. Email susan.corbett@vuw.ac.nz or telephone+64-4-463 5480. 


\title{
9.13 APPENDIX 13. Teachers' consent letter in English (phase one)
}

\author{
TE WHARE WÃNANGA O TE OPOKO O TE IKA A MÃUI

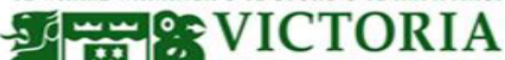 \\ B. $\%$ UNIVERSITY OF WeHUNGTON \\ Promoting learner autonomy in a Malagasy EFL context
}

LETTER OF CONSENT

Researcher: Dominique Vola Ambinintsoa Razafindratsimba, School of Linguistics and Language Studies, Victoria University of Wellington.

- I have read the Information Sheet and the project has been explained to me. My questions have been answered to my satisfaction. I understand that I can ask further questions at any time.

- I agree to take part in audio recorded interviews.

- I accept that the researcher will observe my classes between March 1 and March 23 2018.

I understand that:

- I may withdraw from this study at any point before March 14, 2018, and any information that I have provided will be destroyed.

- The identifiable information I have provided will be destroyed two years after the completion of the study.

- Any information I provide will be kept confidential to the researcher and her supervisors.

- The results will be used for a PhD thesis, academic publications and presented to conferences.

- My name will not be used in reports, nor will any information that would identify me.

\section{Participant's Name}

Participant's Signature

Date: / /

If you would like to receive a copy of a written summary of the study at the end of the research, please provide me with your e-mail address in the box below.

My e-mail address: 


\subsection{APPENDIX 14. Teachers' consent letter in French (phase one)}

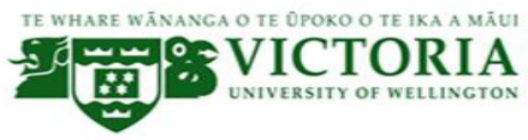

\section{Promouvoir l'autonomie de l'apprenant de l'anglais comme langue étrangère dans un contexte malgache}

\section{LETTRE DE CONSENTEMENT}

(Recherche numéro un)

Chercheure: Dominique Vola Ambinintsoa Razafindratsimba, School of Linguistics and Language Studies, Victoria University of Wellington.

- J'ai lu la fiche d'information et on m'a expliqué le projet. Mes questions ont été répondues à ma satisfaction. Je comprends que j'ai le droit de demander d'autres questions à n'importe quel moment.

- Je suis d'accord pour participer à des interviews qui seront enregistrées.

- J'accepte que la chercheure vienne observer mes classes entre le $1^{\text {er }}$ Mars et 23 Mars, 2018.

Je comprends que :

- je pourrai me retirer de la recherche à n'importe quel moment avant le 14 Mars 2018, et toutes les informations que j'ai fournies seront détruites.

- Les informations identifiables que j'ai fournies seront détruites deux ans après l'achèvement de la recherche.

- Toute information que je fournis sera gardée confidentielle pour la chercheure et ses superviseurs.

- Les résultats seront utilisés pour une thèse de doctorat, des publications académiques et présentés à des conférences.

- Mon nom ne sera pas utilisé dans les rapports, et aucune information ne m'identifiera.

\section{Nom du participant}

\section{Signature du participant}

Date: / /

Si vous voudriez recevoir une copie du résumé de la recherche à la fin de la recherche, veuillez écrire votre adresse e-mail ci-dessous.

E-mail: 


\title{
9.15 APPENDIX 15. Students' information sheet in English (phase two)
}

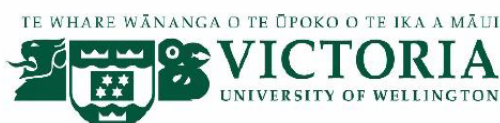

\section{Fostering learner autonomy via reflective practice in a Malagasy EFL context}

\author{
INFORMATION SHEET FOR PARTCIPANTS (Study two, Teaching College students)
}

You are invited to take part in this research. Please read this information before deciding whether or not to take part. If you decide to participate, thank you. If you decide not to participate, thank you for considering this request.

Who am I?

My name is Dominique Vola Ambinintsoa R. and I am a Doctoral student in the School of Linguistics and Applied Language Studies at Victoria University of Wellington. This research project is work towards my thesis.

What are the aims of the project?

This project aims to promote learner autonomy via reflection in EFL (English as a Foreign Language) learning in a Malagasy setting. For this purpose, I will teach a course entitled "Reflective Writing". The course will help you become more self-reliant and better learners in a way that you will be constantly encouraged to reflect on all aspects of your learning: the goals, the content and the process, as well as your strengths and weaknesses. Such reflection will assist you in improving your English proficiency. In this research, the focus will be on writing. Another aim of the project is to enable you to experience the benefits of developing learner autonomy so that you can also help your future students to become autonomous learners.

The course will be among the courses scheduled for the first year university students of the English Department of Ecole Normale Superieure in Semester One 2018. Therefore, the course will be offered to ALL first year university students in that department, whether the students participate in the research or not. The course will include writing tasks, reflective journal writing on the aspects of learning stated above, group discussions, and presentations.

This research has been approved by the Victoria University of Wellington Human Ethics Committee 0000025387.

\section{How can you help?}

Participating in the research means that your writing tasks, your journals, your group discussions, and your presentations during the course will be collected as the research data. Please note that I will not be aware of the identities of those who decide not to take part in the research until the end of the semester. Also, no additional work is required whether you participate in the research or not.

What will happen to the data?

This research is confidential. This means that the researcher named below will be aware of your identity but the research data will be combined and your identity will not be revealed in any reports, presentations, or public documentation.

Only my supervisors, Dr. Peter Gu, Dr. David Crabbe, and I will have access to the data. The writing tasks, the journals and any recordings will be kept securely and destroyed two years after the completion of the research.

\section{What will the project produce?}

The information from my research will be used in my PhD thesis, but the participants will not be individually identified in any way in the thesis, which will be publicly available. The research may also be presented at academic conferences, and published in academic journals, or books, also without identifying any participants.

\section{What are your rights as a research participant?}

Your participation in the research is voluntary. Please note that there is no penalty or negative consequence if you choose not to participate in the research, that is, if you do not want your tasks, journals, discussions, and 
presentations to be used as the research data. You can inform the Head of Department before June 1 if you would like to withdraw from the research, and the data regarding you will be withdrawn.

If you do decide to participate, you have the right to:

- $\quad$ ask any questions about the study at any time;

- $\quad$ ask for the recorder to be turned off at any time during the presentations in class;

- be able to read any reports of this research by emailing the researcher to request a copy.

\section{If you have any questions or problems, who can you contact?}

If you have any questions, or would like to receive further information about the project, please feel free to contact me via the information provided below.

\section{Researcher}

Dominique Vola Ambinintsoa Razafindratsimba

dominique.volaambinintsoa $@$ vuw.ac.nz

School of Linguistics and Applied Language Studies Victoria University of Wellington PO Box 600, Wellington 6140, New Zealand

Phone: +64 44635233 (ext. 8694)

\section{Supervisors}

Dr. Peter Gu

peter.gu@vuw.ac.nz

School of Linguistics and Applied Language Studies Victoria University of Wellington PO Box 600, Wellington 6140, New Zealand

Phone: +64 44765328 (ext. 5606)

Dr. David Crabbe

david.crabbe@vuw.ac.nz

School of Linguistics and Applied Language Studies Victoria University of Wellington PO Box 600, Wellington 6140, New Zealand

Phone: +64 44793799 (ext. 5619)

\section{Human Ethics Committee information}

If you have any concerns about the ethical conduct of the research you may contact the Victoria University HEC Convenor: Associate Professor Susan Corbett. Email: susan.corbett@vuw.ac.nz or telephone +6444635480. 


\subsection{APPENDIX 16. Students' information sheet in French (phase two)}

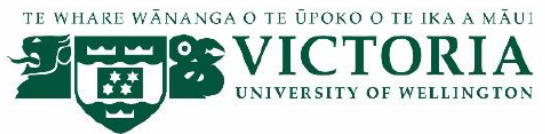

\section{Promouvoir l'autonomie de l'apprenant via la pratique de réflexion dans un contexte malgache où l'anglais est une langue étrangère}

\section{FICHE D'INFORMATION DU PARTICIPANT (Recherche numéro 2, Etudiants ENS)}

Vous êtes invité à participer à cette recherche. Veuillez lire ces informations avant de décider de participer. Si vous décidez de participer, je vous remercie. Si vous décidez de ne pas participer, merci d'avoir considéré cette demande.

\section{Qui suis-je ?}

Mon nom est Dominique Vola Ambinintsoa R. et je suis étudiante en Doctorat à l'Ecole du Linguistique et Etudes Appliquées de Langue à Victoria University of Wellington. Ce projet de recherche est le travail de ma thèse.

\section{Quels sont les objectifs de ce projet ?}

Ce projet a pour objectif de promouvoir l'autonomie de l'apprenant via la réflexion dans l'apprentissage de l'anglais comme langue étrangère dans un contexte malgache. Dans le cadre de ce projet, je donnerai un cours dont le titre est "Reflective Writing ». Le cours vous aidera à devenir meilleur et plus autonome en tant qu'apprenant en vous encourageant constamment de réfléchir sur tous les aspects de votre apprentissage : les objectifs, le contenu et le processus, ainsi que vos points forts et vos points faibles. Un tel travail de réflexion vous aidera à améliorer votre compétence en anglais. Cette recherche se focalisera sur l'expression écrite. Le projet vous permettra aussi de faire l'expérience des avantages du développement de l'autonomie de l'apprenant pour que vous puissiez à votre tour aider vos futurs étudiants à devenir autonomes. Le cours fera partie du programme du premier semestre 2018 pour les étudiants de première année du Département anglais de l'Ecole Normale Supérieure. Donc, le cours sera offert à TOUS les étudiants de première année, qu'ils participent à la recherche ou pas. Le cours inclut des exercices d'expression écrite, l'écriture d'un journal réflectif sur les aspects d'apprentissage décrits ci-dessus, des discussions de groupe, et des exposés.

Cette recherche a été approuvée par le Comité de l'Ethique Humaine de Victoria University of Wellington 0000025387.

\section{Comment pourriez-vous aider ?}

Participer à la recherche signifierait que vos exercices d'expression écrite, votre journal, vos discussions de groupe, et vos exposés pendant le cours seront collectés en tant que données de recherche. Il est à noter que je ne saurai pas l'identité de ceux qui choisiront de ne pas participer à la recherche jusqu'à la fin du semestre. En outre, que vous participez à la recherche ou non, il n'y aura pas de travail supplémentaire. 


\section{Qu'est-ce qui passera avec les données ?}

Cette recherche est confidentielle. Cela veut dire que la chercheure dont le nom est mentionné cidessous connaitra votre identité, mais les données de recherche seront combinées et votre identité ne sera pas révélée dans aucun rapport, présentation, ou documentation publique.

Seulement mes superviseurs, Dr. Peter Gu, Dr. David Crabbe, et moi auront accès aux données. Les exercices d'expression écrite, les journaux et tout enregistrement seront gardés en sécurité et seront détruits deux ans après l'achèvement de la recherche.

\section{Que produira la recherche?}

Les informations émanant de la recherche seront présentés dans ma thèse, mais les participants ne seront pas identifiés individuellement dans la thèse, qui sera disponible publiquement. La recherche pourrait aussi être présentée dans des conférences académiques, et publiées dans des journaux académiques, ou des livres, sans identifier aucun des participants. Deux ans après l'achèvement du projet, toutes les données seront complètement détruites.

\section{Quels sont vos droits en tant que participant ?}

Votre participation à la recherche est volontaire. Veuillez noter qu'il n'y aura aucune sanction ou conséquence négative si vous ne souhaitez pas participer à la recherche, c'est-à-dire, si vous ne souhaitez pas que vos exercices, journaux, discussions, et exposés ne soient utilisés pour la recherche. Vous pourriez informer le Directeur du Département avant le $1^{\text {er }}$ Juin si vous souhaitez vous retirer de la recherche, et les données vous concernant seront retirés.

Si vous décidez de participer, vous avez le droit de :

- demander des questions sur la recherche à tout moment ;

- demander que le camera soit éteint à n'importe quel moment des présentations en classe ;

- $\quad$ pouvoir lire les rapports concernant cette recherche en envoyant un courriel à la chercheure, demandant une copie

\section{Si vous avez des questions ou des problèmes, qui pourriez-vous contacter ?}

Si vous avez des questions, ou vous voudriez avoir plus d'informations sur le projet, n'hésitez pas à me contacter via les coordonnées que vous trouverez à la page suivante. 


\subsection{APPENDIX 17. Students' consent letter in English (phase two)}

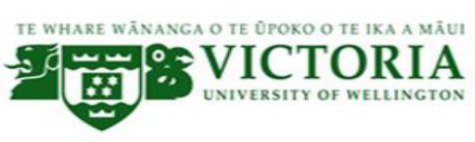

\section{Fostering learner autonomy via reflective practice in a Malagasy EFL context}

\section{LETTER OF CONSENT}

(Study two)

Researcher: Dominique Vola Ambinintsoa Razafindratsimba, School of Linguistics and Language Studies, Victoria University of Wellington.

- I have read the Information Sheet and the project has been explained to me. My questions have been answered to my satisfaction. I understand that I can ask further questions at any time.

- My agreement to participate in the research project means I allow the researcher to analyse my writing work as well as my reflective journals during the course "Reflective learning". She can also record presentations that I and my peers will do during the course. She will inform and will ask the permission of the groups presenting each time before recording.

I understand that:

- I may withdraw from this study at any point before June 1, 2018 by letting the Head of Department know, and any information that I have provided will be destroyed.

- The identifiable information I have provided will be destroyed two years after the completion of the study.

- Any information I provide will be kept confidential to the researcher and her supervisors.

- The results will be used for a PhD thesis, academic publications and presented to conferences.

- My name will not be used in reports, nor will any information that would identify me.

\section{Participant's Name \\ Participant's Signature}

Date: / /

If you would like to receive a copy of a written summary of the study at the end of the research, please provide me with your e-mail address in the box below.

My e-mail address: 


\subsection{APPENDIX 18. Students' consent letter in French (phase two)}

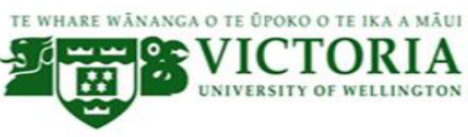

\section{Promouvoir l'autonomie de l'apprenant via la pratique de réflexion dans un contexte malgache où l'anglais est une langue étrangère}

LETTRE DE CONSENTEMENT

(Recherche numéro deux)

Chercheure: Dominique Vola Ambinintsoa Razafindratsimba, School of Linguistics and Language Studies, Victoria University of Wellington.

- J'ai lu la fiche d'information et on m'a expliqué le projet. Mes questions ont été répondues à ma satisfaction. Je comprends que j'ai le droit de demander d'autres questions à n'importe quel moment.

- Mon consentement à participer à ce projet de recherche signifie que je permets à la chercheure d'analyser mes exercices d'expression écrite ainsi que mon journal de réflexion pendant le cours "Reflective learning ». Elle peut aussi enregistrer les exposés que je ferai avec mes pairs pendant le cours. Elle informera et demandera l'accord des groupes qui présenteront à chaque fois avant d'enregistrer.

Je comprends que :

- Je pourrai me retirer de la recherche à n'importe quel moment avant le $1^{\text {er Juin }} 2018$ en informant le Chef de Département, et toutes les informations que j'ai fournies seront détruites.

- Les informations identifiables que j'ai fournies seront détruites deux ans après l'achèvement de la recherche.

- Toute information que je fournis sera gardée confidentielle pour la chercheure et ses superviseurs.

- Les résultats seront utilisés pour une thèse de doctorat, des publications académiques et présentés à des conférences.

- Mon nom ne sera pas utilisé dans les rapports, et aucune information ne m'identifiera.

Nom du participant

Signature du participant

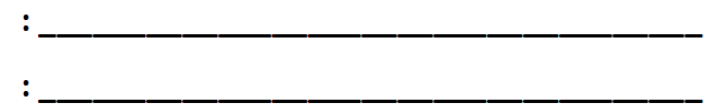

Date: / /

Si vous voudriez recevoir une copie du résumé de la recherche à la fin de la recherche, veuillez ecrire votre adresse e-mail ci-dessous.

E-mail: 